\title{
NGNP Fuel Qualification White Paper
}

July 2010
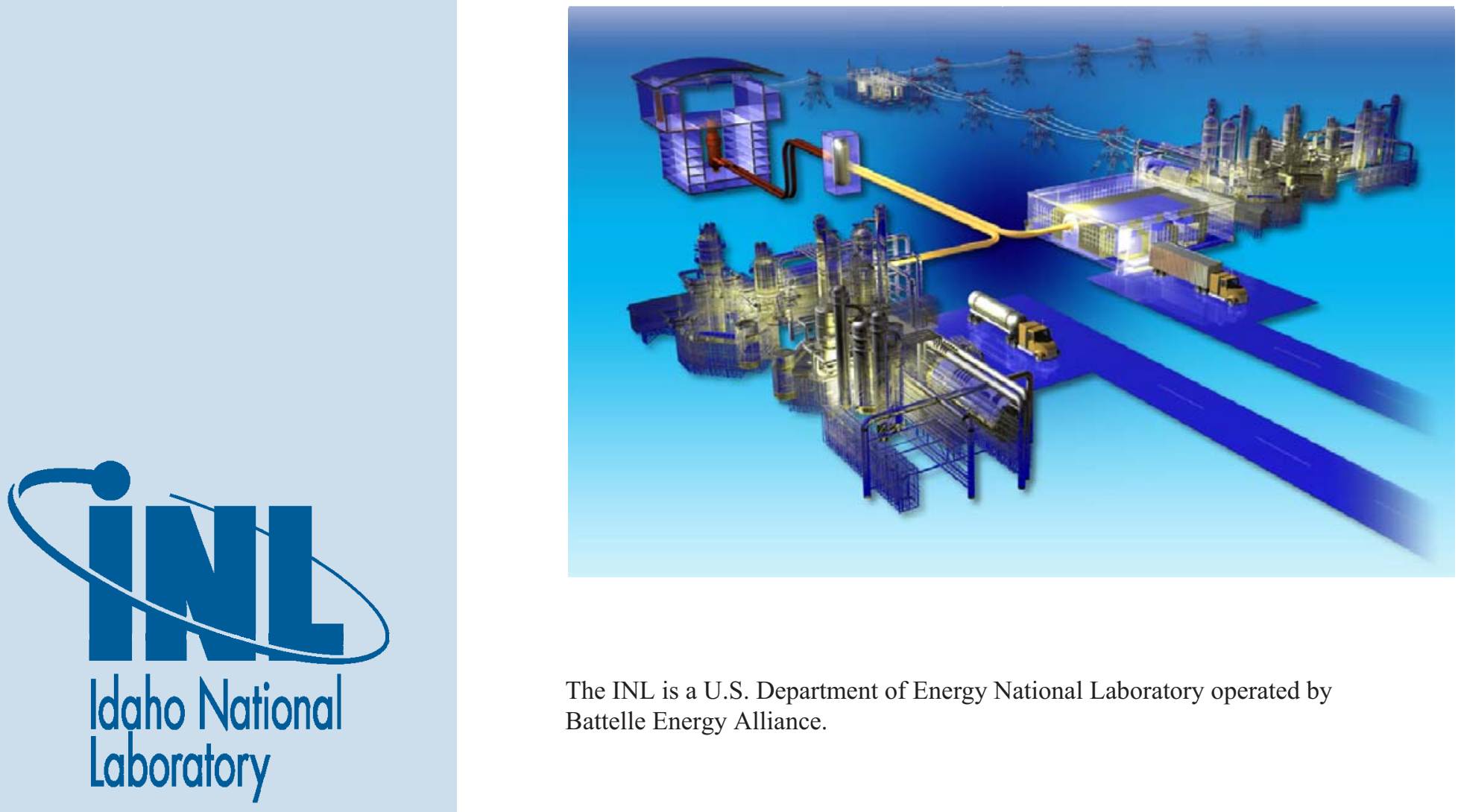

The INL is a U.S. Department of Energy National Laboratory operated by Battelle Energy Alliance. 


\section{DISCLAIMER}

This information was prepared as an account of work sponsored by an agency of the U.S. Government. Neither the U.S. Government nor any agency thereof, nor any of their employees, makes any warranty, expressed or implied, or assumes any legal liability or responsibility for the accuracy, completeness, or usefulness, of any information, apparatus, product, or process disclosed, or represents that its use would not infringe privately owned rights. References herein to any specific commercial product, process, or service by trade name, trade mark, manufacturer, or otherwise, does not necessarily constitute or imply its endorsement, recommendation, or favoring by the U.S. Government or any agency thereof. The views and opinions of authors expressed herein do not necessarily state or reflect those of the U.S. Government or any agency thereof. 
INL/EXT-10--18610

\section{NGNP Fuel Qualification White Paper}

July 2010

Idaho National Laboratory

Next Generation Nuclear Plant Project

Idaho Falls, Idaho 83415

Prepared for the

U.S. Department of Energy

Office of Nuclear Energy

Under DOE Idaho Operations Office

Contract DE-AC07-05ID14517 

Next Generation Nuclear Plant Project

NGNP Fuel Qualification White Paper

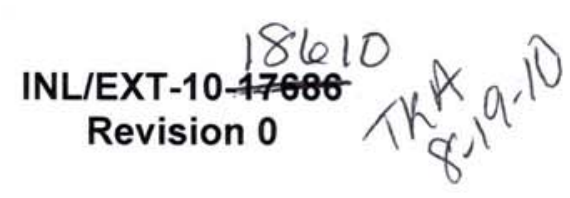

July 2010

Approved by:

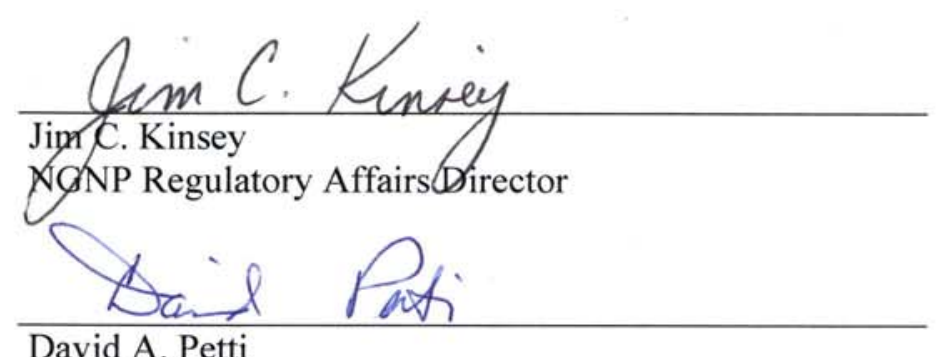

VHTR TDO Director

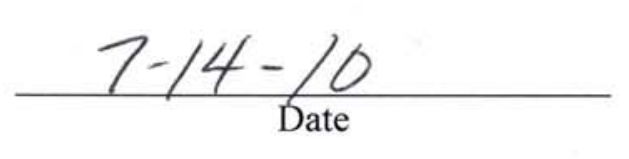

$\frac{7-20-10}{\text { Date }}$

$$
\frac{7-2 /-10}{\text { Date }}
$$





\section{ABSTRACT}

The Next Generation Nuclear Plant (NGNP) will be a licensed commercial high-temperature gas-cooled reactor (HTGR) plant capable of producing electricity and high-temperature process heat for industrial markets supporting a range of end-user applications. The NGNP Project has adopted the 10 CFR 52 Combined License (COL) application process, as recommended in the NGNP Licensing Strategy - Report to Congress, dated August 2008, as the foundation for the NGNP licensing strategy. The NGNP Project will be utilizing this NRC licensing process to demonstrate the efficacy of licensing future gas-cooled reactors for commercial industrial applications. This white paper is one in a series of submittals that will address key generic issues of the COL priority licensing topics as part of the process for establishing HTGR regulatory requirements.

The NGNP Fuel Qualification White Paper summarizes the planned fuel qualification approach for the NGNP HTGR plants. The HTGR concepts under consideration include both pebble-bed and prismatic-block reactors. Both concepts employ tristructural-isotropic (TRISO) fuel particles, but the pebble-bed concept uses $\mathrm{UO}_{2}$ (uranium oxide) fuel particles made into spheres, and the prismatic-block concept uses UCO (uranium oxycarbide) fuel particles made into cylindrical compacts that are then loaded into hexagonal-shaped graphite fuel blocks. The TRISO fuel particle consists of a microsphere (i.e., kernel) of nuclear material encapsulated by multiple layers of pyrocarbon and a SiC (silicon carbide) layer. This multiple-coating-layer system has been engineered to retain the fission products generated by fission of the nuclear material in the kernel during normal operation and all licensing basis events over the design lifetime of the fuel. Although plant safety depends on many factors, the TRISO-coated fuel is particularly critical to the safe operation of the reactor because the fuel particles are the primary (but not the only) barrier to fission-product release in HTGRs.

The information in this paper provides the basis for interactions with Nuclear Regulatory Commission (NRC) staff. The NGNP Project wishes to obtain comments on the adequacy of the planned fuel qualification approach and feedback on a number of issues that can significantly impact the effort and schedule to prepare a combined license application (COLA) for the HTGR-based NGNP. 


\section{FOREWORD}

This white paper presents the planned program for fuel qualification for the NGNP project, which is considering both prismatic and pebble fuel options. There is great similarity between the pebble and prismatic fuels because both build upon the worldwide historical database. For example, many of the same processes are common to the fabrication of these fuels; they have similar specifications, and they use similar quality control methods and associated statistical techniques to judge acceptability of the fuel product. These common considerations are discussed in each section of the paper, followed by a discussion of the specific approaches for prismatic and pebble fuel.

Elements of the existing U.S. regulatory structure relevant to these fuels are discussed to provide a licensing context for fuel qualification. The paper then briefly summarizes international experience with coated-particle fuel resulting in the TRISO fuel used for (HTGR) programs around the world. Based on this experience, there is an international basis for understanding that supports three important tenets of this fuel:

- High-quality TRISO fuel can be fabricated in a repeatable, consistent manner

- Fuel performance with very low in-service failures is achievable under anticipated modular HTGR conditions

- The broad historical international database is relevant to both fuel forms under consideration.

Reactor and fuel performance requirements are addressed to provide an understanding of the relationship between the design and resulting fuel-service conditions and performance requirements for both a prismatic and pebble-bed HTGR. Since the designs are still evolving at the time of this writing, example design descriptions and corresponding analyses are summarized to provide representative fuel-service conditions and performance requirements imposed on the fuel by the design.

While the prismatic and pebble fuel qualification programs use different terminology, the irradiation and accident testing programs for pebble and prismatic fuel share a common objective to establish a design envelope approaching the expected capability of the fuel based on the current understanding of TRISO fuel. This envelope is expressed, respectively, as a set of normal operating and accident conditions that bound those of a broad set of historic modular pebble and prismatic gas reactor designs. Both programs plan to test statistically significant amounts of fuel so that the resultant data can be used with confidence to confirm assumed failure rates under normal and accident conditions for the reactor designs. The exact reactor design and corresponding service conditions and performance requirements may change as the designs evolve, and the corresponding fuel irradiation and testing programs may need to be adjusted to meet these changes. 


\section{CONTENTS}

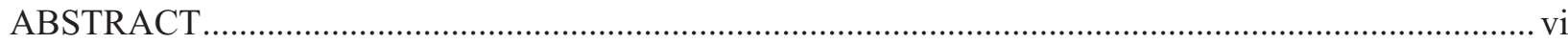

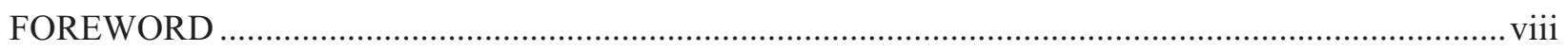

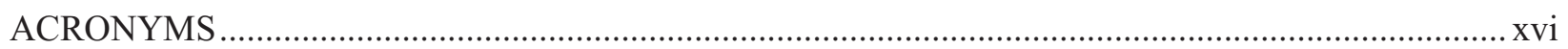

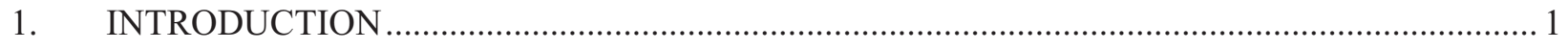

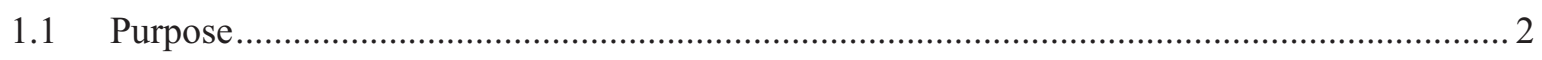

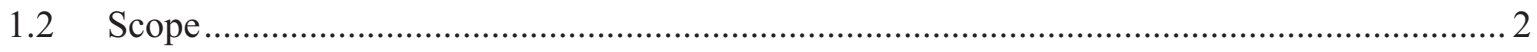

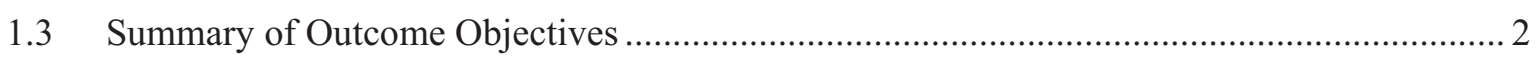

1.4 Relationship of Other NGNP Topics/Papers....................................................................... 3

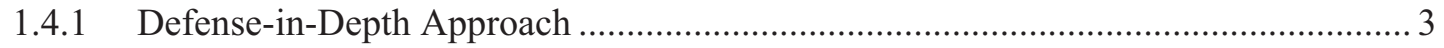

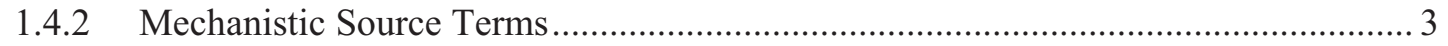

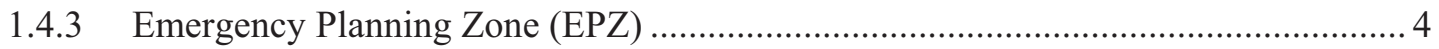

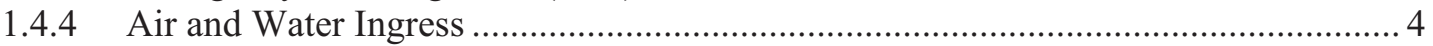

1.4.5 Licensing Basis Event (LBE) Selection ........................................................... 4

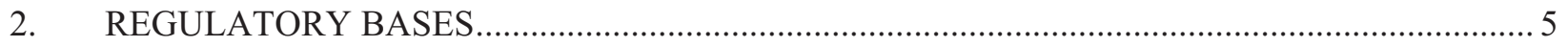

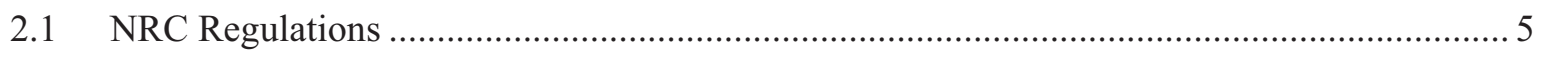

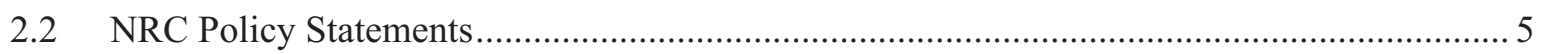

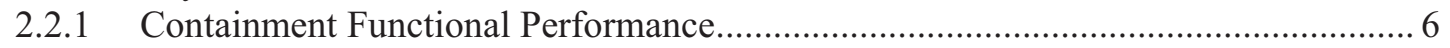

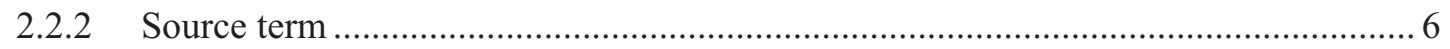

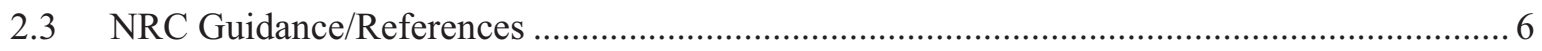

2.3.1 NUREG-1338, "Pre-application Safety Evaluation Report for the MHTGR" ........... 6

2.3.2 NUREG-0111, "Evaluation of High Temperature Gas-Cooled Reactor Particle Coating Failure Models and Data" .............................................................. 7

2.3.3 NUREG-0800, Standard Review Plan, Section 4.2, "Fuel System Design"............... 8

2.3.4 TRISO-Coated Particle Fuel Phenomenon Identification and Ranking Tables ........ 11

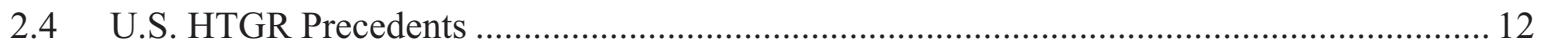

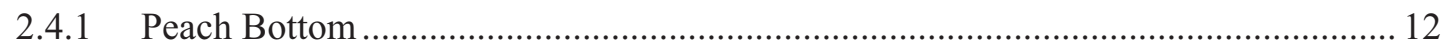

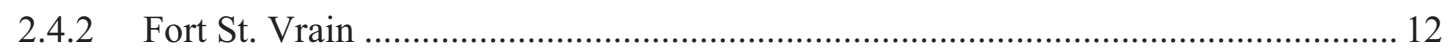

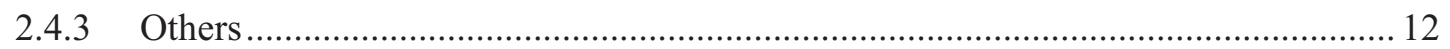

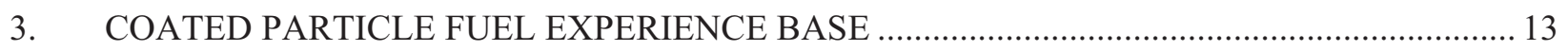

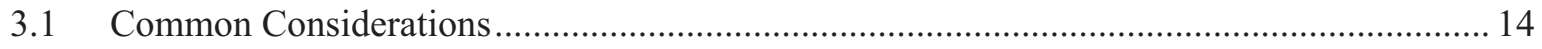

3.1.1 Experience (Evolution of Coated-Particle Fuel) ................................................... 14

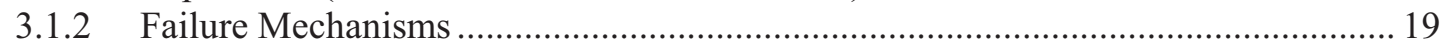

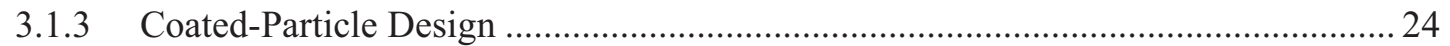

3.2 German High-Quality LEU-UO ${ }_{2}$ Pebble-Fuel Experience ............................................... 25

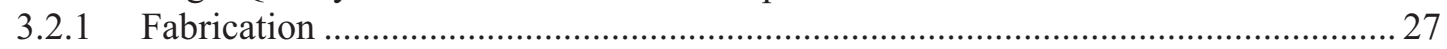

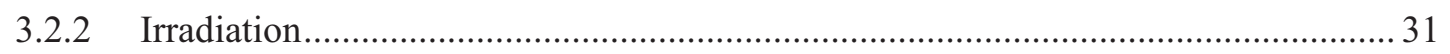

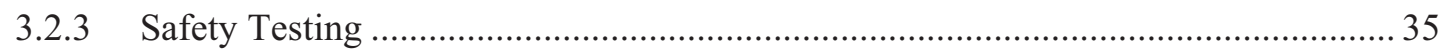

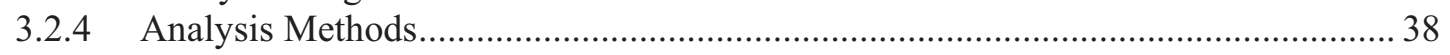

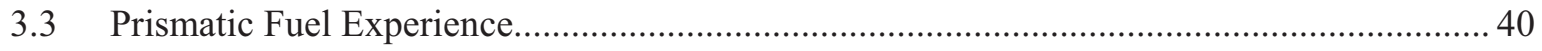

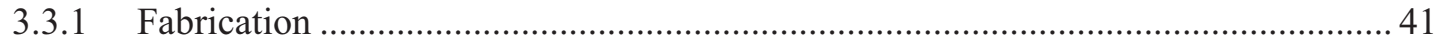

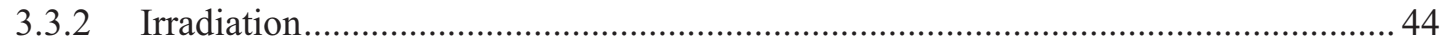




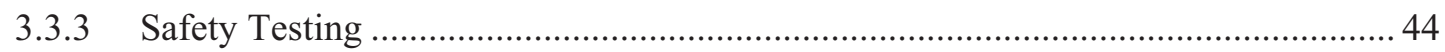

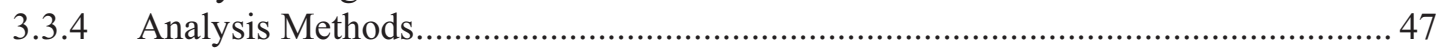

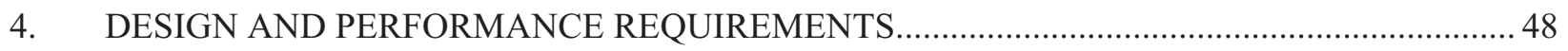

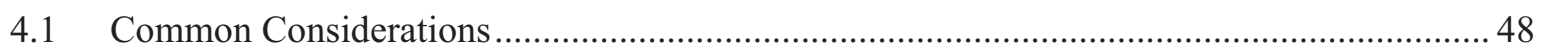

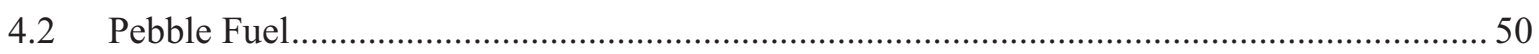

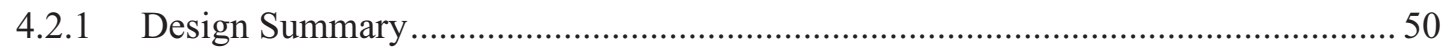

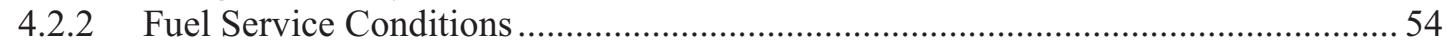

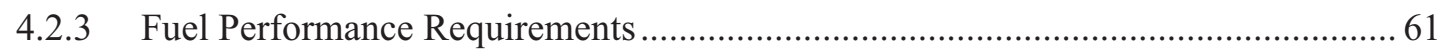

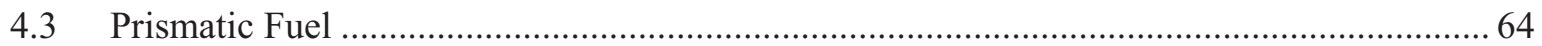

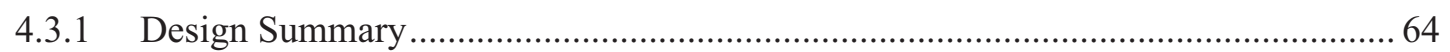

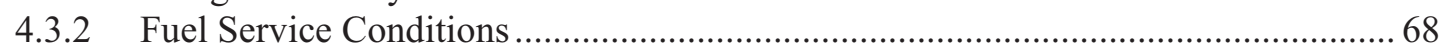

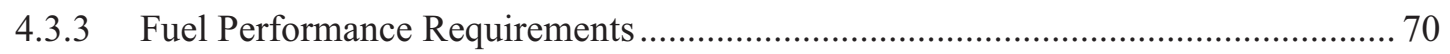

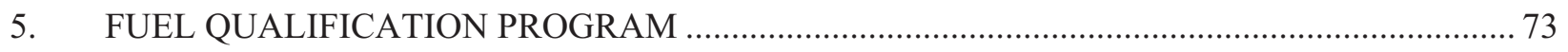

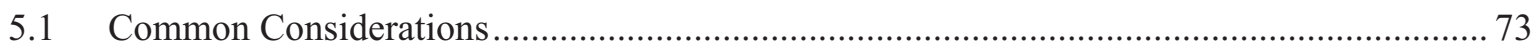

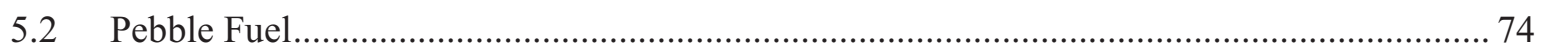

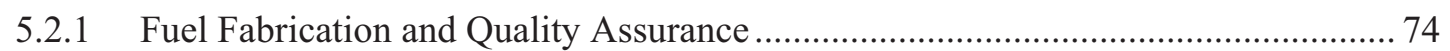

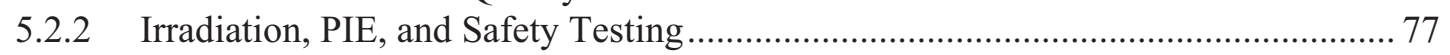

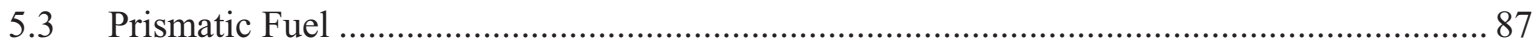

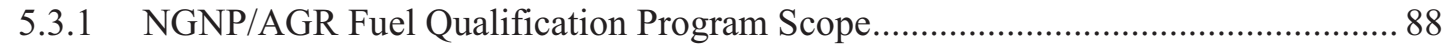

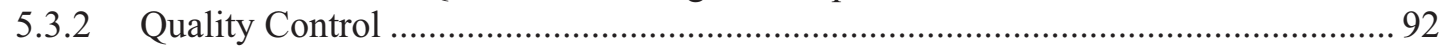

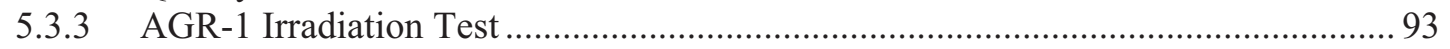

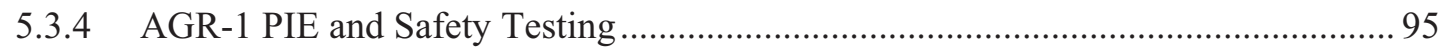

5.3.5 Fuel Performance Model Development ...................................................................... 97

5.3.6 Production-Scale Fuel Manufacturing Facility for NGNP UCO Fuel ..................... 98

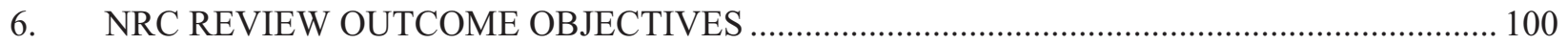

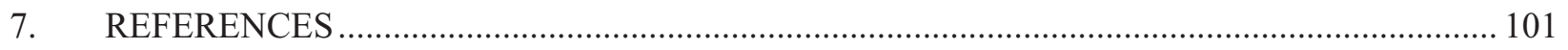

Appendix A German LEU UO U $_{2}$ TRISO Fuel Irradiation Data …..................................................... 105

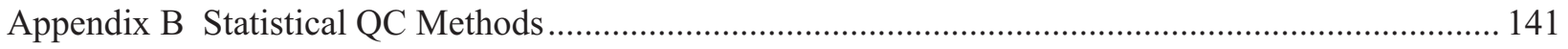




\section{FIGURES}

Figure 1. Early coated-particle designs.

Figure 2. TRISO particle failure mechanisms.

Figure 3. Localized fission-product attack of the $\mathrm{SiC}$ layer......................................................................... 22

Figure 4. The international-consensus TRISO particle design. ................................................................ 24

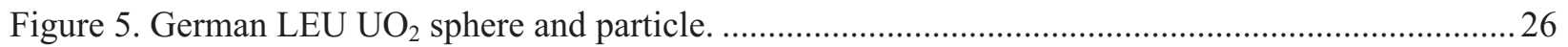

Figure 6. German LEU TRISO irradiation conditions, AVR and MTRs. .............................................. 32

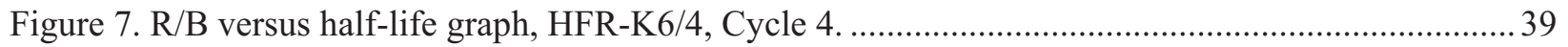

Figure 8. R/B versus half-life graph, HFR-K6/4, Cycle 24 .................................................................. 39

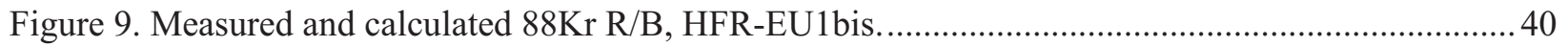

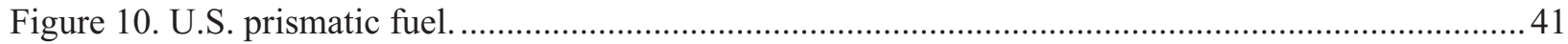

Figure 11. Kr-85m release results for ramp heating tests of candidate HTGR fuel types. .......................45

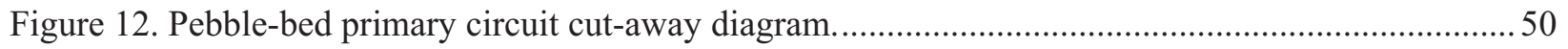

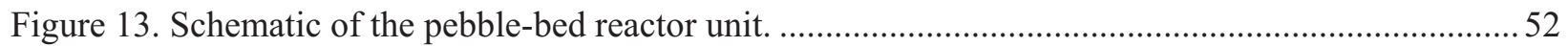

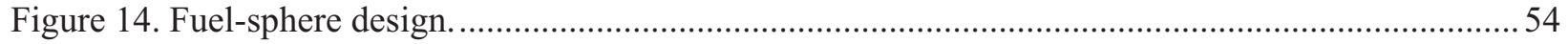

Figure 15. Normal operation fuel temperature (axial profiles for average values in VSOP99

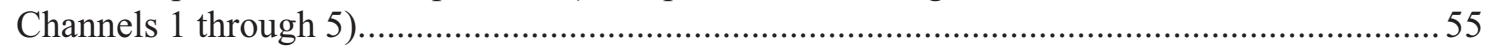

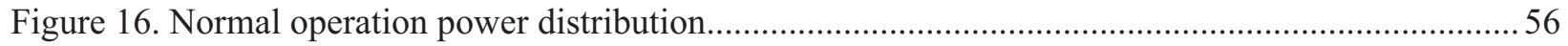

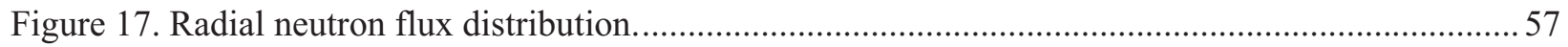

Figure 18. Pebble-bed burnup and fast fluence envelope. .................................................................... 58

Figure 19. Fuel temperature - depressurized loss of forced cooling. .....................................................59

Figure 20. Fuel-temperature distribution at time of maximum temperature-DLOFC........................... 60

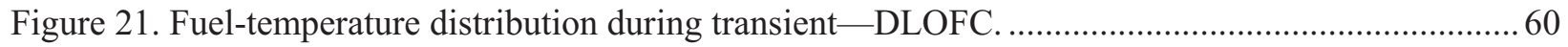

Figure 22. NGNP pebble-bed (PBMR) and HTR-Modul failure fraction vs. temperature curves. ............ 64

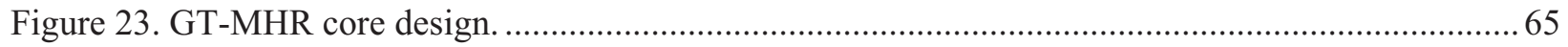

Figure 24. GT-MHR core cross section at vessel mid-plane. ............................................................... 65

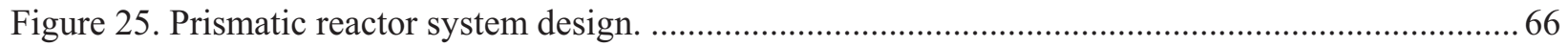

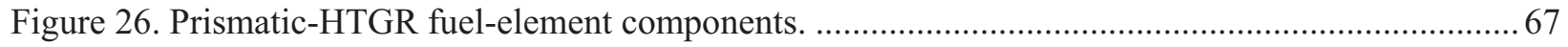

Figure 27. Passive heat removal to the RCCS during HPCC and LPCC events....................................69

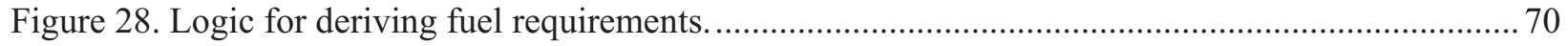

Figure 29. AGR-1 irradiation capsule cross section. ......................................................................... 94

Figure A-1. AVR maximum fuel temperature experiment results......................................................... 109

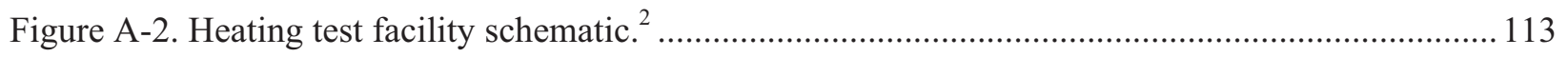

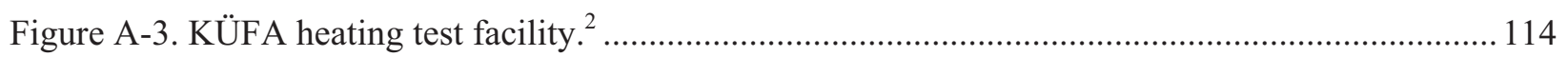

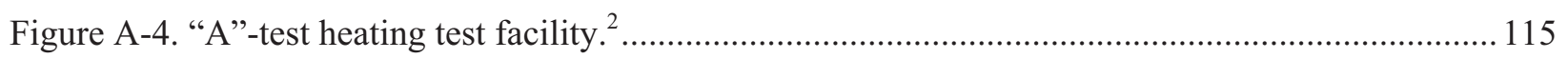




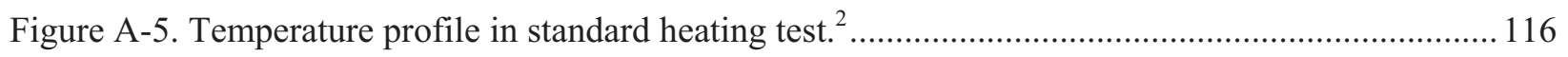

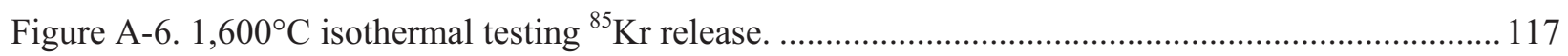

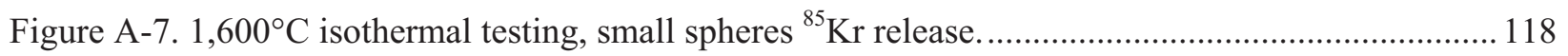

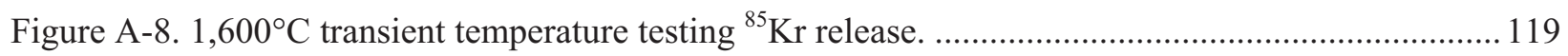

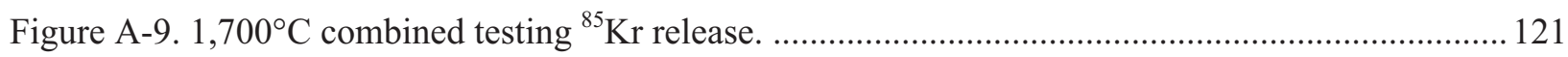

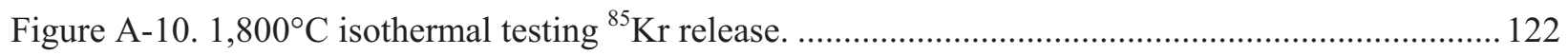

Figure A-11. $1,800^{\circ} \mathrm{C}$ isothermal testing short-term ${ }^{85} \mathrm{Kr}$ release..................................................... 123

Figure A-12. 1,900 to $2,100^{\circ} \mathrm{C}$ isothermal testing ${ }^{85} \mathrm{Kr}$ release results................................................. 125

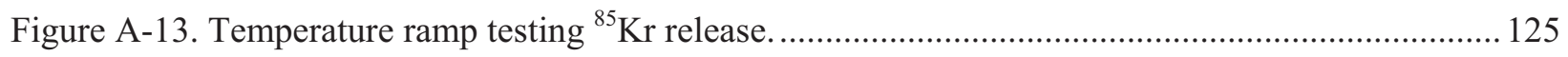

Figure A-14. AVR $71 / 221,600^{\circ} \mathrm{C}$ isothermal testing ${ }^{110 \mathrm{~m}} \mathrm{Ag},{ }^{90} \mathrm{Sr}$, and ${ }^{137} \mathrm{Cs}$ release. ......................... 127

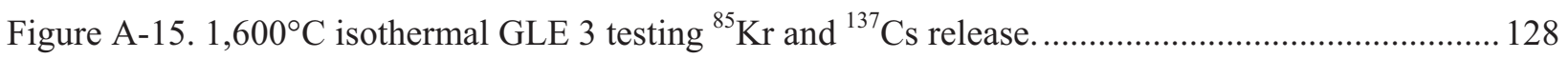

Figure A-16. $1,600^{\circ} \mathrm{C}$ transient GLE 3 testing ${ }^{85} \mathrm{Kr}$ and ${ }^{137} \mathrm{Cs}$ release.............................................. 128

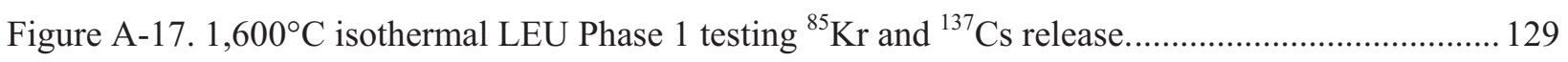

Figure A-18. AVR 74/11 $1,700^{\circ} \mathrm{C}$ isothermal testing ${ }^{110 \mathrm{~m}} \mathrm{Ag},{ }^{90} \mathrm{Sr}$, and ${ }^{137} \mathrm{Cs}$ release. ........................ 130

Figure A-19. $1,700{ }^{\circ} \mathrm{C}$ isothermal and transient GLE 3 testing ${ }^{85} \mathrm{Kr}$ and ${ }^{137} \mathrm{Cs}$ release. ........................ 131

Figure A-20. AVR 76/18 $1,800^{\circ} \mathrm{C}$ isothermal testing ${ }^{110 \mathrm{~m}} \mathrm{Ag},{ }^{90} \mathrm{Sr}$ and ${ }^{137} \mathrm{Cs}$ release. .......................... 132

Figure A-21. $1,800^{\circ} \mathrm{C}$ isothermal GLE 3 testing ${ }^{85} \mathrm{Kr}$ and ${ }^{137} \mathrm{Cs}$ release............................................ 133

Figure A-22. $1,800{ }^{\circ} \mathrm{C}$ isothermal LEU Phase 1 testing ${ }^{85} \mathrm{Kr}$ and ${ }^{137} \mathrm{Cs}$ release.................................... 133

Figure A-23. Representative fission-product profiles in fuel-free zone. ${ }^{3}$............................................... 134

Figure B-1. Probability of rejecting composite for mean kernel diameter.............................................. 146

\section{TABLES}

Table 1. Relationship between fuel-failure mechanisms and fuel-particle properties..............................23

Table 2. LEU UO $\mathrm{UO}_{2}$ TRISO fuels manufactured and tested. ................................................................. 27

Table 3. Manufacturing detail for $\mathrm{LEU} \mathrm{UO}_{2}$ TRISO fuel types. .......................................................28

Table 4. Comparison of fuel irradiation data service conditions with pebble-bed design......................... 33

Table 5. Normal operation prototype sphere irradiation data summary. .................................................. 34

Table 6. Summary of heating test krypton release results. ...................................................................... 35

Table 7. End-of-irradiation fuel condition inferred from heating test data.............................................. 36

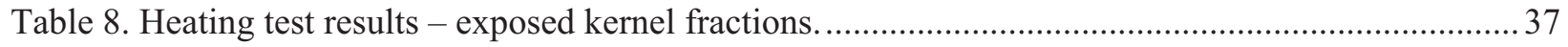

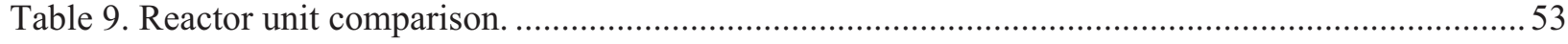

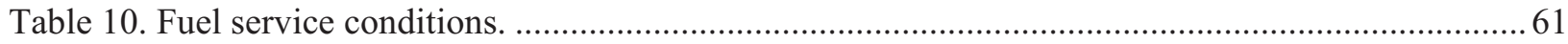

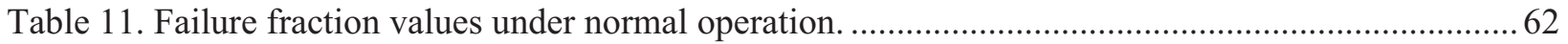

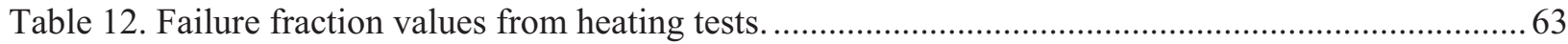

Table 13. NGNP pebble-bed and HTR-Modul failure fraction values. .................................................. 63 
Table 14. Anticipated maximum service conditions for prismatic HTGR fuel for the NGNP.

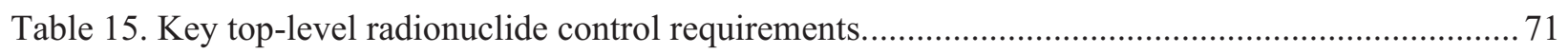

Table 16. Preliminary prismatic HTGR fuel performance requirements................................................ 72

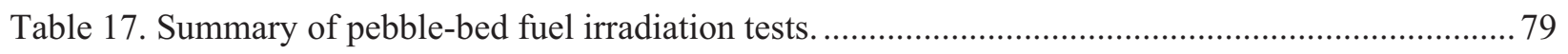

Table 18. PBMR (Pty) LTD AGR-2 fuel compact irradiation test conditions. ........................................ 80

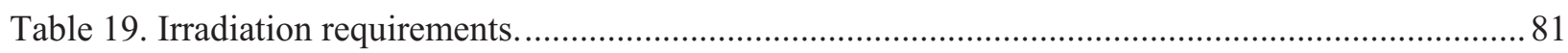

Table 20. Comparison of nominal proof-test irradiation targets with pebble-bed core design

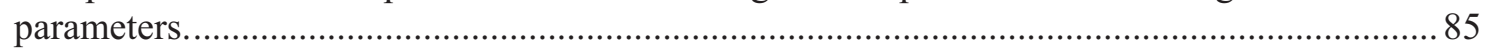

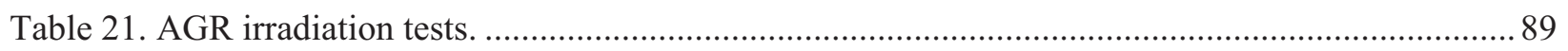

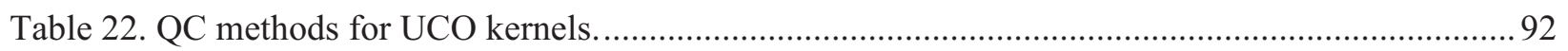

Table 23. QC methods for TRISO fuel particles................................................................................ 92

Table 24. QC methods for fuel compacts. ......................................................................................... 92

Table A-1. Effect of difference in mixed mean coolant temperature rise.............................................. 110

Table A-2. Prototypical sphere materials test reactor irradiations........................................................ 112

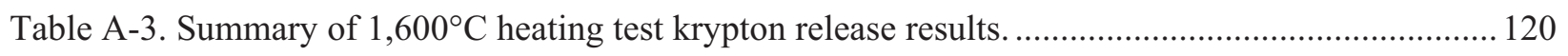

Table A-4. Summary of $1,700^{\circ} \mathrm{C}$ heating test krypton release results................................................ 121

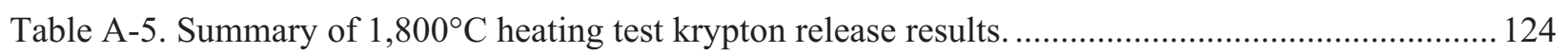

Table A-6. GLE 3 and GLE 4 sphere failure fractions from fission-product profile in fuel-free zone. 135

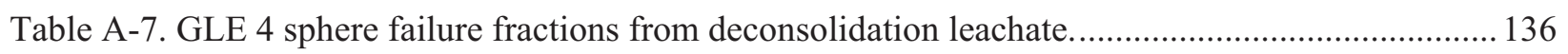

Table A-8. High fluence irradiations in the Netherlands (HFR) and France (SL) ................................ 136

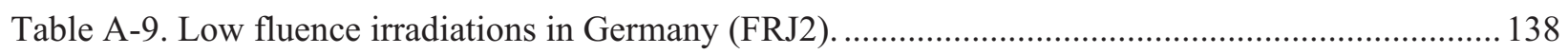

Table B-1. Acceptance number vs. sample size for attribute property acceptance test. ......................... 145 


\section{ACRONYMS}

\begin{tabular}{|c|c|}
\hline ADUN & ammonium diuranate \\
\hline AGR & Advanced Gas Reactor \\
\hline ASME & American Society of Mechanical Engineers \\
\hline ATR & Advanced Test Reactor \\
\hline AVR & $\begin{array}{l}\text { Arbeitsgemeinschaft Versuchsreaktor (Germany; Association Experimental Reactor } \\
\text { Ltd.) }\end{array}$ \\
\hline $\mathrm{B} \& \mathrm{~W}$ & Babcock and Wilcox \\
\hline BAF & Bacon Anisotropy Factor \\
\hline BISO & bistructural isotropic \\
\hline BUMS & Burnup Measurement System \\
\hline CCCTF & Core Conduction Cooldown Test Facility \\
\hline CEDE & committed effective dose equivalent \\
\hline $\mathrm{CO}$ & carbon monoxide \\
\hline $\mathrm{COL}$ & combined licenses \\
\hline COLA & Combined License Application \\
\hline CRDM & control rod drive mechanism \\
\hline CS & core structures \\
\hline $\mathrm{CSC}$ & core structure ceramics \\
\hline DBA & design basis accidents \\
\hline DLOFC & depressurized loss of forced cooling \\
\hline DOE & Department of Energy \\
\hline $\mathrm{EAB}$ & exclusion-area boundary \\
\hline $\mathrm{EBC}$ & equivalent boron content \\
\hline ECCS & Emergency Core Cooling System \\
\hline EFPD & effective full power day \\
\hline EPA & Environmental Protection Agency \\
\hline EPRI & Electric Power Research Institute \\
\hline EPZ & emergency planning zone \\
\hline FACS & Fuel Accident Condition Simulator \\
\hline FDL & Fuel Development Laboratory \\
\hline FFF & Fuel Fabrication Facility \\
\hline FIMA & fissions per initial metal atom \\
\hline FRG & Federal Republic of Germany \\
\hline FRJ & DIDO Reactor (Germany) \\
\hline
\end{tabular}




\begin{tabular}{|c|c|}
\hline FSV & Fort St. Vrain \\
\hline FZJ & Forschungszentrum Jülich \\
\hline GA & General Atomics \\
\hline GDC & general design criteria \\
\hline GLE & Gepresst (pressed) Low Enriched - fuel spheres \\
\hline GT-MHR & gas-turbine modular helium reactor \\
\hline HEU & highly enriched uranium \\
\hline HFEF & Hot Fuel Examination Facility \\
\hline HFIR & High-Flux Isotope Reactor \\
\hline HM & heavy metal \\
\hline HPCC & high-pressure conduction cooldown \\
\hline HTGR & high-temperature gas-cooled reactor \\
\hline HTR-10 & 10-MWt High Temperature Gas-Cooled Reactor (China) \\
\hline HTTR & High Temperature Engineering Test Reactor (Japan) \\
\hline IAEA & International Atomic Energy Agency \\
\hline ICP-MS & inductively coupled plasma-mass spectroscopy \\
\hline IMGA & irradiated microsphere gamma analyzer \\
\hline INL & Idaho National Laboratory \\
\hline INM & Independent News and Media \\
\hline $\mathrm{IPyC}$ & inner pyrolytic carbon or pyrocarbon \\
\hline ISI & in-service inspection \\
\hline KFA & Kernforschungsanlage Jülich \\
\hline LBE & licensing basis event selection \\
\hline LBL & leach-burn-leach \\
\hline LEU & low-enriched uranium \\
\hline LPCC & low-pressure conduction cooldown \\
\hline LTI & low-temperature isotropic \\
\hline LWR & light water reactor \\
\hline MFC & Materials and Fuels Complex \\
\hline MHTGR & modular high-temperature gas-cooled reactor \\
\hline MTR & materials test reactor \\
\hline NAA & neutron activation analysis \\
\hline NGNP & Next Generation Nuclear Plant \\
\hline NP-MHTGR & new production modular high-temperature gas-cooled reactor \\
\hline NPR & new production reactor \\
\hline
\end{tabular}


NRC

O\&M

OECD

OPyC

ORNL

PAG

PARFUME

PBMR

PFP

PIE

PIRT

PLOFC

PSER

PyC

QA

QAP

QC

R\&D

$\mathrm{R} / \mathrm{B}$

R2

RCCS

RCS

RN

ROT

RPV

RSM

RSS

RU

SAFDL

SL

SNR

SRM

TEDE

THTR
Nuclear Regulatory Commission

Operations and Maintenance

Organization for Economic Cooperation and Development

outer pyrolytic carbon or pyrocarbon

Oak Ridge National Laboratory

Protective Action Guide

Particle Fuel Model (code) at INL

Pebble-Bed Modular Reactor

Pilot Fuel Plant (PBMR)

post-irradiation examination

Phenomena Identification and Ranking Tables

pressurized loss of forced cooling

preapplication safety evaluation report

pyrocarbon

Quality Assurance

Quality Assurance Program

Quality Control

research and development

release-to-birth

Material Test Reactor (Studsvik, Sweden)

reactor cavity cooling system

reactivity control system

radionuclide

reactor outlet temperature

reactor pressure vessel

reserve shutdown material

reserve shutdown system

reactor unit

specified acceptable fuel design limit

Siloe Reactor (France)

signal-to-noise ratio

Staff Requirements Memorandum

total effective dose equivalent

Thorium High Temperature Reactor (Hamm-Uentrop, Germany) 
TINTE Time-Dependent Neutronics and Temperatures

TRISO tristructural -isotropic

UCO uranium oxycarbide

$\mathrm{V} \& \mathrm{~V} \quad$ Verification and Validation

VHTR very high temperature reactor 


\section{NGNP Fuel Qualification White Paper}

\section{INTRODUCTION}

The HTGR concepts currently under consideration for the NGNP include both pebble-bed and prismatic-block reactors. Both concepts employ TRISO fuel particles, but the pebble-bed concept uses $\mathrm{UO}_{2}$ (uranium dioxide) fuel particles made into spheres (approximately $60 \mathrm{~mm}$ in diameter), and the prismatic-block concept uses UCO (uranium oxycarbide) ${ }^{\mathrm{a}}$ fuel particles made into cylindrical compacts that are then loaded into hexagonal-shaped graphite fuel blocks, 0.36 meters across the flats and 0.8 meters high. $\mathrm{UO}_{2}$ fuel has been selected for the pebble-bed concept because the existing data, primarily from the German program, demonstrate acceptable performance capability within the range of fuel service conditions required for pebble-bed reactor designs. UCO fuel has been selected for the prismatic-block-type HTGRs because of its inherent capability to achieve acceptable fuel performance at higher burnup, which permits longer fuel cycles and, therefore, fewer refueling outages.

The TRISO fuel particle consists of a microsphere (i.e., kernel) of nuclear material encapsulated by multiple layers of pyrocarbon and a SiC (silicon carbide) layer. This multiple-coating-layer system has been engineered to retain the fission products generated by fission of the nuclear material in the kernel during normal operation and all licensing basis event selections (LBEs) over the design lifetime of the fuel. Although plant safety depends on many factors, the TRISO-coated fuel is particularly critical to the safe operation of the reactor because the fuel particles are the primary (but not the only) barrier to fissionproduct release in HTGRs.

Thus, fuel's ability to retain fission products is extremely important to the safety case and licensing approach for HTGRs. It is a key part of mechanistic source terms because accident analyses are based on high-quality fuel performing predictably during normal reactor operation and accident conditions. Qualification of the fuel to the stringent HTGR fuel performance requirements is essential for licensing these designs.

The approach to qualification of the two fuel types under consideration for the NGNP are described in Section 5 and summarized below:

- Prismatic Reactor - In recognition of the importance of the fuel to commercial deployment of HTGR technology, the Department of Energy (DOE) initiated the Advanced Gas Reactor (AGR) Fuel Development and Qualification Program in 2002. This program has since become part of the NGNP Project and is now called the NGNP/AGR Fuel Development and Qualification Program, which will henceforth be referred to as the NGNP/AGR Fuel Program. The NGNP/AGR Fuel Program has primarily focused on testing and qualification of the UCO fuel type for prismatic-block-type HTGRs and is intended to produce all of the data necessary for qualification of this fuel.

- Pebble-bed Reactor - The qualification of $\mathrm{UO}_{2}$ fuel particles is based on a combination of existing German low-enriched uranium (LEU) $\mathrm{UO}_{2}$ test data and additional testing of fuel replicating the German design and fabrication process. The program for additional testing discussed in this paper was developed primarily to support a demonstration power plant to be constructed in South Africa. That project was recently cancelled, and the pebble-bed testing program may undergo significant changes. As revised testing plans are developed in the near future, they will be described and discussed in the course of revising this paper.

a. The proper notation for uranium oxycarbide is $\mathrm{UC}_{\mathrm{x}} \mathrm{O}_{\mathrm{y}}$ with $\mathrm{x}$ being the mole fraction of carbon and $\mathrm{y}$ being the mole fraction of oxygen. However, for simplicity, $\mathrm{UC}_{\mathrm{x}} \mathrm{O}_{\mathrm{y}}$ is referred to simply as $\mathrm{UCO}$ throughout this paper. 


\subsection{Purpose}

This white paper summarizes the planned fuel-qualification approach for both pebble-bed and prismatic-block reactors and the technology base that provides the foundation for the planned program. The information in this paper is intended to serve as the basis for interactions with NRC staff.

The purpose of this paper is as follows:

- Identify existing regulations, regulatory guidance, and licensing precedents relevant to the qualification of fuel for the NGNP project

- Summarize existing understanding, data, and analysis methods regarding coated-particle fuel performance

- Review reactor and fuel designs and resulting fuel service conditions and performance requirements

- Describe planned fuel fabrication, irradiation, testing activities, and approach to qualify the fuel

- Obtain feedback from the NRC on the planned approach and information required for the combined license application (COLA).

\subsection{Scope}

This paper focuses on the existing licensing framework, use of the existing fuel performance data, the NGNP project design envelope for fuel service, and the planned fuel-qualification program to establish the bases of fuel performance under the intended operating conditions.

Section 2 provides an overview of the regulatory bases that apply to TRISO fuel for the HTGR design. Section 3 summarizes the background information for HTGR fuel-technology basis resulting from decades of fuel-technology developments in the U.S., the United Kingdom, Germany, Russia, Japan, China, and South Africa which is the foundation for both pebble-bed and prismatic HTGR-based NGNP fuel design, fabrication, and qualification programs. Section 4 summarizes the NGNP pebble-bed and prismatic reactor design and performance characteristics to which the fuel must be qualified. Section 5 summarizes the fuel-qualification programs for both pebble-bed and prismatic fuels. Section 6 provides the NRC review outcome objectives.

The release of gaseous and metallic fission products from the kernel and the transport of fission products through the fuel compact matrix, fuel-element graphite, and into the helium primary coolant are key parameters that influence the fuel quality and in-service fuel-performance requirements. The radionuclide-transport properties are important characteristics of the fuel, and the models used to calculate radionuclide releases from the fuel particles require validation. The quality requirements and in-service failure limits for the fuel are partially based on the radionuclide retention/transport characteristics of the fuel components. And because the radionuclide source terms used in accident analyses are based on all of these parameters, it is difficult to separate the topics of fuel-qualification and source term qualification. Therefore, an associated white paper on mechanistic source term qualification has been prepared to address the fission-product retention and transport characteristics.

This paper focuses on the use of the existing and past fuel-performance data, NGNP project design envelope for fuel service, and planned fuel-qualification program to demonstrate acceptable fuel performance under the intended operating conditions.

\subsection{Summary of Outcome Objectives}

The information in this paper is intended to serve as the basis for interaction with NRC staff. As stated above, this paper focuses on the use of the existing fuel-performance data, the NGNP plant design envelope for fuel service, and the planned fuel-qualification program to establish the bases of fuel performance under the intended operating and design conditions. Specifically for $\mathrm{UO}_{2}$ fuel, the service 
condition parameters are being selected based on past German experience and pebble-bed reactor analysis; for the UCO fuel type, the service condition parameters are being developed through the NGNP/AGR Fuel Program, which are driven by the prismatic reactor but will provide improved fuel performance for the pebble-bed reactor. Both fuels will provide consistent, predicable performance during plant operations within their respective performance envelopes.

The primary issues for which NRC staff feedback is requested prior to submission of the COLA include:

- Plans established in Section 5 for qualification of the $\mathrm{UO}_{2}$ pebble fuel type are generally acceptable.

These include:

- Utilization of German data for normal operation irradiation, and transient/accident heat-up conditions,

- Performance of additional confirmatory irradiation and safety tests on fuel manufactured at a qualified facility to (1) statistically strengthen the performance database and (2) demonstrate that the fuel performance is equivalent to or better than the German fuel upon which the $\mathrm{UO}_{2}$ pebble fuel design is based.

- Plans established in Section 5 for qualification of the UCO prismatic fuel type are generally acceptable based on the NGNP/AGR Fuel Program.

- Other activities and information as necessary to support the qualification of both pebble-bed $\mathrm{UO}_{2}$ and prismatic UCO fuels.

Therefore, it is requested that the NRC review either:

- Confirm that the plans presented in this paper are generally acceptable

- Identify any additional information or testing needed to demonstrate adequate NGNP fuel performance.

\subsection{Relationship of Other NGNP Topics/Papers}

The NGNP is developing a series of white papers that address priority-licensing issues as a means of focusing the NRC review and establishing requirements for acceptable COLA contents. In this process, white papers will be prepared, including specific NRC review objectives for each topic. The following subsections provide synopses of white papers related to the topic of fuel qualification. These white papers have been developed, are currently in development, or will be developed for future submittal.

\subsubsection{Defense-in-Depth Approach}

Defense-in-depth is a safety philosophy in which multiple lines of defense and conservative design and evaluation methods are applied to ensure the safety of the public. The philosophy is also intended to deliver a design that is tolerant to uncertainties in knowledge of plant behavior, component reliability, or operator performance that might compromise safety. This paper includes a review of the regulatory foundation for defense-in-depth, a definition of defense-in-depth that is appropriate for advanced reactor designs based on high-temperature gas-cooled reactor (HTGR) technology, and an explanation of how this safety philosophy will be achieved in the NGNP Project. This white paper was submitted on December 9, 2009 (CCN 219274).

\subsubsection{Mechanistic Source Terms}

The NGNP Project will employ a mechanistic source term approach for plant design and licensing. As used here, "mechanistic source term" is defined as a source term that is derived from analysis of fuel and reactor behavior during specific accident scenarios. The information developed in the mechanistic source terms white paper will be generic to prismatic and pebble-bed reactor designs to the extent practicable. However, radionuclide source terms are not completely generic for prismatic and pebble-bed 
HTGR designs; consequently, the mechanistic source terms white paper will describe those aspects of the radionuclide source terms that are generic but will also identify differences between the two reactor types and discuss the design and licensing implications of these differences. The determination of asmanufactured fuel quality and the results of fuel qualification testing to determine fuel performance (failure fraction) described in this fuel qualification paper will support the determination of the radionuclide release from the fuel as input to the determination of the source term. The mechanistic source terms white paper is provided in NGNP report number INL/EXT-10-17997.

\subsubsection{Emergency Planning Zone (EPZ)}

Modular HTGRs result in an accident source term considerably less than that of the current generation of LWRs. Consequently, the reduction of the EPZ to approximately the size of the exclusionarea boundary $(\mathrm{EAB})$ has been a major goal. Information obtained from both the fuel qualification and mechanistic source term white papers are critical input for development of the white paper for EPZ reduction. This white paper is planned for the NRC submittal at a later date.

\subsubsection{Air and Water Ingress}

These white papers will address that the design and safety analysis methods used to demonstrate that air and water ingress into the reactor vessel during licensing basis events. The events and conditions associated with air and water ingress events to be addressed within the licensing basis will be incorporated into the planned accident condition fuel testing. The current scope of fuel testing is discussed in the fuel qualification white paper. These white papers will be submitted to the NRC at a later date.

\subsubsection{Licensing Basis Event (LBE) Selection}

LBEs are event scenarios considered in the licensing process and used to derive regulatory requirements for design certification. LBEs include normal plant operation, events anticipated to occur over the life of the plant, and off-normal events as required by 10 CFR Part 52, including infrequent design basis events (DBEs) and rare events beyond the design basis. This white paper is planned for the NRC submittal at a later date. 


\section{REGULATORY BASES}

\subsection{NRC Regulations}

Regulations related to the scope of this document are codified primarily in: the General Design Criteria (GDC) contained in Appendix A to 10 CFR Part 50 ${ }^{1}$; 10 CFR $\$ 50.46$, acceptance criteria for emergency core cooling systems for light water reactors (LWRs); the quality assurance requirements in Appendix B of 10 CFR Part 50; and 10 CFR $\$ 52.79$, contents of applications for COLs.

The GDC establishes minimum requirements for the principal design criteria for water-cooled nuclear power plants similar in design to existing conventional plants. The GDC, developed in the context of water-cooled designs, do not necessarily apply to other types of reactors, such as HTGRs. Nevertheless, as discussed in the introduction to Appendix A of 10 CFR Part 50, the GDC are considered to be generally applicable to other types of nuclear power units and are intended to provide guidance in establishing the principal design criteria for such units.

GDC 10 and 35 provide some guidance relevant to the scope of this document. Other GDC pertain to the reactor core (GDC 11, 12, 13, and 27), but do not directly pertain to the performance of the HTGR fuel that is the subject of this paper.

GDC 10 and 35 contain the following requirements:

- GDC 10, Reactor Design, states that "the reactor core and associated coolant, control, and protection systems shall be designed with appropriate margin to assure that specified acceptable fuel design limits are not exceeded during any condition of normal operation, including the effects of anticipated operational occurrences."

- GDC 35, Emergency Core Cooling, states that "an emergency core cooling system shall be provided 'such that (1) fuel and clad damage that could interfere with continued effective core cooling is prevented and (2) clad metal-water reaction is limited to negligible amounts."”

Similarly, 10 CFR $\$ 50.46$ requires light-water power reactors fueled with uranium oxide pellets within cylindrical zircaloy or ZIRLO cladding to be provided with an emergency core cooling system (ECCS). The ECCS will be designed so that its calculated cooling performance following postulated lossof-coolant accidents conforms to specified criteria regarding peak cladding temperature, maximum cladding oxidation, maximum hydrogen generation, coolable geometry, and long-term cooling.

Because of design differences between water-cooled and gas-cooled reactors, the ECCS design requirements in GDC 35 and 10 CFR $\S 50.46$, other than those for coolable core geometry, are not directly applicable to the NGNP fuel design. 10 CFR Part 50, Appendix B, applies to the production of fuel-performance data.

10 CFR $\$ 52.79$ (a)(24) provides guidance on the content of the COLA for designs that differ significantly from LWR designs licensed before 1997, or that utilize simplified, inherent, passive, or other innovative means to accomplish their safety functions. It references 10 CFR $§ 50.43(\mathrm{e})$ which, in summary, requires a combination of analyses and test programs to demonstrate the performance of safety features and assure that sufficient data exist to assess the analytical tools used for safety analyses. This applies to the NGNP design. This paper describes how these requirements are met for HTGR fuel.

\subsection{NRC Policy Statements}

No NRC policy statements directly apply to the type of fuel proposed for use in the NGNP or that address testing or monitoring of the fuel, nor does the NRC policy statement on regulation of advanced nuclear power plants explicitly address nuclear fuel. However, NRC policy issues specific to the HTGR concept are identified in SECY-93-092 and in Section 5 of NUREG-1338. Of the ten issues identified in SECY-93-092, both the "Containment Performance" and "Source term" policy issues are related to the 
fuel because the use performance of the HTGR's multi-barrier containment configuration and associated mechanistic source terms for accident analyses are based on the performance of the fuel being both excellent and predictable.

\subsubsection{Containment Functional Performance}

The current LWR containment leakage requirements are in GDC 16 and Appendix J of 10 CFR Part 50. The containment performance issue involves whether an advanced reactor design should be allowed to employ alternative approaches to the traditional "essentially leak-tight" containment structures used in LWRs to provide for the control of fission-product releases to the environment.

Fundamental to the HTGR concept is its emphasis on release prevention by utilizing high-integrity fuel particles rather than a leak-tight containment barrier to minimize radionuclide releases to the environment. In SECY-s-03-0047, 04-0103 and 05-006, ${ }^{3}$ the Commission approved the use of a standard based on containment functional performance to evaluate the acceptability of the proposed designs, rather than relying on prescriptive containment design criteria. As part of the containment evaluation, the Commission instructed the staff to address the failure of the fuel particles, among other issues.

The integrity of the fuel particles is discussed in Section 3, and details of the HTGR barriers to fission product radionuclide release are further discussed in the NGNP mechanistic source term white paper.

\subsubsection{Source term}

The source term for the HTGR technology is defined as the quantities of radionuclides released from the reactor building to the environment. The HTGR definition is judged appropriate for greater emphasis on fuel retention of radionuclides for events rather than reactor building retention following an event. This is further discussed in the NGNP mechanistic source terms white paper.

The Commission conditionally approved the staff's position that the source terms should be based on a mechanistic analysis; one of the conditions was that the performance of the reactor and fuel under normal and off-normal conditions is sufficiently understood to permit a mechanistic analysis. Sufficient data should exist on fuel performance through research, development, and testing programs to provide adequate confidence in this approach.

\subsection{NRC Guidance/References}

\subsubsection{NUREG-1338, "Pre-application Safety Evaluation Report for the MHTGR"}

In 1989, a draft preapplication safety evaluation report (PSER) ${ }^{4}$ documented the NRC staff's preapplication review of the modular high-temperature gas-cooled reactor (MHTGR) design and its conclusions from the review. The DOE submitted additional information for the fuel design in 1991 and 1992 and held two meetings with NRC on fuel design and fission-product transport in $1991 .^{5}$ A draft of the final PSER was completed in December $1995 .{ }^{6}$ The draft of the final PSER is based on the draft PSER issued in 1989 and on a number of reports completed after the draft PSER was issued.

The draft final PSER confirmed the following overall conclusions of the 1989 draft PSER with respect to the fuel design, specifically:

- The NRC staff believes that fuel design and quality can be developed to meet the performance objectives proposed by DOE and required by the safety analyses but notes that this conclusion is dependent on the successful outcome of the research program

- The NRC staff notes that actual fuel performance in the Federal Republic of German (FRG) reactors, together with reported laboratory and in-pile tests, gives promise that fuel performance objectives can eventually be demonstrated. 
However, NUREG-1338 also states that the information provided for the HTGR up to that time had not demonstrated the necessary design and quality of fuel to meet these performance objectives. It identifies the following information that NRC needs to reach a determination on the fuel:

- Design thicknesses of fuel particle coatings and the bases for these thicknesses given the proposed fuel failures from manufacturing, normal operation (neutron fluence), and accidents (temperature)

- Quality control of the manufacturing process for the fuel and resulting tolerances on the coatings

- Fuel performance of specific coated particles and coating tolerances demonstrated from irradiation and safety tests

- Expected fuel temperatures throughout the core during accidents and the resulting volume-averaged failed fuel fraction

- Potential dose consequences shown to be within acceptable limits for the predicted volume-averaged failed fuel fraction.

NUREG-1338 also includes the following conclusions to be considered in qualifying fuel for the HTGR-based NGNP:

- The statistical question of how many fuel particles are needed in the irradiation and safety tests to justify the proposed low failed-fuel fraction within $95 \%$ certainty.

- The fuel design and containment proposed for the MHTGR, which NRC staff considers to be a licensability issue for the MHTGR. (Licensability issues occur when the design departs significantly from what NRC has accepted in the past or when changes in the design to resolve a staff concern could fundamentally alter the proposed design.)

- The credible mechanisms for "weak fuel" (fuel that performs acceptably during normal reactor operation but is subject to failure under more stringent conditions during accidents) to ensure that all mechanisms for fuel failure are recognized and quantitatively accounted for in the fuel-performance models.

The NRC guidance provided in NUREG-1338 indicates that successful completion of the Fuel Research and Development (R\&D) program must provide a statistically significant demonstration that:

- The reference fuel manufacturing processes and quality-control methods ensure the production of fuel meeting specification requirements

- The fuel fabricated using the reference fuel manufacturing processes meets the fuel performance requirements under normal operation and all credible accident conditions

- Validated methods are available to accurately predict fuel performance and fission-product transport.

\subsubsection{NUREG-0111, "Evaluation of High Temperature Gas-Cooled Reactor Particle Coating Failure Models and Data"}

NUREG- $0111^{7}$ addresses highly enriched uranium (HEU) $\mathrm{UC}_{2}$ TRISO fissile particles with a $200-\mu \mathrm{m}$ kernel and $\mathrm{ThO}_{2}$ bistructural isotropic (BISO) fertile particles with a 500- $\mu \mathrm{m}$ kernel for service in a large prismatic HTGR. Major differences in particle design, fabrication specifications, and service conditions relative to the fuel for the HTGR-based NGNP limit the applicability of this report to the current low-enriched uranium (LEU) fuel. Nonetheless, experience with this and other diverse fuel types over the course of HTGR fuel development has provided valuable insights into the development and understanding of the LEU UCO TRISO fuel. 


\subsubsection{NUREG-0800, Standard Review Plan, Section 4.2, "Fuel System Design"}

The purpose of the fuel system safety review under Standard Review Plan (SRP) $4.2^{8}$ is ensure that the fuel design meets the LWR requirements of GDC 10 and 35 and the core coolability requirements of 10 CFR §50.46. To this end, SRP 4.2 contains guidance on specified acceptable fuel design limits (SAFDLs) that ensure that (1) LWR fuel is not damaged as a result of normal operation and anticipated operational occurrences, (2) fuel damage is never so severe as to prevent control-rod insertion when it is required, (3) the number of fuel-rod failures is not underestimated for postulated accidents, and (4) coolability is always maintained. The SAFDL objectives were developed for water-cooled reactors, and no clear acceptance criteria exist for HTGR fuel in the current regulatory framework.

To demonstrate that the SAFDLs have been established and satisfied, SRP 4.2 states that the NRC staff will review:

- Design bases for the fuel

- Description and design drawings for the fuel

- Evaluation of the fuel design

- Plans for fuel testing, inspection, and surveillance.

Each of these four areas is discussed in the following sections.

\subsubsection{Fuel Design Bases}

The SRP indicates that fuel design bases should reflect the SAFDL objectives described in Section 2.3.1. To satisfy these objectives, acceptance criteria are needed for fuel damage, fuel failure, and fuel coolability.

\section{Fuel Damage}

To meet the requirements of GDC 10 as it relates to SAFDL for normal operation, including anticipated operational occurrences, SRP 4.2 states that fuel damage criteria should be given for all known damage mechanisms. Requirements include:

- Stress, strain, or loading limits for spacer grids, guide tubes, thimbles, fuel rods, control rods, channel boxes, and other fuel-system structural members should be provided. Stress limits obtained by methods other than those specified in Section III of the American Society of Mechanical Engineers (ASME) Code should be justified.

- The cumulative number of strain fatigue cycles on the structural members should be significantly less than the design fatigue lifetime, which should be based on appropriate data and include a safety factor of 2 on stress amplitude or a safety factor of 20 on the number of cycles.

- Fretting wear at contact points to structural members should be limited, and allowable fretting wear should be stated in the safety analysis.

- Oxidation, hydriding, and the buildup of corrosion products (crud) should be limited. Allowable oxidation, hydriding, and crud levels should be discussed in the safety analysis and shown to be acceptable. NUREG-1338 (see Pages 4-5 to 4-6) indicates that analogous mechanisms, such as chemical decomposition failure modes applicable to HTGR fuel and the potential effects of water intrusion into the system should be discussed and evaluated.

- Dimensional changes, such as rod bowing or irradiation growth of fuel rods, control rods, and guide tubes, should be included in the analysis to establish operational tolerances.

- Fuel- and burnable-poison-rod internal gas pressures should remain below the nominal system pressure during normal operation unless otherwise justified. 
- Worst-case hydraulic loads for normal operation should not exceed the hold-down capability of the fuel assembly (either gravity or hold-down springs).

- Control-rod reactivity should be maintained.

Except for control rods, these types of components are not contained in the HTGR design. However, NUREG-1338 (Page 4-4) indicates that the essential elements of the TRISO coating should be evaluated and the structural function of each layer of the coating should be analyzed. In NUREG-1338 (Page 4-6), the NRC indicated that the acceptance criteria for the HTGR fuel design should be "at least the functional equivalent of the LWR fuel-acceptance criteria in accordance with Section 4.2 of the Standard Review Plan." The failure mechanisms of TRISO fuel are further discussed in Section 3.

\section{Fuel Failure}

To meet the requirements of GDC 10 as it relates to SAFDL for normal operation, including anticipated operational occurrences (as well as 10 CFR Part 100 as it relates to fission-product releases for postulated accidents), the SRP (Page 4.2-8) states that fuel-rod failure criteria should be given for all known fuel-failure mechanisms. The SRP lists eight failure modes for water-cooled reactor fuel:

- Internal hydriding

- Cladding collapse

- Fretting of cladding

- Overheating of cladding

- Overheating of fuel pellets

- Excessive fuel enthalpy

- Bursting

- Mechanical fracturing.

Internal hydriding, cladding collapse, fretting of cladding, and overheating of cladding failure modes do not apply to HTGRs because no metal cladding is used in the design of HTGR fuel. However, in NUREG-1338 (Page 4-4), the NRC examined the following failure modes for TRISO-coated fuel particles, which differed from those discussed above for conventional water-cooled reactor fuel:

- Pressure-induced failures

- Irradiation-induced failures

- Failures caused by thermal decomposition of $\mathrm{SiC}$ at elevated temperatures

- Failures caused by internal corrosion mechanisms.

Because of the very large number of fuel particles employed in HTGR designs, NUREG-1338 (Page 4-6) states that the use of statistical methods would be emphasized in evaluating such fuel designs. The failure mechanisms of TRISO fuel and statistical methods are further discussed in Section 3.

\section{Fuel Coolability}

SRP 4.2 (Page 4.2-10) states that fuel assemblies should retain coolability, including retaining-rod-bundle geometry with adequate coolant channels to permit removal of residual heat. Reduction of coolability can result from cladding embrittlement, violent expulsion of fuel, generalized cladding melting, gross structural deformation, and extreme coplanar fuel-rod ballooning. The mechanisms for potential blockage of coolant channels are different in HTGR prismatic designs, but retention of fuel element integrity is an issue that will be addressed with respect to fuel coolability. For pebble-bed designs, the spherical fuel design is sufficiently different from traditional designs that the 
majority of fuel coolability considerations typically used for water-cooled reactors would not apply. The service conditions associated with both pebble and prismatic fuel designs is further discussed in Section 4.

\subsubsection{Description and Design Drawings}

SRP 4.2 (Page 4.2-12) states that the NRC should be provided with a description and design drawings that are sufficiently complete to provide an accurate representation of the fuel. This includes comprehensive dimensional and metallurgical information regarding:

- Cladding

- Fuel pellet data - including dimensions, roughness, density, resintering, burnable-poison content, internal void volume, and fill gas type and pressure

- Enrichment data

- Hydraulic diameter

- Coolant design pressure

- Burnup limit.

Equivalent information for the HTGR will be provided in the COLA. Design and performance requirements are further discussed in Section 4.

\subsubsection{Design Evaluation}

SRP 4.2 (Page 4.2-14) states that the NRC will review the methods of demonstrating that the design bases are met. To ensure that the design bases are met, the NRC will examine:

- Operating experience with the fuel and other similar designs

- $\quad$ Prototype testing

- Analytical predictions.

NUREG-1338 (Page 4-7) also stresses that adequacy of the technology-development plan for fuel development is an essential element for staff acceptance of an HTGR. This is further discussed in Section 5.

\section{Operating Experience}

SRP 4.2 (Page 4.2-14) states that the NRC will review operating experience with fuel systems of the same or similar design. The SRP states that such experience should be described in detail, including the maximum burnup achieved, and that the NRC values actual operating experience over prototype testing or analytical predictions. The operating experience of $\mathrm{UO}_{2}$ fuel is further discussed in Section 2.

\section{Prototype Testing}

SRP 4.2 (Page 4.2-14) states that the NRC will look to prototype testing to demonstrate adherence to the fuel design bases. Prototype testing typically includes both out-of-reactor and in-reactor testing. Out-of-reactor tests should be performed when practical to determine the characteristics of the new design. The SRP does not contain definitive requirements regarding design features that should be tested prior to irradiation. However, it states that out-of-reactor tests have been performed for past designs of fuel assembly structural components and hydraulic characteristics. The SRP also states that the NRC will review in-reactor testing of design features and lead-assembly irradiation of whole assemblies of a new fuel design. Of particular interest is the maximum burnup experience achieved in in-reactor prototype testing in relation to the specified maximum burnup limit for the new design. 
For the HTGR, NUREG-1338 (Page 4-9) states that statistically low failure rates assumed in the fuel safety analysis will require a rigorous $\mathrm{R} \& \mathrm{D}$ program that complies with a systematic statistical approach commensurate with the number of parameters and the required accuracy.

\section{Analytical Predictions}

SRP 4.2 acknowledges that some design bases and related parameters can only be evaluated analytically. Page 4.2-15 of SRP 4.2 provides a list of parameters that NRC will review, including analytical models for fuel temperatures (stored energy), densification effects, fuel-rod bowing, structural deformation, rupture and flow blockage, fuel-rod pressure, metal/water reaction rate, and fission product inventory. In NUREG-1338 (Pages 4-6 and 4-8), the NRC relied upon NUREG-0111 to guide the evaluation. NUREG-0111 addresses $\mathrm{HEU} \mathrm{UC}_{2}$ TRISO fissile particles with a $200-\mu \mathrm{m}$ kernel and $\mathrm{ThO}_{2}$ BISO fertile particles with a 500- $\mu \mathrm{m}$ kernel for service in a large prismatic HTGR. Major differences in particle design, fabrication specifications, and service conditions relative to the fuel for the HTGR-based NGNP limit the applicability of this report to the current LEU fuel. Nonetheless, experience with this and other diverse fuel types over the course of HTGR fuel development has provided valuable insights and understanding of LEU UCO TRISO fuel.

\section{Fuel Testing, Inspection, and Surveillance}

SRP 4.2 (Page 4.2-20) states that for a fuel design that introduces new features, a more detailed surveillance program, commensurate with the nature of the changes, is warranted. The program should include appropriate qualitative and quantitative inspections to be carried out at interim and end-of-life refueling outages. This surveillance program should be coordinated with prototype testing. When prototype testing cannot be performed, a special detailed surveillance program should be planned for the first irradiation of a new design. The MHTGR review was based on a preliminary safety information document for a standardized design with a long-term objective of obtaining a final design approval and certification. The scope of the review did not include fuel testing, inspection, and surveillance. For a pebble-bed design, the online recirculation of spherical fuel provides a practical approach for surveying fuel performance.

\subsubsection{TRISO-Coated Particle Fuel Phenomenon Identification and Ranking Tables}

In anticipation of future licensing applications for HTGRs, the NRC commissioned a panel to identify and rank the phenomena associated with TRISO-coated-particle fuel in order to obtain a better understanding of the significant features of TRISO-coated-particle fuel design, manufacture, and behavior during both normal reactor operation and accidents. Six Phenomena Identification and Ranking Tables (PIRTs) were developed by the panel, including PIRTs on:

- Manufacturing

- Operations

- Depressurized heat-up accident

- Reactivity accident

- Depressurized accident with water ingress

- Depressurization accident with air ingress.

In preparing the PIRTs, the panel assumed the plant to be a pebble-bed reactor with $\mathrm{UO}_{2}$ fuel, except for the reactivity accident PIRT, in which case a prismatic reactor was considered. However, the panel also identified and evaluated the importance and knowledge rankings that would be different for prismatic reactor UCO fuel. The PIRTs are documented in NUREG/CR-6844, Vol. 1. ${ }^{9}$ 
According to NUREG/CR-6844, the NRC will use the PIRT results to:

1. Identify key attributes of gas-cooled reactor fuel manufacture that may require regulatory oversight

2. Provide a valuable reference for the review of vendor HTGR fuel qualification plans

3. Provide insights for developing plans for fuel safety margin testing

4. Assist in defining test data needs for the development of fuel performance and fission-product transport models

5. Inform decisions regarding the development of NRC's independent HTGR fuel performance code and fission-product transport models

6. Support the development of NRC's independent models for source term calculations

7. Provide insights for the review of vendor HTGR fuel safety analyses.

\subsection{U.S. HTGR Precedents}

\subsubsection{Peach Bottom}

An HTGR construction permit was issued to Philadelphia Electric Company for the Peach Bottom Unit 1 plant in 1962. This 40 MW(e) plant operated from 1967 to 1974 on BISO fuel. Although the fuel type used for this plant is not closely related to TRISO fuel, it was one of the earlier HTGR plants.

\subsubsection{Fort St. Vrain}

The Fort St. Vrain (FSV) Nuclear Generating Station was a prismatic fuel HTGR that generated $842 \mathrm{MW}(\mathrm{t})$ to achieve a net output of $330 \mathrm{MW}(\mathrm{e})$. FSV operated from 1974 to 1989. Licensing interactions on FSV were based on HEU TRISO fuel.

\subsubsection{Others}

During the last 25 years, the NRC has had two occasions to consider LEU TRISO fuel for modular HTGRs. These include the NRC review of the MHTGR that began in 1985 and resulted in the issuing of NUREG-1338 in 1995. Later in 2001, Exelon initiated pre-application interactions on the Pebble-Bed Modular Reactor (PBMR) design, which resulted in the NRC requesting additional information in June 2002. However, in late 2002, the NRC issued a close-out letter stating the closure of Project 713 based on Excelon's request. The letter also stated that the staff did not perform a detailed technical review of previous documents and was based on limited screening review to ensure that the issues, review status, and views and positions noted within the documents were consistent within the NRC's views and understanding. 


\section{COATED PARTICLE FUEL EXPERIENCE BASE}

This section addresses the existing experience base that supports the development, qualification, and production of fuel for the NGNP Project. A broad base of experience encompassing a range of coated particle designs and service conditions has produced a general understanding of the important phenomena associated with particle fabrication and performance and has served to identify potential fuel failure mechanisms. This experience led to a common international set of particle design features that, in combination with restrictions on service conditions, mitigate or eliminate failure mechanisms. The successful German experience with $\mathrm{LEU} \mathrm{UO}_{2}$ pebble-bed fuel provides general support for all coated particle fuel and directly supports the NGNP pebble-bed design, which directly utilizes both the German pebble and particle designs. The U.S. experience with prismatic block fuel, primarily associated with the FSV reactor, directly supports the utilization of the graphite prismatic block design.

The coated particles must be designed and fabricated to remain intact and retain radionuclides with a high level of effectiveness over the range of conditions that could be encountered in normal operation and under accident conditions. Modular gas reactor design concepts have been developed to limit the fuel service conditions (burnup, fast fluence, temperature) to a range consistent with the performance capabilities of the fuel. The particles must be able to accommodate the following effects:

- Fission-induced changes in the kernel, e.g., production of a wide range of fission-product isotopes, lattice dislocations by fission product recoil, liberation of oxygen from fissioning of $\mathrm{UO}_{2}$ molecules.

- High energy neutron induced changes in material microstructure, e.g., anisotropic shrinkage and/or expansion in pyrocarbon layers, reductions in $\mathrm{SiC}$ layer strength.

- Buildup of pressure within the particles, e.g., release of noble gas fission products from the kernel, production of $\mathrm{CO}$ and $\mathrm{CO}_{2}$ from reaction of excess oxygen with buffer material.

- Redistribution of fission products within the particle and chemical reactions with particle layers, e.g., chemical attack of the $\mathrm{SiC}$ layer, migration of the kernel within the particle.

The last three effects are time and temperature dependent with a wide range of rate constants. The particles must be capable of withstanding the range of conditions experienced during normal operation while maintaining the capability to retain radioisotopes under accident conditions. Particle fabrication specifications established to meet required performance capability include dimensions (mean and variation), densities, pyrocarbon anisotropy, defect levels and selected process conditions. Meeting the specifications requires precise process control and extensive statistically based characterization procedures. Reactor design features and specifications and limiting conditions of operation are established to limit the service conditions experienced by the fuel within allowed ranges.

Section 3.1 summarizes the broad international experience with coated-particle fuel fabrication and performance covering a wide range of particle designs and material properties explored in the evolution toward the LEU TRISO particle under common development today. It also addresses the failure mechanisms that have been identified from this experience and the common particle design elements that have emerged. Section 3.2 summarizes the fabrication, irradiation, safety testing, and analysis methods experience from the German pebble fuel development program that directly applies to the NGNP pebble-bed reactor design, which utilizes an $\mathrm{LEU} \mathrm{UO}_{2}$ particle design intended to replicate the German design. Section 3.3 summarizes the U.S. prismatic fuel fabrication, irradiation, safety testing, and analysis methods experience that directly applies to the LEU UCO particle design selected for the NGNP prismatic reactor design. The specific pebble and prismatic fuel designs under consideration by the NGNP project, along with their respective reactor designs and resulting service conditions, are described and discussed in Section 4. The activities planned to support the qualification of the pebble and prismatic fuels are addressed in Section 5. 


\subsection{Common Considerations}

Experience with manufacturing coated-particle fuel has demonstrated the feasibility of producing large quantities of fuel with low as-manufactured defect levels (approaching defect fractions of $10^{-5}$ ). This was first demonstrated in Germany, with the production of reload fuel batches for the Arbeitsgemeinschaft Versuchsreaktor (AVR) and subsequently confirmed in fuel production campaigns in Japan for the High Temperature Test Reactor (HTTR) first core and in China for the 10-MW High Temperature Gas-Cooled Reactor (HTR-10) first core. Laboratory-scale production of high-quality fuel has also been demonstrated in Russia, South Africa, and the U.S.

The large body of experience noted in this section includes particle designs with a wide variety of kernel properties. However, the kernel of the coated particle is substantially decoupled from the dense pyrocarbon and $\mathrm{SiC}$ layers by the low-density-carbon buffer layer. Thus, the experience generally applies to both $\mathrm{LEU} \mathrm{UO}_{2}$ and LEU UCO fuel from the standpoint of dense pyrocarbon and SiC-layer design and performance.

Section 3.1.1 addresses the broad base of international coated-particle fabrication, irradiation, and testing experience that forms the basis of common elements of coated-particle designs currently under development. It also summarizes results of the $\mathrm{LEU} \mathrm{UO}_{2}$ coated-particle development activities conducted in Russia, China, and Japan, and within the framework of an ongoing European Commission program. Section 3.1.2 addresses the potential particle failure mechanisms that were identified from the broad experience discussed in Section 3.1.1. Section 3.1.3 describes the common elements of coated-particle designs that evolved from this broad international experience and are under development going forward. These design elements, in combination with limitations established by the reactor designs on fuel-service conditions (temperature, burnup, fast fluence) under normal operation and accident conditions, effectively exclude most of the failure mechanisms and limit the remaining mechanisms to a small fraction of the particles within fuel spheres or compacts within a small fraction of the core.

\subsubsection{Experience (Evolution of Coated-Particle Fuel)}

This section addresses the broad range of existing coated-particle fuel experience that contributes to the general understanding of coated-particle fuel fabrication and performance. This general experience, including a wide range of kernel and coating properties, is summarized along with LEU coated-particle experience in Russia, China, and Japan. The data summarized in the following sections are documented in international publications produced by national programs over several decades. The relevant coated-particle fuel fabrication, irradiation, and testing experience directly supporting the NGNP pebble-bed and prismatic designs is addressed in Sections 3.2 and 3.3.

This discussion is provided as general background regarding the understanding and evolution of coated-particle fuel. The experience and data from these activities has led to a broad understanding of coated-particle fuel fabrication and performance. This background resulted in the identification of failure mechanisms discussed in Section 3.1.2 and the evolution of common coated-particle design features to mitigate or eliminate these failure mechanisms discussed in Section 3.1.3.

\subsubsection{General Experience}

Coated particles start with a spherical kernel of fissile or fertile material that is surrounded by one or more ceramic coatings. By the early 1960s, coated-particle fuel development for graphite-moderated helium-cooled HTGRs was well under way in the United Kingdom in support of the DRAGON research reactor ${ }^{10}$ in the U.S. in support of the Peach Bottom Unit 1 prototype power reactor, ${ }^{11}$ and in Germany in support of the AVR research and power reactor. ${ }^{12}$ Coated particle designs for these reactors varied considerably, as illustrated in Figure 1 (the AVR fuel loadings evolved through many designs in the course of over two decades of plant operation, including the LEU TRISO design discussed in Section 3.1.3). 


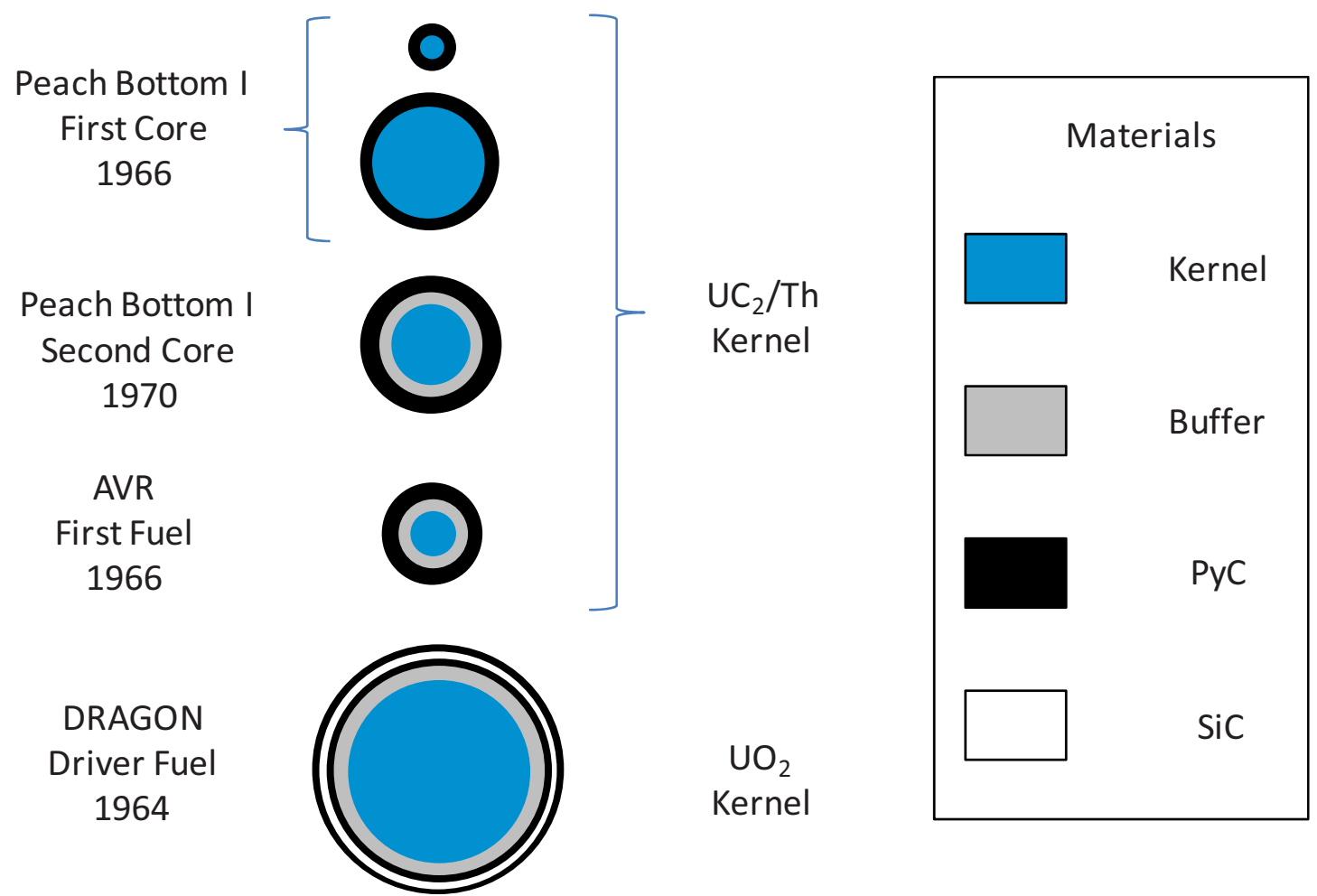

Figure 1. Early coated-particle designs.

Coated-particle fuel development programs have also been conducted in France, Russia, Japan, China, South Africa, and the Republic of Korea. The development of coated-particle fuel technology for both the pebble-bed and prismatic designs has drawn from an extensive international background of coated-particle fuel fabrication and testing experience spanning more than 50 years and covering a broad range of parameters as summarized below:

- Kernel characteristics

- $\quad$ Diameter - 100 to $800 \mu \mathrm{m}$

- Fissile/fertile materials - uranium, thorium, plutonium (mixed and unmixed)

- Chemical forms - oxide, carbide, oxycarbide

- Enrichment - ranging from natural to highly enriched uranium and plutonium

- Coating characteristics

- $\quad$ BISO - variations in buffer and PyC coating thicknesses and properties

- $\quad$ TRISO - variations in buffer, PyC and SiC (or zirconium carbide) thicknesses and properties

- $\quad$ Fuel forms

- $\quad$ Spheres - multiple geometries and fabrication methods

- Compacts - cylindrical and annular shapes with variations in particle packing fractions and fabrication methods

- Irradiation facilities

- $\quad$ Materials Test Reactors - HFR (Netherlands), FRJ 2 DIDO (Germany), IVV-2M (Russia), Siloe (France), R2 (Sweden), BR2 (Belgium), High-Flux Isotope Reactor (HFIR) (U.S.), Advanced Test Reactor (ATR) (U.S.), with wide variations in spectra and degree of acceleration 
- Research and Demonstration Reactors - DRAGON (United Kingdom), Peach Bottom I (U.S.), AVR (Germany), FSV(U.S.), Thorium High Temperature Reactor (THTR) (Germany), HTTR (Japan), HTR-10 (China)

- Irradiation and testing conditions

- Burnup - ranging from below $1 \%$ to above $70 \%$ fissions per initial metal atom (FIMA)

- Fast fluence - ranging from below $1 \times 10^{21}$ to above $10 \times 10^{21} \mathrm{n} / \mathrm{cm}^{2}$

- Irradiation temperature - ranging from 600 to $1,950^{\circ} \mathrm{C}$

- Accident simulation temperature - ranging from 1,400 to $2,500^{\circ} \mathrm{C}$.

This broad range of experience and data has supported development of a detailed understanding of the parameters and phenomena of importance in the fabrication and performance of coated-particle fuel. Extensive bilateral and multilateral international information exchanges facilitated the incorporation of this broad experience base into the German and other modern coated-particle fuels. A detailed review of the United States and German experience and the relationship to fuel performance and fuel performance modeling is documented in an Electric Power Research Institute (EPRI) report. ${ }^{13}$ The evolution of the German fuel design, arriving at the LEU UO $\mathrm{U}_{2}$ TRISO pressed sphere selected as a basis for the pebble-bed design, is summarized in Section 2.4 of a report on the AVR. ${ }^{12}$ A broader range of international experience, focused mainly on LEU TRISO fuel, was addressed in an International Atomic Energy Agency (IAEA) coordinated research project conducted in the early $1990 \mathrm{~s} .{ }^{14}$ In considering this experience and data, the international community has converged on common LEU TRISO particle designs as discussed in Section 3.1.3, having very similar coating thicknesses and properties with variations in kernel diameter, enrichment, and composition $\left(\mathrm{UO}_{2}\right.$ and $\left.\mathrm{UCO}\right)$, depending on the specific service conditions and requirements.

\subsubsection{LEU UO Experience in Russia}

Coated-particle fuel development in Russia was based on a spherical fuel element incorporating $\mathrm{UO}_{2}$ coated particles similar to the German design, with reactor design enrichments ranging from 6.5 to $21 \%{ }^{14}$ Fuel development and testing included both low and high-temperature isotropic pyrocarbon for the dense pyrocarbon ${ }^{\mathrm{b}}$ layers. ${ }^{15}$ In support of these designs, the fuel fabrication, irradiation, and testing program was conducted from 1975 through 1990. As-manufactured particle defect fractions on the order of $10^{-5}$ were achieved at both laboratory and semi-industrial scale. Russian coated-particle fuel fabrication development is described in several papers in the proceedings of an IAEA meeting on gas-cooled reactor fuel development. ${ }^{16}$

The fuel irradiation program was conducted using enrichments higher than the reactor design values, ranging from 21 to $45 \%$. The irradiations covered a wide range of conditions:

- Temperatures: 400 to $1,950^{\circ} \mathrm{C}$.

- Burnup: 1 to $41 \%$ FIMA.

- Fast Fluence: 0.1 to $2.7 \times 10^{25} \mathrm{~cm}^{2}, \mathrm{E}>32 \mathrm{fJ}$.

b. At temperatures between 1,250 and $1,350^{\circ} \mathrm{C}$, a low-temperature isotropic coating is produced by chemical vapor deposition. In the range of 1,800 to $2,100^{\circ} \mathrm{C}$, a different type of pyrocarbon, "high temperature isotropic" is deposited. Both forms were investigated in early coated-particle fuel development, with the low temperature isotropic form selected for further development. 
The irradiation temperature and burnup ranges substantially exceeded typical design ranges for coated particles of design similar to the German fuel. Thus, the Russian program produced valuable irradiation data on the ultimate capability of the fuel and fuel behavior at conditions exceeding the nominal operating range. The investigation of the capability of a particle design similar to the German particle yielded the following conclusions ${ }^{15}$ :

- Irradiation at $1,000^{\circ} \mathrm{C}$ produced insignificant gaseous fission-product release at burnups of $15-20 \%$ FIMA

- Irradiation at $1,200^{\circ} \mathrm{C}$ produced depressurization of separate coated particles ${ }^{\mathrm{c}}$ at burnups of $10-15 \%$ FIMA

- Irradiation at $1,400^{\circ} \mathrm{C}$ produced increased gaseous fission-product release at burnups of 5-13\% FIMA.

The results also indicated that particles with low-temperature isotropic pyrocarbon (LTI) layers achieved higher burnups prior to gas release than those with high-temperature isotropic (HTI) layers.

The Russian program also investigated fuel (both loose particle and sphere forms) response to over-power conditions to explore failure limits. Power pulse experiments of one-second duration were carried out at power levels of $\sim 30,66$, and 124 times the nominal maximum power level with no indications of significant gaseous fission-product release. Extended overpower tests at $\sim 10$ times the nominal maximum under adiabatic conditions for 5, 10, and 30 seconds showed no indications of damage in the first two cases, but failure of the fuel sphere and a significant fraction of the particles in the last case. ${ }^{16}$ These conditions are not achievable in a reactor because of negative temperature reactivity feedback and continued heat removal from the sphere, but the results are relevant to the ultimate capability of the fuel.

\subsubsection{LEU UO $\mathrm{LP}_{2}$ Experience in China}

The coated-particle fuel program in China was initially established to support the construction and operation of the HTR-10 reactor. The HTR-10 project was initiated in 1990, following an HTGR conceptual design and feasibility study. ${ }^{18}$ Development of fuel fabrication methods was based on the German particle and spherical fuel element design using fuel fabrication equipment obtained from Germany. Fabrication of fuel for the first core of HTR-10 began in December $1999^{17}$ with production of 11,700 fuel spheres by September 2000 sufficient to support initial criticality, which was achieved in December 2000 with a core containing a mixture of 16,890 fuel and graphite spheres. ${ }^{\text {d }}$ The low power level (10 MWth) combined with the replication of the German fuel design, which enabled the use of the German fuel-performance data, supported the demonstration of large margins to fuel service condition limits. Thus, the fuel irradiation and testing program was conducted in parallel with initial operation of HTR-10. ${ }^{18}$ Following initial criticality, a series of tests was completed at a power level of $3.44 \mathrm{MWth}$, supporting subsequent operation at 10 MWth, which was achieved in January 2003. ${ }^{19}$

The fuel quality, as indicated by the free-uranium content in the fuel spheres, improved by over an order of magnitude during the course of production for the HTR-10 core (a total of 25 batches of spheres). Free-uranium content (as measured by the burn-leach procedure) in the early batches was typically $\sim 10^{-4}$, while the last fifteen batches were typically $\sim 10^{-5}$ and lower. ${ }^{17}$ In order to facilitate irradiation and testing of HTR-10 fuel as soon as possible, sphere samples were taken from the first and second batches ${ }^{20}$; thus, the as-manufactured quality of the tested spheres was representative of the lower quality early fuel production.

c. The phrase "depressurization of separate coated particles" was taken from the referenced paper. It is interpreted to refer to individual failures of loose particles during the irradiation.

d. The initial core loading for HTR-10 included both fuel and graphite spheres to achieve the desired core volume. As burnup proceeds, the fraction of graphite spheres is decreased to compensate for burnup in the approach to an equilibrium core. 
Irradiation of four fuel spheres taken from early in the first HTR-10 core production, as described above, began in the Russian IVV-2M reactor in July 2000 and was completed in February $2003 .{ }^{20}$ The irradiation rig contained five capsules; Capsules 2 through 5 contained fuel spheres, and Capsule 1 contained matrix graphite specimens. The irradiations were conducted at $\sim 1,000^{\circ} \mathrm{C}$, with short-term increases to $\sim 1,200^{\circ} \mathrm{C}$, and to burnups ranging from 95 to $107 \mathrm{GWd} / \mathrm{tU}$. In-pile gas release measurements indicated the presence of one or two exposed kernels in two of the irradiated spheres from the beginning, consistent with the as-manufactured free-uranium measurements for early production batches. One of the capsules failed during irradiation with loss-of-gas release data, and PIE showed substantial damage to the sphere (in-pile gas-release measurements failed when the capsule failed). Another capsule was subjected to a high temperature test at the end of the irradiation, resulting in temperatures well beyond the planned conditions (and a significant fraction of exposed kernels as determined in the PIE) when a control thermocouple failed. In-pile gas release data indicated that no failures occurred during irradiation when conditions remained within specified levels.

An additional irradiation of fuel spheres produced in China for the HTR-10 was conducted in the HFR Petten reactor in an experiment designated HFR-EU1. ${ }^{21}$ The HFR-EU1 experiment included two spheres from China and three from the German program (from AVR 21-2, representative of the highest quality German fuel), with the two fuels placed in separate capsules, each with in-pile gas release measurement capability. A primary objective of the irradiation was to subject the spheres to high burnups (17\% FIMA for Chinese spheres, 20\% FIMA for German spheres) to investigate the ultimate capability of the coated-particle design developed in Germany. Initial gaseous fission-product release was comparable between the two fuels, with release from the German fuel trending higher as the irradiation proceeded, likely the result of heavy-metal contamination in the matrix material. The irradiation was interrupted after reaching burnups of $8 \%$ FIMA (Chinese spheres) and 11\% FIMA (German spheres) by a high level of thermocouple failures. The irradiation was subsequently resumed, with final results to be addressed by papers at the HTR2010 Conference.

\subsubsection{LEU UO $\mathrm{LP}_{2}$ Experience in Japan}

The Japanese high-temperature gas reactor program is centered on the HTTR, which has a thermal power of $30 \mathrm{MW}$ and $950^{\circ} \mathrm{C}$ maximum coolant outlet temperature. The HTTR achieved criticality in November 1998 and has undergone a series of rise-to-power tests. ${ }^{22}$ In December 2001, an outlet temperature of $850^{\circ} \mathrm{C}$ was achieved, and in April 2004 a temperature of $950^{\circ} \mathrm{C}$ was achieved. As of July 2004, the reactor had operated for 224 effective full-power days (EFPD). The planned core life cycle is $660 \mathrm{EFPD} .^{23}$ It is planned to couple a high-temperature process-heat application to the HTTR through its intermediate heat exchanger in the future.

The fuel elements are prismatic graphite pin-in-blocks with vertical bore holes containing fuel rods (graphite sleeves) that contain annular fuel compacts. ${ }^{24}$ Each compact contains about 13,000 TRISO-coated fuel particles with a 600 - $\mu \mathrm{m}$-diameter $\mathrm{UO}_{2}$ kernel, a $60-\mu \mathrm{m}$-thick buffer, and 30 - $\mu \mathrm{m}$-thick inner pyrolytic carbon (IPyC), $25-\mu \mathrm{m}$-thick $\mathrm{SiC}$, and $45-\mu \mathrm{m}$-thick OPyC layers. Uranium enrichments vary in 12 stages, from 3.4 to $9.9 \%$, and average $6 \%$. The end-of-life core average burnup is designed to be $2.4 \%$ FIMA, and the design limit peak burnup is $3.6 \%$ FIMA. The fuel quality of the HTTR first core is a heavy-metal (HM) contamination of $2.5 \times 10^{-6}$, initial through-coating defects of $2.5 \times 10^{-6}$, and initial $\mathrm{SiC}$ defects of $8 \times 10^{-5}$. The measured release-to-birth (R/B) of $\mathrm{Kr}-88$ at full power, a $950^{\circ} \mathrm{C}$ outlet temperature, and approximately 200 EFPD of reactor operation was $1.0 \times 10^{-8}$, corresponding to gaseous diffusion from HM contamination and no significant in-reactor fuel particle failures. ${ }^{22}$ The high-temperature demonstration was maintained for about 5 days.

HTTR-type fuel was irradiated in the HRB-22 test in the HFIR to burnups in the range 4.1 to $6.7 \%$ FIMA. ${ }^{25}$ Online gamma monitoring detected four fuel-particle failures out of 32,200 particles irradiated, or a failure fraction of $1.2 \times 10^{-4}$. PIE and safety tests were performed at temperatures ranging from 1,600 to $1,800^{\circ} \mathrm{C}$. In one test at $1,600^{\circ} \mathrm{C}$, one failed particle was detected out of about 2,800 particles in 
219.4 hours. Tests at 1,700 and $1,800^{\circ} \mathrm{C}$ revealed large variations in metallic fission-product releases from particle to particle, which could only be explained by the presence or absence of cracks in the SiC layer. ${ }^{25}$ A series of irradiations was carried out with HTTR fuels in Oarai Gas Loop-1 in the Japan Materials Testing Reactor. The results of three irradiations with particle numbers of about 65,000 in each experiment indicate through-wall failures were less than $3 \times 10^{-4}$ at $95 \%$ confidence after burnups up to $3.7 \%$ FIMA. $^{26}$

\subsubsection{Failure Mechanisms}

The following failure mechanisms have been identified as capable of causing partial or total failure of the TRISO-coating system under irradiation and/or during postulated accidents:

- Pressure-vessel failure of standard ("intact”) particles (particles without manufacturing defects)

- Pressure-vessel failure of particles with defective or missing coatings

- Irradiation-induced failure of the OPyC coating

- Irradiation-induced failure of the IPyC coating and potential SiC cracking

- Failure of the $\mathrm{SiC}$ coating caused by kernel migration in the presence of a temperature gradient

- Failure of the $\mathrm{SiC}$ coating caused by fission-product/SiC interactions

- Failure of the $\mathrm{SiC}$ coating caused by $\mathrm{CO} / \mathrm{SiC}$ interactions

- Failure of the $\mathrm{SiC}$ coating resulting from thermal decomposition

- Failure of the SiC coating caused by HM dispersion in the buffer and IPyC coating layers.

These mechanisms are shown schematically in Figure 2. As discussed in Section 5.3.1, phenomenological performance models, typically inspired by first principles and correlated with experimental data, have been developed to model each of these mechanisms.

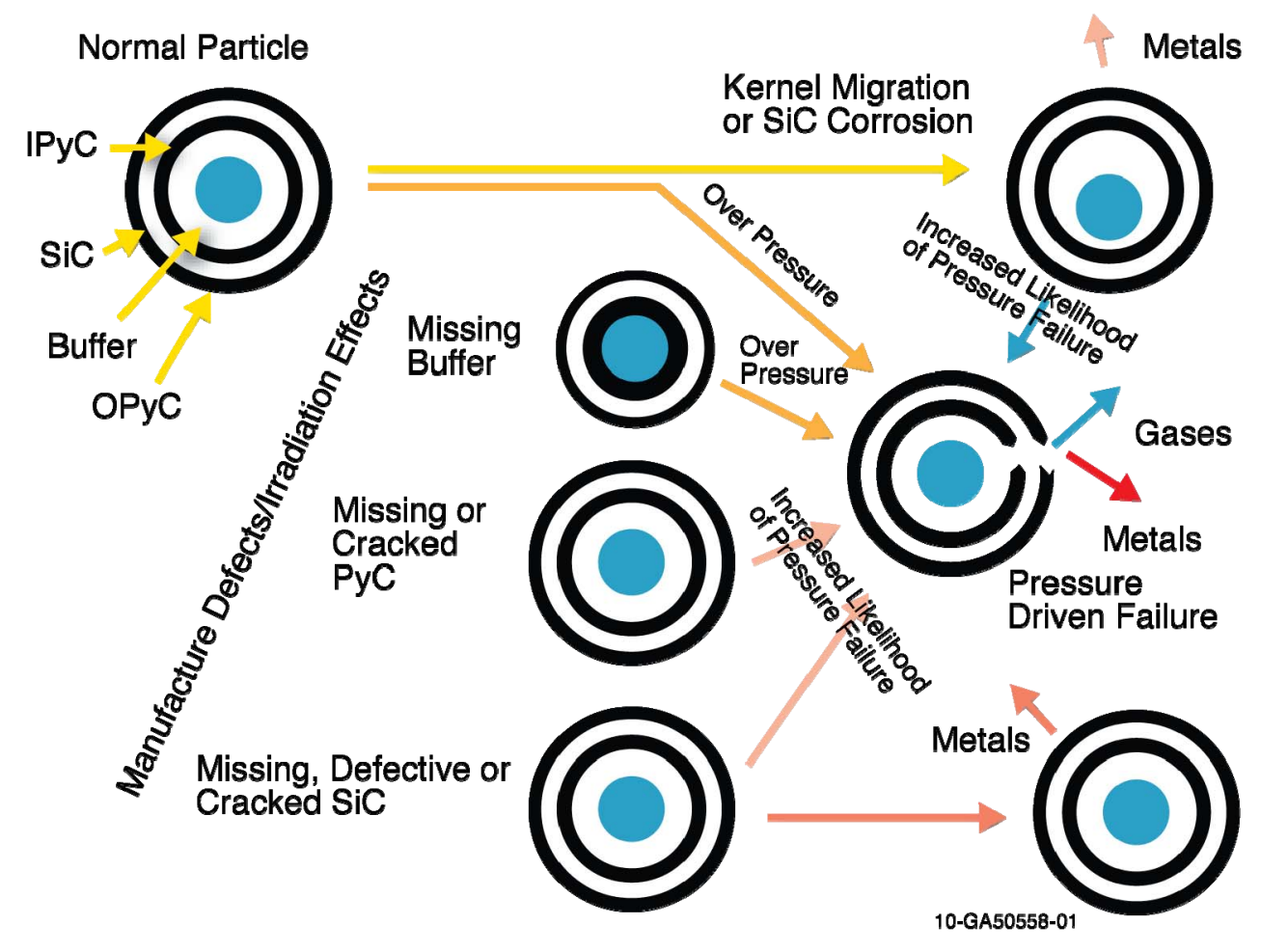

Figure 2. TRISO particle failure mechanisms. 
As-manufactured HM contamination is not an in-service failure mechanism but is very important with respect to fission-product release. It is an extreme case of as-manufactured coating defects, whereby trace amounts of HM are not encapsulated by a single intact coating layer (analogous to "tramp uranium" in LWR fuel). Modern fuel-product specifications only allow small fractions of HM contamination $\left(\sim 10^{-5}\right.$ is typical); nevertheless, it is an important source of fission-product release.

The observed failure mechanisms for TRISO fuel can be categorized as structural/mechanical or thermochemical in nature. Failure mechanisms in both categories can be affected by the release of excess oxygen during fission and subsequent formation of carbon monoxide. The various failure mechanisms are discussed in greater detail in the following sections.

\subsubsection{Structural/Mechanical Mechanisms}

During irradiation, long-lived and stable fission gases are released from the kernel into the buffer, which increases the internal gas pressure. For some particle designs (e.g., $\mathrm{UO}_{2}$ TRISO), carbon monoxide can also be generated during irradiation, which further increases the gas pressure. Because the SiC layer has a much higher elastic modulus than the pyrocarbon (PyC) layers, ${ }^{e}$ it would bear most of the internal pressure force, which produces a tensile stress if the irradiation-induced dimensional changes of the $\mathrm{PyC}$ and $\mathrm{SiC}$ were comparable. However, the PyC layers undergo shrinkage during irradiation, which produces compressive forces in the $\mathrm{SiC}$ layer. Within the range of allowed fuel-service conditions (e.g., temperature and fast neutron fluence), the compressive forces from PyC shrinkage more than compensate for the tensile stresses from internal pressure, such that the $\mathrm{SiC}$ remains in compression provided at least one of the PyC layers remains intact. From a structural/mechanical perspective, the $\mathrm{SiC}$ layer will remain intact provided that it remains in compression or the tensile stress in the SiC layer does not exceed its strength.

\section{PyC Performance}

As discussed above, shrinkage of the PyC layers during irradiation is a favorable attribute in terms of the compressive forces applied to the $\mathrm{SiC}$ layer. However, PyC shrinkage produces tensile stresses in the PyC layers themselves, which can lead to failure of these layers. The strains and stresses generated in the PyC layers are complex functions of fast-neutron fluence, irradiation temperature, and coating-material properties.

A property that greatly affects $\mathrm{PyC}$ performance is anisotropy, which can be quantified using X-ray or optical diffraction techniques. Anisotropy is usually expressed in terms of the Bacon Anisotropy Factor $(\mathrm{BAF})$. For a perfectly isotropic material, $\mathrm{BAF}=1$, and for a perfectly oriented medium, $\mathrm{BAF}=\infty$. Sufficiently isotropic PyC layers (BAFo $\leq 1.035$ ) are able to perform well out to high fast-neutron fluences because the irradiation-induced strains and stresses are relaxed to some extent by irradiation-induced creep.

\section{Irradiation Induced Failure of IPyC Leading to SiC Cracking}

Post-irradiation examination of fuel from the HRB-21 irradiation and the NP-MHTGR irradiations coupled with mechanical analyses showed that fuel particle failures in these irradiation experiments were caused by irradiation induced failure (cracking) of anisotropic IPyC leading to tensile stress intensification in the adjacent well-bonded $\mathrm{SiC}$ layer causing subsequent cracking of the $\mathrm{SiC}$ layer. ${ }^{27,28}$ These failure analyses led to changes in the coating conditions used in the fabrication of fuel particles in the NPNP/AGR Fuel Program ${ }^{29}$ to ensure IPyC coatings with adequate isotropy were produced.

e. In other words, $\mathrm{SiC}$ is much stiffer than pyrocarbon. Because of this property, it is reasonable to assume the IPyC and OPyC are isolated from each other when evaluating performance of these layers and overall performance of the TRISO-coating system. 


\section{Pressure-Vessel Failure}

In the absence of compressive forces from the PyC layers, the tensile stress, $\sigma_{\mathrm{SiC}}$, in the $\mathrm{SiC}$ layer may be calculated with reasonable accuracy using the thin-shell approximation,

$$
\sigma_{S i C}=\frac{P r_{S i C}}{2 t_{S i C}}
$$

where

$\mathrm{P} \quad=$ internal pressure inside the particle

$\mathrm{r}_{\mathrm{SiC}}=$ radius to the middle of the $\mathrm{SiC}$ layer

$\mathrm{t}_{\mathrm{SiC}}=$ thickness of the SiC layer.

Pressure vessel failure occurs when the tensile stress in the $\mathrm{SiC}$ layer exceeds the strength of the $\mathrm{SiC}$ layer. The fraction of particles with a failed $\mathrm{SiC}$ coating ${ }^{f}, \mathrm{f}_{\mathrm{SiC}}$, is calculated using Weibull statistical strength theory, assuming volume flaws and a uniform stress distribution in the $\mathrm{SiC}$ layer as

$f_{\text {SiC }}=1-\exp \left[-\left(\frac{\sigma_{S i C}}{\sigma_{o}}\right)^{m} V_{S i C}\right]$

where

$$
\begin{aligned}
\sigma_{\mathrm{o}} & \equiv \text { Weibull characteristic strength } \\
\mathrm{m} & \equiv \text { Weibull modulus } \\
\mathrm{V}_{\mathrm{SiC}} & \equiv \text { volume of the } \mathrm{SiC} \text { layer. }
\end{aligned}
$$

\subsubsection{Thermochemical Mechanisms}

Fuel failure caused by thermochemical mechanisms can be controlled in large measure through the nuclear and thermal-hydraulic design of the reactor core. In order for the fuel to satisfy performance criteria, peak fuel temperatures must be kept sufficiently low, and the fraction of fuel that experiences relatively high temperatures for long time periods must be kept sufficiently small. Thermochemical failure mechanisms that have been observed to occur in coated-particle fuel are described below.

\section{Kernel Migration}

Local fuel temperatures and temperature gradients across the fuel can be relatively high when the reactor is producing power. Under these conditions, oxide and carbide fuel kernels can migrate up the thermal gradient. This phenomenon is often referred to as the "amoeba effect" and can lead to complete failure of the coating system. For oxide kernels, migration may be caused by carbon diffusion or gas-phase diffusion of $\mathrm{CO}$ or other gaseous carbon compounds. ${ }^{30}$ Failure by this mechanism is correlated as a function of temperature, thermal gradient, and thicknesses of the buffer and IPyC layers. Failure is assumed to occur when the kernel material contacts the $\mathrm{SiC}$ layer. The particle-to-particle variations in the buffer and IPyC thicknesses (expressed as normal distributions with measured variances) are accounted for when calculating the failure probability.

\section{Chemical Attack of SiC}

Noble metals (e.g., $\mathrm{Ru}, \mathrm{Rh}, \mathrm{Pd}$, and $\mathrm{Ag}$ ) are produced with relatively high yield during fission of uranium fuels. During irradiation, the thermochemical conditions are not conducive for these elements to form stable oxides, and they can readily migrate out of the fuel kernel, regardless of its composition. Reactions of SiC with Pd have been observed during PIE of TRISO fuel. ${ }^{31}$ Although the quantity of Pd is

f. This fraction applies to the population of particles that have a failed IPyC layer and a failed OPyC layer. 
small compared with the mass of the SiC layer, the reaction is highly localized, and complete penetration of the SiC layer can occur if high temperatures are maintained for a sufficient period of time (see

Figure 3). The reaction rate is highly dependent on temperature, so the time required to penetrate the $\mathrm{SiC}$ layer decreases rapidly as the temperature increases above about $1,300^{\circ} \mathrm{C}$.

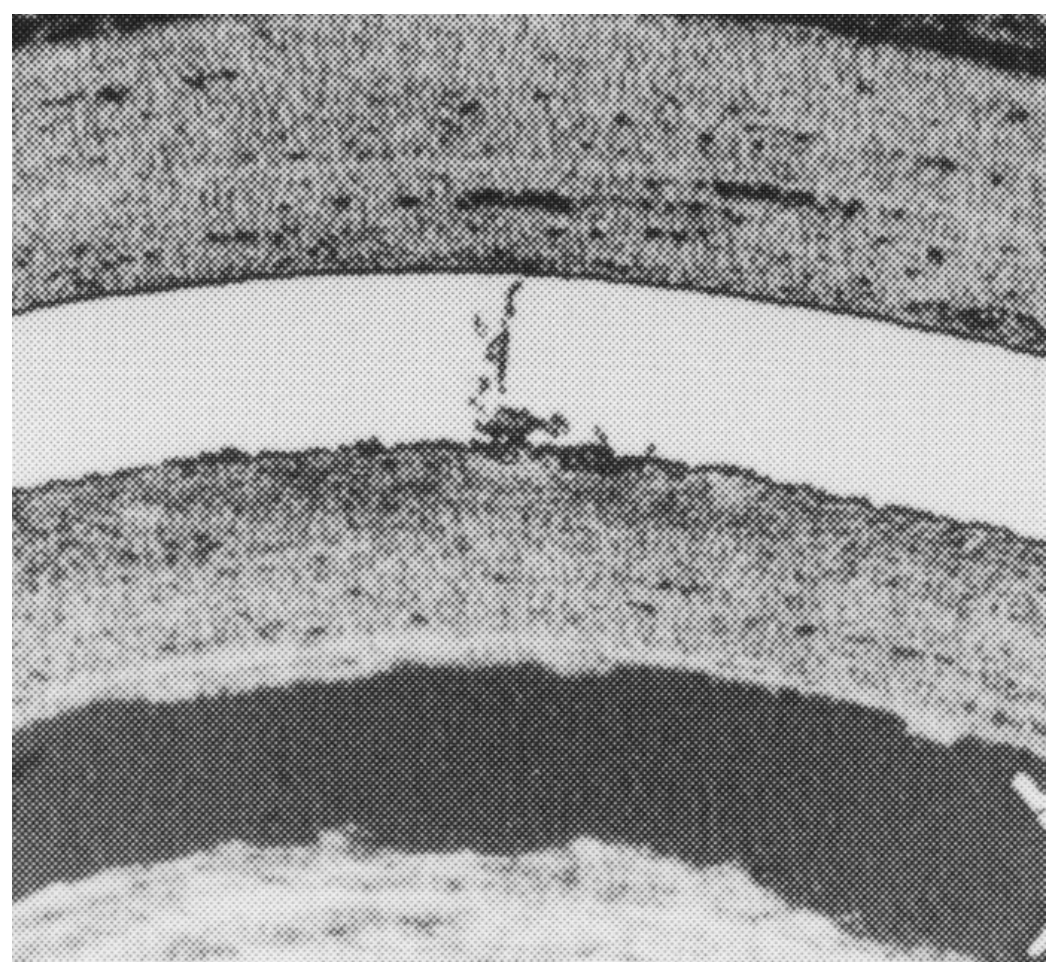

Figure 3. Localized fission-product attack of the $\mathrm{SiC}$ layer.

Excess oxygen is produced in a $\mathrm{UO}_{2}$ kernel during irradiation because the oxygen liberated by fission is not completely consumed by reactions with fission products. At low burnup, some of the excess oxygen may remain trapped in the kernel. However, at high burnup, the kernel becomes more porous, and it is likely that nearly all of the oxygen will escape a $\mathrm{UO}_{2}$ kernel, after which it will quickly react with carbon in the buffer to predominately form CO. Excessive CO not only increases the pressure-vessel and kernel-migration failure probabilities, but can also corrode the $\mathrm{SiC}$ layer at accident-condition temperatures.

Chemical attack of the $\mathrm{SiC}$ layer by $\mathrm{CO}$ has been observed in $\mathrm{UO}_{2}$ particles irradiated at temperatures above approximately $1,400^{\circ} \mathrm{C} .{ }^{32}$ Degradation occurred near locations where the IPyC layer was cracked. The kernels of particles with degraded SiC layers were examined with an electron microprobe, which showed the presence of silicon in the form of fission-product silicides. Thermo-chemical calculations supported the hypothesis that silicon is transported to the kernel in the form of $\mathrm{SiO}$ gas produced by the reaction of $\mathrm{CO}$ with $\mathrm{SiC}$, which then reacts with fission products.

\section{Thermal Decomposition of the SiC Layer}

At very high temperatures, $\mathrm{SiC}$ will decompose into its constituent elements. The silicon vaporizes, leaving a porous carbon structure. Based on calculations performed for previous core designs, this failure mechanism is not an important contributor to fuel failure at normal operating temperatures. However, relatively high failure rates can occur if temperatures are higher than 1,700 to $1,800^{\circ} \mathrm{C}$ for extended periods of time, and thermal decomposition of $\mathrm{SiC}$ occurs rapidly at temperatures above $2,000^{\circ} \mathrm{C}$. 


\section{Relationship between Fuel-Failure Mechanisms and Fuel-Particle Properties}

The fuel-service conditions and fuel-particle properties that influence the fuel-failure mechanisms are summarized in Table 1. The fuel particles must be designed and manufactured such that the properties defined in Table 1 are within limits that result in acceptable fuel performance. The failure mechanisms are correlated with the reactor service conditions in models that are used to predict fuel performance.

Table 1. Relationship between fuel-failure mechanisms and fuel-particle properties.

\begin{tabular}{|c|c|c|}
\hline \multirow[b]{2}{*}{ Failure Mechanism } & \multicolumn{2}{|c|}{ Parameters That Strongly Influence the Failure Mechanism } \\
\hline & Service Conditions & Fuel-Particle Properties \\
\hline Pressure vessel failure & Temperature, burnup, fast fluence & $\begin{array}{l}\text { Strength of SiC } \\
\text { Buffer density (void volume) } \\
\text { Fission-gas release } \\
\text { Kernel type (CO production) } \\
\text { Layer thicknesses } \\
\text { IPyC and OPyC performance }\end{array}$ \\
\hline $\begin{array}{l}\text { Irradiation-induced } \\
\text { PyC failure leading to } \\
\text { SiC cracking }\end{array}$ & Fast fluence, temperature & $\begin{array}{l}\text { Dimensional change of PyC } \\
\text { Irradiation-induced creep of PyC } \\
\text { Anisotropy of PyC } \\
\text { Strength of PyC } \\
\text { PyC thickness } \\
\text { PyC density } \\
\text { Tensile stress in } \mathrm{SiC} \text { at IPyC crack tip } \\
\text { SiC strength }\end{array}$ \\
\hline IPyC partial debonding & Temperature, fast fluence & $\begin{array}{l}\text { Nature of IPyC-SiC interface } \\
\text { Interfacial strength } \\
\text { Dimensional change of IPyC } \\
\text { Irradiation-induced creep of IPyC }\end{array}$ \\
\hline Kernel migration & $\begin{array}{l}\text { Temperature, burnup, temperature } \\
\text { gradient }\end{array}$ & $\begin{array}{l}\text { Kernel type }\left(\mathrm{UO}_{2}, \mathrm{UCO} \text {, etc.) }\right. \\
\text { Buffer and IPyC thickness }\end{array}$ \\
\hline $\begin{array}{l}\text { Diffusive release } \\
\text { through intact layers }\end{array}$ & $\begin{array}{l}\text { Temperature, burnup, temperature } \\
\text { gradient, time at temperature }\end{array}$ & $\begin{array}{l}\text { Chemical state/transport behavior of fission } \\
\text { products } \\
\text { Microstructure of } \mathrm{SiC} \\
\text { SiC thickness }\end{array}$ \\
\hline $\begin{array}{l}\text { Fission product attack } \\
\text { of } \mathrm{SiC}\end{array}$ & $\begin{array}{l}\text { Temperature, burnup, temperature } \\
\text { gradient, time at temperature }\end{array}$ & $\begin{array}{l}\text { Chemical state/transport behavior of fission } \\
\text { products } \\
\text { Kernel type }\left(\mathrm{UO}_{2}, \mathrm{UCO} \text {, etc. }\right) \\
\text { Microstructure of IPyC and } \mathrm{SiC}\end{array}$ \\
\hline $\begin{array}{l}\text { Corrosion of } \mathrm{SiC} \text { by } \\
\mathrm{CO}\end{array}$ & $\begin{array}{l}\text { Temperature, burnup, time at } \\
\text { temperature }\end{array}$ & $\begin{array}{l}\text { Kernel type }\left(\mathrm{UO}_{2}, \mathrm{UCO} \text {, etc. }\right) \\
\text { IPyC integrity }\end{array}$ \\
\hline $\begin{array}{l}\text { SiC thermal } \\
\text { decomposition }\end{array}$ & Temperature, time at temperature & $\begin{array}{l}\mathrm{SiC} \text { thickness } \\
\mathrm{SiC} \text { microstructure }\end{array}$ \\
\hline $\begin{array}{l}\mathrm{SiC} \text { permeability/SiC } \\
\text { degradation }\end{array}$ & Burnup, temperature, fast fluence & $\begin{array}{l}\text { Microstructure of } \mathrm{SiC} \\
\text { Thickness of } \mathrm{SiC} \\
\text { Permeability of } \mathrm{SiC} \\
\end{array}$ \\
\hline
\end{tabular}




\subsubsection{Coated-Particle Design}

The broad coated-particle fuel fabrication, irradiation, and testing experience discussed in Section 3.1.1.1, combined with effective international information exchanges, has resulted in a consensus on basic coated-particle properties among ongoing fuel-development programs, as illustrated in Figure 4 and discussed below. This common coated-particle design approach mitigates or eliminates the failure mechanisms discussed in Section 3.1.2 and incorporates the following elements (mean coating thicknesses are sufficient to perform the required functions with allowance for the particle-to-particle variation in thickness resulting from the coating process):

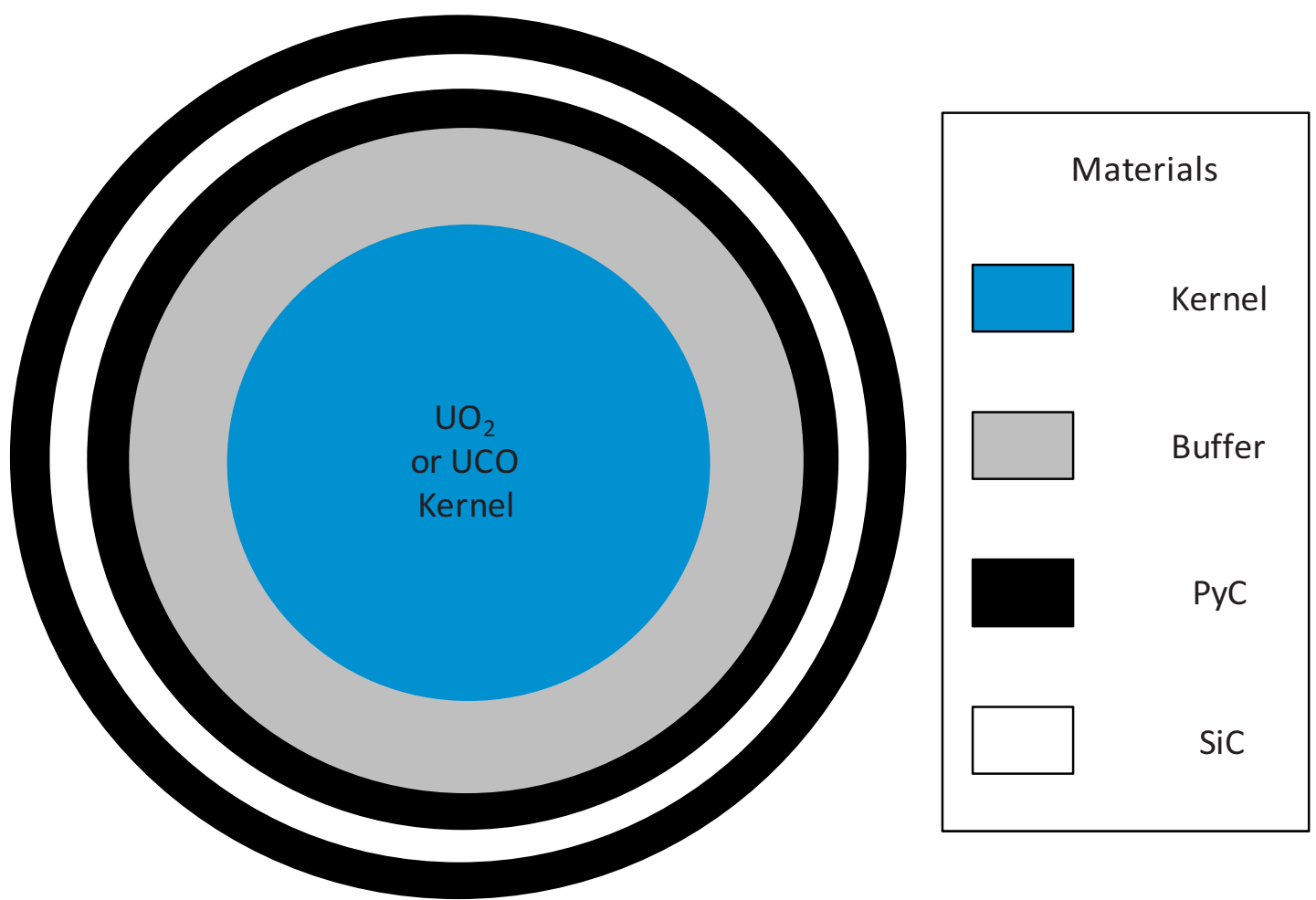

Figure 4. The international-consensus TRISO particle design.

- Kernel - The spherical fuel kernel consists of high-density low-enriched $\left(<20 \%{ }^{235} \mathrm{U}\right) \mathrm{UO}_{2}$ or UCO. ${ }^{\mathrm{g}}$ The kernel serves as an important barrier to radionuclide release by immobilizing many of the fission products and delaying the diffusive release of others, substantially reducing release from the particle by retention in the kernel and radioactive decay before release from the kernel. The $\mathrm{UO}_{2}$ kernel performs effectively within the range of burnup and temperature gradients experienced in the German pebble-bed designs. The UCO kernel option getters excess oxygen produced by fission, limiting the generation of $\mathrm{CO}$ and $\mathrm{CO}_{2}$ and associated increased gas pressure in the particle and kernel migration, thus allowing higher burnup limits and thermal gradients associated with U.S. prismatic designs. The kernel diameter is influenced by enrichment and the related design burnup limits, with higher enrichment and burnup designs typically having smaller diameters.

- Buffer - The buffer layer consists of a low-density ( $\sim 50 \%$ of theoretical density) isotropic pyrocarbon. The primary purpose of the buffer layer is to provide void volume for gaseous fission products to limit pressure buildup within the coated particle. As a compressible material, it serves to mechanically decouple the kernel from the inner pyrocarbon layer to accommodate kernel swelling,

g. Additional coated-particle fuel development using kernels containing actinides, primarily plutonium and neptunium, is under consideration as a means of reducing long-lived radionuclides in spent fuel. 
thereby reducing the buildup of stress in the outer coating layers during irradiation. The buffer layer also absorbs energetic fission products recoiling from near the kernel surface, thus protecting the inner pyrocarbon layer of the coated particle. Mean buffer thickness is typically 90 to $100 \mu \mathrm{m}$.

- Inner Pyrocarbon - The inner high-density ( $~ 85 \%$ of theoretical density) isotropic layer of IPyC forms the first load-bearing barrier against the pressure exerted by gaseous fission products and reaction products $\left(\mathrm{CO}, \mathrm{CO}_{2}\right)$ within the fuel kernel and buffer layer. The IPyC layer also serves to protect the kernel from corrosive gases $\left(\mathrm{HCl}, \mathrm{Cl}_{2}\right)$ liberated during the $\mathrm{SiC}$ coating process. Both the $\mathrm{IPyC}$ and $\mathrm{OPyC}$ layers retain gaseous fission products but become less effective in retaining metallic fission products at higher temperatures. The anisotropy of the IPyC layer is limited to control dimensional changes during irradiation where the IPyC and OPyC layers shrink at first, but may expand again if sufficiently high fast-neutron dose levels are reached. The interaction between the $\mathrm{IPyC}$ and $\mathrm{OPyC}$ high-density pyrocarbon layers and the $\mathrm{SiC}$ layer sandwiched between them plays an important role in keeping the $\mathrm{SiC}$ layer under compressive stress during irradiation. Mean IPyC thickness is typically 35 to $40 \mu \mathrm{m}$.

- Silicon Carbide - As noted above, the IPyC and OPyC layers become less effective in retaining metallic fission products at higher temperatures. A primary purpose of the $\mathrm{SiC}$ layer is to prevent the release of these fission products into the graphite matrix and then into the reactor helium stream. The $\mathrm{SiC}$ layer thus acts as the principal metallic fission-product retention barrier in the coated particle. The $\mathrm{SiC}$ layer also has sufficient strength to withstand internal pressure produced during irradiation; however, the coated particle structure and dimensional stability of the $\mathrm{SiC}$ layer under irradiation, combined with the irradiation-induced shrinkage of the IPyC and OPyC, results in the SiC layer being kept under compression during irradiation. This provides a high level of assurance that the $\mathrm{SiC}$ layer will remain intact. Mean $\mathrm{SiC}$ thickness is $\sim 35 \mu \mathrm{m}$.

- Outer Pyrocarbon - The primary function of the OPyC layer is to protect the SiC layer against damage in the fuel-manufacturing processes following the coating process. It also provides prestress on the outside of the $\mathrm{SiC}$ layer because of its net shrinkage under fast-neutron irradiation during the fuel lifetime in the reactor core - thereby reducing the tensile stress in the $\mathrm{SiC}$ layer-and serves as a redundant barrier to gaseous fission-product release. The anisotropy of the OPyC layer is limited to control dimensional changes during irradiation. Mean OPyC thickness is typically 35 to $40 \mu \mathrm{m}$.

The specific coated-particle dimensions and material properties for the pebble and prismatic NGNP designs are described in Sections 4.2.1.2 and 4.3.1.2.

\subsection{German High-Quality LEU-UO ${ }_{2}$ Pebble-Fuel Experience}

This section addresses the fabrication, irradiation, and PIE and safety testing conducted on high-quality German LEU UO $\mathrm{U}_{2}$ TRISO fuel. The sphere and particle designs that evolved from a series of variations irradiated in the AVR and that are intended to be replicated for the NGNP pebble-bed are shown in Figure 5. More detailed information is provided in Appendix A.

The German LEU UO $\mathrm{U}_{2}$ TRISO fuel design evolved from decades of international coated-particle fuel fabrication, irradiation, and PIE and safety testing experience covering a wide range of particle designs, fuel forms, and irradiation and testing conditions, as noted in Section 3.1.1. Numerous international bilateral and multilateral data and analytical methods exchanges (such as those discussed in Reference 16), facilitated the effective incorporation of this experience into the definition and development of the German LEU UO $\mathrm{U}_{2}$ TRISO fuel particle and sphere design that began in the late 1970s. An extensive German fuel-development program was conducted through the mid 1990s, resulting in a substantial body of fabrication, irradiation, and PIE and testing data. 


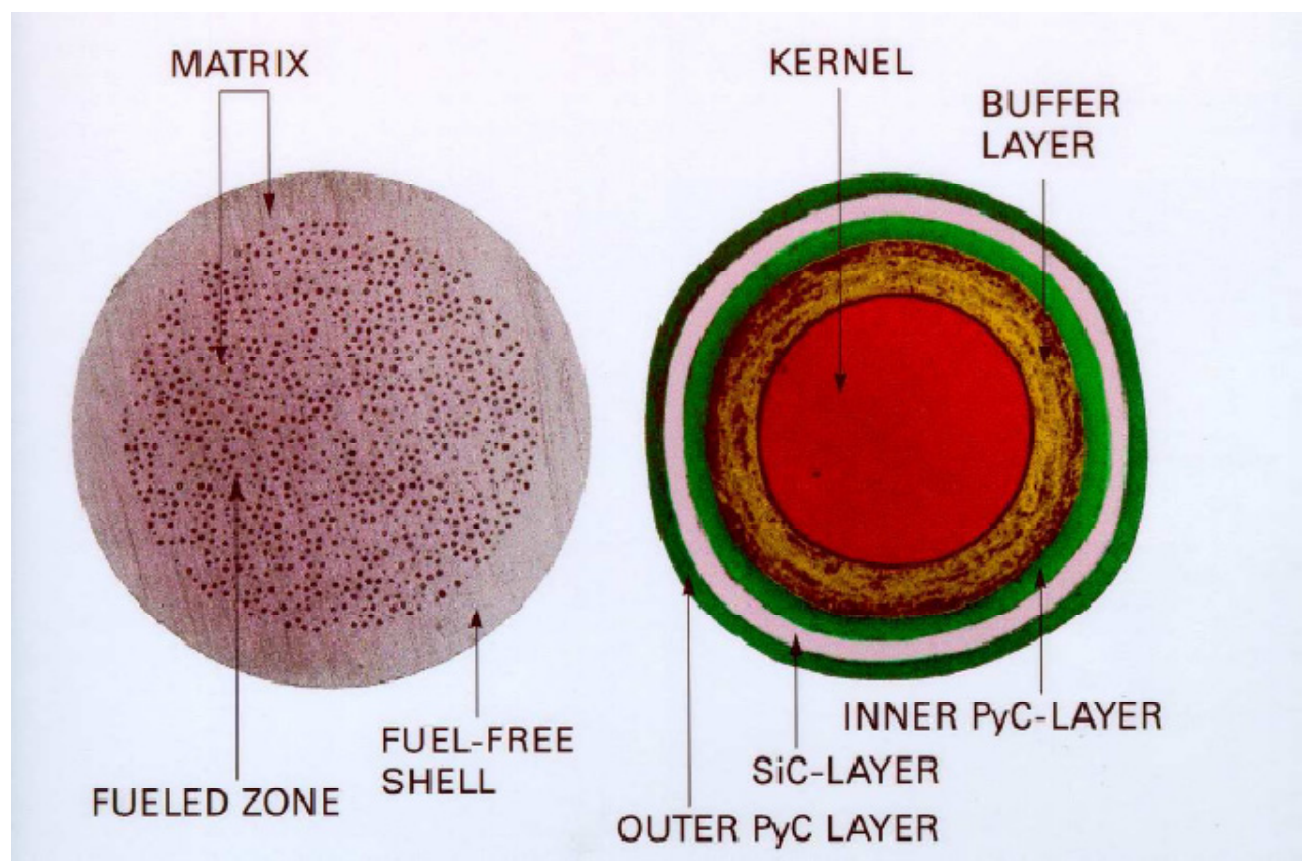

Figure 5. German LEU $\mathrm{UO}_{2}$ sphere and particle.

Fuel spheres produced in Germany for the HTR-Modul reactor proof tests were adopted as the reference design for the NGNP pebble-bed design fuel, with small adjustments in enrichment and sphere particle loading to address NGNP service conditions. Proof test fuel spheres were produced in Germany in 1988 and represent the culmination of the German LEU TRISO fuel-development and qualification program conducted from 1981 to 1988. A large body of experimental data obtained by means of an irradiation and PIE program, covering a wide range of operating parameters, supports the German LEU $\mathrm{UO}_{2}$ TRISO fuel design. This database supports establishment of an operating envelope for this fuel design, covering normal operation as well as transient and accident conditions.

The discussion in Section 3.1.2 addresses coated-particle in-service failure mechanisms, some of which are associated with as-manufactured defects. Two primary types of as-manufactured coating defects that can lead directly to fission product release are defined and detectable for TRISO particles:

- $\quad \mathrm{SiC}$ Defects - Particles with cracked or permeable SiC layers, but at least one intact dense PyC layer. These particles will release metallic fission products (e.g., silver, cesium) to a limited extent during normal operation and at a higher level under the elevated temperatures associated with some accident conditions.

- Exposed Kernels - Particles with connected defects in both dense PyC layers and the SiC layers. These particles will release both gaseous and metallic fission products to a limited extent ${ }^{\mathrm{h}}$ during normal operation and at a higher level under the elevated temperatures associated with some accident conditions.

The burn-leach procedure is used in the German program to determine the fraction of free uranium in sample fuel spheres. The result includes free uranium resulting from both types of as-manufactured fuel defects without distinguishing between the two. Gaseous-radioisotope release measurements during irradiation in material test reactors (MTRs) can be used to identify exposed kernels, but there are no

h. The fuel kernel effectively contains a large fraction of gaseous fission products when the particle coatings have failed. For example, during normal operation approximately 98 to $99 \%$ of the short-lived isotope ${ }^{85 \mathrm{~m}} \mathrm{Kr}$ is retained for sufficient time to allow radioactive decay before release from a particle with failed coatings. The released gas is primarily associated with recoil fission products that are deposited in the buffer region. 
Manufacturing detail for the different LEU UO $\mathrm{UR}_{2}$ TRISO fuel types of Table 2 is given in Table 3.

While German manufacturing experience dates from the 1960s, it is the $\mathrm{LEU} \mathrm{UO}_{2}$ TRISO fuel manufacturing, which started in 1981, that is directly applicable to NGNP pebble-bed fuel. Table 3 shows that the pre-1985 and post-1985 fuel designs are nearly identical, except for enrichment and heavy-metal loading in the spheres. Although the enrichment and heavy-metal loading varied, the amount of ${ }^{235} \mathrm{U}$ per sphere was kept at approximately $1 \mathrm{~g}$.

The delineation between pre-1985 and post-1985 is not based on the fuel design, but rather on two particular improvements in the manufacturing process. Coated particles are "overcoated" with matrix material ${ }^{i}$ prior to mixing them with additional matrix material in preparation for pressing of the fuel sphere. For the pre-1985 category, the overcoating of the particles was done manually, whereas for the post-1985 category, overcoating was automated using a specially designed mixer operated by a robot. This change in the overcoating process and the introduction of vibration tables in three stages to remove odd shaped kernels, coated particles, and overcoated particles during particle manufacturing resulted in a significant improvement in the "free uranium" burn-leach test results for completed fuel spheres. The free uranium fraction decreased by about a factor of four from the average of the pre-1985 results to the average of the post-1985 results (refer to Table 3).

Table 3. Manufacturing detail for LEU UO $\mathrm{UR}_{2}$ TRISO fuel types.

\begin{tabular}{|c|c|c|c|c|c|c|}
\hline Characteristic & \multicolumn{3}{|c|}{ Pre-1985 Production } & \multicolumn{2}{|c|}{ Post-1985 Production } & \multirow{2}{*}{$\begin{array}{l}\text { Pebble-Bed } \\
\text { Design } \\
\text { Specification }\end{array}$} \\
\hline Designation & GLE 3 & $\begin{array}{c}\text { LEU } \\
\text { Phase I }\end{array}$ & GLE 4 & GLE 4-2 & $\begin{array}{c}\text { Proof Test } \\
\text { Phase } 2 \\
\end{array}$ & \\
\hline Kernel Diameter $(\mu \mathrm{m})$ & 500 & 497 & 501 & 502 & 508 & 500 \\
\hline Kernel Density $\left(\mathrm{g} . \mathrm{cm}^{-3}\right)$ & 10.80 & 10.81 & 10.85 & 10.87 & 10.72 & $>10.4$ \\
\hline Coating Thickness $(\mu \mathrm{m})$ & & & & & & \\
\hline Buffer Layer & 93 & 94 & 92 & 92 & 102 & 95 \\
\hline Inner PyC Layer & 38 & 41 & 38 & 40 & 39 & 40 \\
\hline SiC Layer & 35 & 36 & 33 & 35 & 36 & 35 \\
\hline Outer PyC Layer & 40 & 40 & 41 & 40 & 38 & 40 \\
\hline Coating Density $\left(\mathrm{g} \cdot \mathrm{cm}^{-3}\right)$ & & & & & & \\
\hline Buffer Layer & 1.01 & 1.00 & 1.01 & 1.1 & 1.02 & $<1.05$ \\
\hline Inner PyC Layer & 1.86 & $\sim 1.9$ & 1.9 & 1.9 & 1.92 & 1.9 \\
\hline SiC Layer & 3.19 & 3.20 & 3.20 & 3.2 & 3.20 & $\geq 3.18$ \\
\hline Outer PyC Layer & 1.89 & 1.88 & 1.88 & 1.9 & 1.92 & 1.9 \\
\hline Fuel Sphere Loading & & & & & & \\
\hline Heavy Metal (g/FS) & 10 & 10 & 6 & 6 & 9.4 & 7 \\
\hline Uranium 235 (g/FS) & 1 & 1 & 1 & 1 & 1 & 0.545 \\
\hline Enrichment (\% U-235) & 9.82 & 9.82 & 16.76 & 16.76 & 10.6 & 7.8 \\
\hline Coated Particle per FS & 16,400 & 16,400 & 9,560 & 9,560 & 14,580 & 11,200 \\
\hline Free-Uranium Fraction $\left(\times 10^{-6}\right)$ & 50.7 & 35 & 43.2 & 7.8 & 13.5 & $<60^{\mathrm{j}}$ \\
\hline
\end{tabular}

i. The matrix material consists of a mixture of natural and synthetic graphite powder and a resin binder.

j. This is the same value used in the German manufacturing specification; actual manufacturing results are expected to be similar to those reported for German fuel in the previous two columns. 
Since the manufacturing process change that delineates the two categories significantly impacts the determination of the free-uranium fraction, only the burn-leach test results from the post-1985 category were used in the calculation of the expected "coated-particle defect fraction" due to manufacturing defects. Forty GLE 4/2 spheres and 10 Proof Test spheres (Table 3), containing a total of 528,200 coated particles, were subjected to the burn-leach test. Test results indicated that the free uranium in these 528,200 particles was equivalent to the uranium in six coated particles. Therefore, the sample mean failure fraction is $1.1 \times 10^{-5}$ and the expected defect fraction $(50 \%$ confidence that population fraction is no higher) due to manufacturing is $1.3 \times 10^{-5}$, with a $95 \%$ confidence maximum defect fraction of $2.2 \times 10^{-5}$.

The substantial majority of the fuel irradiation and testing data discussed in Sections 3.2.2 and 3.2.3 was produced from the GLE 3 and LEU Phase 1 fuels. As shown in Table 3, the parameters for these fuels are similar to the NGNP pebble-bed design fuel. The primary areas of difference are a somewhat higher number of particles per sphere and a higher free-uranium fraction (relative to the expected value for the NGNP pebble-bed design). These differences are conservative with respect to use of the data in the context of expected performance of pebble-bed fuel.

\subsubsection{German LEU UO $\mathrm{O}_{2}$ TRISO Fuel-Fabrication Process}

The basic steps of the German $\mathrm{LEU} \mathrm{UO}_{2}$ TRISO fabrication process that was used in the production of the Proof Test Phase 2 fuel described above are summarized in this section from the production of the fuel kernel through the final heat treatment of the fuel sphere.

\section{Kernels}

During isostatic pressing of the fuel spheres, non-spherical coated particles show a much greater tendency to crack than spherical particles. Therefore, wet chemical processes that produce highly spherical kernels are used during the initial stages of kernel manufacture. Also, coating process conditions that produce coatings of uniform thickness are established and maintained. Coated-particle failure in fuel spheres can be greatly reduced by removing particles that show an unacceptable deviation from a spherical shape. Unacceptably out-of-round particles are removed on a sorting table whose surface is slightly inclined in one direction as it is vibrated. The basic manufacturing steps for the kernel are as follows:

- $\mathrm{U}_{3} \mathrm{O}_{8}$ powder is dissolved in nitric acid to form uranyl nitrate.

- The solution is neutralized with ammonia and then flows through an oscillating nozzle to produce spherical droplets.

- As the droplets fall through a gaseous ammonia atmosphere, the outer surface of the spherical droplet gels.

- The particles fall into an aqueous ammonia solution, where they solidify into ammonium diuranate (ADUN).

- The particles are then aged and washed to remove ammonium nitrate and organic additives, dried, and calcined.

- The dry kernels are reduced to $\mathrm{UO}_{2}$ in hydrogen, sintered, and sieved to remove odd-shaped or unusual particle sizes. They are then ready to be coated.

The more important process parameters that will be monitored are:

- Casting parameters: nozzle geometry, vibration frequency, and ammonia flow. These parameters affect the size and shape of the kernels. Monitoring of droplet formation will be by stroboscope. 
- Calcining temperature from $\mathrm{ADUN}$ to $\mathrm{UO}_{3}$ : the integrity of the final $\mathrm{UO}_{2}$ product after subsequent reduction and sintering is affected by the stoichiometry of the $\mathrm{UO}_{3}$, and the calcining temperature will be controlled and monitored.

- Reduction and sintering temperature: temperatures for reduction from $\mathrm{UO}_{3}$ to $\mathrm{UO}_{2}$ and for sintering of the kernels will be controlled to ensure that compliant product is obtained.

- Sieve sizes and sorting-table parameters: these ensure that unusual kernel sizes and odd-shaped kernels are removed.

\section{Particle Coatings}

The following coatings are applied to the kernel in an uninterrupted process (particles remain in the coater during transitions between sequential applications of coatings):

- The buffer layer, the first layer in contact with the kernel, is deposited from acetylene $\left(\mathrm{C}_{2} \mathrm{H}_{2}\right)$ in a heated fluidized bed. The temperature and other conditions in the fluidized bed are adjusted to produce a porous pyrocarbon layer that has approximately $50 \%$ of the theoretical density of pyrocarbon.

- The IPyC layer is deposited from a mixture of acetylene and propylene in a heated fluidized bed, using process conditions that produce an average density of approximately $1.9 \mathrm{~g} / \mathrm{cm}^{3}$.

- The SiC layer is deposited from methyltrichlorosilane and, under the correct conditions, a density of $\sim 3.2 \mathrm{~g} / \mathrm{cm}^{3}$ (nearly $100 \%$ theoretical density) with a grain size that is small in comparison to the $\mathrm{SiC}$-layer thickness is obtained. The resulting $\mathrm{SiC}$ layer has high strength and low permeability.

- The OPyC pyrolytic carbon layer is deposited in the same way as the IPyC layer.

The important coating process parameters that will be monitored are:

- Deposition temperatures, times and gas flow rates: the deposition temperatures and times, along with the gas flow rates for the buffer, IPyC, SiC and OPyC layers, determine the thicknesses and densities of the layers, as well as their structures.

- Sieve sizes and sorting-table parameters: these ensure that unusual particle sizes and odd-shaped particles, which may lead to failure, are removed.

\section{Fuel Spheres}

In preparation for fuel-sphere manufacturing, a coating of finely ground matrix graphite and resin binder is applied to the outer surface of each coated particle in a rotating drum. This coating is known as the "overcoat." Its purpose is to prevent coated particles from coming into contact with each other, thereby damaging their coatings during pressing of the fuel spheres.

Overcoated fuel particles are pressed into spheres at high pressure, without application of external heat, to obtain the required density that ensures adequate structural stability and heat conduction. This also provides the correct amount of carbon in the reactor core to determine heat capacity and moderation. Fuel spheres are pressed in two steps:

- In the first step, coated particles overcoated with matrix material, along with additional matrix material, are mixed and pressed to form a fuel-containing region consisting of a sphere $50 \mathrm{~mm}$ in diameter. The number of coated particles within the sphere is adjusted to provide the required heavy metal loading for the fuel, which, for the example pebble-bed design, is approximately 11,200 coated particles. Coated particles are distributed evenly in this inner, fuel-containing region to prevent the development of hot spots in the fuel sphere.

- In the second step, matrix material is added to the mold, and a high-pressure isostatic pressing process is used to form a 5-mm-thick fuel-free region around the fuel-containing region. The purpose of this 
region is to protect the inner zone from mechanical and chemical damage during handling and operation.

The pressed spheres are machined to a dimension that will be within final dimensional tolerance subsequent to heat treatment. The machining also ensures that the surface condition of the spheres supports smooth transition of the sphere through the reactor core and the fuel-handling system. Following the machining, the spheres are carbonized in a heated argon atmosphere prior to being annealed at $1950^{\circ} \mathrm{C}$ under vacuum conditions. The heat treatment not only improves the spheres' strength and resistance to corrosion, but also burns out organic compounds and impurities.

The important product and process parameters that will be monitored are:

- Overcoat thickness and density - These parameters will be controlled to ensure consistency and to prevent contact between coated particles during pressing

- Sieve sizes and sorting-table parameters - These ensure that unusual over-coated particle sizes and odd-shaped particles, which may lead to particle failure, are removed

- Pressing pressure - The fuel sphere pressing pressure will be controlled automatically to ensure that matrix graphite characteristics are within limits

- Carbonizing temperature - The temperature-time profile for carbonizing fuel spheres will be automatically controlled to avoid cracking of matrix graphite caused by excessive ramp rates and to ensure completion of the process

- Annealing temperature - This will be controlled to ensure that impurities are removed from the fuel spheres to ensure sufficient corrosion resistance.

\subsubsection{Irradiation}

The German fuel irradiation experience includes both bulk fuel testing in the AVR and carefully controlled and monitored irradiations in MTRs in Germany, the Netherlands, and France.

The data and analyses summarized in this section and discussed in detail in Section A-1 lead to the following observations and conclusions regarding fuel behavior during normal operation:

- Exposed kernels:

- In-pile MTR gas-release data from eight LEU Phase 1 and eight Proof Test spheres containing a total of 247,800 particles indicated three particles with exposed kernels at the beginning of irradiation, with no additional failures during irradiation.

- Post-irradiation heating test krypton release data from 14 GLE 3 spheres containing 229,400 particles irradiated in the AVR indicated no particles with exposed kernels.

- $\quad \mathrm{SiC}$ defects:

- The nominal as-manufactured free-uranium fraction for GLE 3 spheres irradiated in the AVR was $5.07 \times 10^{-5}$, and for LEU Phase 1 spheres irradiated in MTRs, it was $3.5 \times 10^{-5}$. These results would include both exposed kernels and $\mathrm{SiC}$ defects.

- Post-irradiation heating cesium release data from 13 GLE 3 spheres containing 213,200 particles irradiated in the AVR and four LEU Phase 1 spheres containing 65,600 particles irradiated in MTRs (a total of 278,800 particles) indicated nine particles with defective SiC layers. This results in a $50 \%$ confidence $\mathrm{SiC}$ defect fraction of $3.5 \times 10^{-5}$ and a $95 \%$ confidence value of $5.6 \times 10^{-5}$.

- The weighted as-manufactured SiC defect fraction for the 13 GLE 3 spheres and four LEU Phase 1 spheres, discussed above, is $4.9 \times 10^{-5}$. This is more than the $50 \%$ confidence post-irradiation $\mathrm{SiC}$ defect fraction $\left(3.5 \times 10^{-5}\right)$ and less than the $95 \%$ confidence value 
$\left(5.6 \times 10^{-5}\right)$, indicating that no statistically significant additional $\mathrm{SiC}$ defects occurred during irradiation and that the as-manufactured burn-leach results were dominated by $\mathrm{SiC}$ defects.

- Both the in-pile gas release (exposed kernels) and the post-irradiation heating cesium release (SiC defects) indicated no particle failures during irradiation in a total of 477,400 particles. These results indicated that particle failures during irradiation are highly unlikely.

Pebble-bed fuel performance analysis methods for normal operation require particle-failure fractions for the average burnup, fluence, and temperature history of the fuel in the core as an input parameter. Experience with German LEU UO ${ }_{2}$ TRISO fuel applicable to pebble-bed design normal operation includes time-varying conditions associated with actual reactor operation and controlled conditions in MTRs. Actual reactor operation in the AVR enveloped the pebble-bed conditions, addressed in Section 4.2.2, in terms of mixed mean coolant-outlet temperature and temperature rise across the reactor and exposed the fuel spheres to cyclical power and temperature variations. While the actual temperature history of individual spheres irradiated in AVR is unknown, the variations in temperature history would have been substantially reduced by the multiple cycles through the reactor experienced by most of the AVR spheres. As an aggregate data set, the spheres irradiated in AVR would have experienced substantially more challenging temperature histories than are expected for pebble-bed fuel, as discussed in Section A-1.1.

The MTR data include known temperature histories and extremes in burnup and fluence and time at temperatures well beyond the expected service conditions of pebble-bed fuel. These data also provide insights that support interpretation of the AVR irradiation data, such as particles with exposed kernels present from the beginning of the irradiations.

All the German fuel AVR and MTR irradiation data discussed in Sections 3.2.2 and A-1 are shown in Figure 6 . The AVR fast-fluence values were determined by a correlation with burnup and individually adjusted to reflect the expected $\pm 10 \%$ variation based on different trajectories taken by individual spheres. As shown in Figure 6, the aggregate envelope of the existing data on German LEU UO TRISO fuel $^{2}$ substantially exceeds the example pebble-bed design operating envelope, discussed in Section 4.2.2.1, in terms of burnup and fast fluence.

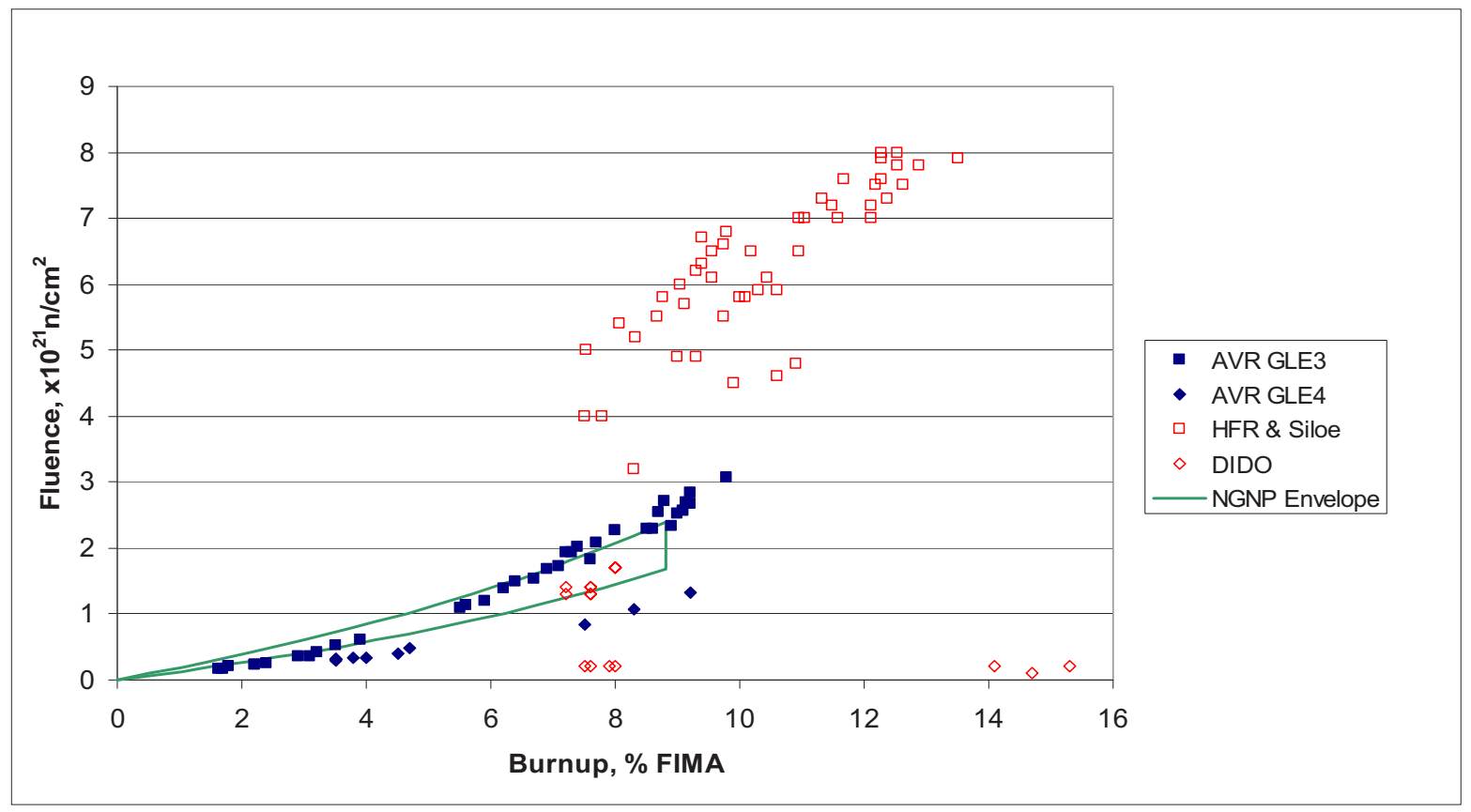

Figure 6. German LEU TRISO irradiation conditions, AVR and MTRs. 
The average and maximum values of the AVR and MTR prototype sphere data, as well as the combined data sets, are compared with the NGNP pebble-bed design service conditions in Table 4. It is clear from Figure 6 that the prototype German LEU UO $\mathrm{U}_{2}$ TRISO sphere irradiation data, in aggregate, substantially exceed the NGNP pebble-bed service conditions.

Table 4. Comparison of fuel irradiation data service conditions with pebble-bed design.

\begin{tabular}{|l|c|c|c|c|}
\hline \multicolumn{1}{|c|}{ Parameter } & AVR Data & MTR Data & Combined & $\begin{array}{c}\text { Pebble-Bed } \\
\text { Design }\end{array}$ \\
\hline Average Discharge Burnup, \% FIMA & 8.2 & 8.5 & 8.4 & 8.31 \\
\hline Maximum Discharge Burnup, \% FIMA & 9.8 & 10.6 & 10.6 & 8.75 \\
\hline Average Fast Fluence, $\times 10^{21} \mathrm{n} / \mathrm{cm}^{2}$ & 2.2 & 3.8 & 3.1 & 2.01 \\
\hline Maximum Fast Fluence, $\times 10^{21} \mathrm{n} / \mathrm{cm}^{2}$ & 2.9 & 5.9 & 5.9 & 2.4 \\
\hline Average Center Temperature, ${ }^{\circ} \mathrm{C}$ & N/D & 1,062 & N/D & 644 \\
\hline Maximum Center Temperature, ${ }^{\circ} \mathrm{C}$ & $\sim 1,350$ & 1,220 & $\sim 1,350$ & 1,048 \\
\hline Number of Particles & 229,600 & 247,800 & 477,400 & - \\
\hline
\end{tabular}

The overall German LEU UO $\mathrm{UR}_{2}$ TRISO prototype-sphere data set for normal operation is given in Table 5. These data are for exposed kernels and SiC defects of irradiated fuel; thus, they would include both manufacturing defects and in-service failures. The basis for determining the number of particles with exposed kernels and with SiC defects for the spheres irradiated in the AVR and in MTRs that underwent heating tests is presented in detail in Section 3.2.3. Exposed kernels for spheres (Table 5) that did not undergo heating tests were identified by analysis of in-pile gaseous fission product release. ${ }^{33}$ As seen in Table 5, the 50\% confidence SiC-defect fraction of $3.5 \times 10^{-5}$, which would include exposed kernels, is somewhat less than the mean as-manufactured free-uranium fraction for the combined fuels of approximately $4.7 \times 10^{-5}$, and the as-manufactured value is well within the $95 \%$ confidence value for $\mathrm{SiC}$ defect fractions in the irradiated fuel of $5.6 \times 10^{-5}$. This provides confidence in the identification of SiC defects from the initial cesium-release response in the heating tests. Also, it is clear that the fraction of particles whose radionuclide-retention capability is degraded in normal operation is exceedingly low. This should not be surprising given that during normal operation, the fuel must retain the capability to withstand transient and accident conditions with very limited particle failure. Data regarding performance under transient and accident conditions are addressed in Section 3.2.3.

Two additional irradiations of archived German fuel spheres, designated HFR-EU1 and HFR EU1bis, were conducted within the framework of the European Commission project on development of HTR technology. The overall objective of the irradiations was to explore the capability of the German coated particle by irradiating archived samples to burnups (HFR-EU1) and at temperatures (HFR-EU1bis) exceeding those of previous irradiations.

The HFR-EU1bis irradiation of five German AVR 21-2 fuel spheres began in September 2004 and was completed in October 2005. ${ }^{34}$ During the irradiation, the central temperature of all spheres was maintained at approximately $1,250^{\circ} \mathrm{C}$, with end-of-irradiation burnup ranging from 9.3 to $11 \%$ FIMA. Early in the irradiation, an operating error resulted in inadvertent introduction of pure neon, resulting in temperatures well above the target values. Post-irradiation thermal modeling of operation with pure neon indicated a temperature at the outer graphite shroud radius of $1,350^{\circ} \mathrm{C},{ }^{35}$ which could result in sphere centerline temperatures approaching $1,600^{\circ} \mathrm{C}$ for an extended period. Gaseous fission-product release data indicate that one or more exposed kernels were present at the beginning of the irradiation, and several more particles failed during the irradiation. PIE examination and testing have been substantially completed, but complete documented results are not yet publicly available. 
Table 5. Normal operation prototype sphere irradiation data summary.

\begin{tabular}{|c|c|c|c|c|c|c|c|c|}
\hline ID & $\begin{array}{c}\text { No. of } \\
\text { Particles }\end{array}$ & $\begin{array}{c}\text { Burnup } \\
\% \text { FIMA }\end{array}$ & $\begin{array}{r}\mathrm{Fa} \\
\text { Flue } \\
10^{25} \\
\end{array}$ & & $\begin{array}{c}\text { Irradiation } \\
\text { Temperature } \\
{ }^{\circ} \mathrm{C} \\
\end{array}$ & $\begin{array}{c}\text { Test } \\
\text { Temperature } \\
{ }^{\circ} \mathrm{C}^{\mathrm{k}}\end{array}$ & $\begin{array}{c}\text { Exposed } \\
\text { Kernels } \\
\end{array}$ & $\begin{array}{c}\mathrm{SiC} \\
\text { Defects }\end{array}$ \\
\hline \multicolumn{9}{|c|}{ AVR Spheres* } \\
\hline AVR 88/15 & 16,400 & 8.7 & \multicolumn{2}{|c|}{2.4} & & 1,600 & 0 & 0 \\
\hline AVR $82 / 20$ & 16,400 & 8.6 & \multicolumn{2}{|c|}{2.4} & & 1,600 & 0 & 1 \\
\hline AVR $88 / 33$ & 16,400 & 8.5 & \multicolumn{2}{|c|}{2.3} & & 1,600 & 0 & 3 \\
\hline AVR 71/22 & 16,400 & 3.5 & \multicolumn{2}{|c|}{0.5} & & 1,600 & 0 & 0 \\
\hline AVR 82/9 & 16,400 & 8.9 & \multicolumn{2}{|c|}{2.5} & & 1,600 & 0 & N/D* \\
\hline AVR 90/20 & 16,400 & 9.8 & \multicolumn{2}{|c|}{2.9} & & $1,620 \mathrm{~T}$ & 0 & 0 \\
\hline AVR 90/2 & 16,400 & 9.2 & \multicolumn{2}{|c|}{2.7} & & $1,620 \mathrm{~T}$ & 0 & 1 \\
\hline AVR 90/5 & 16,400 & 9.2 & \multicolumn{2}{|c|}{2.7} & & $1,620 \mathrm{~T}$ & 0 & 0 \\
\hline AVR 85/18 & 16,400 & 9.15 & \multicolumn{2}{|c|}{2.6} & & $1,620 \mathrm{~T}$ & 0 & 0 \\
\hline AVR 89/13 & 16,400 & 9.1 & \multicolumn{2}{|c|}{2.6} & & $1,620 \mathrm{~T}$ & 0 & 0 \\
\hline AVR 74/11 & 16,400 & 6.2 & \multicolumn{2}{|c|}{1.4} & & 1,700 & 0 & 1 \\
\hline AVR 91/31 & 16,400 & 9.0 & \multicolumn{2}{|c|}{2.6} & & $1,700 \mathrm{~T}$ & 0 & 0 \\
\hline AVR 88/41 & 16,400 & 7.6 & \multicolumn{2}{|c|}{1.9} & & 1,800 & 0 & 2 \\
\hline AVR 76/18 & 16,400 & 7.1 & \multicolumn{2}{|c|}{1.7} & & 1,800 & 0 & 0 \\
\hline \multicolumn{9}{|c|}{ Materials Test Reactor Spheres } \\
\hline HFR-K3/1 & 16,400 & 7.5 & \multicolumn{2}{|l|}{4} & 1,200 & 1,600 & 0 & 0 \\
\hline FRJ2-K13/2 & 16,400 & 8 & \multicolumn{2}{|c|}{0.2} & 1,150 & 1,600 & 0 & 1 \\
\hline FRJ2-K13/4 & 16,400 & 7.6 & \multicolumn{2}{|c|}{0.2} & 1,120 & 1,600 & 0 & 0 \\
\hline HFR-K3/3 & 16,400 & 10.6 & \multicolumn{2}{|c|}{5.9} & 920 & 1,800 & 0 & 0 \\
\hline HFR-K3/2 & 16,400 & 10 & \multicolumn{2}{|c|}{5.8} & 920 & & 0 & $\mathrm{~N} / \mathrm{D}$ \\
\hline HFR-K3/4 & 16,400 & 9 & \multicolumn{2}{|c|}{4.9} & 1,220 & & 0 & $\mathrm{~N} / \mathrm{D}$ \\
\hline HFR-K5/1 & 14,580 & 7.8 & \multicolumn{2}{|c|}{4} & 923 & & 0 & $\mathrm{~N} / \mathrm{D}$ \\
\hline HFR-K5/2 & 14,580 & 10.1 & \multicolumn{2}{|c|}{5.8} & 909 & & 0 & $\mathrm{~N} / \mathrm{D}$ \\
\hline HFR-K5/3 & 14,580 & 10.3 & \multicolumn{2}{|c|}{5.9} & 903 & & 0 & N/D \\
\hline HFR-K5/4 & 14,580 & 9.3 & \multicolumn{2}{|c|}{4.9} & 921 & & 1 & N/D \\
\hline HFR-K6/1 & 14,580 & 8.3 & 3.2 & & 1,090 & & 0 & $\mathrm{~N} / \mathrm{D}$ \\
\hline HFR-K6/2 & 14,580 & 10.6 & 4.6 & & 1,130 & & 0 & $\mathrm{~N} / \mathrm{D}$ \\
\hline HFR-K6/3 & 14,580 & 10.9 & 4.8 & & 1,140 & & 0 & $\mathrm{~N} / \mathrm{D}$ \\
\hline HFR-K6/4 & 14,580 & 9.9 & 4.5 & & 1,130 & & 2 & $\mathrm{~N} / \mathrm{D}$ \\
\hline FRJ2-K13/1 & 16,400 & 7.5 & 0.2 & & 1,125 & & 0 & $\mathrm{~N} / \mathrm{D}$ \\
\hline FRJ2-K13/3 & 16,400 & 7.9 & 0.2 & & 1,150 & & 0 & $\mathrm{~N} / \mathrm{D}$ \\
\hline Analysis Sum & ry of Irrad & ted Spher & & & & & & \\
\hline Para & & $\begin{array}{r}\text { Numbe } \\
\text { Partic }\end{array}$ & & & tal Particles & $\begin{array}{r}\text { Maximun } \\
\text { Par }\end{array}$ & $\begin{array}{l}\text { Parent Por } \\
\text { cle Fractio }\end{array}$ & lation \\
\hline Confide & $\begin{array}{l}\text { Level that } \\
\text { Exceeded }\end{array}$ & $\begin{array}{l}\text { ndicated P } \\
\text { n Parent P }\end{array}$ & $\begin{array}{l}\text { article } \\
\text { ppulat }\end{array}$ & & tion is not & $50 \%$ & & \\
\hline Exposed Ker & & 3 & & & 477,400 & $7.6 \times 10^{-6}$ & 1.6 & $10^{-5}$ \\
\hline SiC Defects & & 9 & & & 278,800 & $3.5 \times 10^{-5}$ & 5.6 & $10^{-5}$ \\
\hline
\end{tabular}

k. " $\mathrm{T}$ " indicates that the fuel particles were subjected to a transient-simulation heat-up test after irradiation. 
The HFR-EU1 experiment contained three spheres of archived German fuel from the AVR 21-2 batch and thus had essentially the same properties as those irradiated in HFR-EU1bis. The irradiation began in September 2006 and was removed from the reactor in February 2008 because of operational concerns associated with the number of thermocouple failures experienced. The German capsule was controlled to achieve a sphere surface temperature of approximately $900^{\circ} \mathrm{C}$, and a maximum burnup of $11.2 \%$ was reached prior to removal from the reactor. Gaseous fission-product release data indicate that no exposed kernels were present at the beginning of the irradiation, and no failures occurred during the irradiation. The irradiation was subsequently resumed, with final results to be addressed by papers at the HTR2010 Conference.

\subsubsection{Safety Testing}

The safety testing results for German $\mathrm{LEU} \mathrm{UO}_{2}$ fuel are discussed in detail in Section A-1.3. The phenomena affecting performance of the coated particles at elevated temperature are time dependent. As indicated in the figures of Section A-1.3, there was considerable variation in the durations of the isothermal tests, but all were carried out for durations beyond those predicted by accident analysis.

\subsubsection{Summary of Heating Test Krypton Release Results}

All of the heating tests included in the statistics of Section A-1.3 utilized full-sized spheres from either the GLE 3 or LEU Phase 1 fuel campaigns. As shown in Table 3, the characteristics of these fuel types are quite similar to the pebble-bed fuel specification. There is a difference in the fuel-particle loadings in the spheres: 16,400 particles for the GLE 3 and LEU Phase 1 fuels and 11,200 for the NGNP pebble-bed specification (see Table 3). Another difference is the use of A3-27 matrix in the test fuel as compared to the A3-3 matrix that will be used for the pebble-bed fuel. The A3-3 matrix formulation was also used in the HFR-K5 and HFR-K6 spheres, which were irradiated but not subjected to heating tests in the German program (heating tests on some of the spheres were conducted recently under an Organization for Economic Cooperation and Development $[\mathrm{OECD}]$ program $^{36}$ ). This small difference in matrix formulation is not expected to alter the fuel performance, which will be confirmed in the planned testing of pebble-bed fuel discussed in Section 5.2.2.

The quantitative results of the German heating tests are summarized in Table 6 . The average burnup and fast fluence of the populations of particles included in the heating tests (particularly at $1,600^{\circ} \mathrm{C}$ ) are very close to the NGNP pebble-bed average discharge burnup of $8.31 \%$ FIMA and average discharge fast fluence of $2.01 \times 10^{21} \mathrm{n} / \mathrm{cm}^{2}$, as reported in Table 6. Keeping in mind that, under accident conditions when these high temperatures are approached, only a small percentage of the spheres within the core will have accumulated burnup and fast fluence approaching the discharge values. Thus, under these accident heating conditions, the complete volume-averaged core burnup of 4.74\% FIMA and fast fluence of $1.01 \times 10^{21} \mathrm{n} / \mathrm{cm}^{2}$ should be considered when considering releases. These average values are significantly lower than the average values of the spheres subjected to heating tests as illustrated in Table 6 below.

Table 6. Summary of heating test krypton release results.

\begin{tabular}{|c|c|c|c|c|}
\hline \multirow[b]{2}{*}{ Parameter } & \multicolumn{4}{|c|}{ Test Temperature } \\
\hline & $1,600^{\circ} \mathrm{C}$ & $1,700^{\circ} \mathrm{C}$ & $1,800^{\circ} \mathrm{C}$ & $1,800^{\circ} \mathrm{C}^{\mathrm{a}}$ \\
\hline Average Burnup, \% FIMA & 8.3 & 7.6 & 6.5 & 8.4 \\
\hline Average Fast Fluence, $10^{21} \mathrm{n} / \mathrm{cm}^{2}$ & 2.2 & 2.0 & 1.8 & 2.6 \\
\hline Number Particles & 213,200 & 36,132 & 83,631 & 50,831 \\
\hline Number Exposed Kernels & 6 & 20 & 69 & 12 \\
\hline Exposed Kernel Fraction $^{\mathrm{b}}$ (50\% confidence) & $3.1 \times 10^{-5}$ & $5.72 \times 10^{-4}$ & $8.33 \times 10^{-4}$ & $2.49 \times 10^{-4}$ \\
\hline Exposed Kernel Fraction ${ }^{\mathrm{b}}$ (95\% confidence) & $5.6 \times 10^{-5}$ & $8.04 \times 10^{-4}$ & $1.01 \times 10^{-3}$ & $3.82 \times 10^{-4}$ \\
\hline
\end{tabular}




\subsubsection{Summary of Heating Test Metallic Fission-Product Release Results}

The cesium release response at the beginning of the tests can be used to identify particles with defective $\mathrm{SiC}$ layers that were present at the end of irradiation. This is of major value, as the results can be compared with the incidence of $\mathrm{SiC}$ defects (as determined by the free uranium fraction) that were detected in the as-manufactured fuel using the burn-leach procedure. The results, as determined by the cesium release analyses of the previous sections, are summarized in Table 7. The implications of these data on irradiation performance are discussed in Section 3.2.2.

Table 7. End-of-irradiation fuel condition inferred from heating test data.

\begin{tabular}{|c|c|c|c|c|c|c|c|}
\hline ID & $\begin{array}{c}\text { Number of } \\
\text { Particles } \\
\end{array}$ & $\begin{array}{l}\text { Burnup } \\
\% \text { FIMA }\end{array}$ & $\begin{array}{c}\text { Fast } \\
\text { Fluence } \\
10^{25} \mathrm{n} / \mathrm{m}^{2} \\
\end{array}$ & $\begin{array}{c}\text { Irradiation } \\
\text { Temperature } \\
{ }^{\circ} \mathrm{C} \\
\end{array}$ & $\begin{array}{c}\text { Test } \\
\text { Temperature } \\
{ }^{\circ} \mathrm{C} \\
\end{array}$ & $\begin{array}{c}\text { Exposed } \\
\text { Kernels }\end{array}$ & $\begin{array}{c}\mathrm{SiC} \\
\text { Defects }\end{array}$ \\
\hline \multicolumn{8}{|c|}{ AVR Spheres* } \\
\hline AVR $88 / 15$ & 16,400 & 8.7 & 2.4 & & 1,600 & 0 & 0 \\
\hline AVR $82 / 20$ & 16,400 & 8.6 & 2.4 & & 1,600 & 0 & 1 \\
\hline AVR $88 / 33$ & 16,400 & 8.5 & 2.3 & & 1,600 & 0 & 3 \\
\hline AVR $71 / 22$ & 16,400 & 3.5 & 0.5 & & 1,600 & 0 & 0 \\
\hline AVR 90/20 & 16,400 & 9.8 & 2.9 & & $1,620 \mathrm{~T}$ & 0 & 0 \\
\hline AVR 90/2 & 16,400 & 9.2 & 2.7 & & $1,620 \mathrm{~T}$ & 0 & 1 \\
\hline AVR 90/5 & 16,400 & 9.2 & 2.7 & & $1,620 \mathrm{~T}$ & 0 & 0 \\
\hline AVR $85 / 18$ & 16,400 & 9.15 & 2.6 & & $1,620 \mathrm{~T}$ & 0 & 0 \\
\hline AVR 89/13 & 16,400 & 9.1 & 2.6 & & $1,620 \mathrm{~T}$ & 0 & 0 \\
\hline AVR 74/11 & 16,400 & 6.2 & 1.4 & & 1,700 & 0 & 1 \\
\hline AVR 91/31 & 16,400 & 9.0 & 2.6 & & $1,700 \mathrm{~T}$ & 0 & 0 \\
\hline AVR 88/41 & 16,400 & 7.6 & 1.9 & & 1,800 & 0 & 2 \\
\hline AVR 76/18 & 16,400 & 7.1 & 1.7 & & 1,800 & 0 & 0 \\
\hline \multicolumn{8}{|c|}{ MTR Spheres } \\
\hline HFR-K3/1 & 16,400 & 7.5 & 4 & 1,200 & 1,600 & 0 & 0 \\
\hline FRJ2-K13/2 & 16,400 & 8 & 0.2 & 1,150 & 1,600 & 0 & 1 \\
\hline FRJ2-K13/4 & 16,400 & 7.6 & 0.2 & 1,120 & 1,600 & 0 & 0 \\
\hline HFR-K3/3 & 16,400 & 10.6 & 5.9 & 920 & 1,800 & 0 & 0 \\
\hline $\begin{array}{c}\text { Total } \\
\text { Particles }\end{array}$ & 278,800 & 8.2 & 2.3 & \multicolumn{2}{|c|}{$\leftarrow$ Average Values Totals $\rightarrow$} & 0 & 9 \\
\hline \multicolumn{6}{|c|}{$50 \%$ confidence maximum parent population fraction } & $2.49 \times 10^{-6}$ & $3.47 \times 10^{-5}$ \\
\hline \multicolumn{6}{|c|}{$95 \%$ confidence maximum parent population fraction } & $1.07 \times 10^{-5}$ & $5.63 \times 10^{-5}$ \\
\hline
\end{tabular}

The release of silver from intact particles was observed at all heating-test temperatures, with the rate of release increasing substantially between 1,600 and $1,800^{\circ} \mathrm{C}$. Cesium was seen to be effectively retained in the intact particles at $1,600^{\circ} \mathrm{C}$ and for the first $100 \mathrm{~h}$ at $1,700^{\circ} \mathrm{C}$, but intact particles dominated the cesium release at $1,800^{\circ} \mathrm{C}$. Strontium was retained within the spheres at 1,600 and $1,700^{\circ} \mathrm{C}$ but was released at $1,800^{\circ} \mathrm{C}$. 
In the initial 1,700 to $1,800^{\circ} \mathrm{C}$ heating periods, retention of metallic fission products (exception: silver) is high by comparison with standard prediction methods, ${ }^{37}$ but the degree of retention is strongly influenced by prior irradiation conditions, notably irradiation temperature, fluence, and burnup.

The data and analyses presented and discussed in this section lead to the following observations and conclusions regarding fuel behavior under accident conditions:

- The heating tests included both isothermal tests at all temperatures and transient simulation tests at 1,600 and $1,700^{\circ} \mathrm{C}$. The krypton release data resulted in the maximum parent population of exposed kernel fractions at 50 and $95 \%$ confidence, as shown in Table 8.

- The krypton release results of the heating tests at 1,600 and $1,700^{\circ} \mathrm{C}$ are dominated by transient simulation data from two AVR spheres at $1,620^{\circ} \mathrm{C}$ and one AVR sphere at $1,700^{\circ} \mathrm{C}$.

Fuel-performance models would predict that the isothermal testing should be more challenging for the fuel, and it is possible that these three spheres experienced exceptionally high temperatures during irradiation in the AVR. Note that three additional spheres were subjected to transient simulation testing at $1,620^{\circ} \mathrm{C}$ with no failures. The data at $1,700^{\circ} \mathrm{C}$ are limited, including only two spheres. Two of the $1,800^{\circ} \mathrm{C}$ tests, which dominate the results, may have seen excessively high temperatures due to fouling of the pyrometer window as discussed in Section A-1.3.1.

- The metallic-radionuclide release results from the heating tests provided a means of identifying particles with $\mathrm{SiC}$ defects that were present at the end of irradiation. They also indicated release of silver at all temperatures, with effective retention of cesium and strontium at $1,600^{\circ} \mathrm{C}$ and increasing release after extended periods at $1,800^{\circ} \mathrm{C}$.

Table 8. Heating test results - exposed kernel fractions.

\begin{tabular}{|c|c|c|c|}
\hline \multirow{2}{*}{\multicolumn{2}{|c|}{ Heating Temperature $\left({ }^{\circ} \mathrm{C}\right)$}} & \multicolumn{2}{|c|}{ Confidence } \\
\hline & & $50 \%$ & $95 \%$ \\
\hline & 1,600 & $3.1 \times 10^{-5}$ & $5.6 \times 10^{-5}$ \\
\hline \multicolumn{2}{|r|}{1,700} & $6.3 \times 10^{-4}$ & $8.9 \times 10^{-4}$ \\
\hline \multirow{3}{*}{1,800} & $30 \mathrm{~h}$ & $8.1 \times 10^{-5}$ & $1.3 \times 10^{-4}$ \\
\hline & $50 \mathrm{~h}$ & $2.7 \times 10^{-4}$ & $3.7 \times 10^{-4}$ \\
\hline & $100 \mathrm{~h}$ & $8.5 \times 10^{-4}$ & $1.03 \times 10^{-3}$ \\
\hline
\end{tabular}

The heating tests conducted on the German fuel included isothermal tests at temperatures as high as $2,100^{\circ} \mathrm{C}$. While increased particle failure and gaseous fission-product release were observed at the elevated temperatures, ${ }^{85} \mathrm{Kr}$ release fractions after $25 \mathrm{~h}$ at the highest temperature was approximately $1 \%$. Taken as a whole, these data support four important overall conclusions:

- Substantial margins exist in the ultimate capability of the fuel relative to the pebble-bed design best-estimate maximum accident-condition temperature of $1,483^{\circ} \mathrm{C}$. As discussed in Section 4.2.2.2, only a small fraction (3\%) of the fuel spheres in the pebble-bed core would experience the maximum temperature and only for a short time relative to the hold times in the underlying heat-up test experiments.

- The degradation in fuel performance at elevated temperatures is regular and gradual. No sudden changes in behavior (cliff-edge effects) as a function of irradiation temperature, burnup, or accident temperature were seen.

- No exposed-kernel failures were observed in any of the MTR irradiations.

- The 50\% confidence SiC-defect fraction after irradiation to substantial burnups in both the AVR and MTRs and heating at $1,600^{\circ} \mathrm{C}$ is approximately equal to the mean free uranium fraction of the as-manufactured fuel, indicating no additional $\mathrm{SiC}$ defects were produced during irradiation. 
Taken as a whole, the body of data produced in the German heat-up testing includes fuels that were irradiated in both the AVR reactor (i.e., prototypical temperature-varying environment of the pebble-bed core) and in MTR isothermal tests. The heat-up testing includes both isothermal conditions and time-temperature profiles that approximate a limiting event temperature transient. The data are generally consistent and coherent with regard to irradiation temperature, burnup, fluence, and heating test temperature, notwithstanding the statistical limitations of dealing with very low probabilities of particle failures, the random nature of outlier particle defects (e.g., SiC layer flaws, faceting) and characteristics (e.g., combinations of kernel diameter and layer thicknesses), and the potential for failure modes with varying ${ }^{85} \mathrm{Kr}$ release characteristics.

\subsubsection{Analysis Methods}

PBMR (Pty) LTD focuses on evaluating manufacturing, irradiation-testing and post-irradiation-testing heating results. Defects caused during manufacture are determined from burn-leach testing of representative samples from fuel batches as the last quality-control step during manufacture. Normal-operation irradiation-induced failures are derived from irradiation testing of complete and representative fuel spheres in material test reactors. High-temperature accident-event-caused failures are derived from heating tests performed at KÜFA-type heating test facilities.

In order to determine the fuel-failure fraction during irradiation and post-irradiation testing, the noble gas release $(\mathrm{Kr}$ and $\mathrm{Xe})$ is evaluated. ${ }^{38}$ The main sources of gaseous release are uranium and thorium contamination in the fuel materials (matrix contamination and outer pyrocarbon layer) and defective/failed coated particles. Krypton and xenon have extremely low diffusion coefficients in PyC, and all the nuclides considered have relatively short half-lives. Intact particles within the specification limits, therefore, are not expected to contribute to the release of gaseous fission products under normal operating conditions.

The transport mechanisms of fission gases produced by the finely distributed uranium and thorium contamination of the matrix material are well understood through the irradiation experiments done at the $\mathrm{R} 2$ test reactor at Studsvik. The fission-gas release behavior from failed particles was studied in detail at the FRJ2 test reactor at Jülich. Fission-gas transport data was measured and calculated for each fuel component material. Krypton data are used for all small nuclides (krypton and bromine), and xenon values for the larger nuclides (xenon and iodine).

The computer code NOBLEG ${ }^{39}$ was developed to simulate the operational conditions of high-temperature reactor cores and irradiation experiments. The code is useful in describing fuel behavior in the Jointly-operated Prototype Reactor (AVR), Thorium High-temperature Reactor (THTR), and in the design and safety analysis of the planned High-temperature Reactor - Modular (HTR-Modul). It calculates the noble gas and halogen release fractions from the core by solving Booth's "equivalent sphere model."

When evaluating fission-gas release from fuel spheres in an irradiation rig during an irradiation test, it is important to distinguish release due to contamination of the fuel and irradiation rig materials from release caused by defective or failed coated particles. The difference lies in the fact that the fuel inside coated particles is enriched compared to the natural uranium and thorium found in contamination. This means that fission gases formed in the fuel kernels are primarily formed from ${ }^{235} \mathrm{U}$ fissions, and fission gases formed in the contamination from ${ }^{233} \mathrm{U}$ and ${ }^{239} \mathrm{Pu}$ (from ${ }^{232} \mathrm{Th}$ and ${ }^{238} \mathrm{U}$ breeding respectively). The fission yields for each fissionable nuclide differ and, therefore, must be accounted for. 


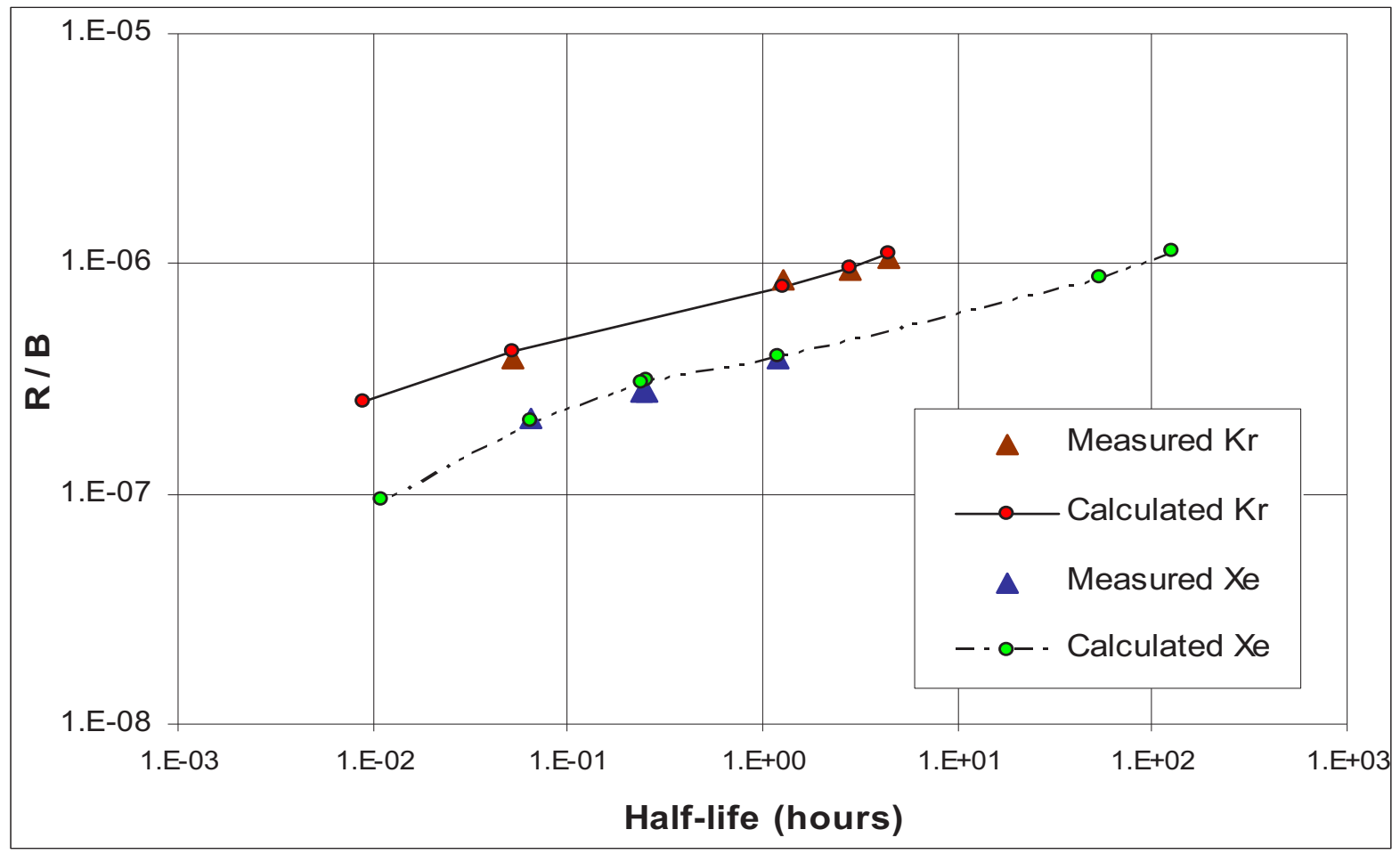

Figure 7. R/B versus half-life graph, HFR-K6/4, Cycle 4.

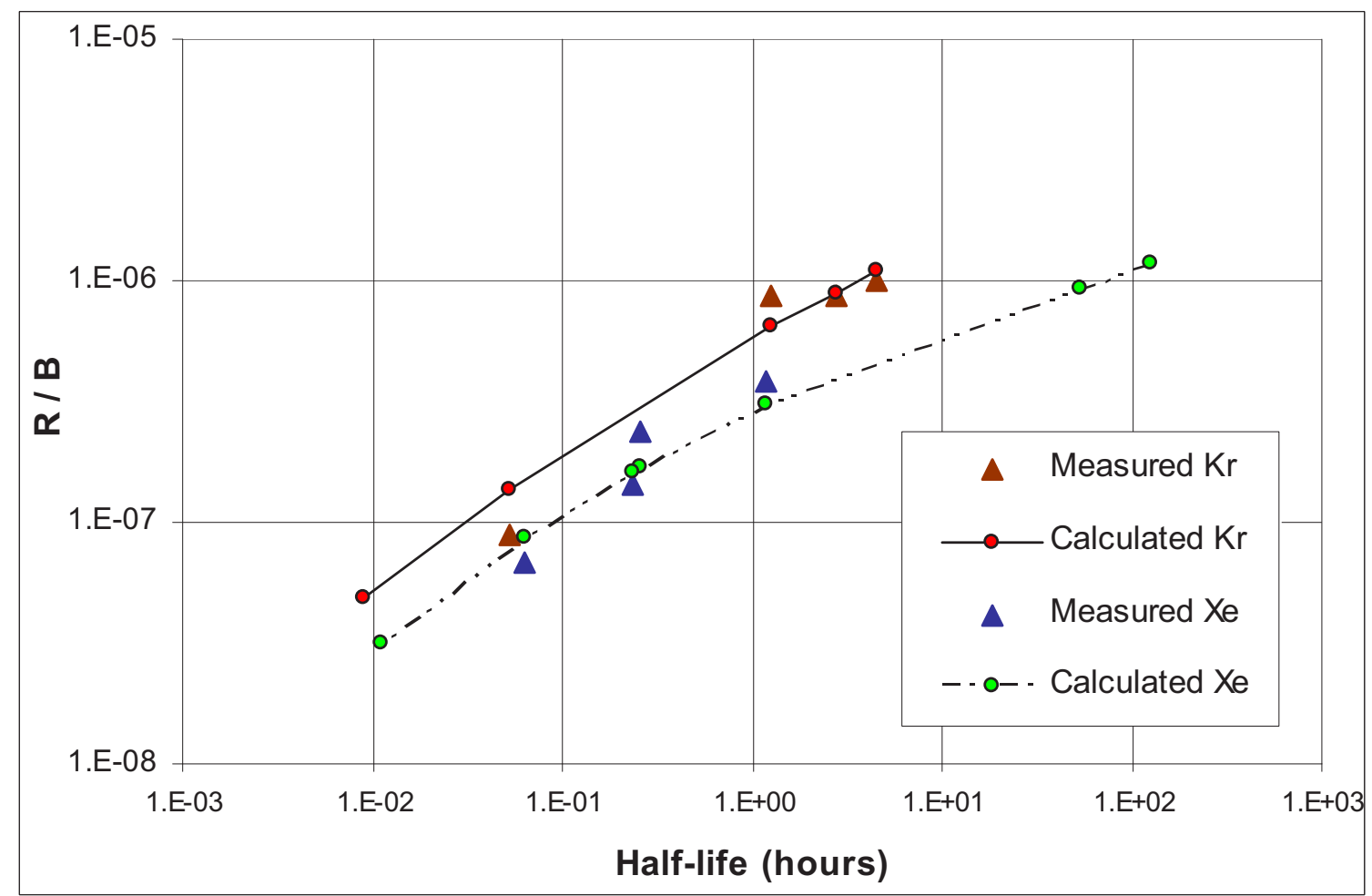

Figure 8. R/B versus half-life graph, HFR-K6/4, Cycle 24. 
The inventory of a single coated particle exceeds the contamination in a fuel sphere by a factor of 35 (considering 14,000 coated particles and $1 \mathrm{~g}{ }^{235} \mathrm{U}$ per sphere). The release from a sphere containing one defective or failed particle will therefore dominate the measured activity, and effective contamination corrections become less important. The contributions from contaminations outside the fuel sphere (irradiation rig materials) also become less of an issue. An example of an evaluation of an irradiation test with defective coated particles can be seen in the two figures above. Irradiation Cycle $4 \mathrm{R} / \mathrm{Bs}$ are plotted at temperatures of $\sim 880^{\circ} \mathrm{C}$ in Figure 7 and irradiation Cycle $24 \mathrm{R} / \mathrm{Bs}$ at temperatures of $\sim 800^{\circ} \mathrm{C}$ in Figure 8 .

An example in which a particle failed during irradiation (it must be noted that irradiation conditions, especially temperature, significantly exceeded planned pebble-bed fuel-service conditions), can be seen in Figure 9 below. The measured R/B values for HFR-EU1bis ${ }^{\mathrm{m}}$ are compared with NOBLEG-calculated contamination and failed particles. It can be seen that the fission-gas release is not just from contamination but corresponds to the release from a failed particle. It appears that an additional in-pile coated-particle failure occurred during the penultimate irradiation cycle as the fission-gas release for all nuclides significantly exceeds the release of contamination and one failed particle only.

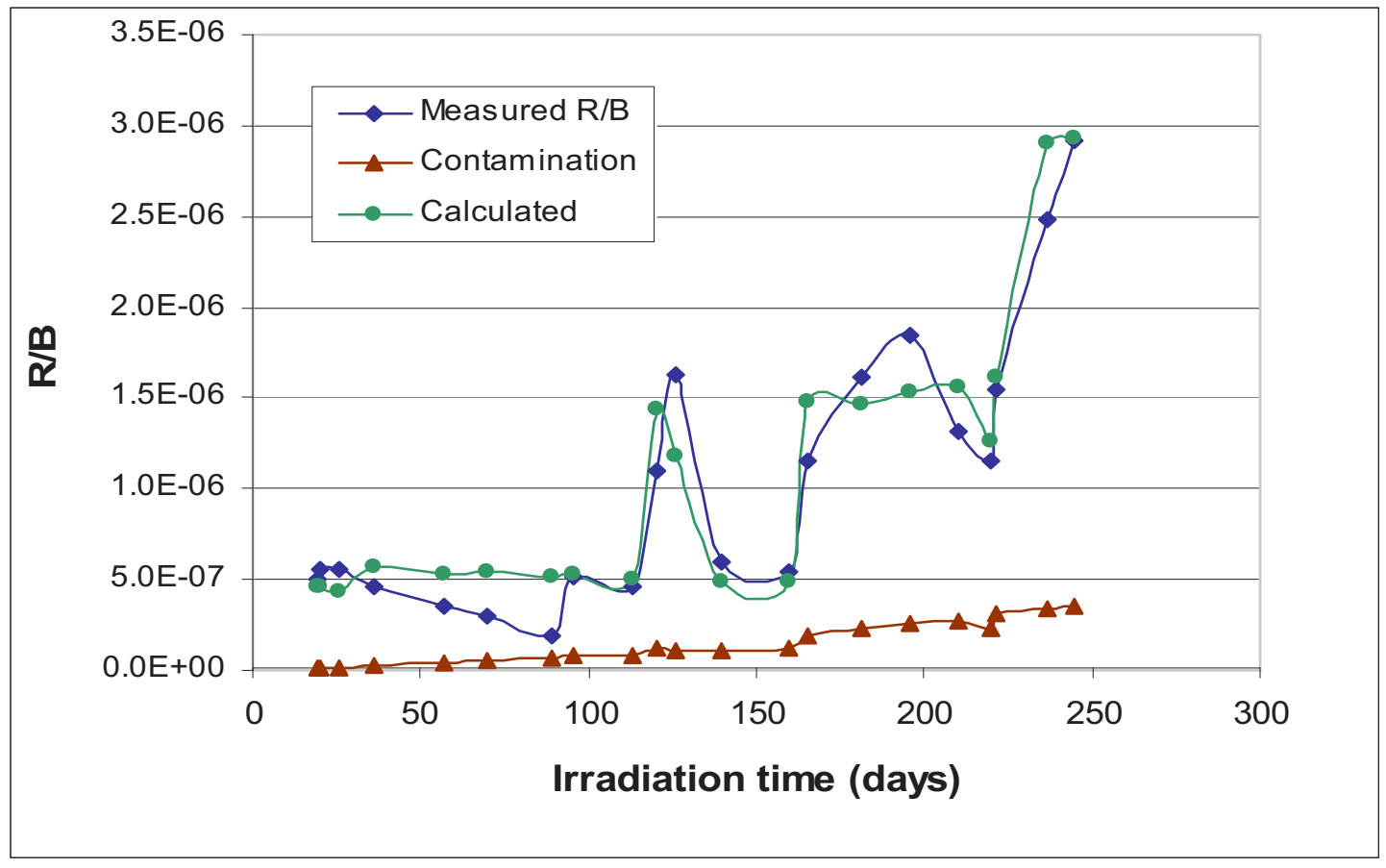

Figure 9. Measured and calculated $88 \mathrm{Kr}$ R/B, HFR-EU1bis.

\subsection{Prismatic Fuel Experience}

The prismatic fuel element that forms the basis for the NGNP prismatic design is shown in Figure 10. The graphite prismatic block, developed and utilized in the Fort St. Vrain reactor, utilized uranium/thorium carbide fissile and thorium carbide fertile particles pressed into cylindrical compacts and loaded into fuel holes drilled in the block. The NGNP prismatic design utilizes a UCO particle. Experience prior to the NGNP/AGR Fuel Program with fabrication, irradiation, safety testing, and analysis methods for fuel to be used in reactors with prismatic fuel elements is discussed in this section.

1. The stated values are consistent with the examples used and the German data presented in this paper, which may differ from the values selected for the PBMR-based NGNP operation.

m. The original HFR-EU1 test was postponed and a pre-test was performed that was called pre-HFR-EU1, or HFR-EU1bis. 


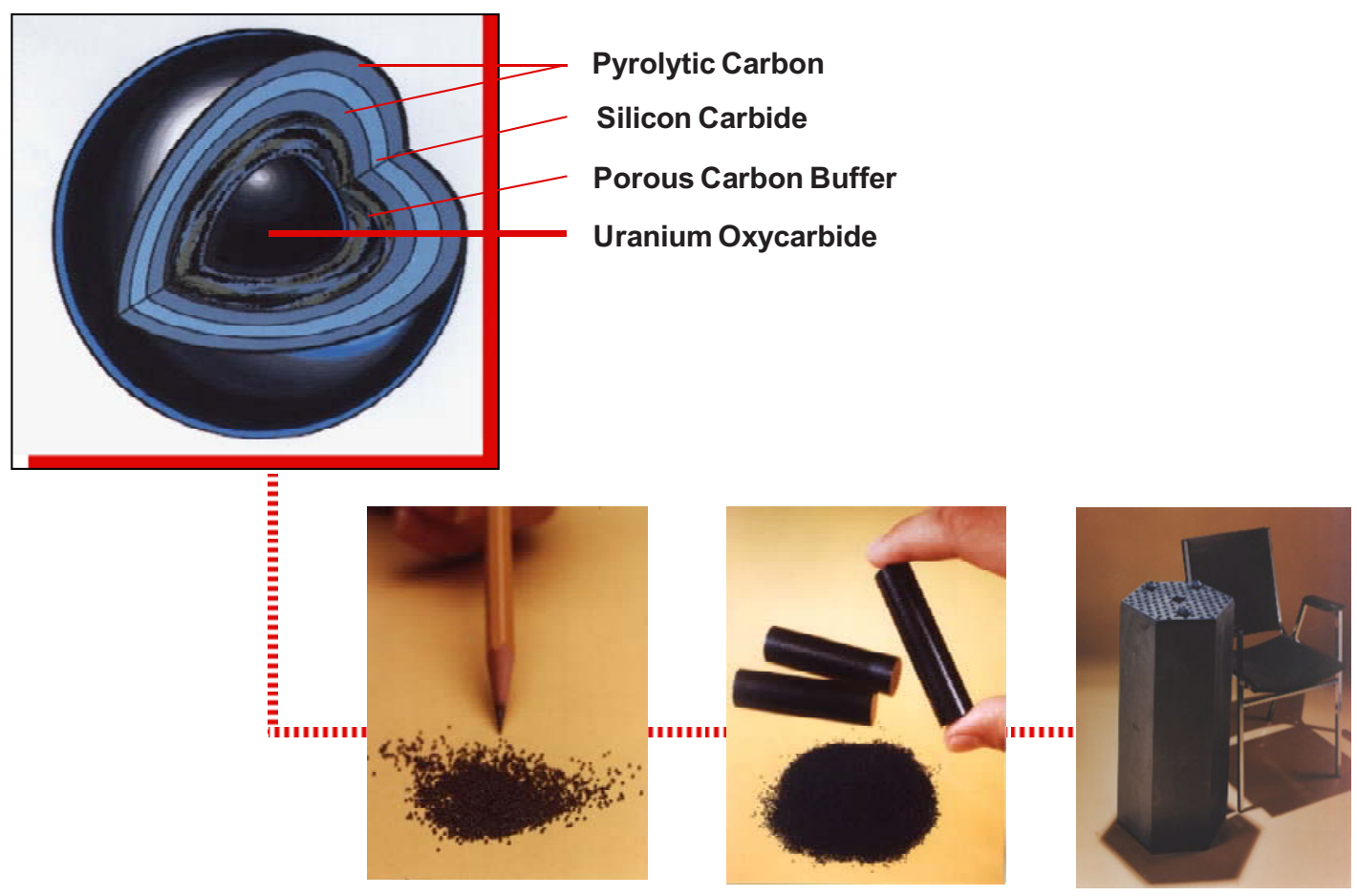

Figure 10. U.S. prismatic fuel.

\subsubsection{Fabrication}

In the 1960s and 1970s, a large-scale coated-particle fuel-fabrication facility was established at General Atomics (GA) in the U.S. to support the operation of the 115-MWth Peach Bottom Unit 1 (fuel rods containing BISO-coated (Th, $\mathrm{U}_{2} \mathrm{C}_{2}$ fuel particles) and the 842-MWt FSV (prismatic fuel elements containing TRISO-coated (Th, $\mathrm{U}) \mathrm{C}_{2}$ fissile particles and TRISO-coated $\mathrm{ThC}_{2}$ fertile particles) high-temperature gas-cooled reactors. ${ }^{40}$ Following the termination of FSV operations in 1989, the fuel fabrication facility was decommissioned and dismantled, so no large-scale fabrication capability currently exists in the U.S.

Prior to the NGNP program, high-density UCO kernels were irradiated in 12 irradiation test capsules in the U.S. and Germany. Three production lots of high-density UCO kernels supplied all United States irradiations. The first United States production lot of $350 \mu \mathrm{m}$-diameter UCO was made at GA using a gel-supported precipitate process with external gelation. These kernels were TRISO-coated, and some were incorporated into petroleum-pitch-injected compacts. Compacts and loose particles from this batch were irradiated in capsules HRB-14, 15A, 15B, 16, 17, and 18, and R2-KI3. A second production run of $350-\mu \mathrm{m}$-diameter UCO was made by this same process for capsule HRB-21. The fuel particles for HRB-21 were coated with the TRISO-P coating (a particle design featuring a sacrificial overcoating of low-density $\mathrm{PyC}$ in a fluidized particle bed to increase crush strength and reduce coating failure during matrix injection). A third batch of high-density, 200- $\mu$ m-diameter UCO was made at Babcock and Wilcox $(B \& W)$ by the internal gelation process for use in the NP-MHTGR capsules. A more complete description of the fuel particles and the United States irradiation experiments is provided in a 2002 report by Petti. ${ }^{41}$

TRISO-particle fuel has been fabricated in many countries, irradiated in numerous irradiation test capsules, and used as the fuel in seven power and experimental reactors; thus, the basic processes for fabricating gas-cooled-reactor fuels are well established. However, the fuel quality requirements for future advanced gas-cooled reactors are considerably more stringent than for these earlier reactors. The capability of TRISO fuel particles to meet these stringent performance requirements has been demonstrated in Germany for the pebble-bed reactor design and in Japan for the high-temperature 
low-burnup HTTR prismatic-design test reactor, but has not yet been demonstrated in the United States (or elsewhere) for prismatic core designs. Both the German and United States programs were discontinued in the early 1990s, and no fuel was made in either program until the United States AGR Fuel Program was initiated in $2002 .^{29}$

\subsubsection{Kernel Fabrication}

The reference UCO-kernel internal-gelation fabrication process begins with the preparation of acid-deficient uranyl nitrate through the dissolution of uranium oxide (or trioxide) powder in nitric acid. Urea, carbon black, and hexamethylenetetramine are added to the acid-deficient uranyl nitrate to make a gelatin broth that is pumped through a vibrating nozzle assembly to produce uniform sized droplets. These droplets form spheres that are immediately dropped into a hot organic liquid in which the kernels undergo gelation reactions which convert them to a matrix of $\mathrm{UO}_{3}$ and carbon, with formaldehyde, excess urea, ammonium nitrate, and water dispersed throughout. The "aged" particles are washed with ammonium hydroxide to remove most of the formaldehyde, urea, and ammonium nitrate and then dried with warm air to remove some of the water and excess ammonium hydroxide. The kernels are then loaded into a furnace and put through a series of heat-treatment steps ranging from 300 to $1,800^{\circ} \mathrm{C}$ to densify the kernels and obtain the required kernel chemistry.

The sintered kernels are then screened and tabled to remove kernels that are oversized, undersized, or nonspherical. Tabling involves passing the kernels over a vibrating, flat, inclined surface upon which non-spherical particles, which do not roll like the spherical particles, tend to take a sideways path off the table and are thereby separated from the spherical particles, which roll down the table. Finally, multiple batches of kernels are mixed together and homogenized to form a kernel composite for the purpose of QC acceptance testing and to improve the uniformity of the intermediate product for the next fabrication step (coating).

\subsubsection{Coated-Particle Fabrication}

As shown in Figure 2, the TRISO-particle coating system consists of multiple layers of PyC sandwiched around a $\mathrm{SiC}$ layer. The coating layers are produced by chemical vapor deposition in a fluidized-bed furnace. The PyC layers are deposited by the thermal decomposition of acetylene or a combination of acetylene and propylene. Argon is used as the fluidizing gas in PyC coating. The SiC layer is deposited by thermal decomposition of methyltrichlorosilane. Hydrogen, or a mixture of hydrogen and argon, is used as the fluidizing gas in SiC coating and as the carrier gas for the methyltrichlorosilane. In the U.S., these coating layers have historically been deposited in a sequence of coating steps in one or more coating furnaces with unloading and handling of the intermediate product. However, coating experience in Japan and Germany has shown that the quality level of the coated particles is better - the fraction of particles with defective SiC coatings is minimized - if all of the coating layers are deposited in an uninterrupted sequence in a single coating furnace (once through coating). Thus, uninterrupted sequential coating is now the preferred coating process for the NGNP/AGR Fuel Program.

Proper fluidization of the particle bed, which is essential for producing high-quality coatings, is a function of the total gas flow, mass and volume of the particles, diameter of the furnace, and design of the gas distributor. Given proper fluidization of the particles, the independent variables that have the greatest influence on the microstructural properties of the coatings are the temperature of the fluidized bed and the active coating gas fraction. (The active coating gas fraction is the coating gas flow divided by the sum of the fluidizing gas flow and the active coating gas flow.) The uniformity of the coating environment is also very important. If the coating gas concentrations in different areas of the coater are substantially different, and if particles are not adequately fluidized to randomize their movement in the coater, then wide variations in coating rate and coating properties will be observed within a coated-particle batch. Lack of coating uniformity within the coater is a major quality issue that must be overcome in scaling up from small-diameter laboratory coaters to large commercial fuel-production coaters. 
As is the case with the kernels, the coated-particle batches are screened and tabled to remove particles that are oversized, undersized, or nonspherical, and then combined into composites for QC acceptance testing and to improve the uniformity of the coated particles delivered to compact fabrication.

\subsubsection{Compact Fabrication}

Extensive experience in the production of cylindrical fuel compacts was gained at GA during mass production of FSV fuel. In the FSV compact fabrication process, a thermoplastic matrix, composed primarily of graphite powder and petroleum pitch as the binder, was injected into a bed of particles in a mold to form a compact. The green compacts from the compact-forming operation were then heated to about $900^{\circ} \mathrm{C}$ in flowing argon to carbonize the matrix and then were heated to about $1,750^{\circ} \mathrm{C}$ in flowing argon to drive out impurities and to partially graphitize the matrix. The thermoplastic-matrix injection process was developed and used for FSV fuel production, primarily because of its suitability for making compacts with high particle-packing fractions. However, this process has a number of drawbacks. The injection process requires compaction of the bed of particles, which is a potential source of coating breakage. Also, the compacts must be supported by alumina powder during carbonization to prevent them from losing their shape. Furthermore, the petroleum pitch and alumina powder are sources of impurities that are known to attack $\mathrm{SiC}$ coatings.

The fuel quality requirements for current HTGR designs are much more stringent than for FSV, so the compact fabrication process must be capable of reducing the level of HM contamination and defective particles in compacts by more than an order of magnitude compared to the levels demonstrated during FSV fuel production.

While General Atomics developed and utilized a thermoplastic-matrix-based compacting process because of the high fuel-particle-packing fraction requirements for FSV, the rest of the international HTGR community focused on a thermosetting-matrix-based compacting process. Successful compacting in which a synthetic thermosetting resin was used as the binder was demonstrated for fuel elements containing overcoated fuel particles for the pebble-bed reactor programs in Germany and China. Annular fuel compacts have been developed in Japan using a similar process. In this process, the matrix, composed of graphite power and a thermosetting-resin binder, is applied as an overcoating to the TRISO-coated particles. In the overcoating process, TRISO-coated particles are loaded into a drum-like overcoating vessel and rotated while matrix powder and methanol are added. The methanol wets the particles and matrix powder, causing the matrix powder to build up as a coating layer on the particles. The amount of graphite powder and methanol and the rate of addition are carefully controlled to achieve the desired overcoating thickness. The overcoated particles are dried at about $80^{\circ} \mathrm{C}$, screened, and tabled to remove undersized, oversized, and nonspherical particles. The overcoated particles are then poured into a mold and hot-press molded to form the fuel compact (or sphere). Depending on the process variation employed, additional matrix material may or may not be mixed with the overcoated fuel particles in the mold. The compacts are heat treated at $900^{\circ} \mathrm{C}$ in argon to carbonize the matrix and then finally heat-treated at about $1,800^{\circ} \mathrm{C}$ in a vacuum furnace.

For large-scale fuel manufacturing, a thermosetting-resin-based-matrix process is preferred for a number of reasons. First, this process results in improved fuel quality because (1) the thermosetting matrix is formulated from raw materials having lower levels of impurities; (2) the thermosetting matrix yields stronger, less friable compacts; and (3) the thermosetting-matrix process involves lower compacting forces and less handling of the compacts, thereby reducing the potential for damage. Second, the thermosetting-matrix-based process eliminates the need to pack the compacts in alumina powder during carbonization and would, therefore, be better suited to automation, which reduces the cost of fuel compact fabrication.

Because of its many advantages, a thermosetting-matrix-based compacting process was selected as the reference compacting process for the NGNP/AGR Fuel Program. 


\subsubsection{Irradiation}

The U.S. irradiation program is described in detail by Petti in Reference 41. Important results are presented here on irradiation of UCO fuel in both U.S. and German experiments.

The UCO fuel in the U.S. irradiation tests generally failed to meet the irradiation-performance requirements for current prismatic HTGR designs, but for reasons that appear unrelated to the performance of the UCO kernel. Rather, the poor performance appears to have resulted from defective $\mathrm{SiC}$ coatings, which were created during coating and/or compacting processes. Examination of UCO particles during the PIE of these capsules did not reveal any evidence of failure that could readily be attributed to the UCO kernels. Indeed, the irradiations generally confirmed that the UCO kernels retained lanthanide fission products in the kernels and suppressed kernel migration and formation of $\mathrm{CO}$ in that no evidence of kernel migration or of attack on the $\mathrm{SiC}$ by $\mathrm{CO}$ or lanthanide fission products was observed. $\mathrm{UO}_{2}$ particles mixed with UCO particles in the same compact exhibited significant kernel migration, while no kernel migration was observed in the UCO particles.

Capsule HRB-21 and the NPR capsules all contained TRISO-P UCO particles. The high coating failure in these capsules was determined to be related to the poor design of the TRISO-P coating system (rapid shrinkage of low-density OPyC) and the properties of the IPyC (high anisotropy), and not to the UCO kernel. ${ }^{27,28,41}$ HRB-21 LEU UCO was irradiated to 22\% FIMA. The three NPR capsules containing 200- $\mu$ m-diameter HEU UCO fuel particles were irradiated up to 78\% FIMA.

The German capsule FRJ2-P24 irradiation of UCO under representative prismatic HTGR temperatures and burnup (but very low fast fluence) showed excellent fuel performance with respect to fission-gas retention. TRISO-coated $300-\mu$ m-diameter $20 \%$ enriched UCO particles formed into annular cylindrical fuel compacts were irradiated in this capsule. The UCO fuel achieved a burnup of up to $22 \%$ FIMA at a time-averaged temperature of about $1,120^{\circ} \mathrm{C}$ with no in-service coating failures observed. No kernel migration or SiC corrosion because of fission product attack was reported by Borchardt and Bauer. $^{42,43}$

In 1977, 5,354 fuel spheres (about 21\% of the full AVR core) containing high-density HEU UCO fuel kernels were inserted into the AVR. This was the first large-scale test of UCO in Germany. The UCO particles were TRISO coated. The fission-gas release in the AVR remained low $\left(2-3 \times 10^{-5} \mathrm{R} / \mathrm{B}{ }^{85 \mathrm{~m}} \mathrm{Kr}\right)$ while the UCO fuel spheres were under irradiation. HEU fuel development was discontinued in Germany because of the non-proliferation treaty signed in 1977. In 1982, the German HTGR program selected $\mathrm{UO}_{2}$ for its reference fuel; consequently, no significant PIE was performed on the HEU UCO fuel spheres irradiated in AVR.

Although the success of the German (and Japanese) fuel development programs provides a high level of confidence that a TRISO UCO fuel that meets prismatic HTGR fuel performance requirements can be fabricated, this capability had not been demonstrated in the U.S. as of the termination of the DOE-sponsored commercial HTGR Program in 1995. To address this risk to future deployment of HTGRs in the U.S., DOE initiated the NGNP/AGR Fuel Program to develop and qualify fuel for the NGNP and follow-on HTGRs. Initial laboratory-scale UCO fuel fabrication and irradiation testing (in the AGR-1 irradiation test) conducted under the AGR Fuel Program has resulted in a highly successful demonstration of the UCO fuel, at least in terms of in-pile gaseous fission-product release. PIE and safety testing of the irradiated AGR-1 fuel is yet to be reported. The AGR Fuel Program and the AGR-1 irradiation test are discussed in Section 5.2.

\subsubsection{Safety Testing}

As noted above, the German capsule FRJ2-P24 irradiation of UCO under representative prismatic HTGR temperatures and burnup showed excellent fuel performance with respect to retention of gaseous fission products. However, the Germans did not perform any post-irradiation simulated-accident heating 
tests on the fuel from this capsule. In the U.S. program, irradiated tests HRB-15A and in HRB-15B were subjected to post-irradiation heating along with several other fuel types, including $\mathrm{UO}_{2}$ and $\mathrm{UC}_{2}$.

In one test series, 186 initially intact LEU UCO fuel particles from HRB-15A and HRB-15B were heated in both temperature ramp and isothermal accident-simulation tests. ${ }^{44}$ Krypton- 85 release from the fuel was used to indicate total TRISO coating failure. The temperature ramp tests covered the range from $\sim 1,100^{\circ} \mathrm{C}$ to as high as $\sim 2,700^{\circ} \mathrm{C}$, with heating rates in the range of $\sim 19^{\circ} \mathrm{C} / \mathrm{h}$ to $\sim 190^{\circ} \mathrm{C} / \mathrm{h}$. The isothermal heating tests were conducted at $2,050^{\circ} \mathrm{C} ; 2,200^{\circ} \mathrm{C}$; and $2,400^{\circ} \mathrm{C}$. These temperatures and heating rates were representative of those expected in the large HTGR (LHTGR) designs under consideration at that time. The test series also involved heating of the following other TRISO fuel types:

- $\mathrm{HEU}, \mathrm{LEU}$, and depleted $\mathrm{UC}_{2}$

- $\mathrm{ThO}_{2}$

- $\quad(\mathrm{Th}, \mathrm{U}) \mathrm{O}_{2}$

- $\quad \mathrm{LEU} \mathrm{UO} 2$ and $\mathrm{UO}_{2}{ }^{\mathrm{n}}$

- $\quad \mathrm{ThC}_{2}$ and $(\mathrm{Th}, \mathrm{U}) \mathrm{C}_{2}$.

Figure 11 (taken from Reference 44) summarizes the results of 30-hour ramp heating tests for the various LEU fuels and $\mathrm{HEU} \mathrm{UC} \mathrm{UC}_{2}$. The primary mechanism for TRISO-coating failure and $\mathrm{Kr}-85 \mathrm{~m}$ release under the simulated LHTGR accident conditions was found to be thermal decomposition of the SiC layer, followed by either diffusion of fission products through the PyC layers or breakage of the PyC. Within the temperature range tested, fuel-particle performance was found to depend on the inherent thermal stability of the SiC coating layer and not to be dependent upon variations in burnup, fast-neutron fluence, or kernel composition.

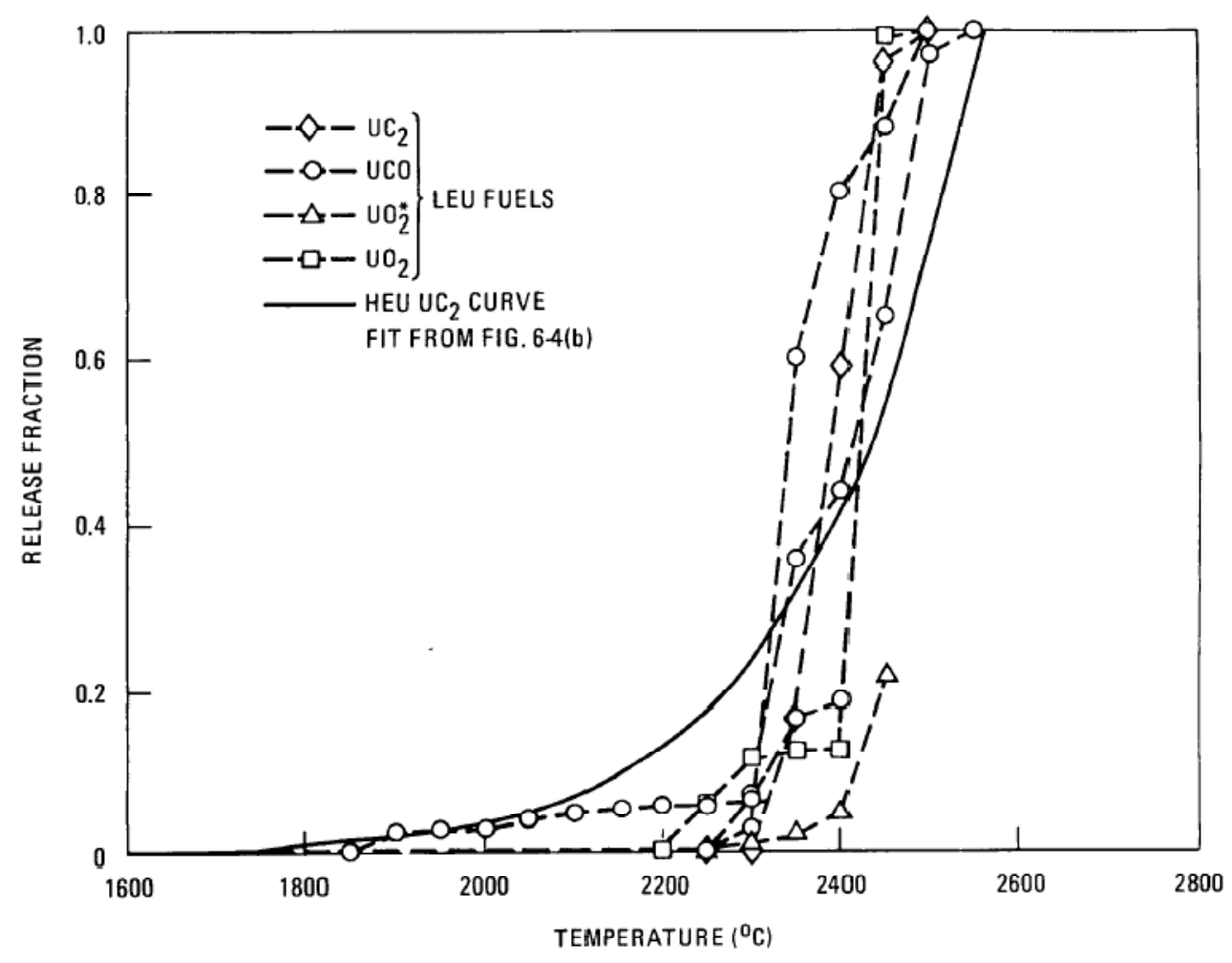

Figure 11. Kr-85m release results for ramp heating tests of candidate HTGR fuel types.

n. $\mathrm{UO}_{2} *$ has a $\mathrm{ZrC}$ layer over the $\mathrm{UO}_{2}$ kernel. 
Given the different chemical compositions of the fuel types, the similarity of the release profiles in Figure 11 is strong evidence that the performance of the fuel particles for the LHTGR accident conditions simulated in this heating-test series is independent of kernel composition and depends only on the TRISO coating. However, note that the temperatures associated with the LHTGR accident conditions are much higher than those during loss-of-forced-cooling accidents in the modular HTGR designs being considered for the NGNP.

In another heating-test series, 30 initially intact LEU UCO fuel particles irradiated in HRB-15B were heated isothermally for 10,000 hours at temperatures of 1,$200 ; 1,350$; or $1,500^{\circ} \mathrm{C}(10$ particles at each temperature). ${ }^{45} \mathrm{LEU} \mathrm{UO} \mathrm{UC}_{2}, \mathrm{UC}_{2}$, and two variations of $\mathrm{UO}_{2}{ }^{* 0}$ were also tested under the same conditions. With respect to the relative heating test performance of the $\mathrm{UCO}$ and $\mathrm{UO}_{2}$ particles, the following differences were observed:

- At $1,500^{\circ} \mathrm{C}, \mathrm{Eu}-154$ release started much earlier in the $\mathrm{UCO}$ fuel particles than the $\mathrm{UO}_{2}$ particles, and the total Eu-154 release from the UCO particles $(\sim 50 \%)$ was considerably higher than from the $\mathrm{UO}_{2}$ particles $(\sim 15 \%)$. The UCO particles also released Eu-154 at both $1,200^{\circ} \mathrm{C}$ and $1,350^{\circ} \mathrm{C}$, but the

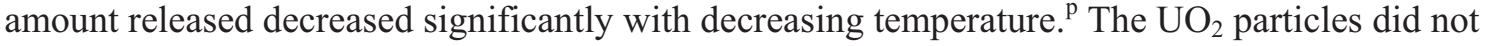
release $\mathrm{Eu}-154$ at $1,200^{\circ} \mathrm{C}$ or $1,350^{\circ} \mathrm{C}$.

- At $1,500^{\circ} \mathrm{C},{ }^{110 \mathrm{~m}} \mathrm{Ag}$ release started much earlier in the $\mathrm{UO}_{2}$ particles than the UCO particles, and the total ${ }^{110 \mathrm{~m}} \mathrm{Ag}$ release from the $\mathrm{UO}_{2}$ particles $(\sim 90 \%)$ was considerably higher than from the UCO particles $(<10 \%)$.

- $\quad{ }^{137} \mathrm{Cs}$ was released only at $1,500^{\circ} \mathrm{C}$ and only from 3 of the 150 particles tested. Two of these were $\mathrm{UO}_{2}$ particles. Diffusion through flawed, but intact, $\mathrm{SiC}$ layers was apparently responsible for the steadily increasing release from the two $\mathrm{UO}_{2}$ particles. None of the $\mathrm{UCO}$ particles released ${ }^{137} \mathrm{Cs}$ at any temperature.

Although the above results suggest some differences in the accident-condition performance of UCO and $\mathrm{UO}_{2}$ fuel particles, note that there were substantial differences in the $\mathrm{SiC}$ coatings on these two types of particles, which likely influenced the fission-product-retention characteristics of the particles. The SiC layer on the UCO particles is characterized in Reference 45 as having a laminar microstructure and a density of only $3.16 \mathrm{Mg} / \mathrm{m}^{3}$; the $\mathrm{SiC}$ layer on the $\mathrm{UO}_{2}$ particles is characterized as having a columnar microstructure and a density of $3.21 \mathrm{Mg} / \mathrm{m}^{3}$.

In an additional heating test of U.S. UCO fuel, fuel-compact-containing graphite body sections from irradiation test R2-K13 were heated in Germany. ${ }^{44}$ However, these samples were heated to $2,500{ }^{\circ} \mathrm{C}$, which resulted in total failure of the $\mathrm{SiC}$.

Although the heating test data for UCO fuel is limited and mostly applicable to large HTGR accident conditions, as opposed to the less-severe modular HTGR accident conditions, there is a large body of heating test data for $\mathrm{UO}_{2}$ fuel from the German HTGR Program that demonstrates the excellent performance of the German $\mathrm{UO}_{2}$ fuel under modular HTGR accident conditions. The heating test data for the German $\mathrm{UO}_{2}$ fuel are considered to be generally applicable to the UCO fuel being developed by the NGNP/AGR Fuel Program because:

1. The NGNP/AGR Fuel Program has established fuel-product specifications and coating process specifications that are intended to replicate German coating properties (and, therefore, the excellent irradiation and accident condition performance of the German $\mathrm{UO}_{2}$ fuel coatings).

o. One version of $\mathrm{UO}_{2}$ * had a $\mathrm{ZrC}$-coated $\mathrm{UO}_{2}$ kernel encapsulated by a standard TRISO coating. The $\mathrm{ZrC}$ coating layer on the kernel had a thickness of about 10 microns. The other version of $\mathrm{UO}_{2}{ }^{*}$ used standard TRISO-coated $\mathrm{UO}_{2}$ particles, except that $\mathrm{ZrC}$ was distributed within the buffer coating layer.

p. Eu is quantitatively retained by the graphite fuel blocks, so the increased release of Eu isotopes from UCO fuel particles relative to $\mathrm{UO}_{2}$ fuel particles is not a significant issue for $\mathrm{UCO}$ fuel. 
2. The results of the heating tests of various fuel types reported in Reference 44, as briefly summarized above, indicate that the accident performance of the various fuel types was not dependent on kernel composition.

As will be discussed in Section 5.2, extensive safety testing of UCO fuel is planned under the NGNP/AGR Fuel Program to confirm the performance of UCO fuel under simulated accident conditions.

\subsubsection{Analysis Methods}

Computer codes have been developed in past prismatic HTGR programs that model fuel performance. These codes are intimately connected to codes that track fission-product release and transport within the core and primary cooling system that are key inputs to the mechanistic source term. Because the fuel performance codes are so closely tied to fission-product transport, these codes are described in detail in the mechanistic source term white paper. Current work on the fuel performance model development in the NGNP/AGR Fuel Program is described in Section 5.3.5. 


\section{DESIGN AND PERFORMANCE REQUIREMENTS}

Section 3 provided a summary discussion of the international development of coated particle fuel leading to a common understanding of failure mechanisms and generally accepted design features to mitigate or eliminate these failure mechanisms. This section discusses the specific pebble-bed and prismatic reactor and fuel designs under consideration by the NGNP project, and the resulting fuel-service condition and performance requirements to which the fuel must be qualified. Section 4.1 discusses considerations common to both the pebble-bed and prismatic designs. Sections 4.2 and 4.3 address the specific aspects associated with the pebble and prismatic designs. The design information is provided to illustrate how service conditions and performance requirements to which the fuel must be qualified are established. Both reactor designs are evolving, and the resulting fuel service conditions and performance requirements can be expected to change. The conditions for the testing programs, addressed in Section 5, are established to support an envelope based on the expected capability of the fuel, allowing flexibility in the evolution of the designs.

\subsection{Common Considerations}

Both the pebble and prismatic NGNP designs embody an emphasis on passive safety, utilizing inherent HTGR core and coated-particle fuel characteristics, a concept initially developed in the early $1980 \mathrm{~s} .{ }^{46}$ This approach relies on the following inherent characteristics of an HTGR reactor core and coated-particle fuel to limit the fuel service conditions under both normal operation and accidents:

- HTGR core:

- Low power density/high heat capacity (limits rate of temperature change due to heat generation/heat-removal mismatch)

- Strong negative temperature coefficient of reactivity (mitigates response to positive reactivity insertion or decrease in core heat removal (e.g., loss of coolant flow or pressure)

- Large neutron-migration length (limits local power peaking)

- Single phase coolant (eliminates thermal and power changes associated with phase change)

- Neutronically and chemically inert coolant (eliminates power change associated with density change and fuel/coolant interactions)

- High effective thermal conductivity with or without coolant to a passive ultimate heat sink (fosters post-shutdown heat removal).

- Coated-particle fuel:

- High degree of fission-product retention

- Large overpower margins (accommodates increases in power)

- $\quad$ Large short-term temperature margins.

A broad base of fuel testing and operating experience, discussed in Section 3.1.1, has shown that the dominant service conditions parameters affecting fuel performance are:

- Burnup (Normal Operation) - Accumulated fissions during normal operation leads to a buildup of fission products primarily in the kernel, but also in the buffer for some radionuclides. Fission-product mobility is affected by chemical form, which can change with changes in the chemical environment (e.g., oxygen potential in the kernel). Gaseous fission products, as well as carbon monoxide and carbon dioxide produced by excess oxygen resulting from fissioning of $\mathrm{UO}_{2}$, can exert excessive pressure on the dense pyrocarbon and silicon carbide coatings. Some metallic fission products (e.g., palladium) can diffuse to and attack the silicon carbide layer, weakening the particle.

- Fast Fluence (Normal Operation) - Interactions with high-energy neutrons $(\mathrm{E}>0.1 \mathrm{MeV})$ during normal operation can cause changes in important material properties (e.g., density, diffusivity). 
Differential shrinkage among the coating layers induces stresses that can ultimately lead to coating failures. This effect is exacerbated if the material properties lead to anisotropic shrinkage (e.g., anisotropic pyrocarbon layers).

- Temperature (Normal Operation) - Diffusion and chemical reaction processes can be highly sensitive to temperature, depending on the temperature range. In normal operation, the temperatures are relatively lower but the duration of exposure is long. If normal operation temperatures are excessive, fission products can diffuse through (e.g., ${ }^{110 \mathrm{~m}} \mathrm{Ag}$ ) or attack (e.g., palladium) the silicon carbide layer, leading to fission-product release or lessening the capability of the particle to perform acceptably under accident conditions.

- Temperature (Accident Conditions) - Temperatures under accident conditions can significantly exceed those for normal operation, although durations are much shorter. These higher temperatures can accelerate phenomena that may be present in normal operation (e.g., cesium diffusion) or, if high enough, introduce new phenomena (e.g., silicon carbide dissociation).

The effects of these service conditions are not independent. For example, higher fission-product inventories associated with burnup, changes in silicon-carbide strength with fast fluence, and silicon-carbide attack from elevated normal operation temperature can jointly reduce margins to particle failure during elevated accident-condition temperatures.

The experience summarized in Section 3.1.1 also shows that for particle designs consistent with Section 3.1.3, the integrity of the fuel is maintained over a range of service conditions. The primary challenges are phenomena associated with extended times at elevated temperatures (e.g., diffusion of fission products through the kernel and coating layers, chemical attack of the $\mathrm{SiC}$ layer). Phenomena that can lead to rapid changes in local conditions or in fuel integrity (e.g., departure from nucleate boiling, fuel/coolant chemical reactions) are eliminated by the characteristics discussed above. Thus, there are no transient perturbations that can lead to sudden initiation and propagation of fuel failures. Melting of the fuel kernel from a sudden large energy deposition and the associated expansion has been shown to produce rapid particle failures, ${ }^{14}$ but the conditions required to induce failure are far beyond those achievable in a reactor core because of the characteristics discussed above. Thus, the reactor design emphasis is on limiting the exposure of the fuel to elevated temperatures for extended periods of time.

The coated particles for the pebble and prismatic designs share common features consistent with the discussion in Section 3.1.3. The primary differences are kernel diameter and chemical form. The pebble fuel kernel has a larger diameter consistent with its lower enrichment and correspondingly lower design burnup. The prismatic fuel kernel includes carbide in addition to oxide to accommodate higher burnup and higher normal-operation temperature gradients.

The inherent safety features of the passive reactor design concept focus on limiting the exposure of the fuel to elevated temperatures for extended periods without reliance on active systems. These features include a relatively high core surface-to-volume ratio (large height-to-diameter ratio and/or internal unfueled reflector region), an uninsulated reactor vessel, and limiting thermal power. The specific reactor and fuel designs of the pebble-bed and prismatic designs under consideration by the NGNP Project are described in the following sections, along with the corresponding limits on fuel service conditions and fuel performance requirements. The fuel development and qualification program is being conducted to demonstrate fuel quality and performance to conditions approaching the ultimate capability of the SiC TRISO fuel. The fuel qualification irradiation and testing plans discussed in Section 5 are intended to demonstrate levels of quality and performance exceeding the requirements of these designs with margin and sufficient to support future designs at higher temperatures and power levels. 


\subsection{Pebble Fuel}

This section addresses design characteristics of the pebble-bed reactor and fuel, fuel-service conditions for both normal operation and accidents, and fuel-performance requirements.

\subsubsection{Design Summary}

The following subsections summarize the design characteristics of the pebble-bed reactor relevant to the service conditions for the fuel and the fuel properties.

\subsubsection{Reactor}

The pebble-bed design is an HTGR employing online fueling. The plant concept described here is that of a steam and electricity cogeneration plant employing a steam generator in the primary circuit capable of driving a variety of steam and electricity configurations, such as a condensing the Rankine cycle with process steam extraction points or a back-pressure expansion turbine. The specific configuration will be defined during the conceptual design of the plant and driven by specific customer requirements. A cut-away illustration of the primary circuit is provided in Figure 12 to contextualize the reactor unit description that follows.

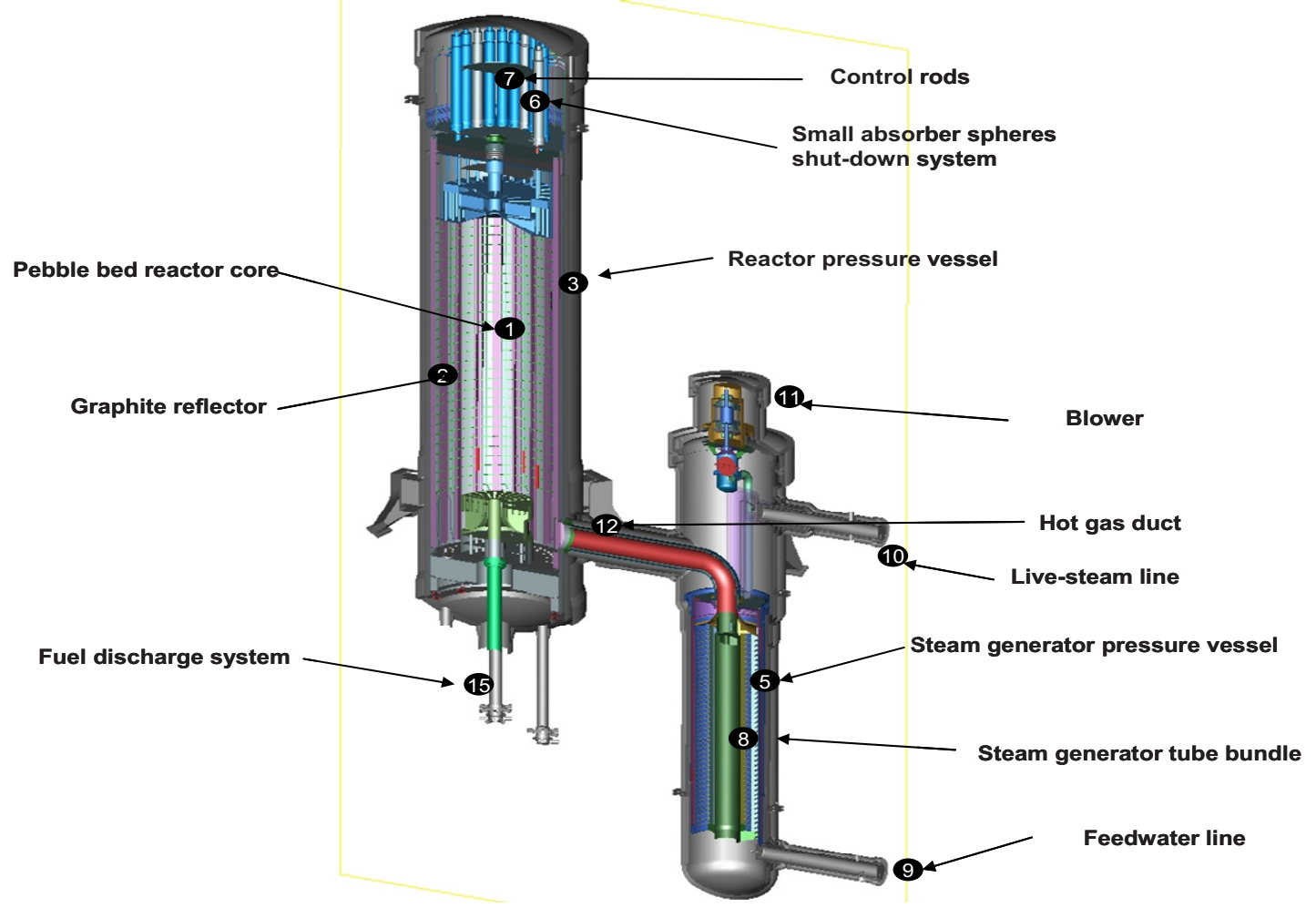

Figure 12. Pebble-bed primary circuit cut-away diagram.

The pebble-bed plant concept described herein is still in conceptual design and is, therefore, subject to change as the initial design decisions are verified. However, the starting point for the reactor core design is the German HTR-Modul design.

The reactor conditions described here are for the purposes of identifying an operational envelope for the fuel assuming that the reactor is operating at a mixed-mean coolant outlet temperature of $750^{\circ} \mathrm{C}$ (ROT) and power level of $250 \mathrm{MWt}$. As noted in the introduction to this section, this is for illustration purposes as the design is evolving and these conditions may change. 


\section{Design Description of Pebble-Bed Reactor Unit}

The purpose of the reactor unit is to provide heat that can be used as process heat for cogeneration applications. A cut-away schematic of the reactor unit showing the internal components is provided in Figure 13.

As shown in Figure 13, the reactor unit (RU) consists of the fuel, the core structures (CS), the Reactivity Control System (RCS), and the Reserve Shutdown System (RSS). The equilibrium fuel core consists of approximately 400,000 fuel spheres in a loose cylindrical pebble-bed with an outer diameter of $3 \mathrm{~m}$, and an equivalent cylindrical height of approximately $10.5 \mathrm{~m}$. In addition, approximately 35,000 fuel spheres are in the defueling region below the reactor core. The fuel spheres are inserted at the top of the core through a single fueling line and are removed from the core at the bottom through a single fuel discharge chute with a single core unloading device. Each fuel sphere is recycled through the core an average of 15 times.

The fuel is based on German TRISO fuel particles with $\mathrm{LEU} \mathrm{UO}_{2}$ as developed for the HTR-Modul reactor (a reactor concept developed in Germany). German LEU TRISO fuel was extensively used in the AVR and irradiated in three MTRs, showing improvement in results as the fuel design evolved over time. The fuel spheres are contained in a tall cylindrical core volume shaped and supported by the reflectors of the core structure.

The main components of the core structure are the metallic core barrel assembly and the core structure ceramics (CSC). The CSC includes the reflectors, which are grouped into the top, side, and bottom reflectors. The basic structural material of the reflectors is graphite, machined in the form of blocks. The graphite blocks are stacked in vertical columns that are supported by the core barrel assembly. The core barrel assembly is a steel cylindrical shell located and supported within the steel reactor pressure vessel. The CSC allows the gas to flow through the pebble-bed from the top to the bottom.

The RCS and RSS provide two independent and diverse shutdown means. The RCS consists of 6 control-rod units approximately $5.25 \mathrm{~m}$ in length, containing $\mathrm{B}_{4} \mathrm{C}$. The rods are suspended in the control-rod channels located in the side reflector of the CSC. Control-rod drive mechanisms (CRDMs) raise and lower the control rods in the control-rod channels. The CRDMs also release the control rods in the event of a reactor trip, allowing them to drop, thereby adding the negative reactivity required to maintain the core at shutdown conditions. The primary rapid reactivity control response is from the prompt-negative temperature coefficient, which shuts the reactor down passively as temperature rises.

The reserve shutdown system consists of 18 independent small absorber sphere insertion systems. The small absorber spheres are $10-\mathrm{mm}$-diameter graphite spheres containing $\mathrm{B}_{4} \mathrm{C}$. They are stored in containers in the reactor pressure vessel head. Core shutdown is achieved by releasing the absorber spheres to fall freely under gravity into the small absorber sphere channels located in the side reflector of the CSC. The absorber spheres are pneumatically extracted from the small absorber sphere channels and transported back to the storage containers when they are no longer required to be inserted. 


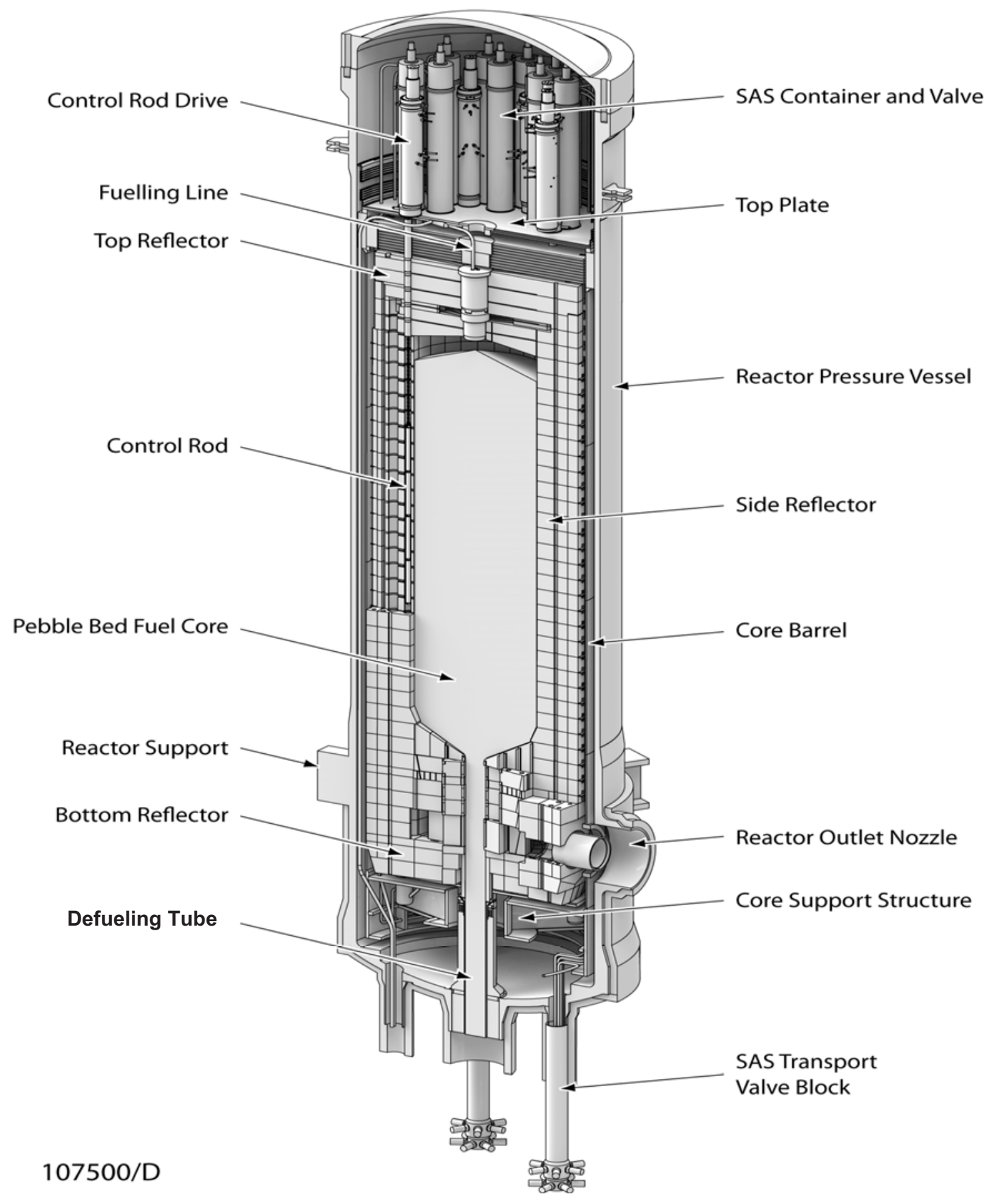

Figure 13. Schematic of the pebble-bed reactor unit. 


\section{NGNP Pebble-Bed vs. German Reactor Design}

NGNP pebble-bed fuel is based on the development, production, and operation of fuel for pebble-bed reactors designed and built in Germany, specifically the fuel manufactured by HOBEG for the 1988 HTR-Modul proof test and the subsequent bulk test in the AVR 21-2 reload. The first pebble-bed reactor to operate in Germany was the AVR; the second was the THTR. While many of the design principles used in the pebble-bed reactor unit are derived from the THTR design, the HTR-Modul reactor provides the primary design bases. The HTR-Modul, like the NGNP pebble-bed design, had a tall, slender core in a steel pressure vessel and could rely on passive safety features to remove heat from the reactor and reactor cavity. Table 9 summarizes the principal mechanical, neutronic, gas, and thermodynamic design parameters of the NGNP pebble-bed reactor unit compared to other pebble-bed reactor designs from Germany.

Table 9. Reactor unit comparison.

\begin{tabular}{|c|c|c|c|c|}
\hline Parameter & $\begin{array}{c}\text { NGNP } \\
\text { Pebble-Bed }\end{array}$ & HTR-Modul & THTR & AVR \\
\hline Reactor thermal power & $250 \mathrm{MW}$ & $200 \mathrm{MW}$ & $750 \mathrm{MW}$ & $46 \mathrm{MW}$ \\
\hline Heat transport medium & Helium & Helium & Helium & Helium \\
\hline Reactor inlet temperature & $250^{\circ} \mathrm{C}$ & $250^{\circ} \mathrm{C}$ & $250^{\circ} \mathrm{C}$ & $275^{\circ} \mathrm{C}$ \\
\hline Reactor outlet temperature & $750^{\circ} \mathrm{C}$ & $700^{\circ} \mathrm{C}$ & $750^{\circ} \mathrm{C}$ & $950^{\circ} \mathrm{C}$ \\
\hline Mass flow rate & $96 \mathrm{~kg} / \mathrm{s}$ & $85 \mathrm{~kg} / \mathrm{s}$ & $296 \mathrm{~kg} / \mathrm{s}$ & $13 \mathrm{~kg} / \mathrm{s}$ \\
\hline System operating pressure & $6 \mathrm{MPa}$ & $6 \mathrm{MPa}$ & $3.9 \mathrm{MPa}$ & $1.08 \mathrm{MPa}$ \\
\hline Pressure Vessel & Steel & Steel & $\begin{array}{l}\text { Pre-stressed } \\
\text { concrete }\end{array}$ & Steel \\
\hline Reactivity Control System & $\begin{array}{l}6 \text { control rods in } \\
\text { the side reflector }\end{array}$ & $\begin{array}{l}6 \text { control rods in the } \\
\text { side reflector }\end{array}$ & $\begin{array}{l}36 \text { control rods in } \\
\text { the side reflector }\end{array}$ & $\begin{array}{l}4 \text { control rods in } \\
\text { side reflector } \\
\text { buttresses }\end{array}$ \\
\hline Reserve Shutdown System & $\begin{array}{l}18 \text { channels in the } \\
\text { side reflector filled } \\
\text { with absorber } \\
\text { spheres }\end{array}$ & $\begin{array}{l}18 \text { channels in the } \\
\text { side reflector filled } \\
\text { with absorber spheres }\end{array}$ & $\begin{array}{l}42 \text { rods inserted into } \\
\text { the pebble-bed }\end{array}$ & \\
\hline Fuel type & Spherical & Spherical & Spherical & Spherical \\
\hline Fuel sphere diameter & $60 \mathrm{~mm}$ & $60 \mathrm{~mm}$ & $60 \mathrm{~mm}$ & $60 \mathrm{~mm}$ \\
\hline Fueling method & Multiple recycle & Multiple recycle & Multiple recycle & Multiple recycle \\
\hline Helium flow direction & Downwards & Downwards & Downwards & Upwards \\
\hline Pebble-bed diameter & $3.0 \mathrm{~m}$ & $3.0 \mathrm{~m}$ & $5.60 \mathrm{~m}$ & $3.0 \mathrm{~m}$ \\
\hline Pebble-bed height & $10.5 \mathrm{~m}$ & $9.4 \mathrm{~m}$ & $6.00 \mathrm{~m}$ & $2.8 \mathrm{~m}$ \\
\hline Volume of pebble-bed & $\sim 74 \mathrm{~m}^{3}$ & $\sim 66 \mathrm{~m}^{3}$ & $\sim 125 \mathrm{~m}^{3}$ & $\sim 20 \mathrm{~m}^{3}$ \\
\hline Fuel spheres in core & $\sim 400,000$ & $\sim 360,000$ & $\sim 675,000$ & $\sim 100,000$ \\
\hline Mean power density & $3.4 \mathrm{MW} / \mathrm{m}^{3}$ & $3.0 \mathrm{MW} / \mathrm{m}^{3}$ & $6 \mathrm{MW} / \mathrm{m}^{3}$ & $2.6 \mathrm{MW} / \mathrm{m}^{3}$ \\
\hline Mean fuel sphere output & $\sim 0.6 \mathrm{~kW}$ & $\sim 0.6 \mathrm{~kW}$ & $\sim 1.1 \mathrm{~kW}$ & $\sim 0.5 \mathrm{~kW}$ \\
\hline Status & In design & $\begin{array}{l}\text { Progressed to } \\
\text { Preliminary Design }\end{array}$ & Operated & Operated \\
\hline
\end{tabular}




\subsubsection{Fuel}

The pebble-bed core consists of numerous individual spherical fuel elements, each containing a mixture of fuel particles and matrix graphite. A fuel sphere is divided into two regions. The inner spherical region is known as the fuel region; the outer shell surrounding the fuel region is known as the fuel-free region. The fuel region of each fuel sphere contains a large number of distributed spherical fuel particles known as TRISO fuel particles. There are no coated particles in the fuel-free region. Quality assurance requirements are summarized in Section 5.2.1.2. The design of the coated particles and fuel sphere is depicted in Figure 14.

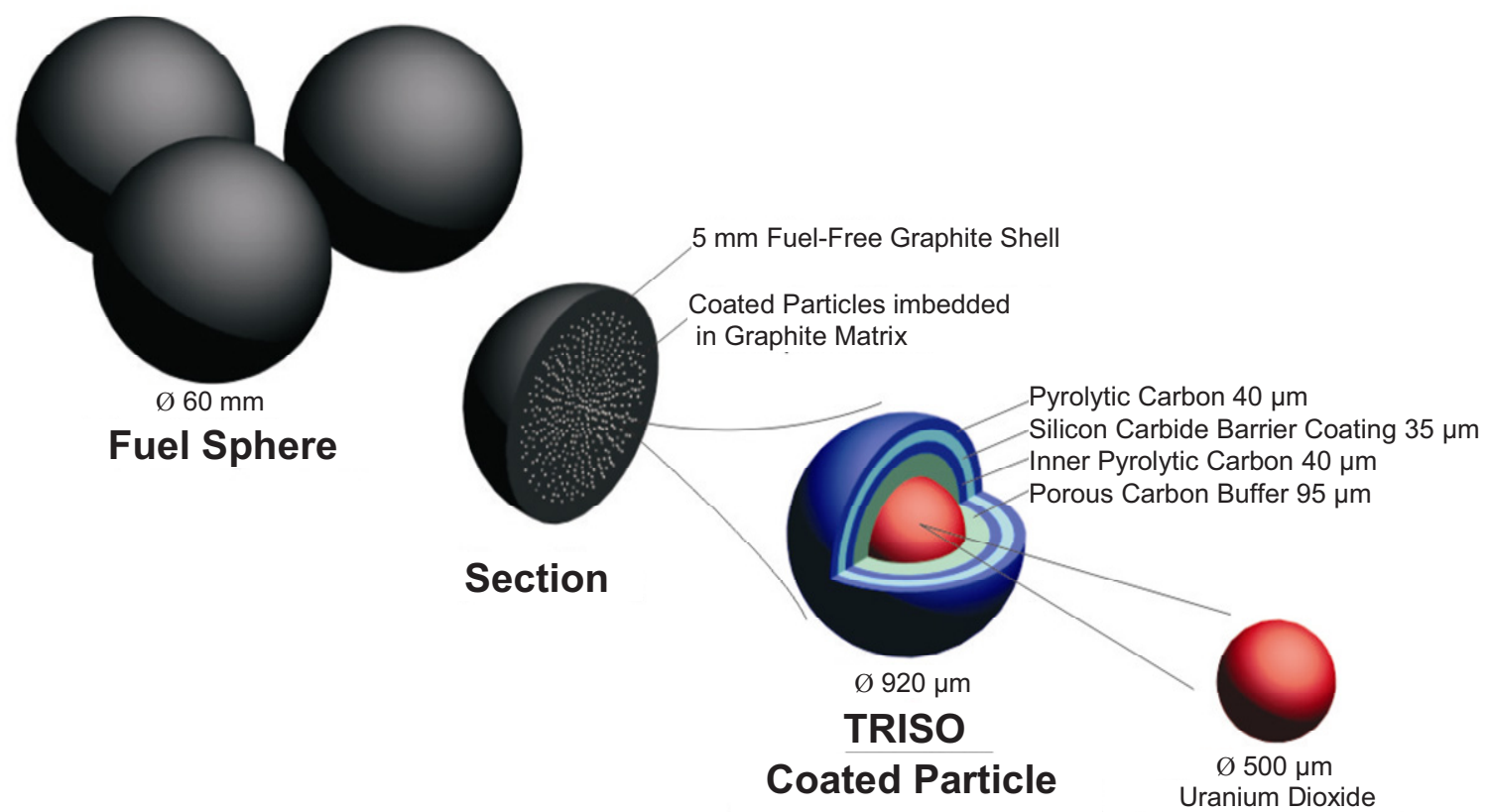

Fuel Kernel

Figure 14. Fuel-sphere design.

The kernel and coating layers of the coated particles are discussed in general terms in Section 3.1.3. Coated-particle property specifications for the pebble-bed core are given in Table 3 .

\subsubsection{Fuel Service Conditions}

Experimental results and analytical modeling of LEU $\mathrm{UO}_{2}$ TRISO fuel have indicated that the integrity of the coated particles and retention of fission products can be assured if the fuel is properly manufactured (according to the manufacturing specifications) and the normal operation and accident service conditions are maintained within an allowed performance envelope. This section addresses the range of service conditions expected for pebble-bed fuel, which replicates German LEU UO $\mathrm{TRISO}_{2}$ fuel (specifically the AVR21-2 reload fuel). The fuel temperature, power, and flux levels are calculated using the VSOP99 code. ${ }^{47}$ The existing experimental basis for establishing an allowed envelope for the German LEU $\mathrm{UO}_{2}$ TRISO fuel is addressed in Section 3.2. The parameters that influence pebble-bed fuel performance are the temperature history, burnup and fast fluence experienced during normal operation, and the temperature history experienced during transient and accident conditions. Steady-state temperature gradients across fuel elements, in combination with the aforementioned parameters, have driven kernel migration. Kernel migration is effectively controlled in the pebble bed by limiting the maximum sphere power and by the constant movement through the core that results from continuous cycling (reloading) of fuel spheres. The other parameters and their expected values for the pebble-bed design are discussed in the following sections and summarized in Section 4.2.2.3. 
The fuel service conditions described here are derived for an equilibrium core of fuel spheres, each containing $7 \mathrm{~g}$ of $\mathrm{UO}_{2}$, whose ${ }^{235} \mathrm{U}$ enrichment is $7.8 \%$. The pebble-bed reactor will be started up with fuel also containing $7 \mathrm{~g}$ of $\mathrm{UO}_{2}$, but enriched to approximately 4.2 to $4.5 \%{ }^{\mathrm{q}}{ }^{235} \mathrm{U}$ to control start-up reactivity and will then be transitioned to the use of equilibrium fuel.

\subsubsection{Normal Operation}

\section{Temperature}

The chemical interaction and diffusion processes that can affect coated-particle integrity and fission-product retention are governed by time and temperature, with the rate constants typically following an exponential Arrhenius function of temperature. Thus, the integrated temperature history, rather than the instantaneous temperature value, is of primary interest during normal operation. Fuel spheres are inserted onto the top of the pebble-bed core at the center of the cylindrical core. Since both coolant and sphere flow are downward, the initial fuel temperature is only slightly greater than the inlet coolant temperature, with temperatures increasing as the spheres flow through the core. The core is modeled by five annular flow channels, tracking numerous layers within each of the channels as they pass downward through the core. Fuel temperatures in the core vary as the spheres progress through the core; equilibrium core-temperature distributions are shown in Figure 15. The channels listed in Figure 15 are annular core segments, with Channel 1 being the segment in the center of the cylindrical core, Channels 2 through 4 interior channels, and Channel 5 immediately adjacent to the outer reflector. The temperatures shown are sphere center temperatures based on the average power in the layer that contains a mixture of spheres on different passes through the core. The highest maximum temperature $\left(1048^{\circ} \mathrm{C}\right)$ is calculated for a sphere in Channel 1 on its first pass at the bottom of the core, while the average temperature for spheres in that channel at that layer is $986^{\circ} \mathrm{C}$. The core average temperature, which corresponds to the time-averaged temperature experienced by the average fuel sphere, is $644^{\circ} \mathrm{C}$.

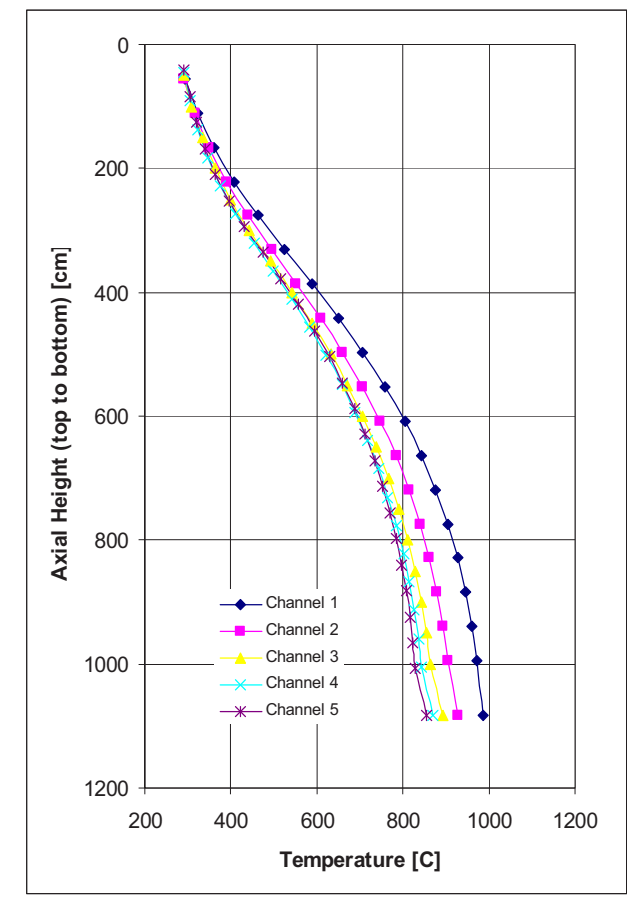

Figure 15. Normal operation fuel temperature (axial profiles for average values in VSOP99 Channels 1 through 5).

q. The enrichment of the start-up fuel is expected to be in this range, with a final determination to be made following more detailed analysis of the startup and initial operation of the core. 


\section{Burnup}

On average, fuel spheres pass through the pebble-bed core 15 times $^{\mathrm{r}}$ before exceeding the discharge setpoint of the burnup measurement system (BUMS). The sphere power and corresponding burnup rate vary as a function of position within the core and recirculation pass. Figure 16 shows the axial power distribution for the average of the spheres in each layer of the five flow channels. The sphere powers within each layer vary according to the recirculation pass, with low burnup spheres on initial or early passes having higher power and higher burnup spheres on later passes having lower power. Spheres passing near the radial center of the core (Channel 1) have higher power due to the higher thermal flux.

The volume-averaged fuel burnup in the equilibrium core is calculated to be $4.74 \%$ FIMA. The discharge burn-up distribution is primarily determined by the BUMS setpoint, above which the spheres are routed to spent-fuel storage. The setpoint is not firmly established at present, but initial studies indicate an average discharge burnup of $\sim 8.31 \%$ FIMA, with a maximum of $\sim 8.75 \%$ FIMA, including an error allowance on the burn-up measurement. Only a small number of spheres would approach the maximum discharge burnup as they would require a multi-pass burnup just below the setpoint including error, experience a large negative measurement error, and be circulated through the central core segment (i.e., Channel 1).

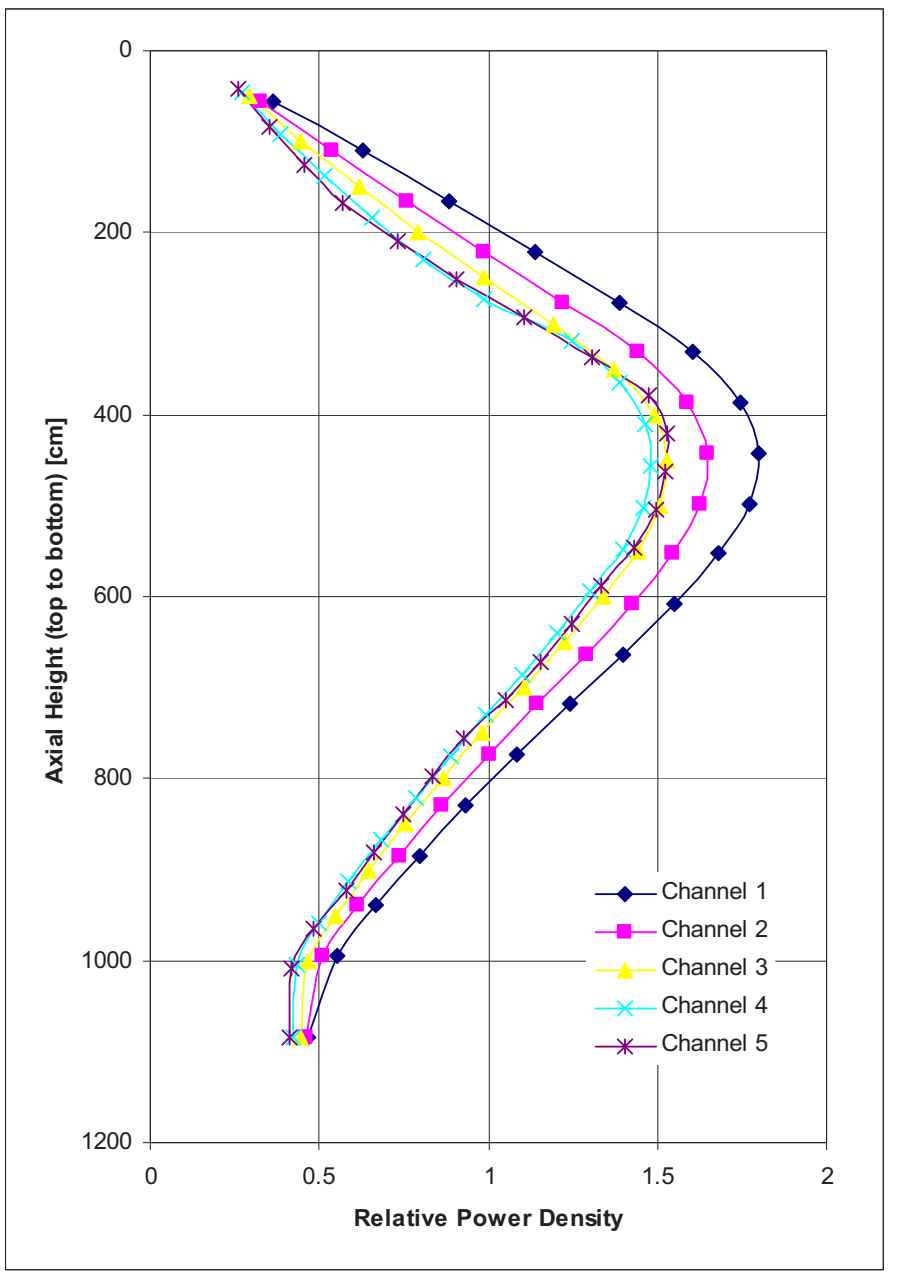

Figure 16. Normal operation power distribution.

r. The 15-pass approach was implemented to aid in reducing accident temperatures through reducing and spreading the normal operation core power peak while at the same time improving economics through narrowing the discharge burn-up spectrum. 


\section{Fast Fluence}

Figure 17 shows the radial variation of thermal and fast neutron flux in the reactor core.

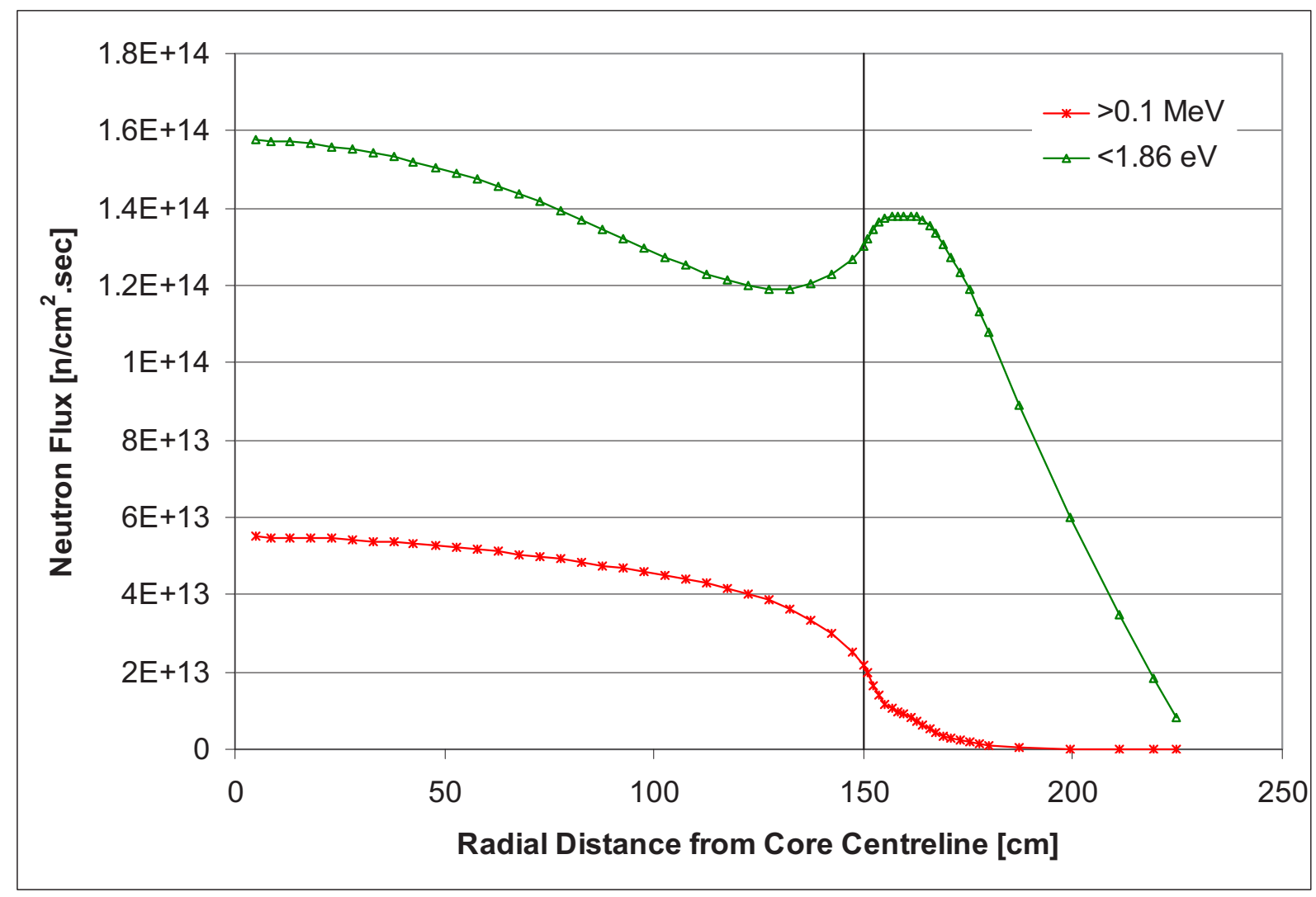

Figure 17. Radial neutron flux distribution.

The overall effect is that a sphere passing near the center of the core will accrue relatively higher burnup and higher fast fluence than a sphere passing near the reflector; however, the ratio of power (thermal flux) to fast flux will be highest near the reflector. Thus, the ratio of burnup to fast fluence of individual spheres is dependent on their trajectories through the core. The net result is a distribution of burnup and fast fluence over a range, as illustrated in Figure 18. The VSOP99 analyses produced an equilibrium core average fast fluence of $\sim 1.01 \times 10^{21} \mathrm{n} / \mathrm{cm}^{2}$ with an average discharge fluence of $\sim 2.01 \times 10^{21} \mathrm{n} / \mathrm{cm}^{2}$. Initial estimates of maximum discharge fast fluence, allowing for worst-case sphere trajectory and burnup management system tolerance, indicate a maximum value of $\sim 2.39 \times 10^{21} \mathrm{n} / \mathrm{cm}^{2}$. As was the case with burnup, only an extremely small fraction of discharged spheres would approach the maximum value, including error allowance.

The sphere population would be skewed toward the upper side of the envelope, shown in Figure 18, as most of the sphere passes are through the center portion of the core. 


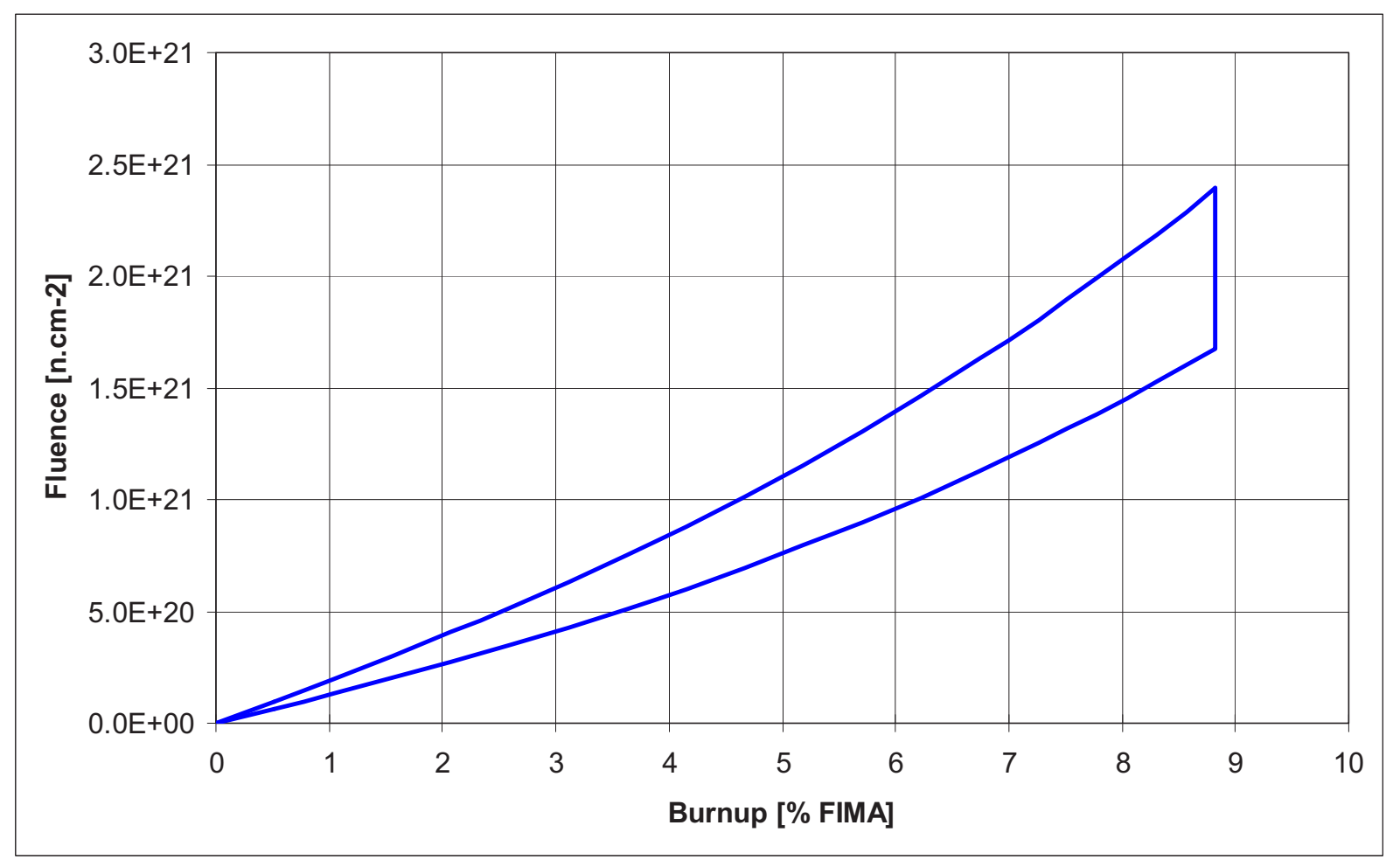

Figure 18. Pebble-bed burnup and fast fluence envelope.

\subsubsection{Accident Conditions}

The TINTE code was developed by the Kernforschungsanlage Jülich (KFA) to investigate nuclear and thermal transient behavior of HTRs with full neutron, temperature, and xenon feedback effects taken into account in 2-D r-z diffusion theory. TINTE was developed and has been benchmarked against AVR data $^{48}$ and test facility data. ${ }^{49}$ Because of the large heat capacity of graphite, overall temperature changes are generally very slow in pebble-bed fuel. In contrast, any changes in the $\mathrm{UO}_{2}$ kernel temperature will result in an immediate feedback to the nuclear behavior. The code is therefore able to handle feedback effects over a very wide range of time constants. The code incorporates numerous material property correlations for graphite and other core structures, including the temperature and fast-fluence dependence of the pebble-bed effective thermal conductivity.

The depressurized loss of forced cooling (DLOFC) event represents a category of accidents involving a coincident depressurization of the reactor unit and loss of all active heat-removal systems from initial full-power steady-state operation. Typical best estimate time-dependent traces of the maximum and average fuel sphere temperatures for the DLOFC accident are shown in Figure 19. 


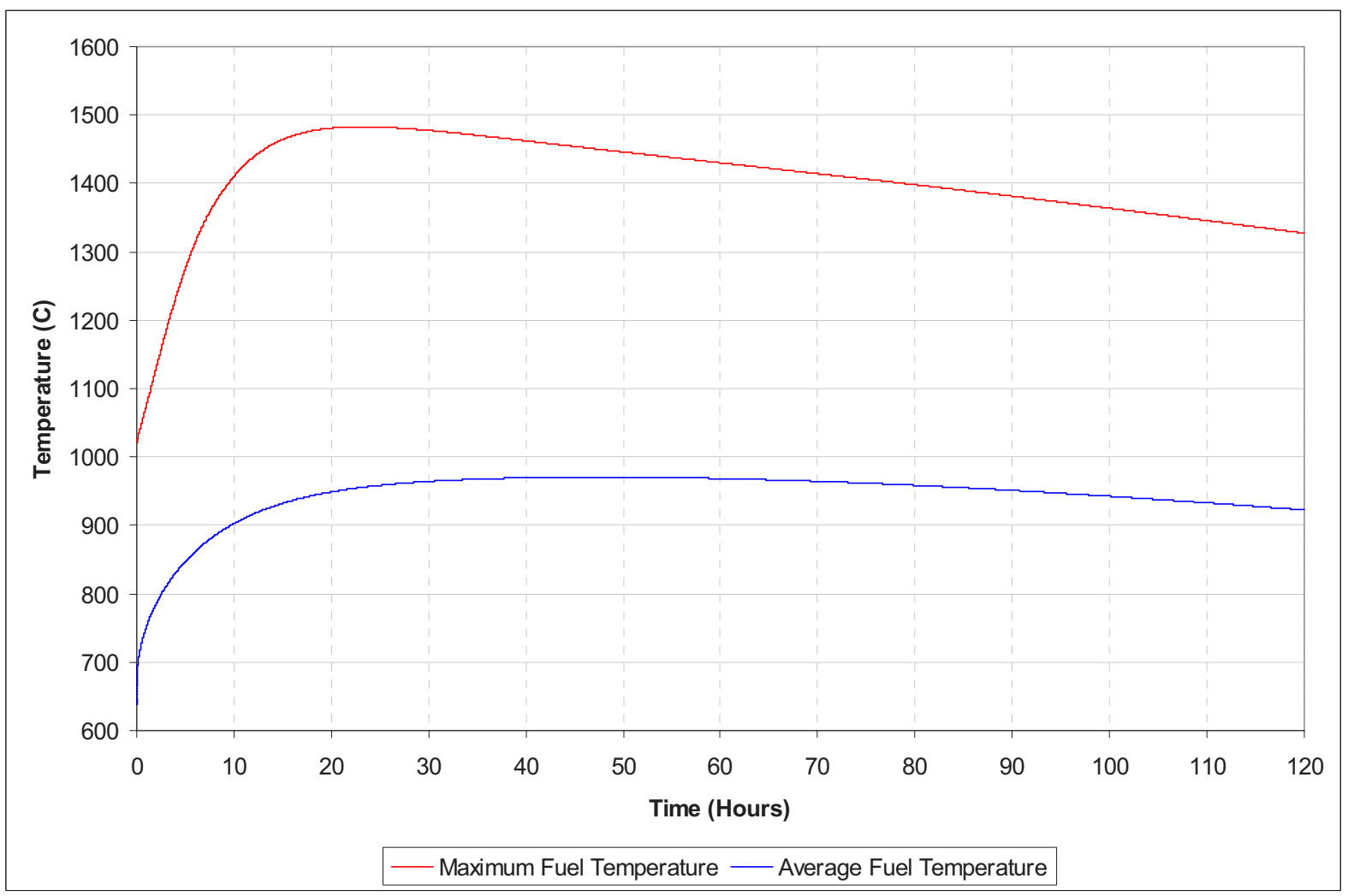

Figure 19. Fuel temperature-depressurized loss of forced cooling.

TINTE analysis also shows that for the typical DLOFC accident, only small fractions of the spheres in the core approach the maximum fuel temperature of $1,483^{\circ} \mathrm{C}$. Figure 20 is a histogram of DLOFC fuel temperatures at the time of the maximum temperature. This figure shows that approximately $3 \%$ of the core would experience temperatures in the range of 1,400 to $1,500^{\circ} \mathrm{C}$, while no spheres are expected to exceed $1,600^{\circ} \mathrm{C}$.

Figure 21 presents a time-based view of this histogram, showing the duration over which there are spheres within the core at these temperatures. What is important to note is that due to the migration of the high-temperature zone within the fuel core over time during the transient, the specific spheres experiencing the highest temperatures do not necessarily see these temperatures for the full duration of such temperatures within the core. From these figures, it can be seen that relative to the total duration of the transient $(>120 \mathrm{~h})$, the maximum temperatures are experienced for only a limited duration by any specific sphere. 


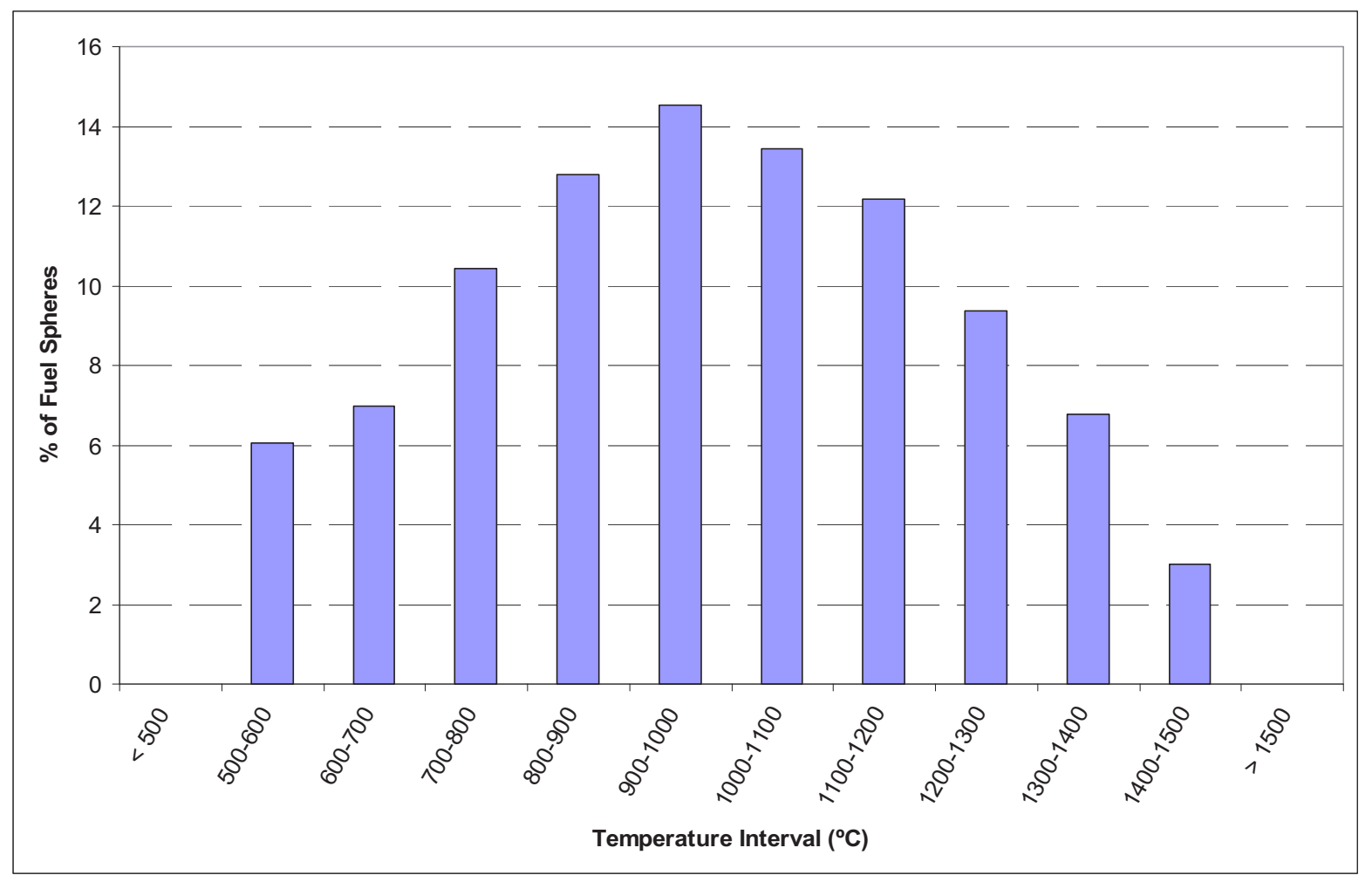

Figure 20. Fuel-temperature distribution at time of maximum temperature-DLOFC.

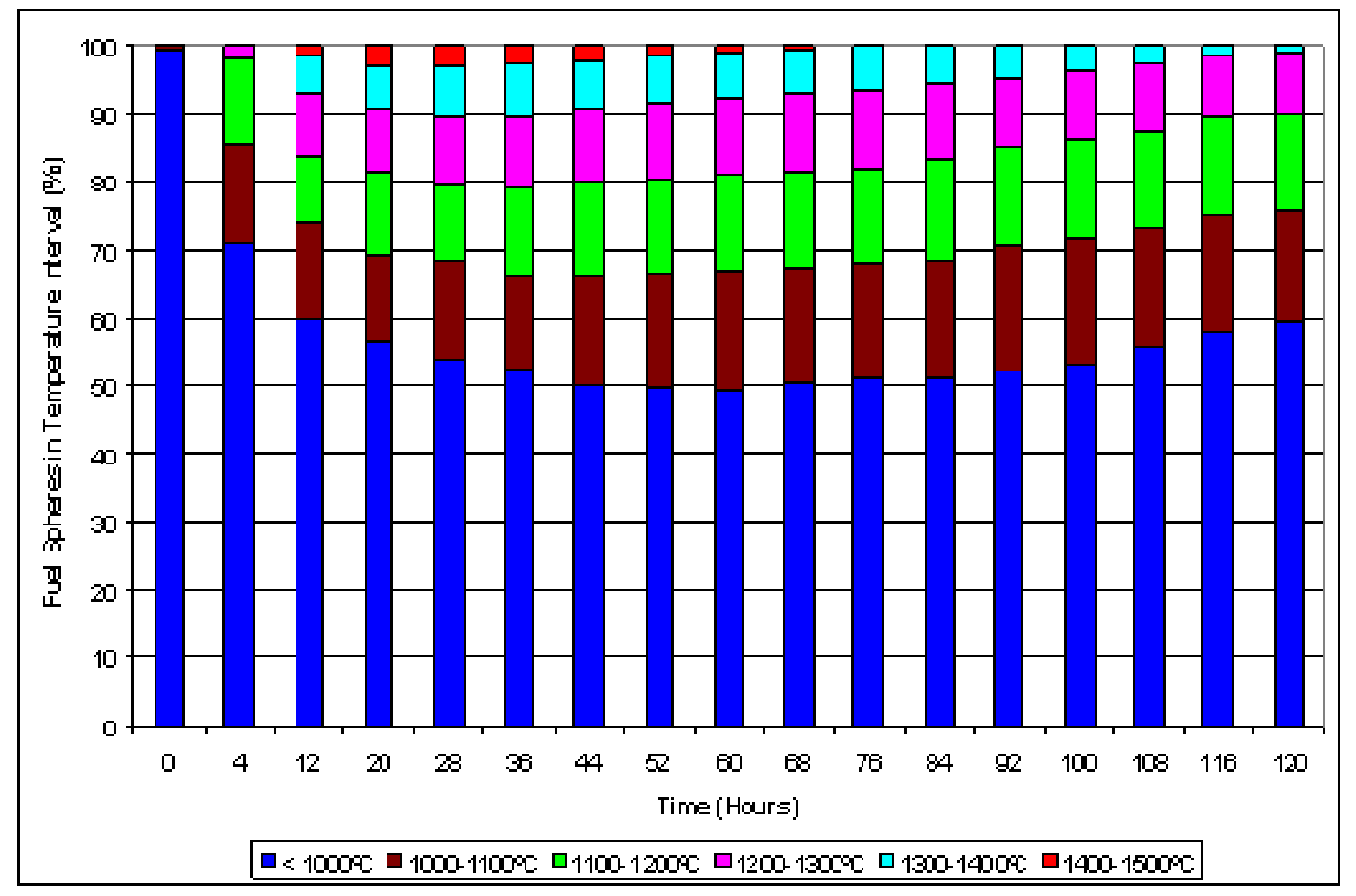

Figure 21. Fuel-temperature distribution during transient—DLOFC. 


\subsubsection{Summary of Pebble-bed Fuel-service Conditions}

Based on the data discussed in the previous sections, the pebble-bed fuel-service conditions are summarized in Table 10. These values will be compared with the historical German data in Section 3.2

Table 10. Fuel service conditionss.

\begin{tabular}{|c|c|c|}
\hline Parameter & Core Average Value & Maximum Value \\
\hline \multicolumn{3}{|l|}{ Normal Operation } \\
\hline Discharge Burnup, \% FIMA & 8.31 & 8.75 \\
\hline Discharge Fast Fluence, $10^{21} \mathrm{n} / \mathrm{cm}^{2}(\mathrm{E}>0.1 \mathrm{MeV})$ & 2.01 & 2.39 \\
\hline Sphere Center Temperature, ${ }^{\circ} \mathrm{C}$ & 644 & 1,048 \\
\hline \multicolumn{3}{|c|}{ Accident Conditions - Best Estimate Maximum Transient Conditions } \\
\hline Sphere Temperature, ${ }^{\circ} \mathrm{C}$ & 970 & 1,483 \\
\hline
\end{tabular}

\subsubsection{Fuel Performance Requirements}

The high degree of safety of HTGRs results from the ability of coated particles in the fuel to retain fission products at their site of origin, even at high temperatures. For fresh fuel, the maximum allowed amount of free uranium in a fuel sphere is a specified characteristic known as the 'free-uranium fraction'. The free-uranium fraction consists of enriched uranium contained in coated particles that have defective $\mathrm{SiC}$ layers (with or without defective PyC layers), enriched uranium on the outer surfaces of coated particles due to contamination in the coater during the coating process, and natural uranium contained in natural graphite, which is the main component of the matrix graphite body of a fuel sphere. The free-uranium fraction for fresh fuel is measured as the last step in the quality control process during fuel manufacture by means of the burn-leach test. ${ }^{t}$

As uranium in the kernels of coated particles in fuel spheres is fissioned in the reactor core, additional failure of a small fraction of coated particles might occur due to an increase in pressure within coated particles as a result of the accumulation of gaseous fission products within intact coating layers. Failure of an additional small fraction of coated particle failures might occur when coated particles are heated during a core heat-up accident due to an increase in internal pressure resulting from an increase in temperature.

The number of failed coated particles present in a fuel sphere at any time is expressed as the failed coated-particle fraction, abbreviated to "failure fraction," which is the number of failed coated particles in a fuel sphere relative to the total number of coated particles in the sphere. As explained above, the irradiation history of a fuel sphere in the reactor core determines its failure fraction. Initially, the failure fraction for a fuel sphere is equal to the free-uranium fraction for fresh fuel, and it might increase slightly during the life of the sphere in the reactor core.

s. The core average and maximum discharge burnup and fast fluence values include the effects of variations resulting from uncertainties in the burnup measurement system (BUMS) and trajectory-dependent variations in burnup and fluence accrual in the last cycle of a pebble before it is discharged by the fuel handling system.

t. This characterization test involves removing the exposed PyC layers (OPyC for all particles plus IPyC and buffer in particles with defective $\mathrm{SiC}$ layers) by oxidation, followed by leaching with a concentrated acid solution to remove exposed heavy metal. 


\subsubsection{Free-Uranium Fraction in Fresh Fuel}

It was shown by statistical analysis of burn-leach results for German LEU TRISO fuel that expected and design values for the free-uranium fraction derived from production data for state-of-the-art German fuel were $1 \times 10^{-5}$ and $3 \times 10^{-5}$ respectively, although the specified value of the free uranium fraction for a single fuel lot was $6 \times 10^{-5}$. The same value is specified for NGNP pebble-bed fuel.

The free-uranium fraction for fresh fuel is measured by the fuel manufacturer by means of a burn-leach test on a sample taken from each fuel sphere lot before release. As each fuel sphere lot that does not meet the specification is rejected, all fuel-sphere lots that are loaded into the pebble-bed core will meet the specification. It is expected that, similar to German fuel, the expected and design values for the free-uranium fraction for fresh pebble-bed fuel will be less than the free-uranium fraction specified for a pebble-bed fuel lot. However, in the absence of production data for pebble-bed fuel to confirm this, the specified value of $6 \times 10^{-5}$ for a single fuel lot will be used as the design value for the free-uranium fraction in the core for establishing the relationship between failure fraction and temperature described in Section 4.2.3.4, and not the design value of $3 \times 10^{-5}$ derived for German state-of-the-art fuel spheres.

\subsubsection{Normal Operation}

In order to derive a value for the number of coated-particle failures resulting from irradiation for fuel spheres, results from a number of German irradiation tests on fuel spheres and fuel samples containing LEU TRISO-coated particles and performed under controlled irradiation conditions were used. Irradiation conditions for all German irradiation tests performed under controlled conditions in MTRs (see Section 3.2.2) are distributed around expected values for pebble-bed fuel spheres (Section 4.2.2.3).

No particle failures occurred during irradiation in all irradiation tests considered. Failure fractions were calculated at the $95 \%$ one-sided upper confidence levels for a binomial distribution.

Failure fractions calculated are shown in Table 11.

Table 11. Failure fraction values under normal operation.

\begin{tabular}{|c|c|}
\hline Confidence Level & Failure Fraction \\
\hline $50 \%$ (Expected) & $8.70 \times 10^{-6}$ \\
\hline $95 \%$ & $3.76 \times 10^{-5}$ \\
\hline
\end{tabular}

\subsubsection{Accident Conditions}

In the German LEU TRISO fuel irradiation program, the effect of accident conditions on coated-particle failure fraction was measured by subjecting fuel spheres irradiated to end-of-life conditions to heating tests and measuring the release of fission gas and other fission products. The failure of coated particles during heating tests were observed as step increases in the release of fission gas that occurred whenever a coated particle failed and released a large fraction of its fission-gas inventory in a short time.

Heating tests were performed at 1,$600 ; 1,700$; and $1,800^{\circ} \mathrm{C}$. Expected values for failure fractions were calculated from the number of coated particles that actually failed during heating tests. Expected and $95 \%$ one-sided upper confidence values obtained are summarized in Table 12. 
Table 12. Failure fraction values from heating tests.

\begin{tabular}{|c|r|c|c|c|}
\hline $\begin{array}{c}\text { Heating } \\
\text { Temperature }\left({ }^{\circ} \mathrm{C}\right)\end{array}$ & $\begin{array}{c}\text { Number of } \\
\text { Coated Particles }\end{array}$ & $\begin{array}{c}\text { Number of } \\
\text { Failed Coated } \\
\text { Particles }\end{array}$ & $\begin{array}{c}\text { Expected Failure } \\
\text { Fraction (Average) }\end{array}$ & $\begin{array}{c}\text { 95\% One-sided Upper } \\
\text { Confidence Limit }\end{array}$ \\
\hline 1,600 & 86,893 & 7 & $8.06 \times 10^{-5}$ & $1.51 \times 10^{-4}$ \\
\hline 1,700 & 36,062 & 20 & $5.55 \times 10^{-4}$ & $8.06 \times 10^{-4}$ \\
\hline 1,800 & 132,831 & 108 & $8.13 \times 10^{-4}$ & $9.54 \times 10^{-4}$ \\
\hline
\end{tabular}

\subsubsection{Summary: Fuel Performance Requirements}

In the absence of irradiation and accident test data specific to NGNP pebble-bed fuel, a preliminary coated-particle failure fraction versus temperature relationship for fuel is derived based on data obtained from German irradiation tests performed on LEU TRISO fuel from 1981 to 1988. This relationship will be updated as failure-fraction data from irradiation and accident tests on NGNP pebble-bed fuel becomes available.

Expected, 95\%-confidence-level and design-failure fractions were derived for pebble-bed fuel using some production data from burn-leach tests on mass-produced AVR21-2 fuel and limited-production HTR-Modul Proof Test fuel, and from the specified free-uranium-fraction value for a single pebble-bed fuel lot. The values so obtained are compared with HTR-Modul values in Table 13 below. It is assumed conservatively that all failures are burn-up and fast fluence independent and occur immediately once a temperature is reached.

Table 13. NGNP pebble-bed and HTR-Modul failure fraction values.

\begin{tabular}{|c|c|c|c|c|}
\hline $\begin{array}{c}\text { Temperature } \\
\left({ }^{\circ} \mathrm{C}\right)\end{array}$ & $\begin{array}{c}\text { NGNP } \\
\text { Expected }\end{array}$ & $\begin{array}{c}\text { NGNP 95\% } \\
\text { Confidence }\end{array}$ & NGNP Design & Modul Design \\
\hline 800 & $1.44 \times 10^{-5}$ & $4.88 \times 10^{-5}$ & $1.06 \times 10^{-4}$ & $1.6 \times 10^{-4}$ \\
\hline 1,200 & $1.44 \times 10^{-5}$ & $4.88 \times 10^{-5}$ & $1.06 \times 10^{-4}$ & $1.6 \times 10^{-4}$ \\
\hline 1,600 & $2.08 \times 10^{-4}$ & $4.11 \times 10^{-4}$ & $5.04 \times 10^{-4}$ & $6.6 \times 10^{-4}$ \\
\hline 1,700 & $6.12 \times 10^{-4}$ & $9.31 \times 10^{-4}$ & $1.04 \times 10^{-3}$ & - \\
\hline 1,800 & $1.85 \times 10^{-3}$ & $2.21 \times 10^{-3}$ & $2.33 \times 10^{-3}$ & - \\
\hline
\end{tabular}

The three failure-fraction curves derived above, as well as the design failure-fraction curve for the HTR-Modul, are shown in Figure 22. 


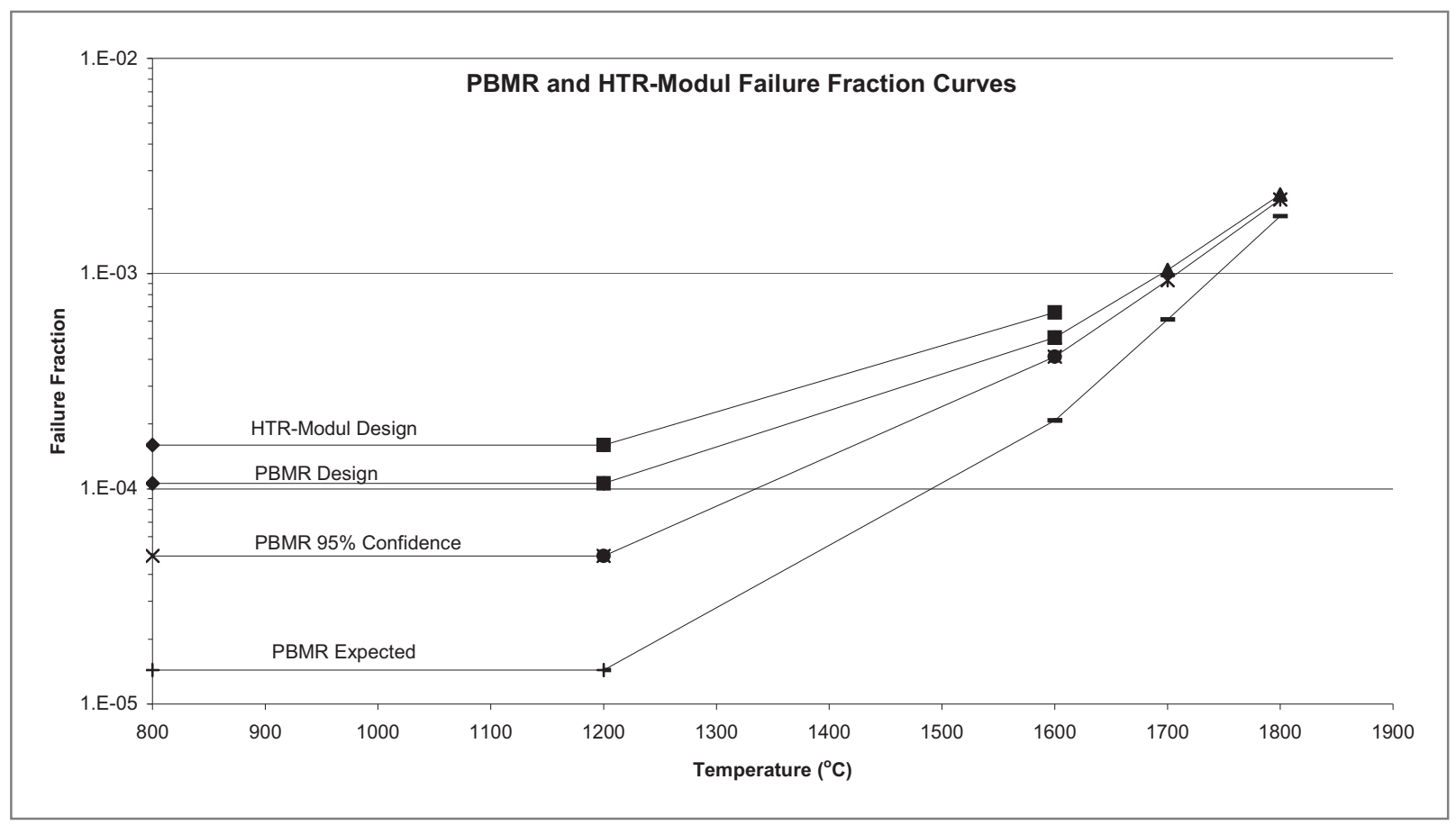

Figure 22. NGNP pebble-bed (PBMR) and HTR-Modul failure fraction vs. temperature curves.

\subsection{Prismatic Fuel}

The designs of the reactor and fuel for the prismatic NGNP are described in this section, followed by a discussion of fuel-service conditions and fuel-performance requirements under normal operating and accident conditions.

\subsubsection{Design Summary}

The reactor design concept and the fuel design for the NGNP using prismatic fuel are summarized in this section.

\subsubsection{Reactor}

The prismatic HTGR concept is a high-temperature, gas-cooled, graphite-moderated reactor utilizing a prismatic graphite block fuel form. In this design, hexagonal graphite fuel blocks are used, each containing TRISO fuel particles bonded together within a carbonaceous matrix material to form cylindrical fuel compacts (see Section 4.2.1.2). This concept results in a fixed-core configuration that requires periodic refueling.

The NGNP prismatic reactor concept is in the beginning stages of conceptual design. The point of departure for the conceptual design will be either the 350-MWth MHTGR design or the 600-MWth gas-turbine modular helium reactor (GT-MHR) design. Figure 23 and Figure 24 show the GT-MHR core design and its cross section at vessel midplane, respectively. The GT-MHR reactor core consists of hexagonal (prismatic) graphite fuel elements, 793-mm long by $360-\mathrm{mm}$ across flats. The prismatic fuel elements (blocks) are stacked 10 blocks high in 102 columns to form an annular core. Reflector graphite blocks are provided inside and outside of the active core. The MHTGR also has an annular arrangement but has two rings of fuel elements rather than three. 


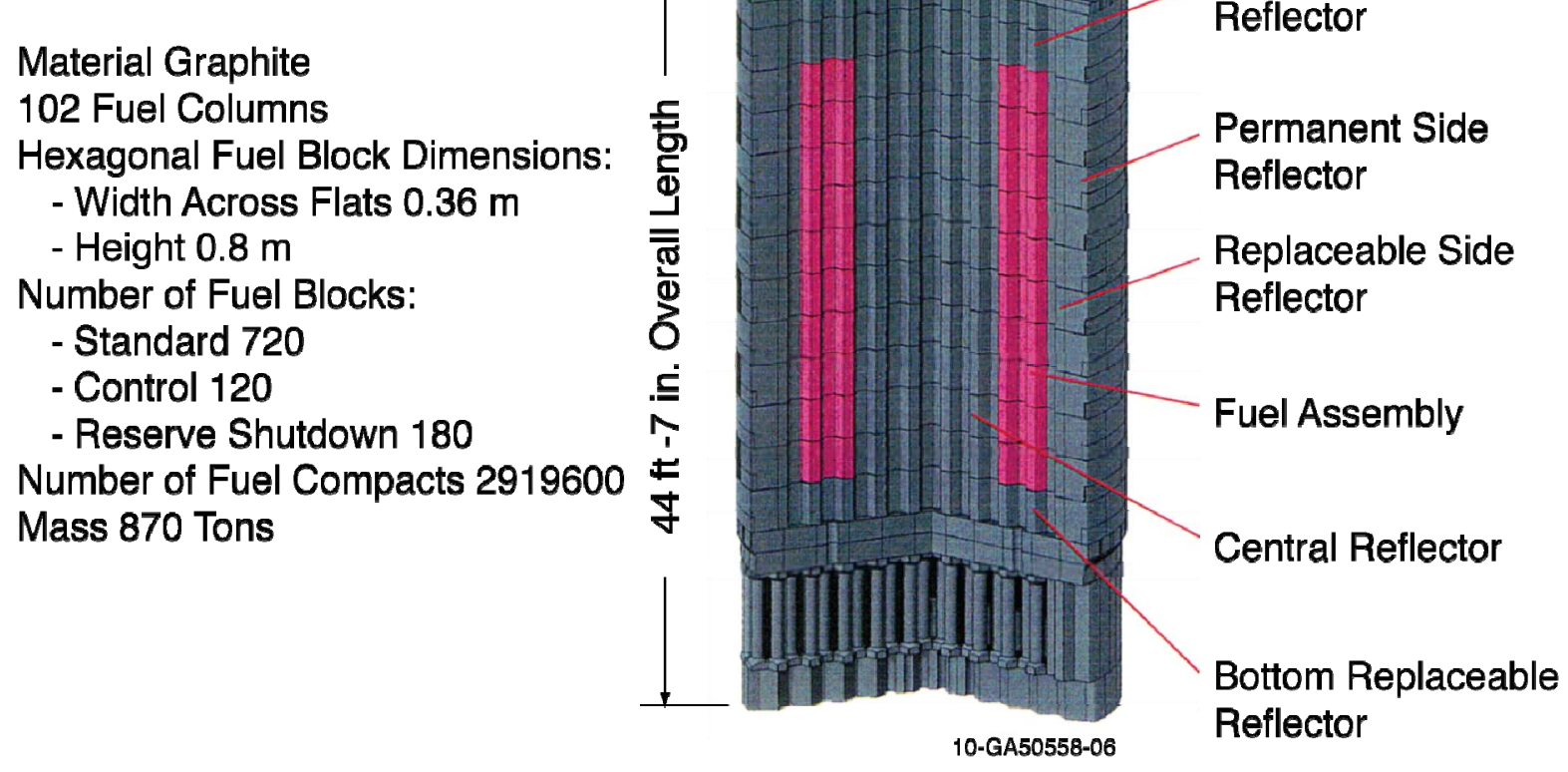

Figure 23. GT-MHR core design.

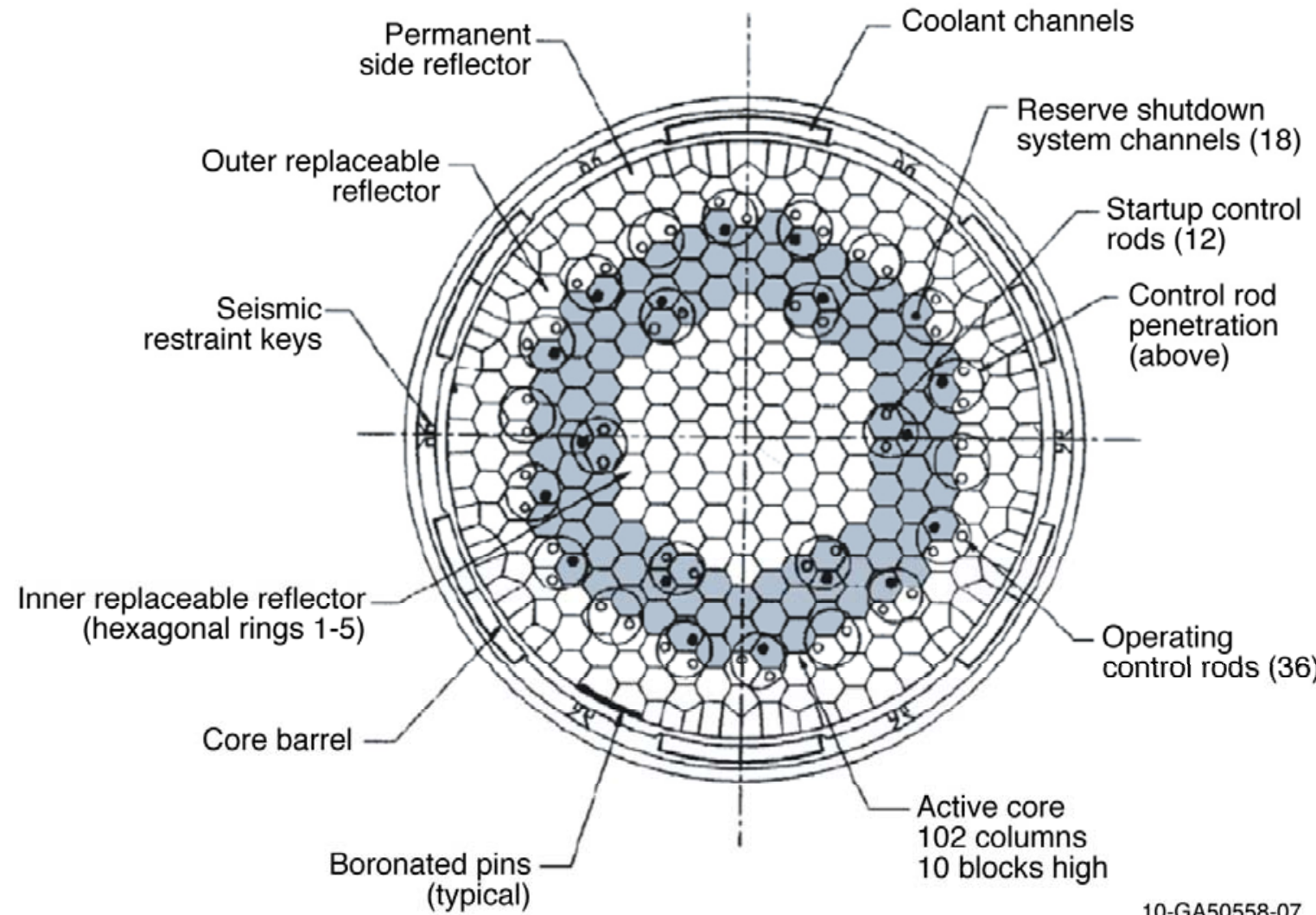

Figure 24. GT-MHR core cross section at vessel mid-plane. 
The reactor system design shown in Figure 25 labels the primary components of the reactor vessel. Removal of thermal energy generated in the reactor core is provided by the heat transport system, with the main circulator providing the driving force to supply helium coolant into an upper core inlet plenum and to draw heated coolant from a bottom core outlet plenum. The primary coolant is distributed to numerous coolant channels running vertically through the core. The outlet plenum directs the flow to the central portion of the coaxial cross duct, which channels the helium flow to the heat exchanger.

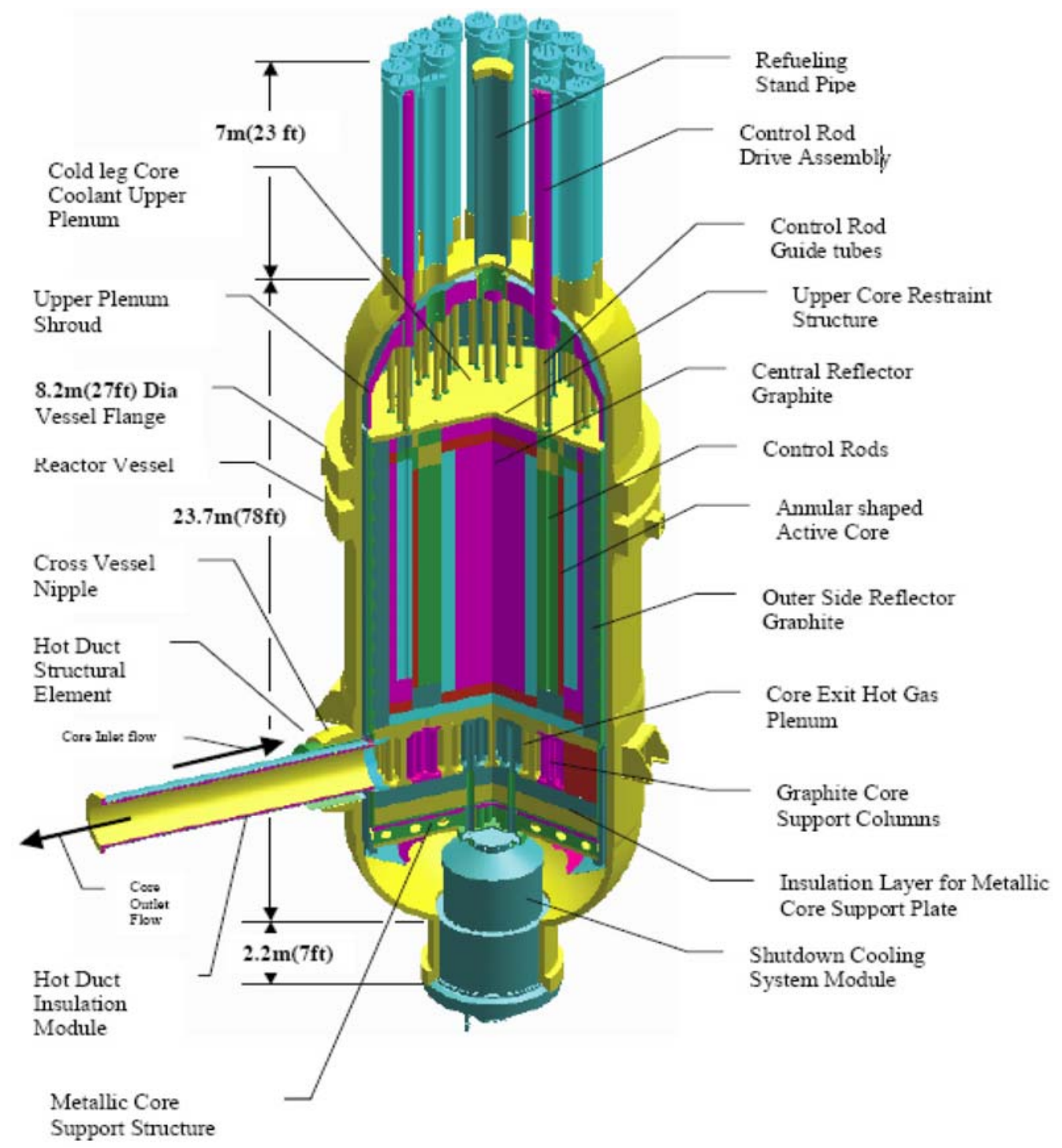

Figure 25. Prismatic reactor system design.

Movable control rods control the fission energy generation rate during reactor power operation and ensure an adequate shutdown margin. The mechanisms that drive the control rods are located in penetrations in the reactor vessel top head. The control-rod assemblies in the neutron control system are designed to prevent accidental ejection of a control rod from the core. Thus, significant reactivity-insertion accidents caused by a control-rod ejection are not feasible. Ex-vessel neutron flux detectors monitor the core power level during power operation. Source range detectors are located in the side reflector monitor flux at lower powers and at shutdown conditions. The reactor core and reflectors rest vertically on a support structure below the core and are restrained by a core lateral restraint structure located between the outer side reflector and the reactor vessel. 
The basic design concept for the prismatic HTGR has evolved through a series of design choices, which individually and in combination emphasize passive or inherent safety, thereby ensuring that both user and top-level regulatory requirements will be met by the design. A few of the more important design choices include the power density, annular core configuration and dimensions, core height, and gravity-assisted control for both the primary and backup (diverse) control system(s).

\subsubsection{Fuel}

The fuel for a prismatic HTGR is shown in Figure 26. The reference fuel particle consists of a UCO microsphere that is coated with multiple layers of $\mathrm{PyC}$ and $\mathrm{SiC}$. The buffer, $\mathrm{IPyC}, \mathrm{SiC}$, and OPyC layers are referred to collectively as a TRISO coating. The coating system constitutes a miniature pressure vessel that provides containment of the radionuclides and gases generated by fission of the nuclear material in the kernel.

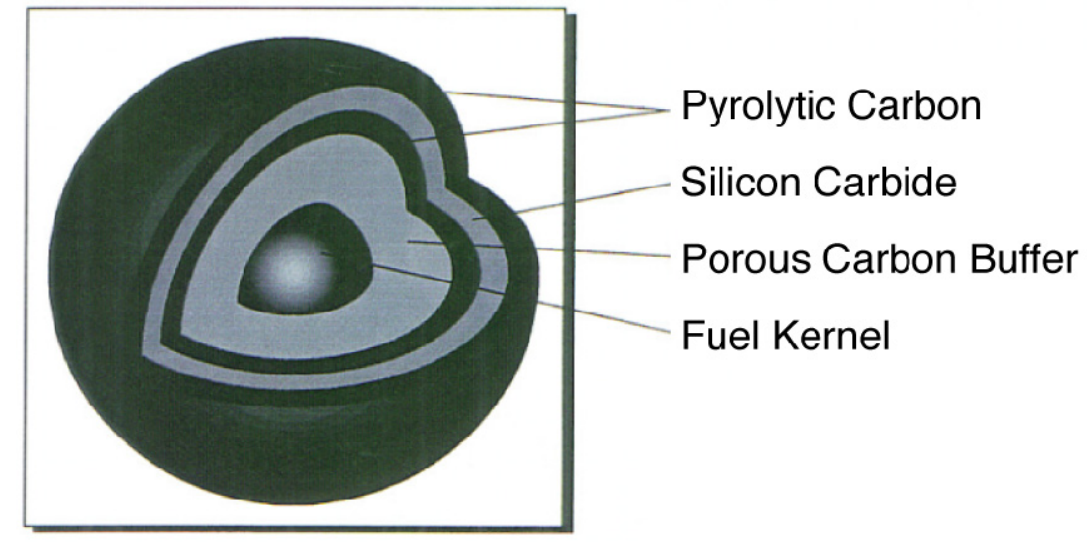

Fuel Particle

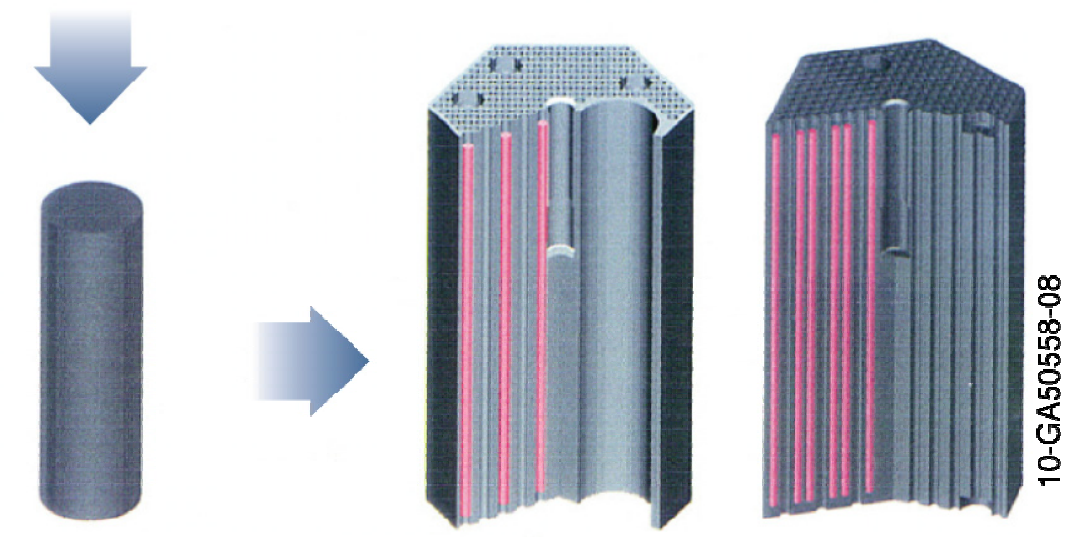

Fuel Compact

Fuel Assemblies

Figure 26. Prismatic-HTGR fuel-element components.

The fuel type selected by the U.S. prismatic HTGR Program is UCO, which is a mixture of uranium dioxide and uranium carbides ( $\mathrm{UC}$ and $\left.\mathrm{UC}_{2}\right)$. ${ }^{\mathrm{u}}$ The $\mathrm{UCO}$ kernel composition was selected primarily because of its ability to perform well at relatively high fuel burnup, which significantly improves the economics of prismatic HTGRs. The UCO kernel, which is actually a $\mathrm{UO}_{2}$ kernel to which $\mathrm{UC}_{2}$ and/or

u. UCO is also expected to be the fuel type for an NGNP prismatic reactor and was the fuel type selected for development and qualification by the NGNP/AGR Fuel Program, as discussed in Section 5.2. 
UC has been added, is an example of a gettered $\mathrm{UO}_{2}$ kernel, in which a material has been added to the kernel to reduce the oxygen potential of the kernel. The carbide component of the kernel undergoes oxidation to getter excess oxygen released during fission. If the carbide component were not present, excess oxygen would react with carbon in the buffer to form carbon monoxide. High levels of carbon monoxide can lead to failure of the coating system by over pressurization or by kernel migration. At full NGNP burnup, the UCO kernel contains sufficient $\mathrm{UC}_{2}$ and/or $\mathrm{UC}$ to maintain its thermodynamic buffer function.

In an $\mathrm{UC}_{\mathrm{x}} \mathrm{O}_{\mathrm{y}}$ kernel, the oxygen potential depends on the kernel stoichiometry parameter $\mathrm{x}$, the temperature, and the mix of fission products. The parameter $\mathrm{x}$ is currently specified at $0.5 \pm 0.2$ to provide sufficient carbon to getter the excess oxygen while also sufficiently limiting the carbide content to prevent lanthanides from escaping the kernel and chemically attacking the $\mathrm{SiC}$ layer.

The fuel particles are bonded together in a carbonaceous matrix to form cylindrical compacts that are approximately $12.5 \mathrm{~mm}$ in diameter and up to about $50-\mathrm{mm}$ long. These compacts are loaded into hexagonal-shaped graphite. The graphite blocks have a pattern of blind fuel holes and coolant holes through which helium coolant flows. The fuel compacts are stacked in the blind fuel holes of the graphite fuel blocks. Graphite plugs are cemented into the tops of the fuel holes to enclose the stacked compacts.

Because of sorption mechanisms, the fuel-compact matrix provides an additional barrier to the release of metallic fission products. The graphite blocks are fabricated from high-purity, nuclear-grade graphite. Each block is a right hexagonal prism 793- $\mathrm{mm}$ (31.2 in.) long and 360-mm (14.2 in.) across the flats of the hexagonal cross section. Fuel and coolant holes run parallel through the length of the block in a regular triangular pattern of nominally two fuel holes per coolant hole. The pitch of the coolant and fuel-hole array is $18.8 \mathrm{~mm}(0.74 \mathrm{in}$.). The minimum web thickness between a coolant hole and fuel hole is $4.5 \mathrm{~mm}$ (0.18 in.). This web provides an additional barrier to release of metallic fission products. A standard fuel element has 210 blind fuel holes and 108 coolant holes, and contains 6,252 fuel compacts (of approximately $25-\mathrm{mm}$ length). In addition to standard fuel elements, the active core contains fuel elements having large diameter channels to allow for insertion of control rods (102-mm-diameter channels) or reserve shutdown material (920-mm-diameter channel). A control/RSM element has 186 blind fuel holes, 95 coolant holes, and contains 5,532 fuel compacts (of approximately 25-mm length).

\subsubsection{Fuel Service Conditions}

Fuel service conditions under normal operation and accident conditions are described in this section.

\subsubsection{Normal Operation}

Table 14 summarizes the anticipated maximum service conditions, including accidents, for prismatic HTGR-based fuel where it is assumed that a single UCO fuel particle system is used with a 425 - $\mu \mathrm{m}$-diameter kernel of $14 \%$ enrichment. These values are intended to be design guidelines

Table 14. Anticipated maximum service conditions for prismatic HTGR fuel for the NGNP.

\begin{tabular}{|l|c|}
\hline \multicolumn{1}{|c|}{ Parameter } & Maximum Value \\
\hline Maximum fuel temperature - normal operation, ${ }^{\circ} \mathrm{C}$ & 1,400 \\
\hline Maximum time averaged fuel temperature, ${ }^{\circ} \mathrm{C}$ & 1,250 \\
\hline Fuel temperature (accident conditions), ${ }^{\circ} \mathrm{C}$ & 1,600 \\
\hline Fuel burnup, $\%$ FIMA & $17^{\text {a }}$ \\
\hline Fast fluence, $10^{25} \mathrm{n} / \mathrm{m}^{2}(\mathrm{E}>0.18 \mathrm{MeV})$ & 5 \\
\hline a. $\quad$ Estimated value for $14 \%$ enriched $425-\mu \mathrm{m}$ reference fuel particle. \\
\hline
\end{tabular}




\subsubsection{Accident Conditions}

In terms of safety consequences, the bounding accidents for the NGNP are a loss of flow leading to a high-pressure conduction cooldown (HPCC) and loss of coolant leading to a low-pressure conduction cooldown (LPCC). The HPCC event is typically initiated by trip of the helium circulator. Because the system remains at high pressure, the decay heat is more uniformly distributed within the core and vessel than during an LPCC event. The LPCC event is typically initiated by a small primary coolant leak, causing the system to depressurize to atmospheric pressure. The reactor protection system automatically initiates a reactor trip on low coolant pressure. For both events, it is assumed that the shutdown cooling system fails to start and that decay heat is removed by thermal radiation and natural convection from the reactor vessel to the reactor cavity cooling system (RCCS) as illustrated in Figure 27.

Heat Removed by:

- Core Conduction

- Core Internal Radiation

- Vessel Radiation

- RCCS Convection

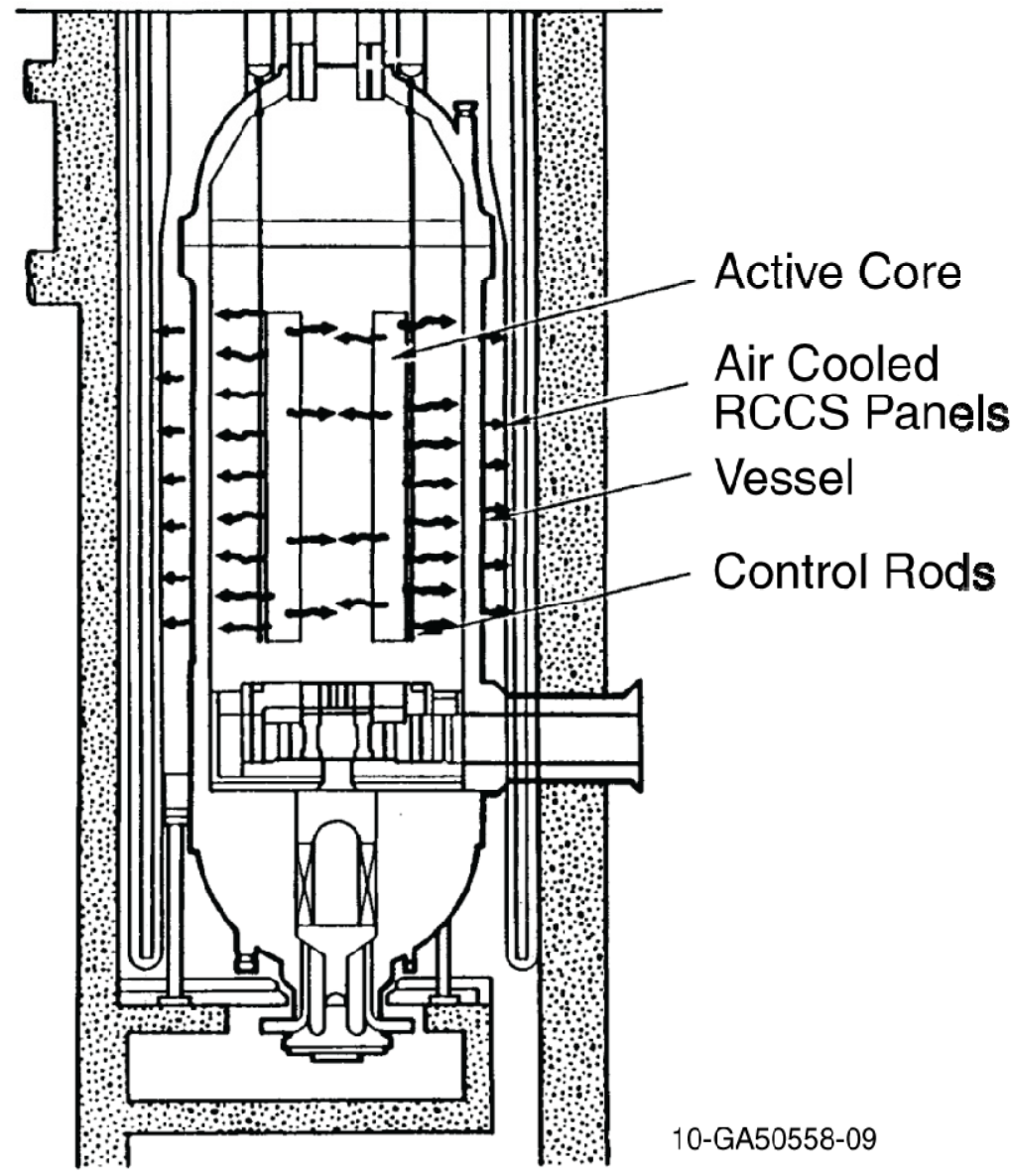

Figure 27. Passive heat removal to the RCCS during HPCC and LPCC events.

Chemical attack on fuel particles and on the graphite core structure can result from air or water ingress into the primary system. Steps have been taken to prevent ingress of contaminants, and consequences are expected to be acceptable if they occur. Exposure to moisture does not affect fuel particles, except for the very small fraction with defective coatings. Fission-product release from defective particles would increase, but fission products would be adequately contained. The likelihood of a breach of the primary coolant boundary such that air ingress becomes a concern is limited by the high integrity associated with pressure vessels and the limited size of penetrations. Also, any air that enters the primary coolant must react with graphite elements and fuel compact matrices before it can reach and chemically react with the embedded refractory-coated fuel particles. 


\subsubsection{Fuel Performance Requirements}

The radionuclide containment system for a prismatic HTGR is comprised of multiple barriers to limit radionuclide release from the core to the environment to insignificant levels during normal operation and a spectrum of postulated accidents. The five principal release barriers are (1) the fuel kernel, (2) particle coatings, particularly the SiC coating, (3) fuel-element structural graphite, (4) primary coolant pressure boundary, and (5) the reactor building. Of these barriers, the particle coatings are the most important. Moreover, the in-reactor performance characteristics of the coated-particle fuel are influenced by its asmanufactured attributes. Consequently, the fuel-performance requirements and fuel-quality requirements must be systematically defined and controlled.

The logic for deriving these fuel requirements is illustrated in Figure 28. Top-level requirements for the NGNP will be defined by both the regulators and the end user. Lower-level requirements will then be systematically derived using a top-down functional analysis method. With this approach, the radionuclide control requirements for each of the release barriers can be defined. For example, starting with the allowable doses at the site boundary, limits on curie releases from the reactor building, reactor vessel, and reactor core will be successively derived. Fuel-failure criteria will, in turn, be derived from the allowable core radionuclide release limits. Finally, the required as-manufactured fuel attributes will be derived from the in-reactor fuel-failure criteria, providing a logical basis for the fuel-quality specifications.

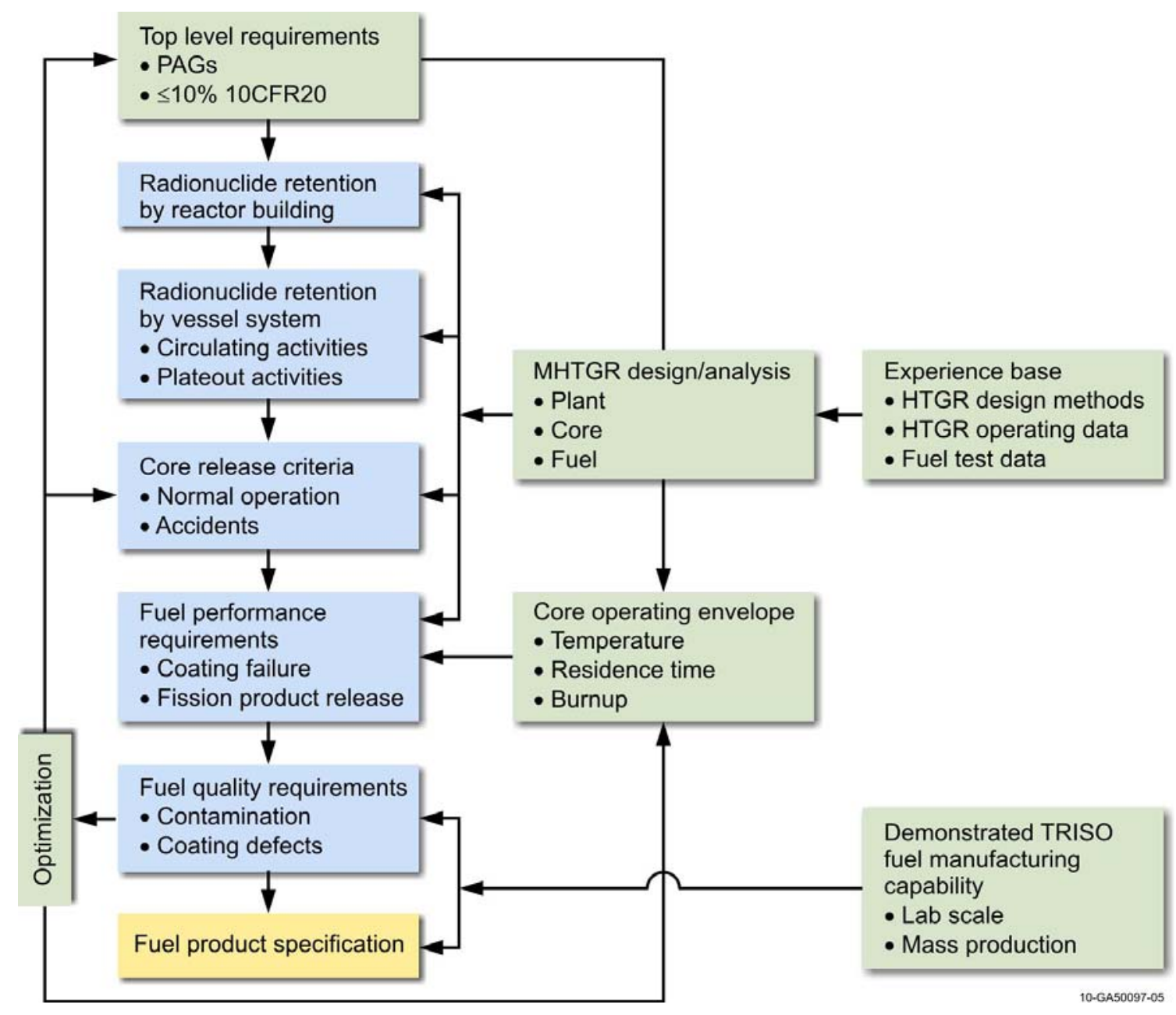

Figure 28. Logic for deriving fuel requirements. 
The process illustrated in Figure 28 was used to develop preliminary as-manufactured fuel quality and fuel performance requirements for a prismatic, steam-cycle HTGR operating with a reactor outlet helium temperature of $750^{\circ} \mathrm{C},{ }^{50}$ based on the top-level radionuclide control requirements for the NGNP as defined in NGNP SRM. ${ }^{51}$ The most constraining top-level requirements are listed in Table 15.

Table 15. Key top-level radionuclide control requirements.

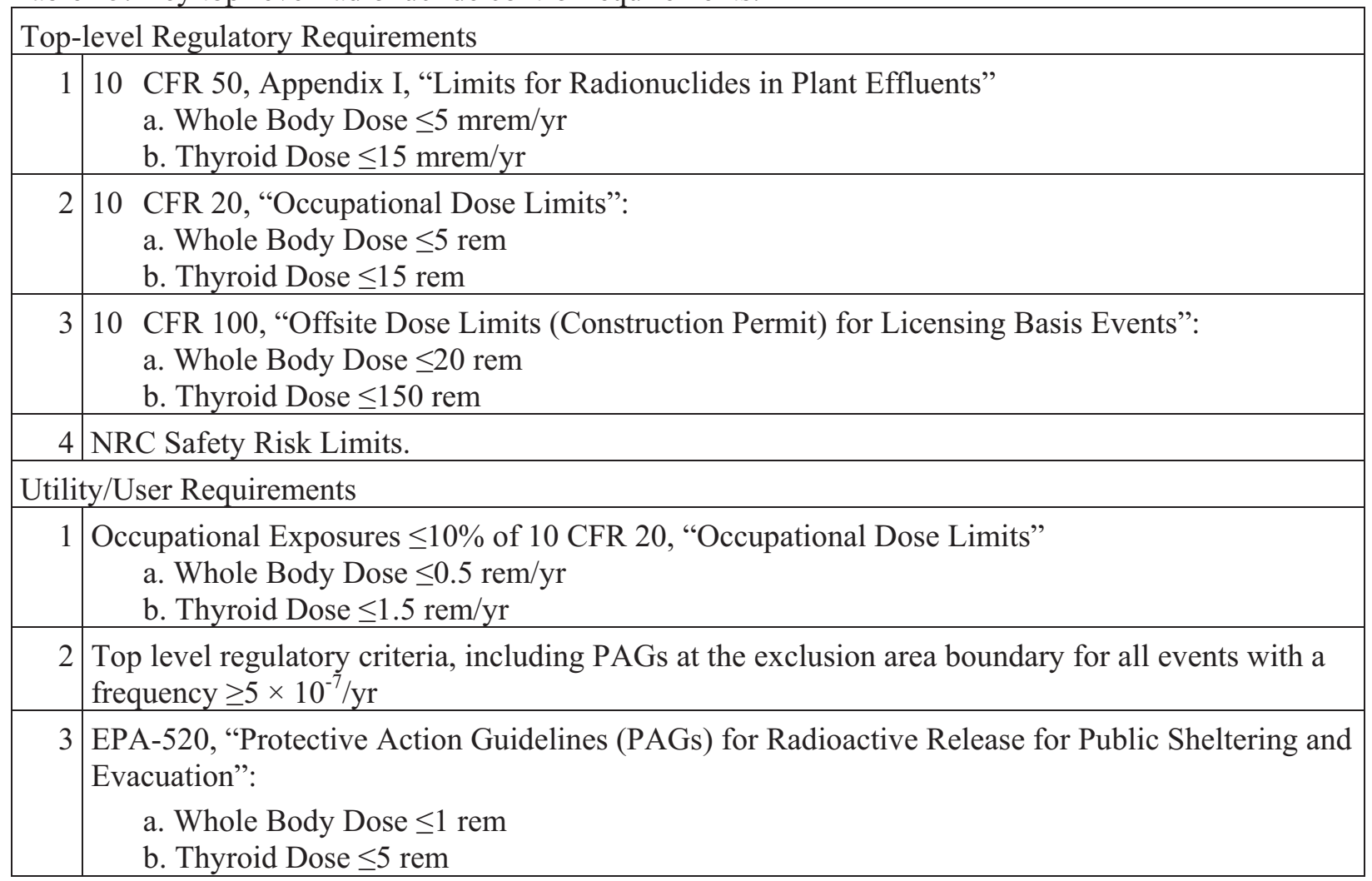

Meeting the Environmental Protection Agency (EPA) Protective Action Guidelines (PAG) limits at a 425-m exclusion-area boundary is considered the most restrictive requirement for setting fuel performance and quality requirements for a steam-cycle HTGR. In the 1992 version of the PAGs, the Total Effective Dose Equivalent (TEDE) dose protocol ${ }^{\mathrm{V}}$ was used instead of the earlier whole-body dose protocol. The 1992 PAG also includes a 5-rem thyroid dose limit to preclude the need for public sheltering, which is more constraining than the 1-rem TEDE limit.

The second-most constraining, top-level radionuclide $(\mathrm{RN})$ control requirement is to limit the occupational exposure to $\leq 10 \%$ of the 10 CFR 20 goal. Typically, occupational exposures result primarily from operations and maintenance (O\&M) activities, especially in-service inspection (ISI) during normal plant operation. Plateout activity throughout the primary coolant circuit, especially on the steam generator of a steam-cycle HTGR, is expected to be a dominant source of occupational exposure. A detailed occupational exposure assessment has not yet been performed for a steam-cycle HTGR. Hence, in deriving limits on plateout activity consistent with the subject goal, it was necessary to rely heavily upon previous occupational exposure assessments and engineering judgment. On that basis, it was projected that the $\leq 10 \%$ of 10 CFR 20 goal would be met if the gamma radiation fields around the primary circuit caused by fission-product plateout were limited to $\leq 10 \mathrm{mR} / \mathrm{hr}$ for scheduled maintenance activities (e.g., circulator ISI) and to $\leq 100 \mathrm{mR} / \mathrm{hr}$ for unscheduled maintenance activities (e.g., steam-generator tube

v. The TEDE dose is the sum of the deep-dose equivalent for external exposures and the committed effective dose equivalent (CEDE) for internal exposures. 
plugging). These limits on gamma dose rates were in turn used to set limits on primary circuit plateout (in particular, limits on ${ }^{137} \mathrm{Cs}$ and ${ }^{110 \mathrm{~m}} \mathrm{Ag}$ plateout).

The preliminary as-manufactured fuel quality requirements and in-service performance requirements for prismatic HTGR fuel for the $\mathrm{NGNP}^{50}$ are given in Table 16. The requirements for in-service performance are specified on a core-average basis. The allowable release fractions for ${ }^{137} \mathrm{Cs}$ and ${ }^{110 \mathrm{~m}} \mathrm{Ag}$ are included because these nuclides are expected to be the strongest contributors to worker dose. The requirements for as-manufactured fuel quality and in-service fuel performance in Table 16 are based on a two-tier set of radionuclide design criteria (allowable core release rates), referred to as the "Design" and "Maximum Expected" criteria. The "Design" criteria represent upper limits for all normal operating conditions and any off-normal events expected to occur during plant operation. These criteria are used when assessing the impact of plant operation on public safety, to size helium purification and radwaste systems, and to design plant hardware and shielding. The "Design" criteria account for uncertainties in the design methods and supporting data, and represent a design margin over the "Maximum Expected" criteria, which are used for applications where "best-estimate" results are appropriate, including developing component-removal and maintenance procedures. The fuel and reactor core are to be designed such that there is at least a 50\% probability that the radionuclide releases will be less than the "Maximum Expected" criteria, and at least a 95\% probability that the releases will be less than the "Design" criteria.

At this early stage of NGNP design development, the fuel quality and fuel performance requirements in Table 16 are preliminary values; however, they are considered sufficient to provide the necessary guidance to the NGNP/AGR Fuel Program. Eventually, after the reactor core and plant designs have been more fully developed and more experience has been gained with manufacturing and testing of the fuel, these requirements will be finalized.

Table 16. Preliminary prismatic HTGR fuel performance requirements.

\begin{tabular}{|l|c|c|}
\hline \multicolumn{2}{|c|}{ Parameter } & NGNP - 750 ${ }^{\circ}$ C Core Outlet Temperature \\
\cline { 2 - 3 } & Maximum Expected & Design \\
\hline As-Manufactured Fuel Quality: & $\leq 1.0 \times 10^{-5}$ & $\leq 2.0 \times 10^{-5}$ \\
\hline HM contamination & $\leq 1.0 \times 10^{-5}$ & $\leq 2.0 \times 10^{-5}$ \\
\hline Missing or defective buffer & $\leq 4.0 \times 10^{-5}$ & $\leq 1.0 \times 10^{-4}$ \\
\hline Missing or defective IPyC & $\leq 5.0 \times 10^{-5}$ & $\leq 1.0 \times 10^{-4}$ \\
\hline Defective SiC & 0.01 & 0.02 \\
\hline Missing or defective OPyC & $\leq 5.0 \times 10^{-5}$ & $\leq 2.0 \times 10^{-4}$ \\
\hline In-Service Fuel Failure: & $\leq 1.5 \times 10^{-4}$ & $\leq 6.0 \times 10^{-4}$ \\
\hline Normal operation & \multicolumn{2}{|c|}{} \\
\hline Core heat-up accidents & $\leq 7.0 \times 10^{-6}$ & $\leq 7.0 \times 10^{-5}$ \\
\hline Core Release Limits for Metals: & $\leq 2.0 \times 10^{-4}$ & $\leq 2.0 \times 10^{-3}$ \\
\hline${ }^{137}$ Cs fractional release &
\end{tabular}




\section{FUEL QUALIFICATION PROGRAM}

This section addresses the qualification of the fuel for the pebble-bed and prismatic-fuel-based NGNP designs. The scope includes a summary discussion of the planned fabrication and quality control of the fuel and the irradiation and testing required to qualify the as-fabricated fuel. The pebble fuel qualification approach is to include German irradiation and testing data from fuel with equivalent properties to the NGNP pebble-bed fuel design, augmented by additional data produced for the NGNP pebble fuel in the program discussed in Section 5.2. The prismatic fuel qualification approach is to produce all required data from the program discussed in Section 5.3. Section 5.1 addresses considerations common to both designs, Section 5.2 addresses the pebble-bed design, and Section 5.3 addresses the prismatic fuel based NGNP.

\subsection{Common Considerations}

Qualification of the fuel requires fabrication in compliance with a comprehensive product specification to produce fuel meeting required performance under normal operation and accident conditions. Common elements of a qualification program include:

- Establishment of a fuel-product specification

- Implementation of a fuel-fabrication process capable of meeting the specification

- Implementation of statistical quality assurance procedures to demonstrate that the specification has been met

- Irradiation of statistically sufficient quantities of fuel with monitoring of in-pile performance and PIE to demonstrate that normal operation performance requirements are met

- Safety testing of statistically sufficient quantities of irradiated fuel to demonstrate that accident condition performance requirements are met.

In addition to demonstration of the performance capability of the fuel, data from the fuel and from the qualification programs are used to develop models to predict fuel performance in the reactor.

As discussed in Section 3, the coated-particle characteristics and fabrication processes are very similar in the pebble-bed and prismatic-fuel-based NGNP designs. The substantive differences are in the kernel ( $\mathrm{UO}_{2} / \mathrm{UCO}$, diameter, and enrichment). The coating processes and properties of the prismatic design were developed to substantially replicate the German fuel-coating properties. Thus, while the German high-quality LEU TRISO fuel fabrication, irradiation, and testing experience discussed in Section 3.2 is directly supportive of the pebble-bed design, it is also substantially supportive of the prismatic design. The irradiation, PIE, and safety testing programs are thus similar and directed toward confirming expected performance within their respective operating envelopes (addressed in Sections 4.2.2 and 4.3.2). Both prismatic and pebble design approaches have empirical and analytical elements; one has more of the former and one has more of the latter. The pebble-bed will take a more empirical approach to use of the resulting data, further developing a conservative projection of failure fraction as a function of fuel temperature in normal operation and accident conditions. The prismatic approach will be to validate codes for prediction of failure fractions as a function of fuel operating conditions.

As discussed in Sections 5.2 and 5.3, planned accident-condition testing is focused on conservatively enveloping the time-temperature projections for DLOFC events. As discussed in Section 3.1.1, testing in Japan and Russia has shown particle failures resulting from large pulse and adiabatic ramp overpower tests. However, beyond design basis analyses for the MHTGR ${ }^{52}$ and recent benchmark analyses of a PBMR design ${ }^{53}$ have shown that non-mechanistic bounding reactivity-insertion events result in short-term maximum fuel temperatures far below values that produced particle failures in Japanese and Russian testing. Thus, the time-temperature history of the DLOFC testing is considered more challenging for the fuel than conditions produced by reactivity-insertion events. 
The fuel irradiation and testing plans for the pebble and prismatic fuel ${ }^{29}$ designs were originally developed based on use of a direct cycle gas-turbine power conversion system. Current design options in both cases include steam generation for process heat and/or electricity generation, possibly with a steam generator in the primary loop. This option would substantially increase the likelihood and magnitude of steam/water ingress events, and it is expected that the next revision of the planning will include testing to address steam/water ingress events. The possibility of fuel testing to address air ingress events will also be revisited in the next revision to the plan.

\subsection{Pebble Fuel}

The pebble-bed program in South Africa has been substantially altered during the production of this paper and may undergo additional changes. The material presented here does not reflect these recent changes and can be expected to be significantly revised in the course of discussions with the NRC staff. The approach to pebble-fuel qualification is to ensure that the manufacturing process is at least equivalent to that used for manufacture of German LEU $\mathrm{UO}_{2}$ TRISO fuel. However, some additional fuel performance data will be gathered to confirm satisfactory performance of spherical fuel and will add to the database for application to the pebble-bed fuel-service conditions. Therefore, additional irradiation and post-irradiation testing and examination will be performed on manufactured spherical $\mathrm{UO}_{2}$ fuel. This section summarizes the plans for pebble-bed fuel fabrication, as well as the irradiation and safety testing program, PIEs, and plant start-up surveillance.

The NGNP pebble-bed fuel design is based on the German LEU UO $\mathrm{UR}_{2}$ TRISO design for which an extensive experience base exists, as discussed in Section 3.2. This experience base consists of mechanical, irradiation, and post-irradiation heating tests performed on fuel produced in Germany from 1981 to 1988. The German fuel-development program culminated in state-of-the-art fuel manufactured in 1985 for bulk testing in the AVR (AVR 21-2 reload) and in 1988 for the HTR-Modul Proof Tests. As the pebble-bed design uses both the German Proof Test spherical fuel design and a manufacturing process that is at least equivalent to that for German fuel, it is not necessary to repeat all the irradiation tests from which the operating envelope for the German $\mathrm{LEU} \mathrm{UO}_{2}$ TRISO fuel was derived. However, expanding the existing database is planned. With successful completion of the spherical-fuel qualification program discussed in Section 5.2.2 the additional data will:

- Demonstrate successful replication of the German fuel design and manufacturing in both the Fuel Development Laboratory (FDL) and PBMR Fuel Plant (PFP)

- Cover the full range of the pebble-bed design and operating conditions

- Strengthen the statistical confidence of the performance base for pebble-bed fuel

- Reaffirm expected in-reactor performance under conditions that envelope the pebble-bed operating conditions

- In combination with the German data, demonstrate that the NGNP pebble-bed fuel meets applicable NRC requirements, policy statements and guidance.

A comparison of the NGNP pebble-bed-fuel operating envelope to the German LEU $\mathrm{UO}_{2}$ TRISO irradiation and heating test experience was presented in Section 3.2.2.

\subsubsection{Fuel Fabrication and Quality Assurance}

The following sections summarize the fabrication steps, control of process parameters, and monitoring of product properties to ensure that the fuel will meet the required as-manufactured specifications and in-service performance. 


\subsubsection{Fabrication and Process Control}

The properties of LEU TRISO fuel particles are among the most important factors determining the radiological safety of the HTGR. This is because fission-product retention in fuel spheres and the fuel burnups and temperatures that can be tolerated in the reactor core are primarily determined by the properties of the coated particle. The fabrication and process control methods used for the NGNP pebble-bed fuel will be the same as those used for production of the German Proof Test Fuel as summarized in Section 3.2.1.2.

\subsubsection{Manufacturing Quality Assurance}

The PBMR Quality Assurance Plan (QAP) states the quality requirements for all aspects of the design, manufacture, and testing of pebble-bed fuel. The PFP will be designed, built, and commissioned in accordance with the quality standard ISO $9001 .^{54}$ Fuel manufacture will comply with the requirements of ASME NQA-1. ${ }^{55}$

The fuel-production QAP will specify quality assurance (QA) requirements for each of the components of the overall program, such as the manufacture and delivery of nuclear fuel products by the PFP and any relevant subcontractors. Each component of the overall program will establish appropriate control arrangements to ensure that the quality requirements are fully implemented. A specific fuel-production line quality management program will be established to ensure adherence to the QA requirements for fuel manufacture and materials procurement.

The fuel qualification program will satisfy the intent of 10 CFR 50, Appendix B, with respect to the conduct of testing, acquisition, and documentation of data through the use of ASME NQA-1 or equivalent, where appropriate.

In the course of the COLA review, a description of the PBMR QAP will be submitted to show that the program meets the requirements of 10 CFR 50, Appendix B.

Within the following subsections, the parameters important to the manufacture of quality fuel are highlighted, along with the importance of the selected parameters. Characterization of many of these parameters involves destructive methods performed on samples of product materials. The statistical methods applied to ensure that the product meets specifications at the required confidence levels are discussed in Appendix B-1.

\section{Kernels}

The following kernel characteristics will be monitored:

- Kernel diameter. The diameter distribution of kernel lots will be measured, and upper and lower tolerance limits will be applied. The kernel diameter is an important factor in determining the heat-generation rate and the ultimate size of the coated particle.

- Kernel density. The mean density of each kernel lot will be determined to ensure that the minimum density is achieved. The physical properties of the $\mathrm{UO}_{2}$ kernels depend upon this characteristic being at least $95 \%$ of the theoretical value.

- Stoichiometry. The stoichiometry of each kernel lot will be determined, helping to ensure that the physical properties of $\mathrm{UO}_{2}$ are obtained.

- Sphericity. The sphericity distribution $\left(\mathrm{d}_{\max } / \mathrm{d}_{\min }\right)$ of each kernel lot will be determined, and an upper tolerance limit applied. Out-of-roundness is magnified through further processing to manufacture coated particles, and the limit reduces the risk of damage during fuel-sphere pressing.

- Impurities. The impurities in each lot of kernels will be analyzed to ensure that the equivalent boron content is below a defined limit. 


\section{Coated Particles}

The following coated-particle characteristics will be monitored:

- Buffer layer thickness. The buffer layer thickness will be determined, and upper and lower tolerance limits will be applied. The buffer layer thickness, together with its density, determines the volume available to accommodate gases within the coated particle and, thus, to control internal pressure.

- IPyC and OPyC layer thicknesses. The thicknesses of the IPyC and OPyC layers will be determined and upper and lower tolerance limits will be applied. These layers support the SiC layer, as described above, and their thicknesses determine their strength.

- $\mathrm{SiC}$ layer thickness. The thickness of the $\mathrm{SiC}$ layer will be determined, and upper and lower tolerance limits will be applied. The strength of the $\mathrm{SiC}$ layer, which is the main pressure-containing component of the coated particle, is determined to a large extent by its thickness.

- Buffer layer density. The density of the buffer layer will be determined, and a maximum limit will be applied. The density is a factor in determining the volume available to accommodate gases, as described above.

- IPyC and OPyC layer densities. The densities of the IPyC and OPyC layers will be determined, and upper and lower limits will be applied. The density of these layers determines their strength and their ability to retain fission gases.

- $\quad \mathrm{SiC}$ layer density. The density of the $\mathrm{SiC}$ layer will be determined, and a minimum limit will be applied. The density is an important factor in determining the strength of the $\mathrm{SiC}$ layer.

- Optical anisotropy. The optical anisotropy factors of the IPyC and OPyC layers will be determined, and a maximum limit will be applied. The irradiation behavior of these layers is affected by excessive anisotropy.

\section{Fuel Spheres}

The following fuel-sphere characteristics will be monitored; some characteristics will be determined on fuel-free graphite spheres made from the same lot of material as the fuel spheres and processed together with them:

- Fuel-sphere carbon content. A minimum statistical limit will be applied to the carbon mass per fuel sphere to ensure that a minimum amount of neutron moderation is present. This will also confirm that the matrix graphite density exceeds a minimum value, as applied during acceptance testing of the matrix constituent materials.

- Matrix-graphite thermal conductivity at elevated temperature. This will be measured on samples cut from graphite spheres to ensure that design input values for heat transfer within the fuel sphere are met.

- Matrix-graphite abrasion rate. This determination will be made on sample graphite spheres by means of a standardized test in a rotating drum. A maximum limit ensures that the wear rate of spheres is limited.

- Matrix-graphite corrosion rate at elevated temperature. This determination will be made on sample graphite spheres by means of a standardized test in helium that contains moisture. A maximum limit ensures consistent quality regarding resistance to oxidation during potential moisture ingress incidents.

- Matrix-graphite coefficient of thermal expansion. This will be measured between set temperatures on samples cut from graphite spheres and will be used to calculate anisotropy between with-grain and against-grain directions. A maximum anisotropy limit ensures that spheres will not undergo excessive distortion during irradiation. 
- Impurities. The impurities in the matrix graphite of each lot, or group of lots, of spheres will be analyzed to ensure that the equivalent boron content $(\mathrm{EBC})$ is below a defined limit. The EBC limit ensures that the core reactivity is not suppressed by excessive neutron absorption in impurities, which would reduce fuel burnup.

- Uncontained uranium. Uncontained uranium (i.e., uranium not contained by intact SiC layers) will be determined by means of burn-leach testing of sample fuel spheres. A maximum limit ensures that the fission-product release from fuel spheres is within the design value.

- Impact Strength. The impact strength of fuel spheres will be determined by means of a standardized drop test from a height of $4 \mathrm{~m}$ onto a bed of graphite spheres. A minimum number of 50 drops without breaking ensures that spheres are able to withstand loads in the fuel-handling system and during transport.

- Crushing strength. The crushing strength of fuel spheres between flat steel plates will be measured, and a minimum limit will be applied. This also ensures that spheres are able to withstand loads in the reactor and during transport.

- Diameter. The diameter of each fuel sphere will be gauged to ensure that handling and other system requirements are met.

- Fuel-free shell thickness. Each fuel sphere will be radiographed to ensure that the minimum fuel-free shell thickness is present and to check for coated particles in the fuel-free shell.

\subsubsection{Irradiation, PIE, and Safety Testing}

While the German LEU $\mathrm{UO}_{2}$ TRISO fuel irradiation and safety testing database provides a firm basis for projecting performance of pebble-bed fuel, some areas will be subject to further work to support operation of the pebble-bed design:

- Data will be generated to ensure that the pebble-bed fuel manufacturing quality is at least equivalent to that of the German fuel and that its performance is consistent with the performance of the German fuel.

- The existing data at 1,600 and $1,700^{\circ} \mathrm{C}$ suggest that the transient temperature profile could be more limiting than the isothermal test. The statistics are limited and analytical models and a general understanding of the relevant phenomena indicate that the isothermal test should be more challenging to the fuel. This area may be addressed analytically or by conducting additional transient simulation tests.

- The existing data at $1,700^{\circ} \mathrm{C}$ are sparse and not consistent with the expected exponential dependence of particle failure on temperature, relative to the 1,600 and $1,800^{\circ} \mathrm{C}$ data. Additional data will be needed to provide sufficient confidence in the fuel performance at $1,700^{\circ} \mathrm{C}$.

- The existing data at $1,800^{\circ} \mathrm{C}$ are dominated by the results of tests conducted in the "A"-test furnace that may have experienced temperatures significantly above the recorded temperature because of fouling of the pyrometer window. Additional data will provide greater confidence regarding the actual failure fraction at this temperature, even though this is well beyond the anticipated transient and accident envelope.

Irradiation and testing of "prequalification" fuel fabricated in a full-sized coater within the FDL using process control parameters expected to be used in production coaters will be conducted on full-sized fuel spheres in both the HFR reactor in the Netherlands and the IVV-2M reactor in Russia, and on particles formed into compacts in the ATR reactor at Idaho National Laboratory (INL). The results of these tests will provide early indication of successful replication of the German fuel with comparable performance. Subsequent irradiation and testing will be conducted in the IVV-2M reactor on equilibrium fuel spheres from the PFP, which will produce fuel for the startup and continued operation of the pebble-bed reactor. 
The data produced will include pre-irradiation characterization, in-pile gas release, and PIE and safety testing data. Production fuel irradiation and testing will be conducted in two phases ${ }^{\mathrm{w}}$ :

- Partial Burnup - This test will consist of a single irradiation rig containing four spheres and taken to a burnup of approximately $\{5 \%\}^{\mathrm{x}}$ FIMA. The resulting data will be used to support startup and initial operation of the pebble-bed design. ${ }^{\mathrm{w}}$

- Full Burnup - These tests will consist of three irradiation rigs in the IVV-2M reactor, each containing four spheres. The irradiations will be conducted to levels of fast fluence and burnup that exceed the maximum values achievable during pebble-bed design reactor operation. Samples of the matrix graphite used in fuel sphere manufacturing will also be tested in the IVV-2M reactor to confirm the irradiated properties of the pebble-bed A3-3 matrix graphite.

The data produced by the successful completion of the MTR irradiation and testing of pebble-bed fuel, in combination with the existing data on German LEU UO $\mathrm{U}_{2}$ TRISO fuel, will demonstrate that PFP-produced fuel spheres meet all coated-particle-failure and fission-product-release requirements under normal operation, anticipated operational occurrences, and design basis accident (DBA) conditions of the pebble-bed design.

Additional confirmatory data under actual service conditions may be provided by a post-irradiation test and inspection program to be conducted on fuel discharged from the pebble-bed design. This program will be continued until the target burnup for the first equilibrium fuel load is reached.

The pebble-bed fuel irradiation and testing program can be considered to be an evolving program in that it will be revised to address new requirements, revised analyses, or new understandings of fuel performance based on early results and as new knowledge is gained. Values provided in the following subsections are nominal or best-estimate and may be revised as the particular test is specified in more detail prior to its initiation. A summary of the planned irradiation and testing for pebble-bed fuel is provided in Table 17 (test reactors listed are described below).

\subsubsection{Materials Test Reactors}

The pebble-bed fuel irradiation and testing program will be conducted in the following facilities:

- $\quad I V V-2 M$. The test reactor planned to be used for the pebble-bed fuel qualification program is the IVV-2M reactor located at Zarechny in the Russian Federation. ${ }^{56}$ The IVV-2M reactor consists of a water-moderated reactor core with a nominal power output of $15 \mathrm{MWth}$, surrounded by a beryllium reflector. The reactor is operated in 300-hour cycles, with shutdowns of approximately 2 days between cycles, and is shut down twice yearly for refueling. Fuel sphere irradiation tests (each sphere in its own capsule) are performed in irradiation rigs that can accommodate four full-sized fuel spheres ${ }^{\mathrm{y}}$ per rig.

- HFR. Irradiation of preliminary, nonqualification fuel spheres manufactured by FDL will also be conducted in the HFR reactor located at Petten in the Netherlands. ${ }^{57}$ The HFR consists of a water-moderated reactor core with a nominal power of 45 MWth, surrounded by a beryllium reflector. The reactor is operated on a nominal annual schedule consisting of 10 to $11 \sim 28$-day cycles with two shutdowns of several weeks for maintenance and related activities. Fuel-sphere irradiation

w. The planning for the RSA Demonstration Plant had a schedule overlap in which the licensing criteria allowed fuel qualification and plant startup to proceed simultaneously as long as the qualification results were always ahead of the actual in-core usage. The extraction and testing of partial burnup spheres may not be performed in conjunction with the NGNP project, with additional full burnup spheres used to enhance the statistical basis for fuel qualification.

x. Numbers presented in script parentheses \{\} indicate that these are preliminary values which are subject to confirmation or change as the program matures.

y. Capsules are independently controlled and monitored containers for fuel samples. 
tests are performed in irradiation rigs with multiple independent capsules and up to a total of five full-sized fuel spheres.

- ATR. Prequalification FDL-produced fuel particles fabricated into compacts will be irradiated in the ATR reactor located at INL in the U.S. The ATR reactor consists of a water-moderated core surrounded by a beryllium reflector. The ATR maintains an availability of nearly $80 \%$, with reactor cycles on approximately 8 -week intervals. ${ }^{58}$ Fuel compact and sphere irradiations can be conducted in irradiation rigs with multiple independent capsules.

Table 17. Summary of pebble-bed fuel irradiation tests.

\begin{tabular}{|c|c|c|c|c|c|c|c|c|c|}
\hline \multirow[b]{2}{*}{ Test } & \multicolumn{2}{|c|}{ Fuel to be Tested } & \multicolumn{6}{|c|}{ Test Description } & \multirow[b]{2}{*}{$\begin{array}{l}\text { Technical } \\
\text { Objective }\end{array}$} \\
\hline & $\begin{array}{l}\text { Production } \\
\text { Source }\end{array}$ & No. & $\begin{array}{c}\text { Test } \\
\text { Reactor }\end{array}$ & $\begin{array}{l}\text { Burnup } \\
(\% \\
\text { FIMA })\end{array}$ & $\begin{array}{c}\text { Temperature } \\
\left({ }^{\circ} \mathrm{C}\right)\end{array}$ & Cycle & $\begin{array}{l}\text { Post } \\
\text { Heat }\end{array}$ & PIE & \\
\hline AGR-2 & FDL & $\begin{array}{l}\text { Particles in } \\
\text { Compacts }\end{array}$ & ATR & $>10$ & 1,150 & No & No & $\mathrm{Y}$ & $\begin{array}{l}\text { Performance } \\
\text { demonstration of } \\
\text { irradiated } \\
\text { particles }\end{array}$ \\
\hline $\begin{array}{l}\text { Pre-qualification } \\
\text { fuel testing }\end{array}$ & FDL & 5 spheres & HFR & $10.1 \pm 1$ & $\begin{array}{l}1,200 / \\
1,100\end{array}$ & No & No & $\mathrm{Y}$ & $\begin{array}{l}\text { Confirm the } \\
\text { capability of the } \\
\text { FDL fuel }\end{array}$ \\
\hline $\begin{array}{l}\text { Pre-qualification } \\
\text { fuel testing }\end{array}$ & FDL & 4 spheres & IVV-2M & $10.1 \pm 1$ & $\begin{array}{l}1,200 / \\
1,100\end{array}$ & No & No & $\mathrm{Y}$ & $\begin{array}{l}\text { Confirm the } \\
\text { capability of the } \\
\text { FDL fuel }\end{array}$ \\
\hline $\begin{array}{l}\text { Partial Burnup } \\
\text { Demonstration }\end{array}$ & $\begin{array}{l}\text { Pebble Fuel } \\
\text { Plant }\end{array}$ & 4 spheres & IVV-2M & $\{5\}$ & 1,200 & No & $\begin{array}{l}\text { Four fuel } \\
\text { spheres to } \\
1,600^{\circ} \mathrm{C} \text {, } \\
\text { then to } \\
1,800^{\circ} \mathrm{C}\end{array}$ & $\mathrm{Y}$ & $\begin{array}{l}\text { Qualification to } \\
\{5\} \% \text { FIMA. } \\
\text { Zero or low } \\
\text { number of } \\
\text { coated particle } \\
\text { failures. }\end{array}$ \\
\hline $\begin{array}{l}\text { Full Burnup } \\
\text { Demonstration }\end{array}$ & $\begin{array}{l}\text { Pebble Fuel } \\
\text { Plant }\end{array}$ & 12 spheres & IVV-2M & $\{\sim 9.8\}$ & $900 / 1,150$ & Yes & $\begin{array}{l}\text { Eleven fuel } \\
\text { spheres, } \\
\text { five to } \\
1,600^{\circ} \mathrm{C}, \\
\text { six to } \\
1,800^{\circ} \mathrm{C}\end{array}$ & $\mathrm{Y}$ & $\begin{array}{l}\text { Full fuel proof } \\
\text { test, including } \\
\text { simulated } \\
\text { PLOFC transient } \\
\text { in test reactor. } \\
\text { Detailed PIE. }\end{array}$ \\
\hline $\begin{array}{l}\text { Matrix Graphite } \\
\text { testing }\end{array}$ & $\begin{array}{l}\text { Pebble Fuel } \\
\text { Plant }\end{array}$ & $196^{z}$ & IVV-2M & - & $900 / 1,100$ & No & No & $\mathrm{Y}$ & \begin{tabular}{|l|} 
Confirm matrix \\
graphite \\
irradiated \\
properties
\end{tabular} \\
\hline
\end{tabular}

\subsubsection{Irradiation and Testing of Laboratory-Produced Fuel}

\section{Testing of Laboratory-Produced Fuel Particles}

PBMR (Pty) LTD-produced coated particles are included in the AGR-2 tests in the ATR at INL. The specification for the testing to be conducted by INL at the ATR within the AGR Program (AGR-2) is illustrated in Table 18. These tests will be preceded by leach-burn-leach tests on a sufficient number of compacted particles in order to assess the quality/unirradiated integrity of the coatings.

z. The number of samples to be irradiated is listed, which is more relevant than the number of spheres from which the samples are to be cut. 
Table 18. PBMR (Pty) LTD AGR-2 fuel compact irradiation test conditions.

\begin{tabular}{|l|l|}
\hline \multicolumn{1}{|c|}{ Parameter } & \multicolumn{1}{|c|}{ Specification } \\
\hline Instantaneous peak temperature for all PBMR compacts $\left({ }^{\circ} \mathrm{C}\right)$ & $\leq 1,400$ \\
\hline Time average, peak temperature for all PBMR compacts $\left({ }^{\circ} \mathrm{C}\right)$ & $\leq 1,150$ \\
\hline Time average, volume average temperature for all PBMR compacts $\left({ }^{\circ} \mathrm{C}\right)$ & $950-1,100$ \\
\hline Minimum compact average burnup (\% FIMA) & $>9$ \\
\hline Compact average burnup goal for majority of fuel compacts $(\% \mathrm{FIMA})$ & $>10$ \\
\hline Peak fast neutron fluence for each compact $\left(\mathrm{n} / \mathrm{m}^{2}, \mathrm{E}>0.18 \mathrm{MeV}\right)$ & $<5 \times 10^{25}$ \\
\hline Minimum peak fast neutron fluence for each compact $\left(\mathrm{n} / \mathrm{m}^{2}, \mathrm{E}>0.18 \mathrm{MeV}\right)$ & $>1.5 \times 10^{25}$ \\
\hline Instantaneous peak power per particle (mW/particle) & $\leq 400$ \\
\hline
\end{tabular}

\section{Testing of Laboratory-Produced Fuel Spheres}

A total of nine prequalification fuel spheres manufactured in the FDL will be irradiated to provide an early indication of the effectiveness of the pebble-fuel manufacturing process. Five spheres will be irradiated in the HFR at Petten in the Netherlands, and four will be irradiated in the IVV-2M reactor in the Russian Federation. The fuel spheres for these tests contain coated particles produced in a full-sized coater. The spheres were manufactured with $9 \mathrm{~g}$ of heavy metal enriched to $9.6 \%{ }^{235} \mathrm{U}$, giving a total of 14,400 particles per sphere. The results of these tests will be used to assess the performance of the full-scale pre-qualification coater as part of the manufacturing assurance program.

\section{Pre-irradiation Characterization}

Pre-irradiation characterization will be performed on fuel spheres and coated particles withdrawn from fuel spheres to determine their main characteristics and compare with the results to be obtained at the PIE stage. The scope will include:

- Non-destructive procedures for fuel spheres. All the delivered fuel spheres shall be subjected to the following non-destructive procedure: the mass of each fuel sphere shall be determined and recorded and the equatorial dimension of each fuel sphere shall be measured parallel and perpendicular to the pressing axis.

- Destructive procedures for fuel spheres. The content of uranium in the matrix graphite of deconsolidated spheres shall be determined.

- Destructive procedures for coated particles. A part of the outer OPyC layer of coated-particle coatings shall be removed mechanically and the free-uranium fraction for the OPyC layer shall be determined by neutron-activation analysis. Ceramography of coated particles shall also be performed.

\section{Irradiation}

Release of fission products shall be measured for each capsule throughout the irradiation test. Measured values shall be recorded in the form of R/B values. Irradiation test data (fast fluence, burn-up, temperatures of fuel spheres and $\mathrm{R} / \mathrm{B}$ values for fission-gas isotopes shall be reported. The irradiation requirements for the HFR and IVV-2M irradiation test are indicated in Table 19. 
Table 19. Irradiation requirements.

\begin{tabular}{|l|l|}
\hline \multicolumn{1}{|c|}{ Parameter } & \multicolumn{1}{c|}{ Value } \\
\hline $\begin{array}{l}\text { Fuel Temperatures: } \\
\text { two central fuel spheres } \\
\text { two other fuel spheres }\end{array}$ & $1,200 \pm 50^{\circ} \mathrm{C}$ \\
\hline Burn-up & $1100 \pm 50^{\circ} \mathrm{C}$ \\
\hline Fast Neutron Dose $(\mathrm{E}>0.1 \mathrm{MeV})$ & $10.1 \pm 1.0 \% \mathrm{FIMA}$ \\
\hline Maximum power per fuel sphere & at least $2.72 \times 10^{21} \mathrm{n} / \mathrm{cm}^{2}$ \\
\hline Irradiation time & $2.76 \mathrm{~kW}$ \\
\hline
\end{tabular}

$\mathrm{R} / \mathrm{B}$ values shall be measured for the following fission-gas isotopes during irradiation: ${ }^{88} \mathrm{Kr},{ }^{135} \mathrm{Xe}$, ${ }^{87} \mathrm{Kr},{ }^{138} \mathrm{Xe}$, and ${ }^{85 \mathrm{~m}} \mathrm{Kr}$.

$\mathrm{R} / \mathrm{B}$ values should be measured for the following fission-gas isotopes during irradiation if available in the spectra: ${ }^{90} \mathrm{Kr},{ }^{133} \mathrm{Xe},{ }^{89} \mathrm{Kr},{ }^{135 \mathrm{~m}} \mathrm{Xe}$, and ${ }^{137} \mathrm{Xe}$.

\section{Post-irradiation Examination}

\section{Non-Destructive PIE of Irradiated Fuel Spheres}

- The mass of each fuel sphere shall be determined and recorded.

- The equatorial dimension of each fuel sphere shall be measured parallel and perpendicular to its pressing axis.

- The contents of fission products in each of four fuel spheres shall be measured by gamma spectrometry.

- The contents of fission products in each of eight graphite caps shall be measured by gamma spectrometry.

- The contents of fission products on the inner surface of the internal case of each capsule shall be measured by chemical etching and subsequent surface and gamma spectrometry.

\section{Destructive PIE of Irradiated Fuel Spheres}

One of the irradiated fuel spheres shall be selected and subjected to PIE as follows:

- The sphere will be deconsolidated

- The fission-product inventory in the radial and axial deconsolidated matrix graphite and the major fission-product profiles along the fuel sphere diameter shall be measured by gamma spectrometry.

Coated particles loosened during deconsolidation shall be subjected to examination as follows:

- Determination of a failed-coated-particle fraction by irradiated microsphere gamma analysis (IMGA)

- Measurements of fission-product profiles in coated-particle coatings to determine the fission-product retention capability of the coatings

- Ceramography of coated particles

- Determination of fuel burn-up by gamma spectrometry of fuel kernels exposed from coated particles.

\section{Heating Tests}

Fuel spheres shall undergo heating to $1,600^{\circ} \mathrm{C}$, at which point the accumulation of fission-gas isotopes and metallic-fission-product release shall be measured at predetermined intervals. The release of 
${ }^{137} \mathrm{Cs}$ and other gamma-emitting fission products shall be measured by gamma spectrometry while the release of ${ }^{90} \mathrm{Sr}$ shall also be measured.

\section{Non-Destructive PIE on Heated Fuel Spheres}

The following non-destructive PIE shall be performed on all heated fuel spheres:

- Visual inspection

- Mass determination

- Dimensional measurements parallel and perpendicular to its pressing axis

- Measurement of the contents of ${ }^{134} \mathrm{Cs}$ and ${ }^{137} \mathrm{Cs}$ in the fuel spheres by gamma spectrometry.

\section{Destructive PIE on Heated Fuel Spheres}

The fission-product inventory in the radial and axial deconsolidated matrix graphite and the major fission-product profiles along the fuel sphere's diameter shall be measured by gamma spectrometry.

Coated particles loosened during deconsolidation shall be subjected to examination as follows:

- Determination of a failed-coated-particle fraction by IMGA

- Measurements of fission-product profiles in coated-particle coatings to determine the fission-product retention capability of the coatings

- Ceramography of coated particles

- Determination of fuel burn-up by gamma spectrometry of fuel kernels exposed from coated particles.

\subsubsection{Irradiation and Testing of Production Line Fuel Spheres}

A fuel plant will be constructed to produce fuel to support the startup and continued operation of the pebble-bed design. Sixteen fuel spheres representative of the equilibrium product from the fuel plant will be inserted into the test reactor ${ }^{\mathrm{aa}}$ and four will be extracted at $\{5 \%\}^{\mathrm{bb}}$ FIMA to undergo heating tests to provide partial proof test results while the remainder will continue in the reactor to full proof burnup (of $\{>9.8 \%\}$ FIMA) before undergoing post-irradiation heating tests to provide the nominal proof-test results. The partial proof-test point is intended to correspond to the planned maximum burnup of the start-up fuel spheres in the reactor.

In addition to the irradiation proof tests performed to validate the performance of the spherical fuel elements, the matrix-graphite material that contains the coated particles in the fuel sphere will also be subjected to irradiation and heating tests.

\section{Testing Objectives}

The fuel spheres manufactured on a qualified pebble-bed fuel production line will meet all specified requirements in accordance with quality-control procedures discussed in Section 5.2.1.2, and this will be confirmed independently during pre-irradiation characterization. Tests will confirm that the behavior of pebble-bed fuel spheres under irradiation and post-irradiation heating-test conditions meets the pebble-bed reactor design requirements for normal operating and accident conditions regarding:

- Fission-gas release. Fission-gas release will be measured in an external gas loop during irradiation and during heating tests.

aa. The test reactor identified for this testing is the IVV-2M at INM in Russia.

bb. Numbers presented in script parentheses \{\} indicate that these are preliminary values which are subject to confirmation or change as the program matures. 
- Metallic-fission-product release. Metallic-fission-product releases that occur during irradiation will be determined in the PIE by measuring deposition in the irradiation capsule's materials that surround the fuel spheres during irradiation. Releases from the fuel spheres during heating tests will be periodically determined by removing and replacing deposition plates in the test furnace.

- Failure of coated particles. Exposed-kernel coated-particle failures that may occur during irradiation and during heating tests can be quantified by means of fission-gas-release analysis.

\section{Pre-irradiation Characterization}

Fifteen production-line fuel spheres, in addition to the 16 to be irradiated, will be made available for precharacterization. This will form part of an independent assessment of the as-manufactured properties of coated particles, fuel spheres, and matrix graphite. Pre-irradiation characterization of fuel spheres and coated particles will consist of:

- Determining geometrical sizes of kernels, coated particles, and coating-layer thickness

- Determining kernel density, coated-particle density, and density of all coating layers

- Determining kernel and coated-particle mass

- Determining kernel impurities

- Ceramography of coated particles to:

- Investigate the structure of the kernel, buffer, PyC, and $\mathrm{SiC}$ layers

- Determine anisotropy of dense PyC layers, including in particles removed from a heat-treated fuel sphere

- Determine uranium distribution in coated-particle layers

- Determining free-uranium content in spheres

- Determining U/O ratio (i.e., stoichiometry) in kernels

- Determining compression strength of coated particles.

\section{Irradiation and Testing of Production Line Fuel Spheres-Partial Burnup ${ }^{\mathrm{cc}}$}

The purpose of this test is to confirm that fuel manufactured for use in the pebble-bed design can be burned to approximately $\{5 \%\}$ FIMA, the maximum burnup calculated for the start-up fuel, and will perform satisfactorily under transient and accident conditions. Four equilibrium fuel spheres containing a total of approximately 44,800 coated particles will be loaded into an irradiation rig and inserted into the IVV-2M test reactor. At a burnup of nominally $\{5 \%\}$ FIMA, the fuel spheres will be removed from the test reactor and subjected to PIE and heating tests. The successful completion of these tests will confirm production fuel integrity for normal operation and transient and accident conditions to a burnup of $\{5 \%\}$ FIMA.

All irradiated fuel spheres will be subjected to heating tests simulating transient and accident temperatures, first at $1,600^{\circ} \mathrm{C}$ for 100 hours and then at $1,800^{\circ} \mathrm{C}$ for 100 hours. Following the heating tests, all heated fuel spheres will be visually examined and their fission-product inventories measured.

One heated fuel sphere will then be deconsolidated to provide coated particles for ceramography and fission-product-distribution measurements, including:

- Fission-product distribution in fuel spheres

cc . The planning for the RSA Demonstration Plant had a schedule overlap in which the licensing criteria allowed fuel qualification and plant startup to proceed simultaneously as long as the qualification results were always ahead of the actual in-core usage. The extraction and testing of partial burnup spheres may not be performed in conjunction with the NGNP project, with additional full burn-up spheres used to enhance the statistical basis for fuel qualification. 
- Optical ceramography of coated particles

- IMGA on coated particles

- Fission-product distribution in coated particles.

\section{Irradiation and Testing of Production Line Fuel Spheres-Full Burnup Proof Test}

The purpose of the proof test is to demonstrate, using a test sample that is statistically sufficient, that production fuel spheres meet all coated-particle-failure and fission-product-release requirements under normal operation, anticipated operational occurrences, and DBA conditions, including DLOFC and PLOFC temperature transients. The existing plan is to irradiate 12 spheres, each containing $\{14,400\}$ coated particles, in the IVV-2M reactor. This will be reviewed for the adjusted fuel design $(11,200$ coated particles per sphere) during the course of the plant design in order that sufficient coated particles are included in the irradiation tests to ensure an adequate statistical base.

\section{Full Burnup Irradiation Target}

The average target burnup for NGNP pebble fuel spheres is approximately $8.31 \%$ FIMA, which was calculated based on the average discharge burnup after fifteen cycles through the reactor core. In pebble-bed reactor operation, a small number of fuel spheres could be recycled near the maximum BUMS setpoint and pass through the high burnup path at the center of the reactor core, resulting in a maximum burnup of $8.33 \%$. When one applies BUMS measurement and statistical uncertainty to these spheres, they could achieve a burnup as high as approximately $8.75 \%$ FIMA $(84,350 \mathrm{MWd} / \mathrm{t})$. The maximum discharge fast-neutron dose calculated using the same assumption set is approximately $\left\{2.39 \times 10^{21} \mathrm{~cm}^{-2}\right\}$. For this reason, the values of $\{\sim 9.8 \%\}$ FIMA and $\left\{3.63 \times 10^{21} \mathrm{~cm}^{-2}\right\}$ are listed in Table 20. Normal temperature cycles in the reactor core will be simulated by irradiation at two representative core temperatures - one interval at a temperature representative of the low-temperature part of the pebble-bed fuel temperature cycle and a second interval at a temperature representative of the high-temperature part of the pebble-bed fuel temperature cycle. At the end of irradiation, the fuel spheres in one of the irradiation rigs will be subjected to a temperature transient simulating the first part of a PLOFC transient. 
In Table 20, nominal irradiation targets are compared to core design parameter values.

Table 20. Comparison of nominal proof-test irradiation targets with pebble-bed core design parameters.

\begin{tabular}{|c|c|c|c|}
\hline Parameter & $\begin{array}{l}\text { Core Design } \\
\text { Limits }\end{array}$ & $\begin{array}{l}\text { Core Nominal } \\
\text { Design }\end{array}$ & $\begin{array}{l}\text { Nominal Proof Test } \\
\text { Irradiation Target }\end{array}$ \\
\hline Number of Cycles & $\{17\}$ & 15 & $\{19\}$ \\
\hline Maximum power per fuel sphere $(\mathrm{kW})$ & 3.4 & 1.57 & $\{3\}^{\mathrm{dd}}$ \\
\hline Average residence time (days) & 1,038 & 916 & 731 \\
\hline $\begin{array}{l}\text { End of life fast neutron dose }(\mathrm{E}> \\
0.1 \mathrm{MeV})\left(\mathrm{cm}^{-2}\right)\end{array}$ & $\left\{2.39 \times 10^{21}\right\}$ & $2.01 \times 10^{21}$ & $\left\{3.63 \times 10^{21}\right\}^{\text {ee }}$ \\
\hline Discharge burnup (MWd/h / \% FIMA) & $84,350 / 8.75$ & $80,100 / 8.31$ & $\{\sim 94,400 />\sim 9.8\}$ \\
\hline \multicolumn{4}{|l|}{ Maximum Temperature $\left({ }^{\circ} \mathrm{C}\right)$ : } \\
\hline Normal operation & $\{1,048\}$ & 644 & $900 / 1,150$ cycles \\
\hline DLOFC (transient peak) & 1,483 & 970 & $1,600 / 1,800$ \\
\hline PLOFC (transient peak) & & TBD & $\{1,350\}$ \\
\hline
\end{tabular}

\section{PIE of Full Burnup Spheres}

The following PIEs will be performed on one or more of the 12 irradiated fuel spheres:

- Appearance

- Mass

- Diameter

- Burnup

- Fission-product inventory

- Deconsolidation

- Fission-product distribution in fuel sphere

- Optical ceramography of coated particles

- IMGA on coated particles

- Fission-product distribution in coated particles.

\section{Heating Tests of Full Burnup Spheres}

Following irradiation, irradiated fuel spheres will be externally examined and their burnup measured. One fuel sphere will be deconsolidated to enable ceramography of coated particles to be carried out and to measure the fission-product distribution through the fuel sphere.

Of the remaining 11 fuel spheres, five spheres will be subjected to heating tests simulating maximum reactor fault transient temperatures, nominally $1,600^{\circ} \mathrm{C}$ for about 100 hours, and six spheres will be

dd. The power per sphere achieved during irradiation testing is a function of the position of the spheres in the test reactor, the manner in which the reactor is operated, and the characteristics of the spheres themselves. Thus, this value will be determined closer to the irradiation tests when the detailed plan is finalized.

ee. The end-of-life fast-neutron dose achieved during irradiation testing is a function of the position of the spheres in the test reactor and the manner in which the test reactor is operated. Thus, this value will be determined closer to the irradiation tests when the detailed plan is finalized. 
subjected to temperatures of approximately $1,800^{\circ} \mathrm{C}$ for about 100 hours. Following heating tests, all heated fuel spheres will be visually examined and their fission-product inventories measured.

\subsubsection{Fuel Matrix Graphite Irradiation Tests and PIE}

The objective of these tests is to acquire relevant material data pertaining to irradiation behavior of the fuel-matrix graphite over the fluence-temperature regime for the pebble-bed fuel. The data will then be used to verify that the A3-3 matrix graphite component of the pebble-bed fuel spheres exhibits the same behavior as the German produced A3-3 matrix graphite. The IVV-2M reactor will be used to test the fuel-matrix graphite.

\section{Pre-irradiation Examination}

Samples for investigation and irradiation will be cut from fuel-free-matrix graphite spheres provided for the test. These samples will be cut parallel and perpendicular to the grain direction. A maximum of two specimens (parallel and perpendicular to the sphere pressing direction) per specimen type shall be extracted from each sample sphere. Following sample preparation, the characteristics listed below will be measured prior to the irradiation tests.

- Geometrical size

- Mass

- Calculation of sample density

- Measurement of sample density

- Sample porosity

- Thermal conductivity in the range $20^{\circ} \mathrm{C}$ to $\mathrm{T}_{\text {irr }}{ }^{\circ} \mathrm{C}^{\mathrm{ff}}$

- Electric conductivity in the range $20^{\circ} \mathrm{C}$ to $\mathrm{T}_{\text {irr }}{ }^{\circ} \mathrm{C}$

- Thermal coefficient of linear expansion in the range $20^{\circ} \mathrm{C}$ to $\mathrm{T}_{\text {irr }}{ }^{\circ} \mathrm{C}$

- Dynamic Young's modulus

- Compression strength

- Ultimate bending strength

- Optical ceramography

- Uranium and thorium content (neutron activation analysis [NAA] to be used)

- Visual record of samples selected for irradiation.

\section{Irradiation}

The A3-3 matrix graphite samples are to be irradiated to three different fast-neutron doses at the specified irradiation temperatures as follows:

- Fluence $=1.0 \times 10^{21} \mathrm{~cm}^{-2}(\mathrm{E}>0.1 \mathrm{MeV}) ;$ Temperature $=900^{\circ} \mathrm{C}$

- Fluence $=2.0 \times 10^{21} \mathrm{~cm}^{-2}(\mathrm{E}>0.1 \mathrm{MeV}) ;$ Temperature $=900^{\circ} \mathrm{C}$

- Fluence $=4.0 \times 10^{21} \mathrm{~cm}^{-2}(\mathrm{E}>0.1 \mathrm{MeV}) ;$ Temperature $=900^{\circ} \mathrm{C}$

- Fluence $=1.0 \times 10^{21} \mathrm{~cm}^{-2}(\mathrm{E}>0.1 \mathrm{MeV}) ;$ Temperature $=1,100^{\circ} \mathrm{C}$

- Fluence $=2.0 \times 10^{21} \mathrm{~cm}^{-2}(\mathrm{E}>0.1 \mathrm{MeV}) ;$ Temperature $=1,100^{\circ} \mathrm{C}$

ff. $\mathrm{T}_{\text {irr }}$ is anticipated to be at a maximum of $1100^{\circ} \mathrm{C}$ for the purposes of these tests. 
- $\quad$ Fluence $=4.0 \times 10^{21} \mathrm{~cm}^{-2}(\mathrm{E}>0.1 \mathrm{MeV})$; Temperature $=1,100^{\circ} \mathrm{C}$.

\section{Post-irradiation Examination}

Following irradiation, the samples are to be measured for the same characteristics as per the pre-irradiation measurements. The measured characteristics are to be compared to the values obtained during pre-irradiation characterization, from which the resulting irradiation changes will be determined for comparison to the results obtained for the German A3-3 matrix graphite.

\subsubsection{Fuel Spheres from Operation}

The German design basis for the pebble-bed spherical fuel includes conservative design requirements on graphite abrasion resistance, drop-test integrity and crush-test integrity. The appropriateness of these requirements with regard to assuring mechanical integrity during in-reactor operation was addressed via German laboratory tests as well as tests on fuel spheres that had been irradiated in the AVR. During the startup and initial operation of the pebble-bed core, observations and tests will confirm the German design bases for mechanical integrity. The structural integrity of the fuel spheres removed from the pebble-bed core will be monitored during normal operation by the BUMS. In addition, irradiated fuel spheres are anticipated to be removed from the pebble-bed core and subjected to mechanical tests and PIE. This post-irradiation mechanical test and inspection program will be continued until the target burnup for the first equilibrium fuel load is reached.

\subsection{Prismatic Fuel}

A primary principle of the modular HTGR concept is to passively maintain core temperatures below fission-product release thresholds under all reactor operating and accident conditions. This level of fission-product retention reduces the radioactive source term to a level that allows for potential elimination of the need for evacuation and sheltering of the public beyond a small exclusion zone. However, this level is predicated on exceptionally high as-manufactured fuel quality and fuel performance under normal operation and accident conditions. The Germans consistently produced and demonstrated fuel having the necessary quality and irradiation performance in the 1980 s, but the fuel development effort under the U.S. commercial HTGR program in the 1970s through the early 1990s was less successful, and the irradiation performance of the fuel in the final irradiation test, HRB-21, carried out by this program in the early 1990 s did not meet requirements in spite of the very high as-manufactured quality of the fuel.

The PIE of HRB-21, plus extensive multi-organizational reviews of fuel fabrication, irradiation testing, and safety testing data for both U.S. and German fuel ${ }^{27,28,41}$ resulted in an understanding of the causes of the poor performance of the fuel in HRB-21 and in revisions to the fuel-product specifications. However, the U.S. Commercial HTGR Program was terminated by Congress in 1995 before fuel could be manufactured to the new specifications and subjected to irradiation testing. Further, upon termination of the HTGR program in 1995, the pilot-scale fuel fabrication facility at GA, in which HTGR fuel development had been conducted, was decommissioned. Thus, at the beginning of 2,000, essentially no coated-particle fuel manufacturing and characterization capability existed in the U.S.

In support of the National Energy Policy, the DOE initiated programs, including the Generation IV Nuclear Energy Systems Roadmap (Gen-IV), in the early 2000s to revitalize nuclear-power generation growth within the U.S. In recognition of the very high-temperature reactor (VHTR; a version of the HTGR operating at very high reactor outlet helium temperatures) being selected as one of the Gen-IV concepts, the importance of coated-particle fuel to commercial deployment of HTGR technology, and the absence of coated-particle fuel manufacturing capability in the U.S., the DOE initiated the AGR Fuel Development and Qualification Program in 2002. This program has since become part of the NGNP Project and is now called the NGNP/AGR Fuel Program. This section describes the NGNP/AGR Fuel Program approach to coated-particle fuel development and qualification. 


\subsubsection{NGNPIAGR Fuel Qualification Program Scope}

The NGNP/AGR Fuel Qualification Program has been defined and guided by a Technical Program Plan that was originally developed in 2002 and has been updated periodically as the work has proceeded.

The overall goals of the NGNP/AGR Fuel Program, as stated in most recent version of the AGR Technical Program Plan, ${ }^{29}$ are to:

- Provide a baseline fuel-qualification data set in support of the licensing and operation of the Gen-IV VHTR (which DOE has also selected as the reactor type for the NGNP)

- Support near-term deployment of a VHTR for commercial energy production in the U.S. by reducing market-entry risks posed by technical uncertainties associated with fuel production and qualification

- Utilize international collaboration to extend the value of DOE resources.

The activities under the NGNP/AGR Fuel Program are described in the AGR Technical Program $\operatorname{Plan}^{29}$ and include fuel-manufacturing process and quality-control methods development, irradiation testing and PIE, accident-simulation heating tests (safety testing), and fuel-performance model development and validation. These activities are intended to first demonstrate that fuel fabricated to a particular set of fuel-product and process specifications will meet the fuel performance requirements for the HTGR. The next step is to qualify fuel manufactured in production-scale equipment by irradiating and safety testing statistically significant quantities of fuel. The final step is to establish limiting service conditions for the fuel and to validate fuel-performance models with respect to their ability to accurately predict the performance of the fuel under both normal reactor operating and accident conditions.

The NGNP/AGR Fuel Program also includes major activity to develop and validate fission-product transport and source term models. This element addresses transport to the EAB of fission products produced in the coated particles to provide a technical basis for HTGR source terms under normal and accident conditions. The technical basis will be codified in computer models validated by experimental data as needed to support plant design and licensing. Although fission-product transport behavior in the fuel is extremely important in calculating source terms for HTGR accident analyses, it is also an important consideration in fuel qualification because it strongly influences the as-manufactured fuel quality and in-service fuel performance requirements for the fuel. A separate white paper on the mechanistic source term has been developed to fully describe the research planned in the area of fission-product transport.

The NGNP/AGR Fuel Program is intended to support both the prismatic-block and pebble-bed reactor designs, but the initial work has focused on manufacturing and testing the UCO fuel preferred by the prismatic-block reactor concept because of the higher technical uncertainties considered to be associated with this fuel design. Thus, the NGNP/AGR Fuel Program selected SiC TRISO-coated UCO as the reference fuel-particle design and the starting point for the fuel development and qualification effort.

A series of irradiation tests planned for the NGNP/AGR Fuel Program is currently progressing, initially to demonstrate, and then qualify fuel for the NGNP and follow-on HTGRs. The objectives of these tests are to provide irradiation performance data to support fuel process development, to qualify fuel for normal operating and accident conditions, and to support development and validation of fuel-performance and fission-product-transport models. An underlying theme for the NGNP/AGR Fuel Program is to further the development of a fundamental understanding of the relationship between the fuel-fabrication process, fuel-product properties, and irradiation and safety testing performance, which will lead to improved models for predicting the performance of the fuel in the NGNP. Table 21 summarizes the planned irradiation-testing program in support of fuel qualification. Pebble-bed $\mathrm{UO}_{2}$ fuel is included along with prismatic UCO fuel in Test AGR-2. Tests AGR-3/4 and AGR-8 in support of fission-product release and transport are not included here but are discussed in the companion white paper 
on mechanistic source terms. More detailed information on all the tests planned is available in the AGR Technical Program Plan, ${ }^{29}$ which is currently in the process of revision.

Table 21. AGR irradiation tests.

\begin{tabular}{|c|c|c|}
\hline Capsule & Test Description & Test Objective/Expected Results \\
\hline AGR-1 & $\begin{array}{l}\text { Shakedown Test/Early Fuel Performance } \\
\text { Demonstration Test } \\
\text { Contents included compacts made from } \\
\text { UCO fuel particles coated in 2-in. } \\
\text { laboratory-scale coater at Oak Ridge } \\
\text { National Laboratory (ORNL). A baseline } \\
\text { fuel-particle composite and three variant } \\
\text { fuel-particle composites were tested. The } \\
\text { variants included two particle composites } \\
\text { coated using different IPyC coating } \\
\text { conditions, and one particle composite } \\
\text { coated using different SiC coating } \\
\text { conditions. }\end{array}$ & $\begin{array}{l}\text { Gain experience with multi-cell capsule } \\
\text { design, fabrication, and operation to reduce } \\
\text { chances of capsule or cell failures in } \\
\text { subsequent capsules. Obtain early data on } \\
\text { irradiated fuel performance and support } \\
\text { development of a fundamental } \\
\text { understanding of the relationship between } \\
\text { fuel-fabrication process and fuel-product } \\
\text { properties and irradiation performance. } \\
\text { Provide irradiated UCO fuel for } \\
\text { accident-simulation testing (heating tests). }\end{array}$ \\
\hline AGR-2 & $\begin{array}{l}\text { Fuel Performance Demonstration Test } \\
\text { Contents to include compacts containing } \\
\text { UCO particles made in large coater and } \mathrm{UO}_{2} \\
\text { particles made by B\&W, AREVA, and } \\
\text { PBMR (Pty) Ltd in different size coaters. } \\
\text { AGR-2 will have six independently } \\
\text { monitored and controlled capsules in a test } \\
\text { train design essentially the same as } \\
\text { demonstrated in AGR-1. One capsule of } \\
\text { UCO fuel will be operated with a maximum } \\
\text { time-averaged temperature of up to } 1,400^{\circ} \mathrm{C} \\
\text { as a performance margin test of the fuel. }\end{array}$ & $\begin{array}{l}\text { Provide irradiated fuel performance data for } \\
\mathrm{UCO} \text { and } \mathrm{UO}_{2} \text { fuel variants and irradiated } \\
\text { fuel samples for safety testing and PIE to } \\
\text { broaden options and increase prospects for } \\
\text { meeting fuel performance requirements and } \\
\text { to support development of a fundamental } \\
\text { understanding of the relationship between } \\
\text { fuel fabrication process and fuel product } \\
\text { properties and irradiation performance. }\end{array}$ \\
\hline AGR-5/6 & $\begin{array}{l}\text { Fuel Qualification } \\
\text { Contents to include a single fuel type made } \\
\text { using process conditions and product } \\
\text { parameters considered to provide best } \\
\text { prospects for successful performance based } \\
\text { on process development results and } \\
\text { available data from AGR-1 and AGR-2; } \\
\text { variations in cell irradiation temperatures per } \\
\text { test specification. }\end{array}$ & $\begin{array}{l}\text { Provide irradiated-fuel performance data } \\
\text { and irradiated fuel samples for safety testing } \\
\text { and PIE in sufficient quantity to } \\
\text { demonstrate compliance with statistical } \\
\text { performance requirements under normal } \\
\text { operation and accident conditions. }\end{array}$ \\
\hline AGR-7 & $\begin{array}{l}\text { Fuel Performance Model Validation } \\
\text { Contents to include same fuel type as used in } \\
\text { AGR- } 5 / 6 \text {. The irradiation tests fuel beyond } \\
\text { its operating envelope so that some } \\
\text { measurable level of fuel failure would occur } \\
\text { (i.e., margin test). }\end{array}$ & $\begin{array}{l}\text { Provide irradiated-fuel performance data } \\
\text { and irradiated fuel samples for safety testing } \\
\text { and PIE in sufficient quantity to validate the } \\
\text { fuel-performance codes and models and to } \\
\text { demonstrate capability of fuel to withstand } \\
\text { conditions beyond AGR-5 and } 6 \text { in support } \\
\text { of plant design and licensing. }\end{array}$ \\
\hline
\end{tabular}


The key elements of the NGNP/AGR Fuel Program, as grouped under the irradiation tests and in approximate chronological sequence, are to develop an initial set of fuel-product specifications to guide the fuel-development effort by accomplishing goals associated with each of the following tests.

\section{AGR-1 Shakedown Test/Early Fuel-Performance Demonstration Test}

- Resolve technical issues associated with UCO kernel fabrication process.

- Resolve technical issues associated with coating and the TRISO-particle design via studies in a laboratory-scale coater.

- Develop and demonstrate a thermosetting matrix based compacting process similar to the processes used in Japan, China, and Germany.

- Implement the full range of fuel characterization capabilities required to demonstrate conformance of the fuel to the fuel-product specifications.

- Conduct the AGR-1 irradiation test, PIE, and safety testing to confirm the reference fuel-particle design and the initial set of fuel-product specifications (and also to demonstrate the multi-capsule test train design developed for the NGNP/AGR Fuel Program).

\section{AGR-2 Fuel-Performance Demonstration Test}

- Develop reference process conditions for a "prototypic" large coater

- Conduct the AGR-2 irradiation test, PIE, and safety testing to demonstrate acceptable performance of the fuel made in the prototypic large coater.

\section{AGR-5/6 Fuel-Qualification Test}

- Further, optimize coating process conditions for the large coater and develop a compact fabrication process that is conducive to scale-up to a viable commercial fuel-manufacturing process

- Finalize the NGNP fuel product and process specifications based on irradiation and safety testing results from AGR-1, irradiation test results from AGR-2, and the results of fuel process development

- Fabricate qualification test fuel per the fuel-product and process specifications developed above and conduct AGR-5/6 irradiation test, PIE, and safety testing on statistically significant quantities of fuel to qualify the fuel product and fuel-process specifications.

\section{AGR-7 Fuel-Performance Test and Fuel-Performance Model Validation}

- Conduct activities to develop (a) fuel performance models based, to the greatest extent possible, on first principles and (b) the requisite material properties data needed for these models.

- Conduct the AGR-7 irradiation test, PIE, and safety testing to establish the performance margins available in the fuel and to validate the fuel-performance models.

\section{Technology for Commercial-Scale Production of HTGR Fuel}

- Develop technology for mass production of coated-particle fuel:

- Develop and demonstrate automated nondestructive QC methods for mass production

- Develop a conceptual design for an automated fuel-manufacturing plant

- Prepare a waste-minimization plan

- Prepare a cost evaluation to assist in design of a commercial fuel-manufacturing facility.

The irradiation tests listed in Table 21 were defined early in the NGNP/AGR Fuel Program based on the assumption that the advanced gas-cooled reactor would have a power-conversion system similar to that of the GT-MHR (i.e., no steam generator in the primary circuit). Consequently, it was anticipated that large water-ingress events would be extremely unlikely, and a low priority was assigned to characterizing 
the effect of water ingress on fuel performance and fission-product transport. However, the NGNP Project is currently focusing on process-steam applications, ${ }^{59}$ and some of the reactor design concepts under consideration include a steam generator in the primary circuit. For such designs, water ingress is anticipated to be a dominant risk based upon safety assessments done for earlier steam-cycle HTGR designs, including the MHTGR ${ }^{60}$ The NGNP/AGR Fuel Program recognizes that additional tests are needed to characterize the effects of water ingress on fuel performance and fission-product transport ${ }^{61}$ but has not yet defined these tests. ${ }^{\text {gg }}$

Also, the current NGNP/AGR Fuel Program plan does not explicitly address the potential effects of air ingress or reactivity-insertion events on fuel performance. With respect to air ingress, recent analyses have indicated that a substantial flow of air through the core could result from a major cross-duct failure as a result of stratified flow. This type of failure has not been considered to be within the licensing basis for past HTGR designs; however, smaller breaks in other locations have been considered and generally do not result in significant exposure of the core to air. Furthermore, reaction of air with reactor internals and fuel-element graphite would generally preclude exposure of fuel compacts to air, but some exposure to nitrogen and reaction products (e.g., $\mathrm{CO}$ ) could result. Testing of fuel in a helium atmosphere with fractional amounts of air, nitrogen, and/or CO might be possible in existing heating-test facilities, but a detailed assessment of the necessary facility modifications will be required. The NGNP/AGR Fuel Program currently considers it necessary that the NGNP design and licensing approach be further developed before air-ingress-related fuel testing needs (if any) can be addressed.

With respect to reactivity transients, past prismatic HTGR designs have precluded ejection of a control rod as a credible event, ${ }^{\text {th }}$ and the results for reactivity-insertion transients within the licensing basis have been bounded by conduction cooldown events in terms of challenges to fission-product retention by the fuel. Because of the much larger neutron-migration length in an HTR core relative to an LWR, the power peak resulting from a local reactivity insertion would be broader, and the increase in temperature would be slower, with a stronger temperature feedback on reactivity. Thus, even an extreme reactivity-insertion event, such as a control-rod ejection, would not be expected to result in substantial fuel-particle failure. ${ }^{\text {ii }}$ This conclusion is supported by an analysis of a beyond-licensing-basis event for the MHTGR in which the maximum worth control rod was ejected over a period of one-second. ${ }^{62}$ The analysis was performed using a point kinetics model with a 2D thermal model that addressed the fuel temperature distribution within an average channel. The maximum fuel temperature in the average channel was $1245^{\circ} \mathrm{C}$, with maximum fuel temperature in the hot channel estimated to be $\sim 1560^{\circ} \mathrm{C}$.

Thus, the available analytical and experimental data indicate large margins to fuel failure in an HTGR under predicted fuel conditions, even for beyond-design-basis reactivity-insertion events. Given the difficulty of conducting power excursion testing of irradiated fuel and the anticipated large margins to failure under bounding reactivity-insertion conditions, the NGNP Project has concluded that reactivity-insertion testing is not warranted and should not be added to the NGNP/AGR Fuel Program. However, the NGNP Project understands the substantial interest of the NRC in the potential consequences of reactivity-insertion events in HTGRs and has, therefore, identified this as an important topic to be discussed with the NRC in the priority licensing topic interactions associated with this white paper.

gg. The NGNP Project is planning to prepare and submit white papers on air and water ingress to the NRC.

hh. In the MHTGR design, the control-rod drive assemblies are captured by the top plug arrangement in the refueling floor; consequently, a rod ejection was not considered credible and was not included within the design basis.

ii. Power pulse testing of unirradiated coated-particle fuel has recently been performed in Japan, and no fuel particle failures were observed before the kernels reached the melting point, after which widespread failures occurred. The test conditions established for the Japanese tests were based on facility capabilities without consideration of the conditions that could be achieved in a modular HTGR core. 


\subsubsection{Quality Control}

QC methods for TRISO fuel particles are well established and have been used for large-scale fuel production in the U.S. and in Germany. ${ }^{63}$ This section provides an overview of the fuel-particle sampling techniques and QC inspection/testing methods used at GA for FSV fuel manufacturing and for fabrication of irradiation test fuel for the MHTGR and GT-MHR. Table 22, Table 23, and Table 24 identify the QC methods that have been used historically to characterize UCO kernels, TRISO-coated particles, and fuel compacts, respectively.

Table 22. QC methods for UCO kernels.

\begin{tabular}{|l|l|}
\hline \multicolumn{1}{|c|}{ Property } & \multicolumn{1}{c|}{ QC Method } \\
\hline Uranium content & Wet chemistry \\
\hline U-235 enrichment & Mass spectrometry \\
\hline Impurities & Emission spectrometry, wet chemistry, and ICP-MS \\
\hline C/U ratio & Combustion (carbon) and wet chemistry (uranium) \\
\hline O/U ratio & Combustion (oxygen) and wet chemistry (uranium) \\
\hline Bulk density & Mercury pycnometry \\
\hline Diameter & Radiography or ceramography \\
\hline
\end{tabular}

Table 23. QC methods for TRISO fuel particles.

\begin{tabular}{|l|l|}
\hline \multicolumn{1}{|c|}{ Property } & \multicolumn{1}{c|}{ Method } \\
\hline Missing buffer fraction & Radiography (or screening) \\
\hline Buffer density & $\begin{array}{l}\text { Calculated from particle density (by mercury } \\
\text { pycnometry) and carbon content (by combustion) }\end{array}$ \\
\hline Coating thicknesses & Radiography or ceramography \\
\hline IPyC and OPyC anisotropy & BAF $_{\mathrm{o}}$ by reflection of polarized light \\
\hline IPyC and OPyC density & Liquid gradient column \\
\hline SiC density & Liquid gradient column \\
\hline OPyC crystallite size & X-ray diffraction \\
\hline OPyC surface connected porosity & Mercury porosimetry \\
\hline SiC microstructure & Ceramography \\
\hline Faceting & Radiography or ceramography \\
\hline Missing or defective OPyC fraction & Optical microscopy \\
\hline Gold spots (inclusions) in SiC coatings & Optical microscopy \\
\hline
\end{tabular}

Table 24. QC methods for fuel compacts.

\begin{tabular}{|l|l|}
\hline \multicolumn{1}{|c|}{ Property } & \multicolumn{1}{c|}{ QC Method } \\
\hline Uranium loading & Wet chemistry \\
\hline Uranium homogeneity & Gamma spectroscopy \\
\hline Integrity and dimensions & Visual inspection and manual gauging \\
\hline Crush strength & Instron \\
\hline Matrix density & Calculation \\
\hline Heavy metal contamination & Acid leach or gaseous HCl leach \\
\hline Defective SiC coating fraction & Burn-leach \\
\hline Defective IPyC coating fraction (fuel dispersion) & Radiography \\
\hline Defective OPyC coating fraction & Compact deconsolidation/optical microscopy \\
\hline Impurities & ICP-MS \\
\hline Iron and transition metal content outside SiC & ICP-MS \\
\hline
\end{tabular}


Given that the quantities of fuel particles and fuel compacts in the reactor core number in the billions and millions, respectively, acceptance testing of the fuel particles and fuel compacts to determine conformance to specification requirements is necessarily performed on a statistical basis (i.e., statistical quality control). The statistical methods are summarized in Appendix C, where the risks of false acceptance and false rejection that are inherent in statistical sampling are discussed.

\subsubsection{AGR-1 Irradiation Test}

The first of the NGNP/AGR irradiation tests, AGR-1, is discussed in this section. Irradiation of AGR-1 began in the ATR at INL in late 2006 and was completed in November 2009. The AGR-1 test train included six separately controlled and monitored capsules, each approximately $1.375 \mathrm{in}$. (35 mm) in diameter and 6-in. (152-mm) long. The capsules were welded end-to-end to form a cylinder 36-in. (914-mm) long. Each capsule contained 12 fuel compacts approximately $0.5 \mathrm{in}$. $(12.7 \mathrm{~mm})$ in diameter by 1-in. (25.4-mm) long. Each capsule was independently supplied with a flowing mixture of helium and neon gases, which have substantially different thermal conductivities. Temperature control for each capsule was accomplished by adjusting the mixture ratio of the two gases. Gas exhaust lines transported fission products released from the fuel compacts within a capsule to the fission-product monitor for that capsule, which was able to detect individual particle failures - up to at least 256 particle failures in a single capsule - and measured the rate of release of specific gaseous isotopes of interest.

A cross section of a capsule is shown in Figure 29. Multiple thermocouples were provided for each capsule, with junction locations varying axially, radially, and azimuthally, and differing thermocouple types located in accordance with their temperature limitations. Flux wires and melt wires were encapsulated in vanadium and inserted into each graphite fuel holder.

All of the fuel within a given capsule was fabricated to the same specification and taken from the same coating batch composite. The contents of each of the capsules, numbered consecutively from the bottom to the top, were as follows, and all variant fuel specifications were identical to the baseline fuel with the exceptions noted below:

Capsule 6 - Baseline fuel specified with the intent of maximizing the prospects of successful performance

Capsule 5 - Variant 1 fuel, containing an IPyC layer produced at an increased temperature

Capsule 4 - Variant 3 fuel, containing a $\mathrm{SiC}$ layer produced at a reduced temperature with a mixture of argon and hydrogen

Capsule 3 - Baseline fuel

Capsule 2 - Variant 2 fuel, containing an IPyC layer produced with an increased coating gas ratio Capsule 1 - Variant 3 fuel. 


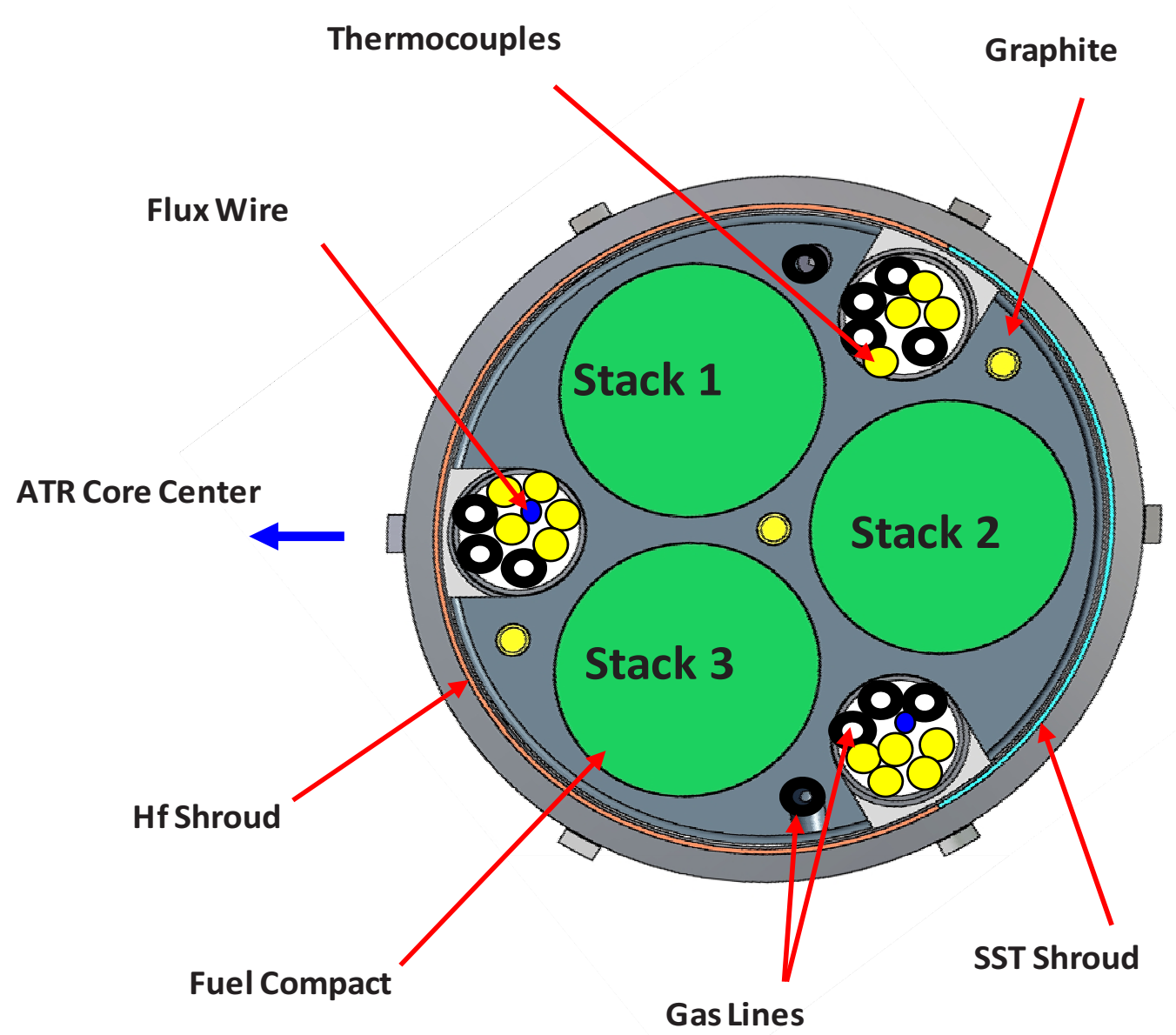

Figure 29. AGR-1 irradiation capsule cross section.

As noted above, there were 12 fuel compacts in each capsule. Each fuel compact contained approximately 4,100 fuel particles. Consequently, the AGR-1 irradiation test included approximately 98,000 baseline particles; 49,000 Variant 1 particles; 49,000 Variant 2 particles; and 98,000 Variant 3 particles.

The service conditions for the fuel in irradiation test AGR-1 were based on the service conditions shown in Table 14.

A peak burnup of $\sim 19 \%$ FIMA and a peak fast fluence of $\sim 5 \times 10^{25} \mathrm{n} / \mathrm{m}^{2}$ were achieved, and no fuel particle failure, as evidenced by fission-gas release, was observed in AGR-1. These results indicate that $100 \%$ of the particles in the irradiation test fully retained the fission gas generated in the particles during irradiation (no as-manufactured defective particle or irradiation-induced particle failures resulting in exposed kernels). These results suggest that the German experience and the lessons learned from the HRB-21 and NPR irradiations have been successfully interpreted and incorporated into the U.S. fuel development effort. They also suggest that the TRISO-particle design is sufficiently robust to tolerate relatively minor deviations in the $\mathrm{IPyC}$ and $\mathrm{SiC}$ coating conditions. However, the effectiveness of the fuel particles in retaining mobile metallic fission products such as ${ }^{137} \mathrm{Cs},{ }^{110 \mathrm{~m}} \mathrm{Ag}$, and ${ }^{90} \mathrm{Sr}$ cannot be determined from the online fission-product measurements. The metallic-fission-product retention and accidentcondition performance of the fuel particles will be determined during PIE and safety testing. 


\subsubsection{AGR-1 PIE and Safety Testing}

The PIE and safety testing of the AGR-1 test train and fuel will focus on:

- Assessing the performance of the multicapsule instrumented test train and components

- Evaluating the fission-product retention of the fuel during irradiation and during post-irradiation accident testing

- Characterizing the compacts and individual particles to observe the condition of the matrix material, kernels, and coatings and to document any concerns.

The planned examinations and safety testing outlined below will provide the program with early data on UCO particle-fuel performance and on the fundamental effects of irradiation on fuel properties. The results will indicate if the program's current approach to fuel fabrication has been successful in producing high-quality fuel that exhibits good irradiation and accident-condition performance.

\subsubsection{PIE}

Comparisons of the different fuel types included in AGR-1 will be an important aspect of the PIE effort, providing a better understanding of the coating traits that lead to optimal performance and aiding in the selection of a reference fuel for fuel-qualification test AGR-5/6. The PIE for the AGR-1 experiment will include the following key activities ${ }^{64}$ :

- Test-train inspections and nondestructive analyses to determine the overall condition of the test-train exterior and the condition and location of internal components

- Test train disassembly, extraction of fuel, and other interior components (including the graphite fuel holders, melt wires, and flux wires), and evaluation of test-train performance by characterization of thermocouples, melt wires, and flux wires

- Dimensional measurements of the fuel compacts and graphite holders

- Measurement of fuel and graphite properties, including fuel burn-up determinations and measurement of fuel and graphite thermal conductivity and thermal expansion

- Post-irradiated fission-metals-release analysis by measurement of fission-metal inventories on metal capsule components and gamma scanning of graphite fuel holders

- Deconsolidation of compacts to provide particles for subsequent analyses and leach-burn-leach analysis to quantify $\mathrm{SiC}$ failure fractions and evaluate fission-product inventories in the compact matrices

- Microanalytical characterization of fuel compacts and particles using optical metallography, scanning electron microscopy, and electron-probe microanalysis to investigate fuel microstructures, the condition of coatings, and fission-product migration within the fuel

- Accident testing to investigate release of selected fission products (including radioisotopes of Ag, Cs, $\mathrm{I}, \mathrm{Sr}, \mathrm{Te}$, and $\mathrm{Eu}$ ) at elevated temperatures in pure helium

- IMGA to measure fission-product inventories and evaluate fission-product retention for individual particles.

\subsubsection{Safety Testing}

Selected fuel compacts from AGR-1 will be subjected to heating tests to assess the fission-product retention characteristics of the fuel under simulated high-temperature accident conditions. The facilities to be used for this activity are the Fuel Accident Condition Simulator (FACS) at INL and the Core Conduction Cooldown Test Facility (CCCTF) at ORNL. The fuel will be heated up to temperatures of $1,800^{\circ} \mathrm{C}$ in a helium atmosphere while measuring fission-product releases as a function of time and 
temperature. Released fission gases (krypton and xenon radioisotopes) will be measured in dedicated cold traps during the heating tests. Condensable fission products, including radioisotopes of strontium, silver, iodine, cesium, europium, and tellurium, will be collected on water-cooled surfaces that can be periodically exchanged during the tests to obtain time-dependent release values.

Selected fuel compacts will be reirradiated prior to accident-simulation testing to generate short-lived I-131 (8-day half-life) in the fuel via fission, such that iodine released during accident testing can be measured. Compacts will be irradiated in the core of the Neutron Radiograph Reactor Training, Research, and Isotope area located in the basement of the Hot Fuels Examination Facility (HFEF) at Materials and Fuels Complex (MFC) of INL. After reirradiation, the compacts will be quickly transferred to the fuel-heating furnace installed in the HFEF main cell for accident tests. Only a selected number of the compacts to undergo accident testing will be reirradiated prior to the experiments since this step adds considerable complexity to the tests, and the correlations between the release of iodine and other fission products (xenon, for example) can be adequately established on a subset of accident test samples. Short-lived fission products Xe-133 and I-131 will only be measured for compacts that have been reirradiated prior to furnace testing and, therefore, will only be measured at INL.

The first priority for accident testing will be fuel that has exhibited good in-pile $\mathrm{R} / \mathrm{B}$ data and low $\mathrm{SiC}$ failure fractions, as determined by leach-burn-leach (LBL) testing. The primary objectives of these tests will be to identify the fuel type (baseline or one of the three variants) with the best accident performance by quantifying fission-product-release fractions over a range of temperatures. It is expected that, for fuel that has passed these criteria, there will be six to seven compacts available for accident testing (after initial metallography and LBL analysis). If all fuel types pass these criteria, the Baseline and Variant 3 fuel will be the highest priority for accident testing.

Both isothermal and nonisothermal heating tests will be performed for each selected fuel type. The majority of the isothermal tests will be performed in the temperature range of $1,600-2,000^{\circ} \mathrm{C}$. Non-isothermal heating tests will be performed to more realistically simulate the peak fuel temperature-time profiles during a postulated accident scenario. The maximum temperature of these tests and specific temperature-time profile will be established based on input from the NGNP reactor design activity.

The tentative plan for testing fuel from the capsules is as follows:

1. One compact from each selected capsule will be heated in an isothermal test at $1,600^{\circ} \mathrm{C}$. This will provide initial isothermal release data at the temperature closest to the maximum reached during a postulated accident and will provide an indication of fuel performance under relatively mild temperatures.

2. If release performances of the various compacts at $1,600^{\circ} \mathrm{C}$ show no significant differences, a second compact from each selected capsule will be heated in an isothermal test at $1,800^{\circ} \mathrm{C}$. This test will help to highlight differences in accident performance of the different fuel types and provide release data at the more extreme end of the temperature scale. If accident-release data for the different fuel types is noticeably different after the initial $1,600^{\circ} \mathrm{C}$ test, then the $1,800^{\circ} \mathrm{C}$ test may be skipped, and testing can proceed to the next step.

3. One to two additional isothermal tests will be performed, if needed, to help clarify any differences in the accident performance of the fuel types and help eliminate the possibility of statistical compact-to-compact variations in performance. The temperature of these tests should be $1,600^{\circ} \mathrm{C}$ or $1,800^{\circ} \mathrm{C}$, as appropriate, based on the results of the first two experiments. If $1,800^{\circ} \mathrm{C}$ testing is necessary to highlight differences in accident releases, for example, then these tests should be performed at this temperature.

4. An isothermal test at $1,700^{\circ} \mathrm{C}$ should be performed in order to provide release data for a temperature between the two extremes of 1,600 and $1,800^{\circ} \mathrm{C}$. 
5. A higher temperature test (up to $2,000^{\circ} \mathrm{C}$ ) may be performed, if necessary, to explore specific effects.

6. Any additional compacts should undergo isothermal testing at $1,600^{\circ} \mathrm{C}$ to provide additional release data at this temperature with a greater number of particles.

Heating tests may also be performed on individual particle samples, with gamma analysis of each particle being performed both before and after heating. This will allow the amount of fission products released from each particle to be independently measured to compare with the fission-product releases measured during the accident tests. This data comparison will also provide an additional opportunity to calibrate the furnace collection efficiencies (in addition to the initial system calibrations performed during furnace testing and qualification activities).

\subsubsection{Fuel Performance Model Development}

All of the various major international HTGR technology-development programs, including the U.S. HTGR program, have included extensive efforts to model the performance of coated-particle fuel. These development efforts have addressed the structural, thermal, and chemical processes that can lead to coated-particle failures. Fission-product release from the particles, and the transport of such releases within the fuel-compact matrix and fuel-element graphite, have also been modeled. However, these efforts have not been entirely successful in developing models capable of predicting fuel performance with sufficient accuracy to replace the need for comprehensive test data in both fuel design and licensing. The primary reasons for the limited success of the modeling efforts are (1) incomplete coating-property data as a function of irradiation conditions, and (2) insufficient understanding of the interactions between phenomena as irradiation proceeds. Thus, the goals of the fuel-performance modeling effort under the NGNP/AGR Fuel Program, as stated in AGR Plan 2008, ${ }^{29}$ are as follows:

- Develop fuel-performance models of coated-particle fuel (either with $\mathrm{UO}_{2}$ or UCO) that are more based on first principles

- Develop a prioritized list of material properties and constitutive relations needed for accurate modeling of coated-particle fuel under normal and off-normal conditions

- Develop advanced models that take advantage of new data and methods

- Benchmark these models/codes against U.S. and international irradiation and safety experiments where possible.

Developing fuel-performance models requires a fundamental understanding of potential failure mechanisms and how these mechanisms depend on the irradiation conditions and the materials constituting the fuel. The current knowledge on the key fuel-failure mechanisms associated with TRISO coated-particle fuel is summarized in Section 3.1.2. Accurate fuel-performance modeling also requires good material-properties data and constitutive relations, including:

- Thermo-mechanical and thermo-chemical properties of coating layers as a function of fast fluence and deposition conditions. These properties include anisotropy of $\mathrm{PyC}$, irradiation-induced dimensional change of $\mathrm{PyC}$, irradiation-induced creep of PyC, PyC poison's ratio in creep, interfacial bond strength between $\mathrm{SiC}$ and $\mathrm{PyC}$, irradiation-induced swelling of $\mathrm{SiC}$, irradiation-induced creep of $\mathrm{SiC}$, and Weibull strength of PyC and SiC.

- Thermo-chemical properties of the kernel as a function of burnup, including fission-gas release from $\mathrm{UCO}$ as a function of both burnup and temperature and kernel swelling for both $\mathrm{UO}_{2}$ and $\mathrm{UCO}$.

- Thermo-mechanical and thermo-physical properties under accident conditions, including thermal expansion coefficients and elastic modulus of $\mathrm{PyC}$ and $\mathrm{SiC}$ as a function of fast fluence and temperature. 
- Thermo-chemical properties under accident conditions, including the impact of palladium attack on the properties of the $\mathrm{SiC},{ }^{\mathrm{jj}} \mathrm{SiC}$ permeability as a function of fast fluence and temperature, and the influence of small quantities of air on SiC.

- Thermo-physical and physio-chemical properties of fuel compacts, including irradiation-induced shrinkage and thermal conductivity of the compact as a function of fast fluence and temperature.

Several of these properties will be measured during PIE on irradiated samples from the various planned irradiation tests, and some properties will be measured on samples of $\mathrm{PyC}$ and $\mathrm{SiC}$ because of the difficulty in taking measurements of $\mathrm{PyC}$ and $\mathrm{SiC}$ layers in coated fuel particles.

The fuel-performance models developed in the 1970s through 1990s by the previous U.S. HTGR program are mostly empirical in nature in that they are based on best fits of the available experimental data. Along with developing better material-properties data, as discussed above, the fuel performance modeling effort under the NGNP/AGR Fuel Program is focused on developing the Particle Fuel Code (PARFUME) at INL to predict fuel failure based on a first-principles understanding of the phenomena that influence fuel performance. Considerable progress with respect to development of the PARFUME code has been made to date by the NGNP/AGR Fuel Program AGR PLAN 2008. ${ }^{29}$

Benchmarking of fuel-performance codes for both normal reactor operating conditions and accident conditions is currently ongoing under an IAEA cooperative research program (CRP-6). Additional fuel-performance code benchmarking is expected under the Gen IV VHTR Fuel and Fuel Cycle Program Management Board, based on the behavior of the current generation of TRISO fuel in planned irradiation and safety tests. Pretest predictions and after-test calculations will be performed for each irradiation test and some of the safety tests. It is expected that the various irradiations and safety tests planned by the NGNP/AGR Fuel Program, along with planned PyC and SiC material irradiations, will provide much of the separate effects data needed to improve the fuel-performance models.

Verification and validation $(\mathrm{V} \& \mathrm{~V})$ of fuel performance codes are required for licensing. An independent integral test-train irradiation (AGR-7) will be the key NGNP/AGR Fuel Program activity for $\mathrm{V} \& \mathrm{~V}$ of fuel performance codes for normal reactor operation. A select number of heating tests of the irradiated fuel from AGR-7 will provide a data set for V\&V of fuel performance codes for accident conditions.

\subsubsection{Production-Scale Fuel Manufacturing Facility for NGNP UCO Fuel}

The fuel development and qualification activities included in the NGNP/AGR Fuel Program are intended to develop and qualify a fuel-manufacturing process that can be handed off to industry to serve as the foundation for commercial-scale coated-particle HTGR fuel manufacturing in the U.S.

Consequently, these activities must encompass both process optimization (to achieve the required kernel, coated-particle, and compact characteristics and quality) and scale-up of the processes to a scale that is sufficient to demonstrate the viability of commercial-scale fuel production. Although the NGNP/AGR Fuel Program includes some limited technology development for commercial-scale fuel production, it does not include implementation of a capability to mass-produce fuel for the NGNP, nor does it include qualification of fuel produced in an NGNP fuel-fabrication facility.

At the present time, there is no fuel supplier in the U.S. (or worldwide) that has the capability to produce UCO fuel on a large scale for a prismatic HTGR. Establishing a domestic fuel supply for the NGNP and for subsequent commercial deployment of HTGRs is, therefore, a critical programmatic need. Accordingly, the NGNP Project conducted an assessment of NGNP fuel-acquisition strategies in $2007 .^{65}$

jj. A finite-element approach that models degradation of the $\mathrm{SiC}$ and assesses the resulting response of the degraded coating has been developed and is being implemented in the Particle Fuel Model (PARFUME) code, which is being developed by INL. 
INL $2007^{65}$ discusses two fuel supply options for a prismatic. One option calls for construction of a DOE-funded pilot fuel fabrication facility (FFF) at INL to produce UCO fuel for the NGNP. DOE would provide the funding to design, build, and operate the FFF with possible cost sharing by an industrial partner. The production capacity of the FFF would be about 510 fuel elements per year, which would be adequate to produce the initial core for the NGNP in two years. The FFF would serve as a pilot line for a commercial fuel-fabrication facility, with the 510 element/year process line to be replicated in the commercial facility. This option is based on the view that demonstration by the NGNP Project of economical fuel manufacturing is as essential to commercial deployment of HTGRs in the U.S. as is demonstration of the HTGR itself.

The second option is to produce a portion of the initial core for NGNP using the current pilot-scale fuel line at B\&W (with modifications, including the addition of an engineering-scale compact fabrication line), which is currently being used for process development and fabrication of irradiation test fuel, and to subsequently build a larger fuel-fabrication facility to complete production of the first core and to produce reload segments. Production of NGNP fuel within the current B\&W pilot-scale facility would begin as soon as fabrication of the irradiation test fuel for AGR-5/6 has been completed. This approach would mitigate production risks and provide for a ready supply of trained operating staff for the production facility. However, the approach of beginning fabrication of NGNP fuel prior to completion of fuel qualification in AGR-5/6 clearly involves some risk.

Both an irradiation proof test and post-irradiation heating tests of fuel so manufactured will be needed to demonstrate the acceptable performance of the fuel and thereby qualify fuel for the NGNP. Following a period of fuel process line operation to demonstrate that the kernel, coating, and compacting processes are both stable and producing product that meets all specification requirements, representative fuel compact samples will be taken from the process line for an irradiation proof test and subsequent post-irradiation heating tests. It is expected that the proof test will be conducted in the ATR and will utilize the same test-train design as used for the AGR-5/6 fuel-qualification test. As previously indicated, the test train for AGR-5/6 has not been designed as of this writing, but it is anticipated that it will allow for the irradiation of at least 144 1-in.-long compacts containing a total of approximately 450,000 fuel particles. ${ }^{\mathrm{kk}}$ Thus, the fuel performance results from the proof test will be statistically significant. Post-irradiation heating tests will be performed on statistically significant numbers of irradiated compacts from the proof test to verify that the accident-condition performance of the production fuel is equivalent to that of the fuel qualified by the AGR-5/6 irradiation. It is expected that the proof test and subsequent heating tests will be conducted in parallel with manufacture of the initial core fuel load for the NGNP.

kk. Assuming a single fissile-fuel particle having a 425- $\mu$ m-diameter kernel. 


\section{NRC REVIEW OUTCOME OBJECTIVES}

The information in this paper is intended to serve as the basis for interaction with NRC staff. As stated above, this paper focuses on the use of the existing fuel-performance data, NGNP plant design envelope for fuel service, and planned fuel-qualification program to establish the bases of fuel performance under the intended operating and design conditions. Specifically for $\mathrm{UO}_{2}$ fuel type, the service condition parameters are being selected based on past German experience and pebble-bed reactor analysis, and for UCO fuel type, the service condition parameters are being developed through the AGR Fuel Development and Qualification Program which are driven by the prismatic reactor, but will provide improved fuel performance for the pebble-bed reactor. Either fuel will provide consistent, predicable performance during plant operations within their respective performance envelopes.

The primary issues for which NRC staff feedback is requested prior to submission of the COLA include:

- Plans established in Section 5 for qualification of the $\mathrm{UO}_{2}$ pebble fuel type are generally acceptable.

These include:

- Utilization of German data for normal operation irradiation, and transient/accident heat-up conditions

- Performance of additional confirmatory irradiation and safety tests on fuel manufactured at a qualified facility to (1) statistically strengthen the performance database and (2) demonstrate that the fuel performs equivalent or better than the German fuel upon with the $\mathrm{UO}_{2}$ pebble fuel design is based.

- Plans established in Section 5 for qualification of the UCO prismatic fuel type are generally acceptable based on the AGR Fuel Development and Qualification Program.

Other activities and information may be necessary to support the qualification of both pebble-bed $\mathrm{UO}_{2}$ and prismatic UCO fuels. Therefore, it is requested that NRC review provide either:

- Confirmation that the plans presented in this paper are generally acceptable

- Identification of any additional information or testing needed to demonstrate adequate NGNP fuel performance. 


\section{REFERENCES}

1. 10 CFR Part 50, "Domestic Licensing of Production and Utilization Facilities, Electronic Code of Federal Regulations," http://ecfr.gpoaccess.gov/cgi/t/text/textidx?c=ecfr\&tpl=/ecfrbrowse/Title10/10cfr50_main_02.tpl.

2. SECY-93-092, "Issues Pertaining to the Advanced Reactor (PRISM, MHTGR, and PIUS) and CANDU 3 Designs and Their Relationship to Current Regulatory Requirements," Nuclear Regulatory Commission, July 16, 1993.

3. System Requirements Manual for SECY-93-092.

4. NUREG 1338, "Draft Preapplication Safety Evaluation Report for the Modular High-Temperature Gas-Cooled Reactor,” U.S. Nuclear Regulatory Commission, (Draft) March 1989.

5. DOE/NRC 1991a.

6. NUREG-1338, "Preapplication Safety Evaluation Report for the Modular High-Temperature GasCooled Reactor (MHTGR)," Nuclear Regulatory Commission, June 1995.

7. NUREG-0111, "Evaluation of High-Temperature Gas-Cooled Reactor Fuel Particle Coating Failure Models and Data," Nuclear Regulatory Commission.

8. NUREG-0800, "Standard Review Plan for the Review of Safety Analysis Reports for Nuclear Power Plants," Nuclear Regulatory Commission, March 2007.

9. NUREG/CR-6844, “TRISO-Coated Particle Fuel Phenomena Identification and Ranking Tables (PIRTs) for Fission Product Transport Due to Manufacturing, Operations, and Accidents," U.S. Nuclear Regulatory Commission, July 2004.

10. Simon, R. P. Capp, 2002, "Operating Experience with the Dragon High Temperature Reactor Experiment," HTR-2002, the Netherlands, April 2002.

11. INEEL/EXT-03-00103, "Fuel Summary for Peach Bottom Unit 1 High-Temperature Gas-Cooled Reactor Cores 1 and 2," April 2003.

12. VDI-Verlag GmbH, “AVR - Experimental High-Temperature Reactor, 21 Years of Successful Operation for a Future Energy Technology,” June 1990.

13. EPRI 1009382, "A Review of Radionuclide Release from HTGR Cores During Normal Operation," February 2004.

14. IAEA-TECDOC-978, "Fuel Performance and Fission Product Behaviour in Gas Cooled Reactors," November 1997.

15. Chernikov, A., and A. Deryugin, 1999, "Irradiation Tests of HTGR Fuel Under Normal and Accident Conditions," OECD Proceedings, Survey on Basic Studies in the Field of High Temperature Engineering, Paris, September 1999.

16. IAEA-IWGGCR/8, “'Specialists' Meeting on Gas-Cooled Reactor Fuel Development and Spent Fuel Treatment," Moscow, October 1983.

17. Tang C., et.al., 2001, "Fabrication of the First Loading Fuel of 10 MW High Temperature Gas Cooled Reactor-Test Module (HTR-10)," Seminar on HTGR Application and Development, Beijing, March 2001. 
18. Zhong D., and Qin Z., 2001, "Overview of the 10 MW High Temperature Gas-Cooled Reactor Test Module," Seminar on HTGR Application and Development, Beijing, March 2001.

19. Jing X., and Y. Yang, 2004, "Physical Designs and Calculations for the First Full Power Operation of the 10 MW High Temperature Gas-Cooled Reactor - Test Module (HTR-10)," 2nd International Topical Meeting on High Temperature Reactor Technology, Beijing, September 2004.

20. Tang C., et.al., 2004, “The Behavior of HTR-10 Fuel Under Irradiation," 2nd International Topical Meeting on High Temperature Reactor Technology, Beijing, September 2004.

21. Marmier, A., et.al., 2008, "Preliminary Results of the HFR-EU1 Fuel Irradiation of INET and AVR Pebbles in the HFR Petten," 4th International Topical Meeting on High Temperature Reactor Technology, Washington, September 2008.

22. Fujikawa, S., et al., 2004, "Achievement of Reactor-Outlet Coolant Temperature of $950^{\circ} \mathrm{C}$ in HTTR," J. Nucl. Sci. Technol., Vol. 41, p. 1245.

23. Verfondern, K., et al., 2000, "Modeling of Fuel Performance and Fission Product Release Behavior during HTTR Normal Operation (A Comparison of the FZJ and JAERI Modeling Approach)," JAERI-Research 2000-067, December 2000.

24. Minato, K., et al., "HRB-22 Capsule Irradiation Test for HTGR Fuel (JAERI/USDOE Collaborative Irradiation Test," Japan Atomic Energy Research Institute, JAERI-Research 98-021, March 1998.

25. Minato, K., et al., 2000, "Fission Product Release Behavior of Individual Coated Fuel Particles for High-Temperature Gas-Cooled Reactors," Nucl. Technol., Vol. 131, p. 36.

26. Hayashi, K., et al., 2000, "Irradiation Experiments of the 13th-15th OGL-1 Fuel Assemblies," Japan Atomic Energy Research Institute, JAERI-Research 2000-001, January 2000.

27. Hobbins, R. R. and R. K. McCardell, 1993, "Summary of NP-MHTGR Fuel Failure Evaluation," EGG-NPR-10967, September 1993.

28. General Atomics, MHTGR TRISO-P Fuel Failure Evaluation Report, DOE-HTGR-90390, Rev. 0, October 1993.

29. Petti, D. A., et. al., eds., 2008, Technical Program Plan for the Next Generation Nuclear Plant/Advanced Gas Reactor Fuel Development and Qualification Program, INL/EXT-05-00465, Rev. 2, July 2008.

30. Wagner-Löffler, M., 1977, “Amoeba Behavior of $\mathrm{UO}_{2}$ Coated Particle Fuel,” Nucl. Technol., Vol. 35, p. 392.

31. Ketterer, J. W. and B. F. Myers, 1985, "Capsule HRB-16 Postirradiation Examination Report," HTGR-85-053, General Atomics, September 1985.

32. Minato, K., et al., 1972, "Carbon Monoxide - Silicon Carbide Interaction in HTGR Fuel Particles," J. Mater. Sci., Vol. 26, p. 2379.

33. Hantke, H., 1992, "Performance of High Quality HTR-LEU Fuel Elements with TRISO Coated Particles," KFA-HTA-IB-7/92, December 1992.

34. "Irradiation Results of AVR Fuel Pebbles at Increased Temperature and Burn-Up in the HFR Petten", 3rd International Topical Meeting on High Temperature Reactor Technology, Johannesburg, October 2006. 
35. De Groot, S., et.al., "Modelling of the HFR-EU1bis Experiment and Thermomechanical Evaluation", 3rd International Topical Meeting on High Temperature Reactor Technology, Johannesburg, October 2006.

36. Toscano, E., et al., 2008, "Post Irradiation Testing of High Temperature Reactor Spherical Fuel Elements Under Accident Conditions," HTR-2008, Washington, October 2008.

37. Schenk, W., R. Gontard, and H. Nabielek, 1994, "Performance of HTR Fuel Samples under HighIrradiation and Accident Simulation Conditions, with Emphasis on Test Capsules HFR-P4 and SLP1,"Jül 2992, Jülich, November 1994.

38. van der Merwe, Hanno and Johan Venter, 2009, “A Method to Evaluate Fission Gas Release During Irradiation Testing of Spherical Fuel, Journal of Engineering for Gas Turbines and Power, Vol. 131, No. 5, September 2009.

39. van der Merwe, J.J., 2004, "Development and Validation of Fission Product Release Models and Software at PBMR," $2^{\text {nd }}$ International Topical Meeting on High Temperature Reactor Technology (HTR2004), Beijing, September 2004.

40. McEachern, D., et al., 2001, "Manufacture and Irradiation of Fort St. Vrain Fuel," International HTR Fuel Seminar, Brussels, Belgium, February 2001.

41. Petti, D., et al., 2002, Key Differences in the Fabrication, Irradiation and Safety Testing of U.S. and German TRISO-coated Particle Fuel and Their Implications on Fuel Performance, INEEL/EXT-02-00300, April 2002.

42. Borchardt, G., et al., 1982, "Experiment FRJ2-P24 Bestrahulungsbericht” KFA Jülich, Interner Bericht KFA-ZBB-1B-19/82, August 1982.

43. Bauer, C. and H. Klöcker, 1983, "Elektrolytische Desintegration an 3 Compacts aus dem Experiment FRJ2-P24, ” KFA Jülich, Interne Notiz IRW-IN-8/83, March 17, 1983.

44. Goodin, D. T., H. Nabielel, and W. Schenk, 1985, “Accident Condition Testing of US and FRG High Temperature Gas-Cooled Reactor Fuels,” GA-A17820, General Atomics, January 1985.

45. Bullock, R. E., 1984, "Fission-Product Release During Postirradiation Annealing of Several Types of Coated Fuel Particles," Journal of Nuclear Materials, Vol. 125, pp. 304-319, Reference 49 in Rev. 2 d.

46. Reutler, H., 2001, "Invention and Development of the HTR Module," Seminar on HTGR Application and Development, Beijing, China, March 2001.

47. E. Teuchert, et al., 'VSOP99(94), Computer Code System for Reactor Physics and Fuel Cycle Simulation Input Manual and Comments,' Jül-2897, April 1994.

48. W. Scherer, H. Gerwin, 'Progress and Problems in Modelling HTR Core Dynamics,' IAEAIWGGCR/24, May 1990.

49. IAEA-TECDOC-1163, "Heat Transport and Afterheat Removal for Gas Cooled Reactors Under Accident Conditions," January 2001.

50. Hanson, D. L., 2009, “Technical Basis for NGNP Fuel Performance and Quality Requirements," Report 911168, Rev. 0, General Atomics, September 2009.

51. INL/EXT-09-16548, Revision 3 Next Generation Nuclear Plant System Requirements Manual, 2009.

52. DOE-HTGR-87-081, "Consequence Assessment of Beyond Licensing Basis Events for the Standard MHTGR,” July 1987. 
53. Reitsma, F., et al., 2008, "The OECD/NEA/NSC PBMR400 MW Coupled Neutronics Thermal Hydraulics Transient Benchmark - Steady-State Results and Status," International Conference on the Physics of Reactors, Interlaken, Switzerland, September 2008.

54. ISO 9001: 2000, Quality Management Systems - Requirements.

55. ASME-NQA-1-1994, “Quality Assurance Requirements for Nuclear Facility Applications,” 1994.

56. Koscheev, K. N., et al., "Experimental Capabilities of IVV-2M Reactor and Its Research Complex to Determine Workability of Coated Particles Na Fuel Elements of High Temperature Gas-Cooled Reactors," OECD Proceedings, Survey on Basic Studies in the Field of High Temperature Engineering, September 1999.

57. Conrad, R. and K. Bakker, 2001, "Irradiation of Fuels for High Temperature Gas-cooled Reactors at the HFR Petten," International HTR Fuel Seminar, Brussels, February 2001.

58. Grover, S. B., 2004, "Testing of Gas Reactor Materials and Fuel in the Advanced Test Reactor," American Nuclear Energy Symposium (ANES 2004), OSTI ID 841400, October 2004.

59. "Next Generation Nuclear Plant System Requirements Manual," INL/EXT-07-12999, Rev. 2, Idaho National Laboratory, March 2009.

60. "Preliminary Safety Information Document for the Standard MHTGR," HTGR-86024, Rev. 13, Stone \& Webster Engineering Corp., September 1992.

61. "Moisture Ingress from Direct Cycle Steam Generation - Effect on Fuel Performance and Fission Product Transport Technology Development," TEV-583, Rev. 0, Idaho National Laboratory, July 2009.

62. Hoot, C. and T. D. Dunn, 1987, "Consequence Assessment of Beyond Licensing Basis Events for the Standard MHTGR,” DOE-HTGR-87-081, Rev. 0, General Atomics, July 1987.

63. Bresnick, S., 1991, “MHTGR Fuel Process and Quality Control Description,” DOE-HTGR-90257, Rev. 0, General Atomics, September 1991.

64. Idaho National Laboratory, "AGR-1 Post-Irradiation Examination Plan "INL Document PLN-2828, Rev. 0, July 2008.

65. "Assessment of Next Generation Nuclear Plant (NGNP) Fuel Acquisition Strategies," INL/EXT-07-12441, Rev. 1, Idaho National Laboratory, October 2007. 
Appendix A

German LEU UO $\mathrm{U}_{2}$ TRISO Fuel Irradiation Data 


\section{Appendix A}

\section{German LEU $\mathrm{UO}_{2}$ TRISO Fuel Irradiation Data}

The following sections provide detailed discussions and data from the German test program on LEU $\mathrm{UO}_{2}$ TRISO fuel.

\section{A-1. IRRADIATION}

German LEU $\mathrm{UO}_{2}$ TRISO fuel normal operation irradiation experience can be classified into two categories: large-scale irradiation in an operating reactor and fuel specimen irradiation in MTRs.

- The AVR Test Reactor program for LEU UO $\mathrm{UO}_{2}$ TRISO fuel covered bulk testing of fuel spheres under actual operating conditions in a pebble-bed core. Mass-produced fuel spheres were irradiated in AVR to design burnup, with some of the fuel spheres removed from AVR at different burnup stages and subjected to ex-reactor heating tests to simulate performance under transient and accident heat-up conditions. Both GLE 3 and GLE 4 spheres were irradiated, but heating tests focused on GLE 3 spheres. The results of the heating tests are discussed in Section 3.3.3, but the initial release from the heat-up testing was used to infer the state of the fuel spheres following irradiation (i.e., normal operation performance).

- MTR irradiations were conducted in three reactors: HFR (Netherlands), FRJ2 (Germany) and Siloe (France), and in two phases:

- Phase 1 included normal fuel spheres, small fuel spheres, compacts, and coupons containing coated particles, all from the same coating batch (EUO 2308), irradiated under a variety of conditions. These irradiation tests were intended to provide an operating envelope for a number of different reactor types designed around $\mathrm{LEU} \mathrm{UO} \mathrm{U}_{2}$ TRISO fuel. One additional irradiation of GLE 4 fuel spheres was conducted in DIDO (FRJ2-K15).

- $\quad$ Phase 2 was performed to provide MTR irradiation proof-tests, specifically for the HTR-Modul reactor design. During Phase 2 tests, fuel spheres were subjected to temperature cycles derived from those expected during normal operation of the HTR-Modul. The German fuel program was terminated before the irradiated Phase 2 fuel could be subjected to heating tests. However, some of the fuel spheres from HFR-K6 were recently heated at ITU, Karlsruhe. For both Phase 1 and Phase 2 irradiation tests, test conditions were tightly controlled; hence, the temperature, burnup, and fast-fluence conditions experienced by the fuel samples are well known.

The conduct and results of these irradiations are discussed in the following section, grouped as AVR irradiations and MTR irradiations (Phases 1 and 2). The primary sources of data for this section as well as the data on heating-test experience in Section 3.2.3 are Forschungszentrum Jülich reports, ${ }^{1,2,3}$ IAEA-TECDOC-978, ${ }^{4}$ and archived spreadsheet data. ${ }^{5}$ Normal-operation fuel-performance data for the core average fuel-service conditions are used to determine the failed-particle fraction assumed in the analysis of the pebble-bed design. The models consider the coated-particle-failure fraction and the spatial burnup, fast fluence, and temperature distribution in the core to calculate gaseous- and metallic-fissionproduct release. In analyzing the German fuel experience, two different classes of particle failures are considered:

- Exposed Kernels - This type of failure is defined as failure of all coatings such that gases released from the kernel are also released from the particle. These failure types are a subset of the failed particles determined by the burn-leach procedure free-uranium fraction. They can be uniquely measured in unirradiated fuel by "weak irradiation" in a reactor and can be identified in irradiated 
spheres by R/B ratio measurements in MTRs and by analysis of krypton release during initial heating tests, as discussed in Section A-1.3.2.

- $\quad$ SiC Defects - This type of failure is defined by a flaw in the SiC layer, either a through-wall crack or a high-permeability section of the layer produced by a coating anomaly, with one or more intact dense pyrocarbon layers. These particles are also identified by the burn-leach procedure free-uranium fraction, as the burn step in the procedure removes the dense pyrocarbon layers. These particles do not release gaseous fission products in normal operation transient and or accident conditions up to $1,700^{\circ} \mathrm{C}$, but do release metallic fission products, including cesium, to a limited extent at the upper end of the operating temperature range, and to a greater degree under transient and accident conditions.

The analysis of German fuel heating data, as discussed in Section 3.2.3, indicates that particles with $\mathrm{SiC}$ defects are more prevalent than particles with exposed kernels.

\section{A-1.1 AVR Irradiation Data}

As reported in the preceding references, a number of $\mathrm{LEU} \mathrm{UO}_{2}$ TRISO fuel spheres were irradiated in the AVR reactor, including 24,615 GLE3 spheres and 28,990 GLE 4 spheres (refer to Table 2 and Table 3 for characteristics). Of these, heating-test data from 14 GLE 3 spheres are used to infer post-irradiation particle-failure fractions. The following discussion is directed toward justification of the use of performance data from these spheres in support of the pebble-bed fuel. While the burnups of the spheres irradiated in the AVR were measured and fluence can be estimated based on the measured burnup, their individual temperature history is unknown. However, to reach full burnup, they were typically recycled 10 times, which would level out the variations in individual trajectories through the core, and the aggregate temperature history can be estimated with reasonable confidence (higher burnup spheres were typically recycled to the center region). During operation with a $950^{\circ} \mathrm{C}$ mixed mean coolant outlet temperature, an experiment was conducted to measure the maximum temperature experienced by the fuel. ${ }^{6}$ In the experiment, 144 spheres containing a series of encapsulated fusible wires covering a range of melting points from 920 to $1,280^{\circ} \mathrm{C}$ were passed through the AVR core. Ninety-five spheres were loaded into the core via the central core tube, and 49 were loaded through the four peripheral tubes. The distribution of maximum fuel temperatures measured in the experiment for the central core, outer core, and combined results is shown in Figure A-1. The maximum temperature experienced by some spheres is not known, as the maximum melt wire temperature was $1,280^{\circ} \mathrm{C}$, but given the distribution, it is reasonable to conclude that it was no more than $1,400^{\circ} \mathrm{C}$. ${ }^{11}$ This value was used to determine the average temperature and fuel-element fraction for the highest temperature points in Figure A-1.

11. There is no way to determine what the peak fuel temperature actually was (a detailed 3D T\&H model of the AVR core with the fuel loading it had at the time of the melt wire tests would be extremely expensive and would still retain a large degree of uncertainty). The value of $1400^{\circ} \mathrm{C}$ is based on a data consistency and plausibility argument. The main point with regard to this paper is that the temperature environment for fuel irradiated in the AVR was more severe than the fuel will experience in the pebble-bed design. Whether the value is $1,350^{\circ} \mathrm{C}$ or $1,450^{\circ} \mathrm{C}$ will not alter that conclusion. 


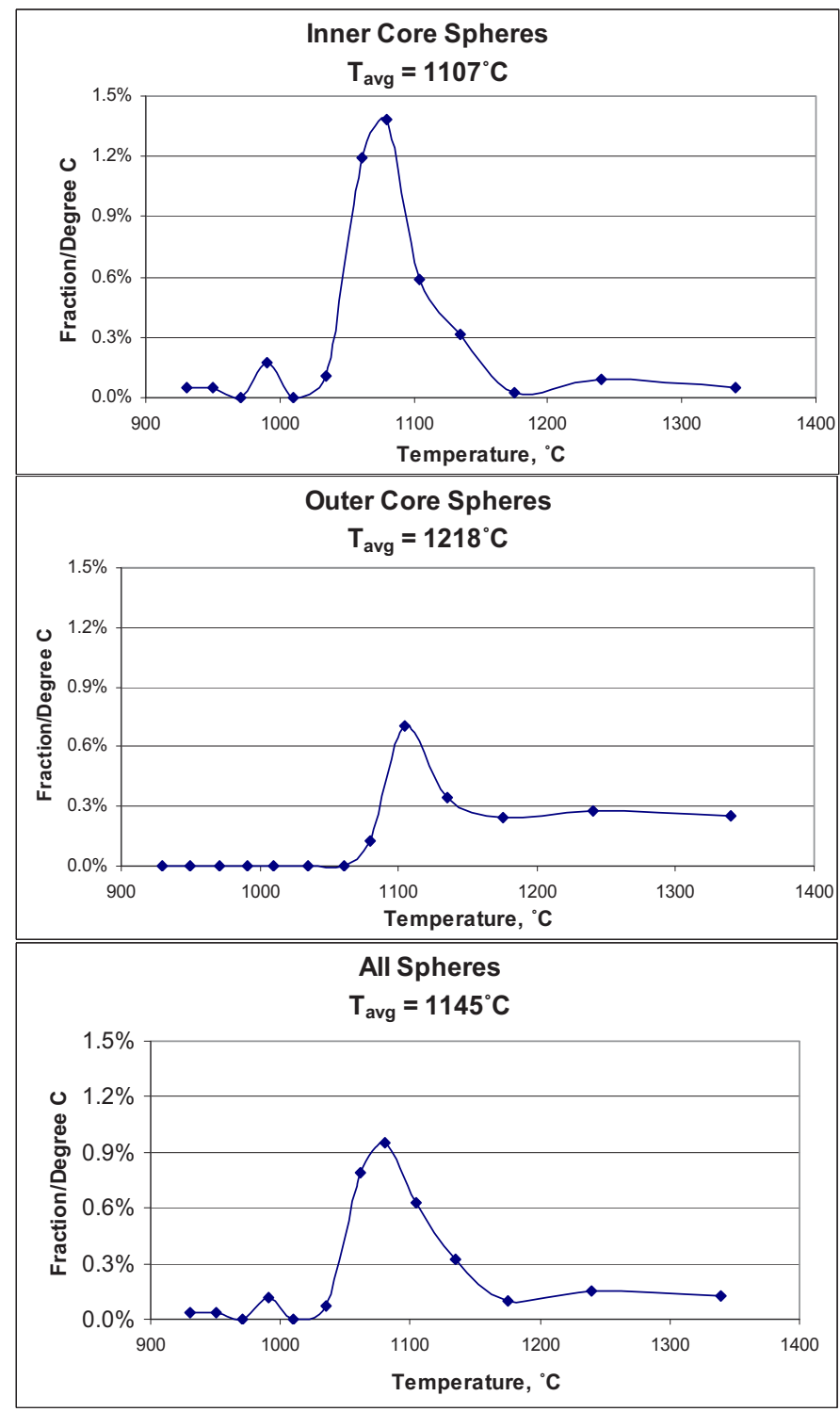

Figure A-1. AVR maximum fuel temperature experiment results.

The high fuel temperatures observed in the AVR were produced by a combination of the high core bypass flow fraction, the high mixed mean coolant outlet temperature $\left(950^{\circ} \mathrm{C}\right)$, the large mixed mean coolant temperature rise across the reactor $\left(675^{\circ} \mathrm{C}\right)$, and the power density distribution due to the control-rod buttresses. Inside the reactor vessel, a significant fraction of the coolant bypasses the core and flows through gaps between reflector blocks, component cooling channels, etc. The high coolant temperature rise of the AVR amplifies the effect of core flow bypass as well as radial and azimuthal variations in coolant flow and power density. The AVR parameters are listed in Table A-1 and were used to determine an "enthalpy rise hot channel factor" (the ratio of maximum fuel temperature rise to reactor mixed mean coolant $\Delta \mathrm{T}$ ) for the AVR. Also provided in Table A-1 are the example pebble-bed design parameters with the maximum fuel temperature and maximum fuel temperature rise calculated by using the AVR enthalpy rise hot channel factor. Having noted in Section 4.2.2 that the calculated maximum fuel temperature of the NGNP pebble-bed design is $1048^{\circ} \mathrm{C}$ and the maximum fuel temperature rise is calculated as $793^{\circ} \mathrm{C}$, one can see that the AVR conditions were more severe than those expected for the pebble-bed design. 
Table A-1. Effect of difference in mixed mean coolant temperature rise.

\begin{tabular}{|l|c|c|}
\hline \multicolumn{1}{|c|}{ Parameter } & AVR & $\begin{array}{c}\text { Pebble-Bed } \\
\text { Design }\end{array}$ \\
\hline $\mathrm{T}_{\text {in }}$ (mixed mean coolant) ${ }^{\circ} \mathrm{C}$ & 275 & 250 \\
\hline $\mathrm{T}_{\text {out }}$ (mixed mean coolant), ${ }^{\circ} \mathrm{C}$ & 950 & 750 \\
\hline$\Delta \mathrm{T}_{\text {reactor }}{ }^{\circ} \mathrm{C}$ & 675 & 500 \\
\hline $\mathrm{T}_{\max }$ fuel,,${ }^{\circ} \mathrm{C}$ & $\sim 1,400$ & $1083^{\mathrm{a}}$ \\
\hline$\Delta \mathrm{T}_{\max }{ }^{\circ} \mathrm{C}$ & 1,125 & $833^{\mathrm{a}}$ \\
\hline "Enthalpy rise hot channel factor" & 1.67 & 1.67 \\
\hline a. Estimated using same "enthalpy rise hot channel factor" as AVR. \\
\hline
\end{tabular}

As a larger reactor with a more regular geometry (the NGNP pebble-bed core is smooth and cylindrical versus AVR's being cylindrical with four large control-rod buttresses protruding into the core), the NGNP pebble-bed is designed to have a lower core bypass and less variation in the integrated axial flow and power distributions (currently a conservative $20 \%$ core bypass is used in the pebble-bed design calculations presented in this paper). Thus, the NGNP pebble-bed "enthalpy rise hot channel factor" would be expected to be lower than for the AVR, resulting in a lower maximum fuel temperature than given in Table A- $1\left(1,083^{\circ} \mathrm{C}\right)$, consistent with the results of the pebble-bed core design in Table 10 $\left(1,048^{\circ} \mathrm{C}\right)$. On the whole, the maximum temperatures and the temperature change upon passage through the core were arguably higher and more challenging for the fuel irradiated in the AVR than will be the case for NGNP pebble-bed; thus, AVR fuel performance data can be used to conservatively project expected pebble-bed fuel performance.

In order to use the fuel performance data for spheres irradiated in the AVR, it is necessary to know the failure fraction at the end of the irradiation. The data from the following procedures are used to identify failed particles in spheres irradiated in the AVR:

- $\quad{ }^{85} \mathrm{Kr}$ and ${ }^{137} \mathrm{Cs}$ Release on Heating - For spheres that were subjected to heating tests in the KÜFA facility following irradiation, the existence of particles with exposed kernels is indicated by the ${ }^{85} \mathrm{Kr}$ release upon initial heating. Particles with $\mathrm{SiC}$ defects are indicated by the ${ }^{137} \mathrm{Cs}$ release upon initial heating. The heating test data are analyzed in detail in Section A-1.3 and found to provide a sound basis for differentiating and quantifying exposed kernels and $\mathrm{SiC}$ defects in fuel irradiated in the AVR. The results of analysis of ${ }^{85} \mathrm{Kr}$ and ${ }^{137} \mathrm{Cs}$ release data for GLE 3 spheres irradiated in the AVR are given in Table 7 of Section 3.2.3. No exposed kernels and a total of eight $\mathrm{SiC}$ defects were identified from these 13 spheres.

- Fission-Product Profile in Fuel-Free Zone - An additional 13 GLE 3 and six GLE 4 spheres were subjected to a PIE procedure whereby the matrix material in the fuel-free zone was progressively removed and measured to determine the fission-product profile. If a sphere had a particle releasing cesium, the ${ }^{137} \mathrm{Cs}$ profile in the fuel-free layer was inverted relative to spheres without failed particles. On this basis, one coated-particle SiC defect was identified in the 13 GLE 3 spheres, and no defects were identified in the six GLE 4 spheres.

- Progressive Deconsolidation of Fuel Spheres - Five GLE 4 spheres were subjected to progressive (chemical) deconsolidation, including determining the fission-product concentration in the leachate as the deconsolidation progressed. The presence of ${ }^{137} \mathrm{Cs}$ in the leachate was used to indicate the presence of a failed particle. One particle with an exposed kernel was identified in the five GLE 4 spheres examined using this procedure. 
The results of the last two procedures identified above support and confirm the results and conclusions of the analysis of post-irradiation heating data. However, the fission-product profile data are not calibrated and would not distinguish between an exposed kernel and a SiC defect since they are based on cesium release. Likewise, the deconsolidation leachate analysis would not identify SiC defects with an intact dense PyC layer, and particles could potentially be damaged by the deconsolidation process. Given that the GLE 4 spheres are not optimally prototypical of pebble-bed spheres, having a slightly smaller particle-packing fraction and higher enrichment, these data are considered confirmatory of the heating test analysis but are not used to quantify performance of fuel irradiated in the AVR. The AVR results of Table 7 will be used in conjunction with MTR data discussed in Section A-1.2 to quantify normal-operation performance projections based on the German experience.

\section{A-1.2 Materials Test Reactor Irradiation Data}

A detailed listing of German fuel specimens irradiated in MTRs is provided in Table A-7 and Table A-8. Irradiations were conducted in three reactors (experiment designations are shown in parentheses):

- $\quad$ HFR in Petten, the Netherlands (HFR-xxx)

- Siloe in Grenoble, France (SL-xxx)

- DIDO in Jülich, Germany (FRJ2-xxx).

Fuel containing LEU UO $\mathrm{UR}_{2}$ TRSO particles was irradiated in the above reactors in three fuel forms:

- $\quad$ Full-size spheres (HFR-K3, HFR-K5, HFR-K6, FRJ2-K13, FRJ2-K15)

- Small (2-cm-diameter) spheres embedded in a cylinder of matrix material (HFR-P4, SL-P1)

- Cylindrical compacts (FRJ2-P27).

The irradiation locations in HFR and Siloe had harder neutron spectra relative to the pebble-bed design, resulting in higher fast fluence for a given burnup. The locations in DIDO had a softer spectrum than the pebble-bed design, resulting in low fast fluence for a given burnup. There are two primary effects of fast fluence that affect the potential for particle failure:

- Exposure to fast fluence in the inner and outer dense pyrocarbon layers produces shrinkage up to approximately $4 \times 10^{21} \mathrm{n} / \mathrm{cm}^{2}$, imposing compressive stresses on the SiC layer, which is more rigid and dimensionally stable

- Exposure to fast fluence in the $\mathrm{SiC}$ layer reduces its tensile strength.

In irradiations conducted in the U.S. in the 1990s, the pyrocarbon properties were such that large failure fractions were observed as a result of excessive pyrocarbon shrinkage leading to cracking of both the pyrocarbon and $\mathrm{SiC}$ layers. ${ }^{7}$ As discussed in Reference 7, the properties of the German pyrocarbon layers are such that this type of failure is not observed. However, the German dense pyrocarbon layers are observed to shrink, imposing a compressive stress on the $\mathrm{SiC}$ layer. This shrinkage can have a beneficial effect on the structural performance of the particle by enhancing the sharing of internal pressure loads among the layers. Without pyrocarbon shrinkage, the more rigid SiC layer would be subjected to most of the tensile load as fission-gas pressure builds up within the particle. Thus, depending on the specific conditions, fast fluence can either increase or decrease the likelihood of particle failure. Having MTR data at both higher and lower fast fluence than the pebble-bed design provides assurance that the range of exposure conditions that can be present in pebble-bed fuel is enveloped by the irradiation data.

All of the irradiation data on the German LEU UO $\mathrm{U}_{2}$ TRISO fuel listed in Table A-7 and Table A-8, including loose particles, compacts (small sphere in a matrix cylinder), and full-sized spheres provide useful data in assessing the performance capability of the fuel. However, only full-sized fuel spheres of 
comparable enrichment and packing fraction are considered sufficiently prototypical to include in a quantified performance projection. This includes the GLE 3 spheres irradiated in the AVR and discussed previously and the LEU Phase 1 and Proof Test spheres irradiated in MTRs. For the spheres subjected to heating tests, the $\mathrm{SiC}$ defects could be identified based on the initial ${ }^{137} \mathrm{Cs}$ release, as discussed in Section A-1.3.3 and listed in Table 7. For the spheres not subjected to heating tests, no data are available on $\mathrm{SiC}$ defects. However, the existence of particles with exposed kernels would be registered by the in-pile gaseous fission-product release for fuels irradiated in MTRs. The data and associated discussion in Table 3-3 of Reference 4 and associated discussion show that the maximum end of irradiation ${ }^{85 \mathrm{~m}} \mathrm{Kr} \mathrm{R} / \mathrm{B}$ ratio was $3 \times 10^{-7}$ for spheres HFR-K5/4 and HFR-K6/4, indicating exposed kernels in these spheres and that none of the other spheres listed in Table A-2 contained an exposed kernel.

Table A-2. Prototypical sphere materials test reactor irradiations.

\begin{tabular}{|c|c|c|c|c|c|c|c|}
\hline ID & $\begin{array}{c}\text { No. of } \\
\text { Particles }\end{array}$ & Burnup & Fast Fluence & $\begin{array}{c}\text { Irradiation } \\
\text { Temperature }\end{array}$ & $\begin{array}{c}\text { Test } \\
\text { Temperature }\end{array}$ & $\begin{array}{c}\text { Exposed } \\
\text { Kernels }\end{array}$ & $\begin{array}{c}\mathrm{SiC} \\
\text { Defects }\end{array}$ \\
\hline \multicolumn{8}{|c|}{ MTR Spheres Subjected to Heating Tests } \\
\hline HFR-K3/1 & 16,400 & 7.5 & 4 & 1,200 & 1,600 & 0 & 0 \\
\hline FRJ2-K13/2 & 16,400 & 8 & 0.2 & 1,150 & 1,600 & 0 & 1 \\
\hline FRJ2-K13/4 & 16,400 & 7.6 & 0.2 & 1,120 & 1,600 & 0 & 0 \\
\hline HFR-K3/3 & 16,400 & 10.6 & 5.9 & 920 & 1,800 & 0 & 0 \\
\hline $\begin{array}{l}\text { Subtotal } \\
\text { Particles } \\
\end{array}$ & 65,600 & 8.4 & 2.6 & 1,098 & $<$ Avg. Subtotal $>$ & 0 & 1 \\
\hline \multicolumn{8}{|c|}{ MTR Spheres Not Subjected to Heating Tests } \\
\hline HFR-K3/2 & 16,400 & 10 & 5.8 & 920 & & 0 & $\mathrm{~N} / \mathrm{D}^{\mathrm{a}}$ \\
\hline HFR-K3/4 & 16,400 & 9 & 4.9 & 1,220 & & 0 & $\mathrm{~N} / \mathrm{D}$ \\
\hline HFR-K5/1 & 14,580 & 7.8 & 4 & 923 & & 0 & $\mathrm{~N} / \mathrm{D}$ \\
\hline HFR-K5/2 & 14,580 & 10.1 & 5.8 & 909 & & 0 & $\mathrm{~N} / \mathrm{D}$ \\
\hline HFR-K5/3 & 14,580 & 10.3 & 5.9 & 903 & & 0 & N/D \\
\hline HFR-K5/4 & 14,580 & 9.3 & 4.9 & 921 & & 1 & $\mathrm{~N} / \mathrm{D}$ \\
\hline HFR-K6/1 & 14,580 & 8.3 & 3.2 & 1,090 & & 0 & $\mathrm{~N} / \mathrm{D}$ \\
\hline HFR-K6/2 & 14,580 & 10.6 & 4.6 & 1,130 & & 0 & $\mathrm{~N} / \mathrm{D}$ \\
\hline HFR-K6/3 & 14,580 & 10.9 & 4.8 & 1,140 & & 0 & $\mathrm{~N} / \mathrm{D}$ \\
\hline HFR-K6/4 & 14,580 & 9.9 & 4.5 & 1,130 & & 2 & $\mathrm{~N} / \mathrm{D}$ \\
\hline FRJ2-K13/1 & 16,400 & 7.5 & 0.2 & 1,125 & & 0 & $\mathrm{~N} / \mathrm{D}$ \\
\hline FRJ2-K13/3 & 16,400 & 7.9 & 0.2 & 1,150 & & 0 & $\mathrm{~N} / \mathrm{D}$ \\
\hline \multicolumn{8}{|c|}{ Exposed Kernels } \\
\hline $\begin{array}{l}\text { Total } \\
\text { Particles }\end{array}$ & 247,800 & 8.5 & 3.8 & 1,062 & $\leftarrow$ Avg. Total $\rightarrow$ & 3 & $\mathrm{n} / \mathrm{a}^{\mathrm{b}}$ \\
\hline \multicolumn{8}{|l|}{ SiC Defects } \\
\hline $\begin{array}{l}\text { Total } \\
\text { Particles }\end{array}$ & 65,600 & 8.4 & 2.6 & 1,098 & $\leftarrow$ Avg. Total $\rightarrow$ & $\mathrm{n} / \mathrm{a}$ & 2 \\
\hline \multicolumn{8}{|c|}{$\begin{array}{l}\text { Notes: } \\
\text { a. N/D - Not Determined (in all cases the cesium release into the surrounding graphite was low enough to demonstrate zero or near-zero } \\
\text { defects). } \\
\text { b. n/a - not applicable. }\end{array}$} \\
\hline
\end{tabular}




\section{A-1.3 Safety Testing}

Data provided in this section are taken from references 1, 2, and 3. Irradiated fuel spheres and compacts from the population described in Section 3.2.2 were subjected to heat-up tests to simulate fuel performance during heat-up accidents. The heating tests covered a range of temperatures up to $2,500^{\circ} \mathrm{C}$, far above temperatures expected under transient and accident conditions in the pebble-bed design.

Isothermal heating tests performed at temperatures from 1,800 to $2,100^{\circ} \mathrm{C}$ and temperature ramp tests to $2,500^{\circ} \mathrm{C}$ showed that there were no "cliff edges" (i.e., sudden or unexpected changes) in the failure behavior of coated particles at high temperatures, below which no failures were observed and above which all coated particles would fail uniformly. Rather, a small fraction of a percent of particle failures was observed as temperatures remained above $1,600^{\circ} \mathrm{C}$ for extended periods (many days). This behavior is assumed to be the result of statistical variations in particle properties, such as kernel diameter, coating thicknesses, and sphericity. Outlier particles (e.g., large kernel, thin coatings, highly aspherical) will fail earlier and at less demanding conditions than the main population of particles with properties near the nominal values. At more elevated temperatures, i.e., above $2,000^{\circ} \mathrm{C}$, widespread particle failures and elevated releases were observed in the test specimens over periods of several hours. This is likely due primarily to the onset of $\mathrm{SiC}$ thermal decomposition. ${ }^{8}$

\section{A-1.3.1 Heating Test Facilities and Procedures}

Irradiated fuel from the AVR and MTRs was subjected to heating tests under controlled conditions with the ability to quantitatively measure the release of both gaseous and metallic fission products. The basic components of the heating test facilities are shown in Figure A-2, which is based on the KÜFA facility. The initial inventories of the isotopes of interest were established by measurement or calculation before starting the test, and the quantities released during the test were trapped and measured to determine the release fraction at a large number of time steps.

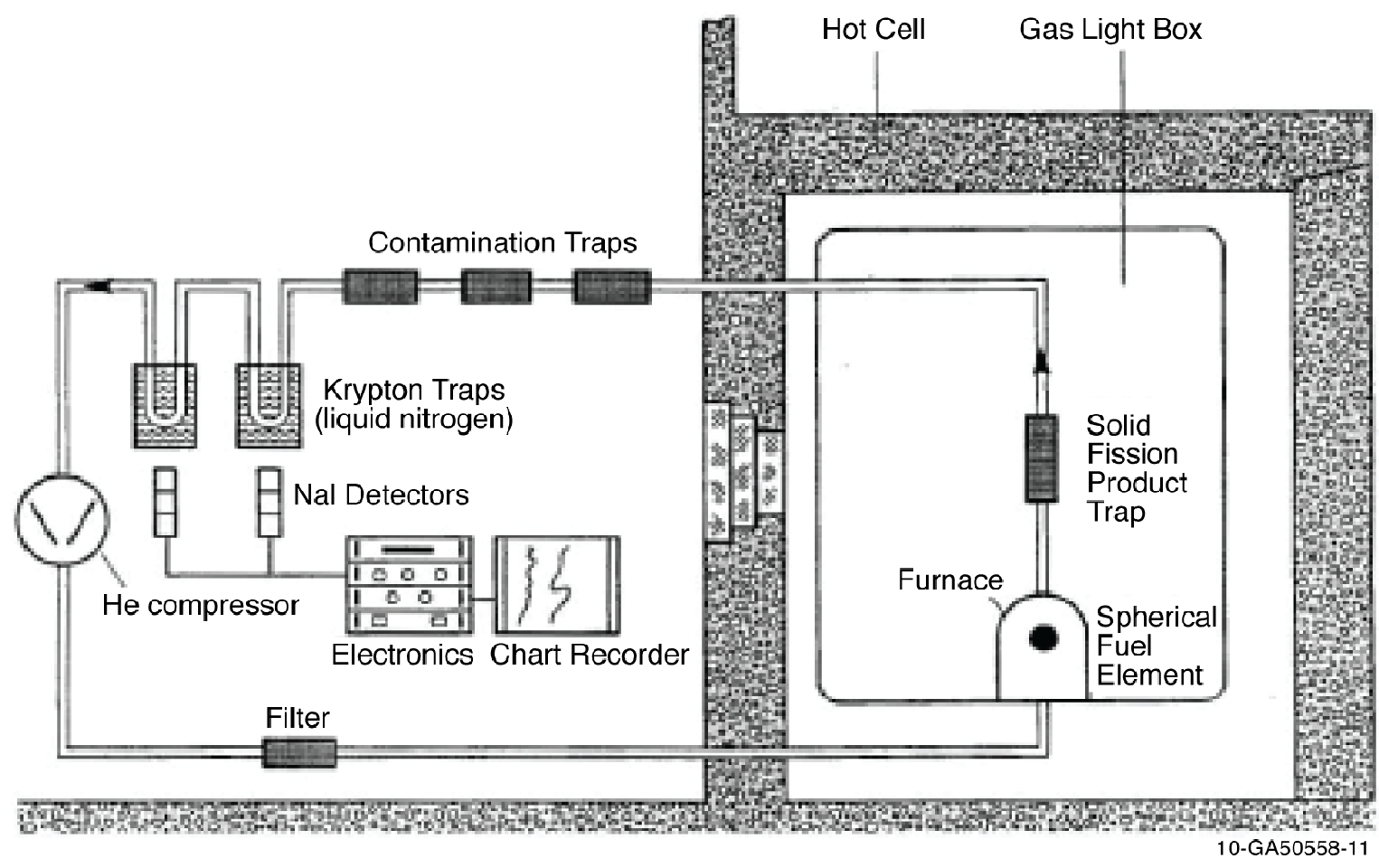

Figure A-2. Heating test facility schematic. ${ }^{2}$ 
Two heating test facilities were used to conduct the tests. The KÜFA facility, shown in Figure A-3, was used to conduct the majority of heating tests on spheres irradiated in the AVR and all of the fuel specimens irradiated in MTRs. In addition to externally trapping and measuring the ${ }^{85} \mathrm{Kr}$ release, it had the capability to remove and replace the cooled in-furnace deposition plates during the course of the test to allow measurement of the time-dependent release of metallic fission products. The tantalum furnace of the KÜFA facility limited temperatures to a maximum of $1,800^{\circ} \mathrm{C}$. Time-dependent temperature control allowed tests simulating the time profile of limiting DLOFC events, as well as isothermal tests as elevated temperature, to be conducted.

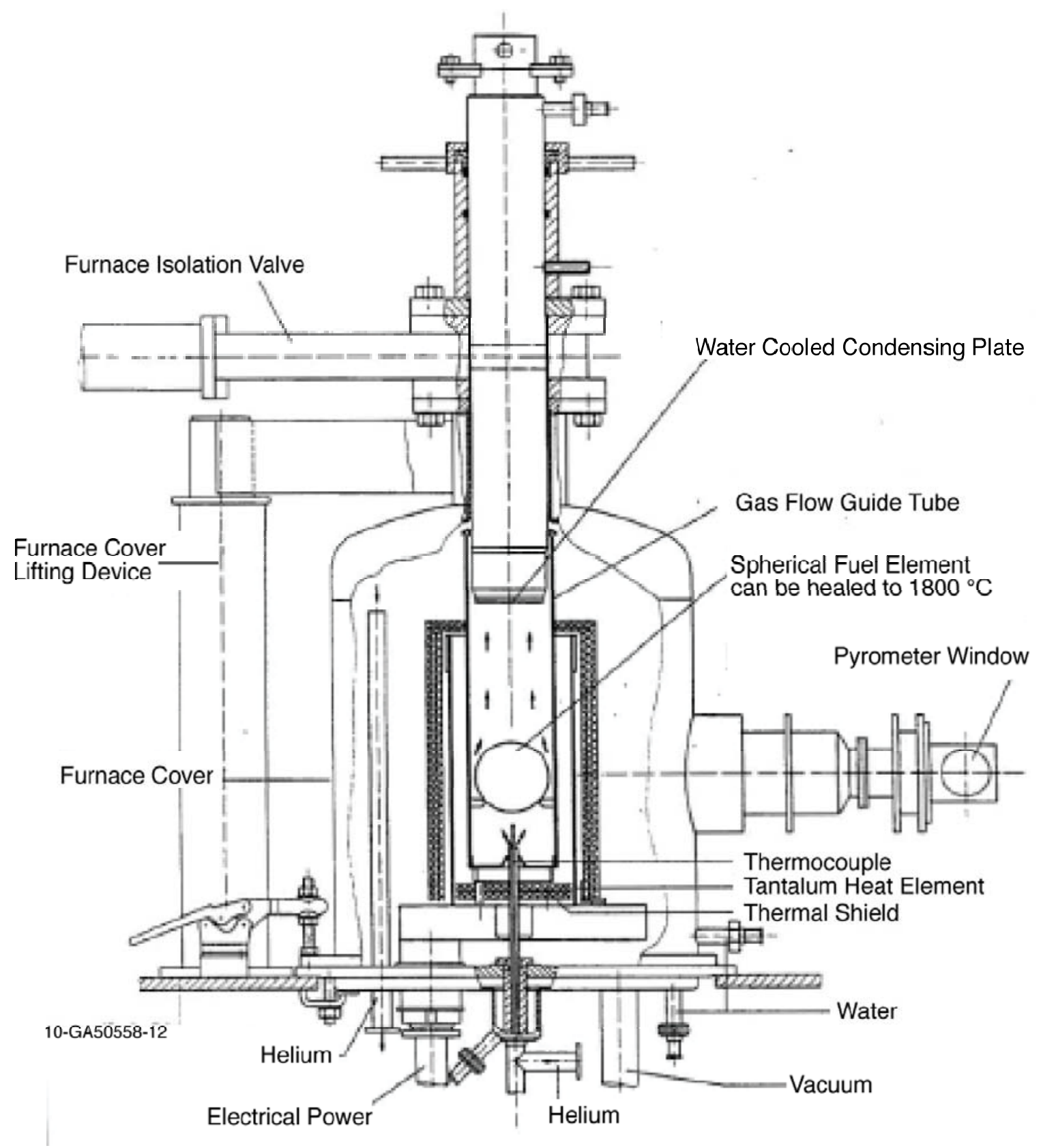

Figure A-3. KÜFA heating test facility. ${ }^{2}$ 
An earlier test facility, labeled the "A"-test graphite furnace, shown in Figure A-4, was capable of conducting tests up to $2,500^{\circ} \mathrm{C}$. This facility was used to conduct isothermal testing on irradiated LEU $\mathrm{UO}_{2}$ TRISO spheres at temperatures from 1,800 to $2,100^{\circ} \mathrm{C}$. It was also used to conduct tests with linearly increasing temperature from 1,250 to $2,500^{\circ} \mathrm{C}$ at a nominal rate of $47^{\circ} \mathrm{C}$ per hour. An important limitation of this facility was the inability to collect time-dependent metallic-fission-product release. In the absence of replaceable deposition plates, the fractional release of solid fission products was only available at the end of the test. In addition, the temperature, which was controlled by a pyrometer, may have been significantly higher than intended during some of the tests due to the effect of fouling of the pyrometer window.

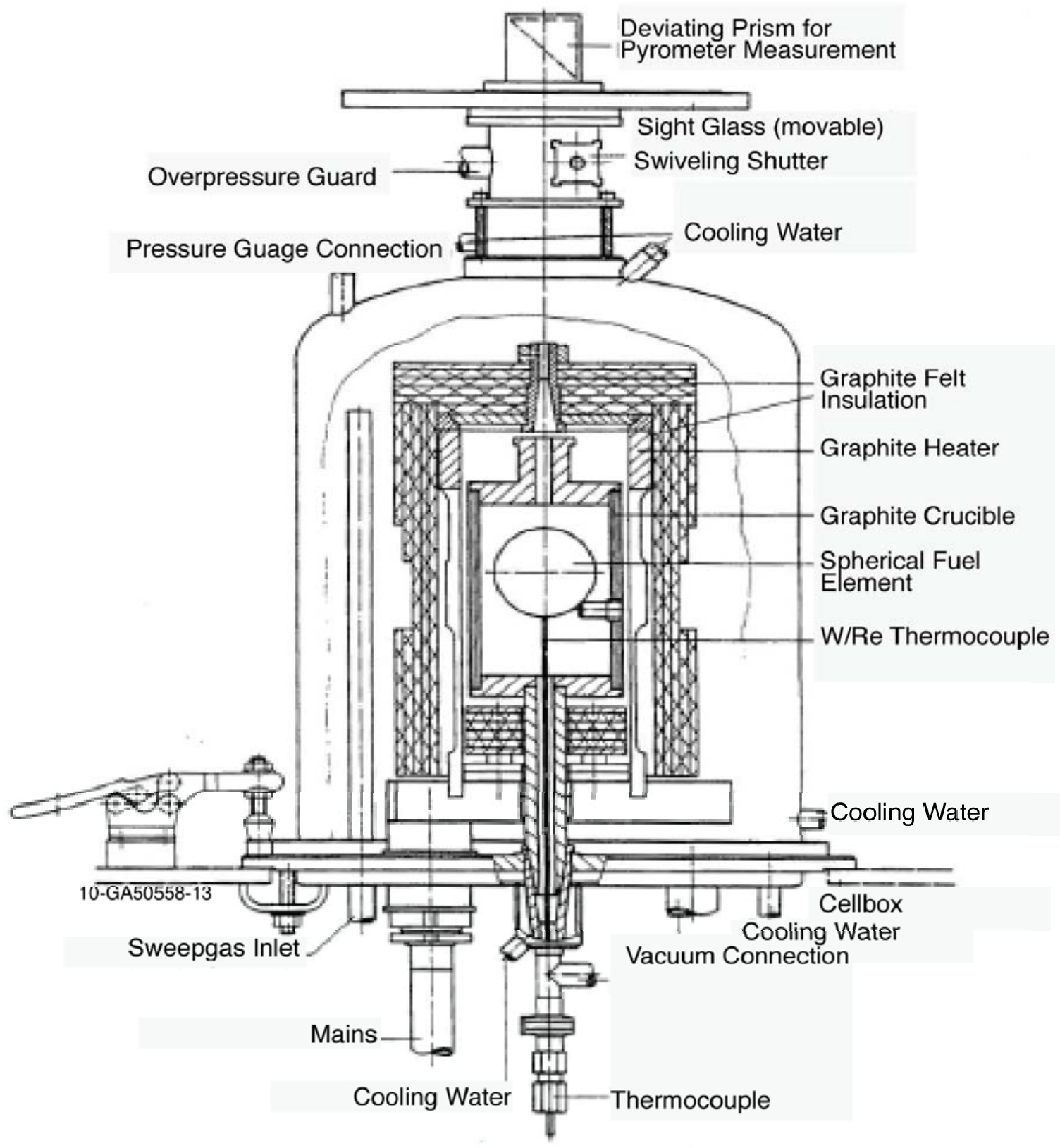

Figure A-4. "A"-test heating test facility. ${ }^{2}$ 
A standard procedure was developed to establish a common initial condition prior to starting the elevated temperature testing, as depicted in Figure A-5. The hold at $300^{\circ} \mathrm{C}$ provided for cleanup of the helium circuit and removal of moisture from graphite components. Holds at 1,050 and $1,250^{\circ} \mathrm{C}$ were for simulation of operating temperatures and equilibration of fuel and fission products. The heat-up rate to the test temperature reflects the thermal characteristics of HTRs.

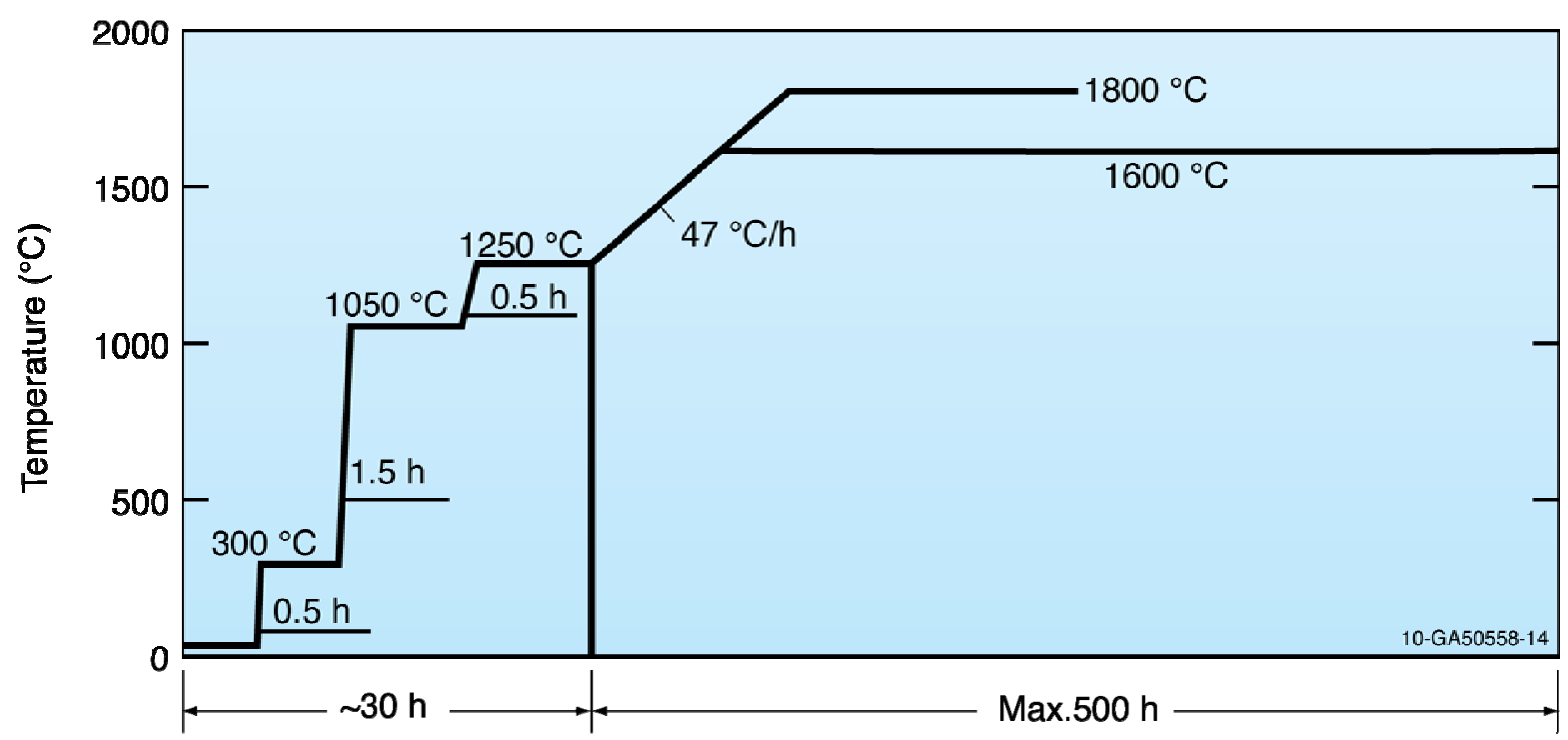

Figure A-5. Temperature profile in standard heating test. ${ }^{2}$

The results of the heating tests conducted on German LEU $\mathrm{UO}_{2}$ TRISO fuel are summarized in the following sections.

\section{A-1.3.2 Heating Test Results $-{ }^{85} \mathrm{Kr}$ Release (Exposed Kernel Failure Fraction)}

A primary input to the accident analysis is the exposed-kernel failure fraction as a function of temperature. At the elevated temperatures of the heating tests, a substantial fraction of the long-lived isotope ${ }^{85} \mathrm{Kr}$ diffuses out of the kernel and is available for rapid release if the coating layers fail. Thus, the

${ }^{85} \mathrm{Kr}$ fractional release data typically give a clear indication of coating failure during the test. In the figures that follow, a line indicating $100 \%$ release from a single particle is shown. This value is $1 /$ (number of particles in the sphere $=16,400$ ) or $6.1 \times 10^{-5}$, and applies to all isotopes. The ${ }^{85} \mathrm{Kr}$ release results as a function of temperature are discussed in the following sections.

\section{$1,600^{\circ} \mathrm{C}$ Isothermal and Transient Testing}

A large number of post-irradiation heating tests of fuel spheres with a maximum temperature of approximately $1,600^{\circ} \mathrm{C}$ were conducted, mainly in support of the HTR Modul design and licensing. The test fuels included fuel irradiated in the AVR as well as in Petten (HFR) and DIDO (FRJ2), and the tests included both isothermal tests at $1,600^{\circ} \mathrm{C}$ and transient simulations with a maximum temperature of $1,620^{\circ} \mathrm{C}$. Burnups ranged from $3.5 \%$ to $9.8 \%$ FIMA. The isothermal ${ }^{85} \mathrm{Kr}$ release data for the fuel spheres irradiated in both the AVR and in MTRs are given in Figure A-6. 


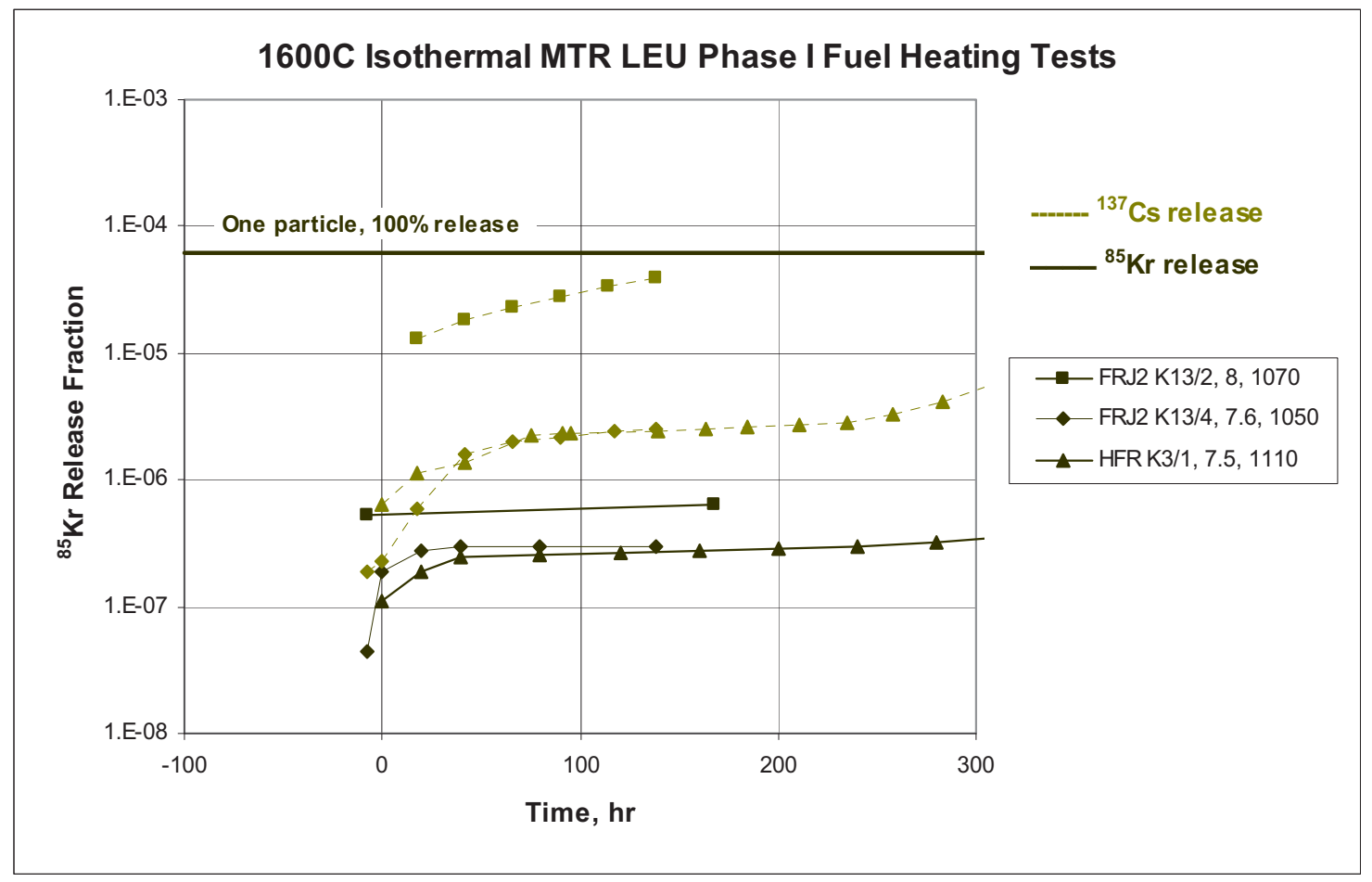

Figure A-6. $1,600^{\circ} \mathrm{C}$ isothermal testing ${ }^{85} \mathrm{Kr}$ release.

The legend in Figure A-6 provides the identifier for each fuel test specimen (FRJ2 refers to irradiation in DIDO, HFR to Petten) along with the end-of-irradiation burnup and, for the MTR irradiations, the irradiation temperature. The tests are listed in the legend approximately in order of decreasing release at $100 \mathrm{~h}$. The theoretical release fraction resulting from $100 \%$ release from a single coated particle is shown for comparison. No particle failures were indicated in any of the spheres tested, with the variation in levels of release associated with variation in levels of HM contamination fraction among the spheres.

Additional $1,600^{\circ} \mathrm{C}$ isothermal tests of irradiated fuel particles were conducted on particles from the same coating batch as was used for the LEU TRISO Phase 1 spheres (EUO 2308). These particles were in a different fuel form, contained in a fueled sphere $2 \mathrm{~cm}$ in diameter located within a cylinder of matrix material. The fueled zone was formed in an isostatic press and surrounded by a 2 -cm layer of matrix to form a sphere that was then machined to a cylinder of dimensions as required by the HFR and Siloe irradiation test rigs. In the data presented here, the burnups for HFR-P4 and SL-P1were adjusted to reflect the results of burnup measurements of selected fuel specimens at Seibersdorf. ${ }^{9}$ This resulted in a reduction of the KFA burnup measurements of approximately 13\%. Although there is no consensus regarding whether the Seibersdorf or the KFA measurements are more credible, it was considered conservative for the purposes of this paper to adjust to the Seibersdorf results. The heating test results, along with burnup, fluence, and irradiation temperature, are shown in Figure A-7. 


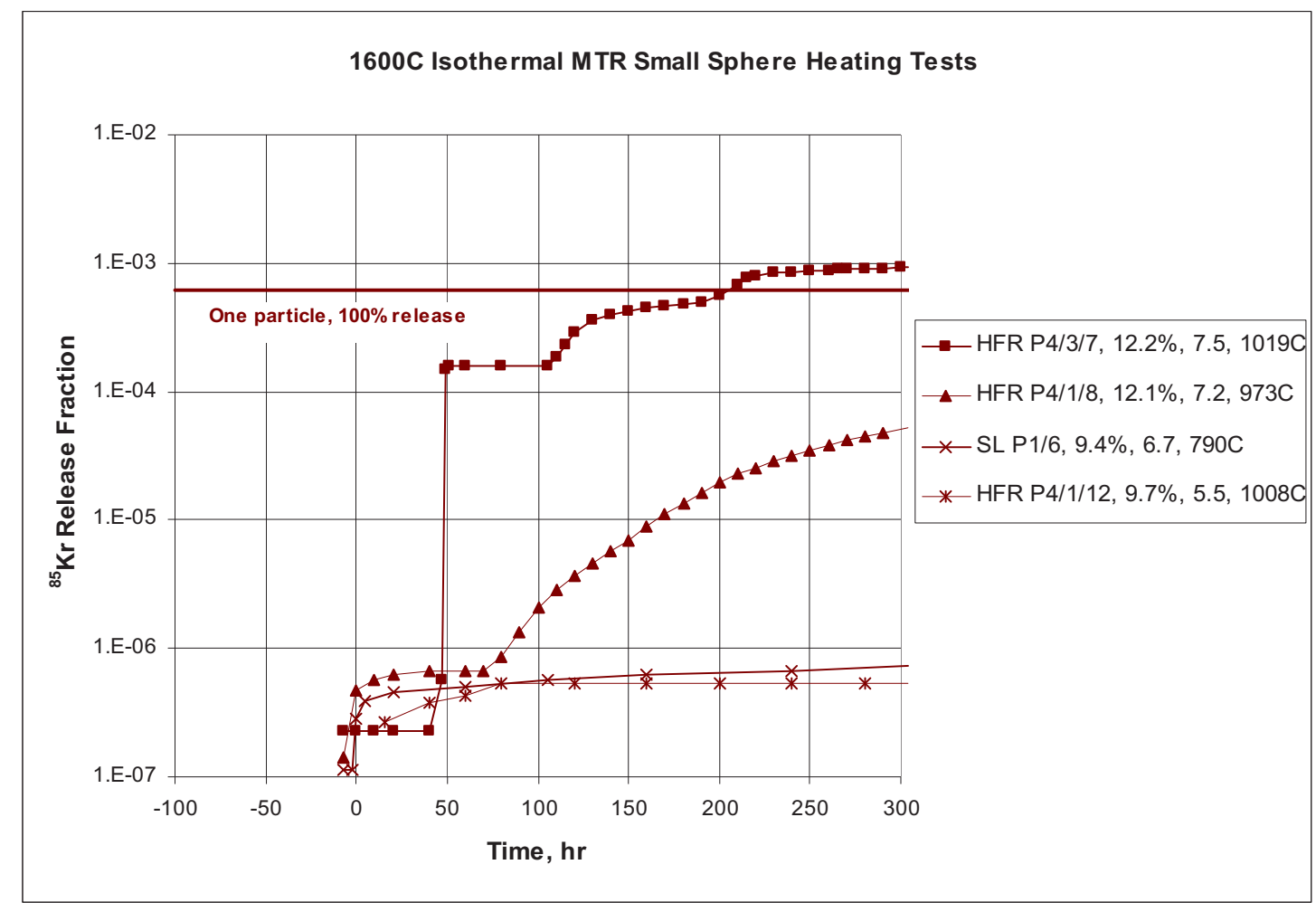

Figure A-7. $1,600^{\circ} \mathrm{C}$ isothermal testing, small spheres ${ }^{85} \mathrm{Kr}$ release.

The theoretical release fraction resulting from $100 \%$ release from a single coated particle is shown for the small spheres from HFR-P4 and SL-P1. The small spheres have a higher release fraction for a single particle failure because they have fewer particles than full-sized spheres (1,631 in the HFR P4 spheres and 1,666 in the SL P1spheres).

The HFR-P4 irradiation rig contained three axial stacks or "legs" of small spheres. HFR-P4 Leg 1 and Leg 3 contained small spheres with particles from coating batch EUO 2308, and Leg 2 contained small spheres with particles from batch EUO 2309, having 51- $\mu$ m-thick SiC. The results from Leg 2 were not included in this assessment because of the different particle design. The results may indicate a dependence of heating test performance on the combination of burnup, fast fluence, and irradiation temperature at these elevated values.

Several fuel spheres irradiated in the AVR were subjected to a simulated thermal transient with a maximum temperature of $1,620^{\circ} \mathrm{C}$; results are shown in Figure A-8 (burnup for each sphere is indicated in the legend). The temperature traces are included, showing the close replication of the temperatures among the tests. 


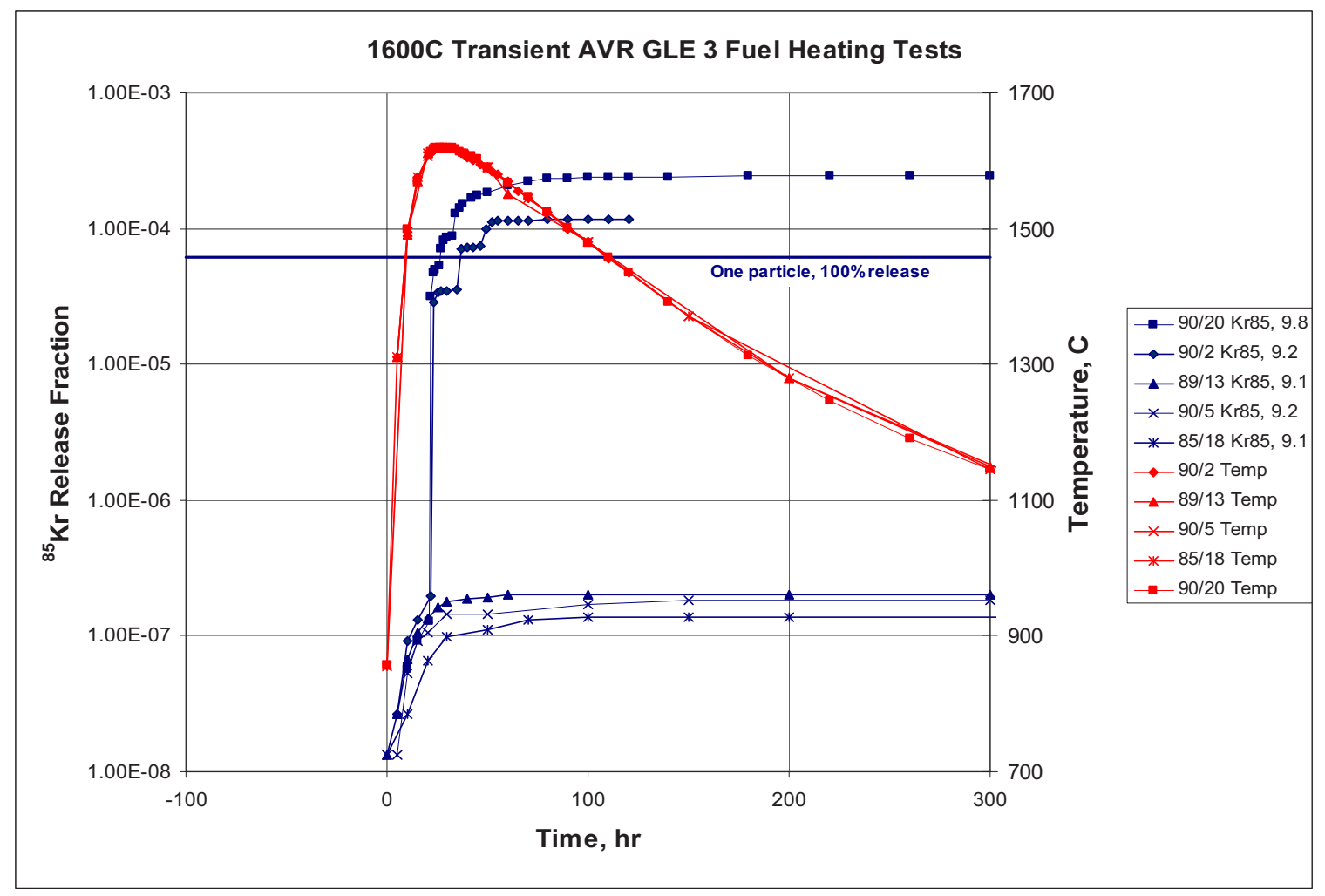

Figure A-8. $1,600^{\circ} \mathrm{C}$ transient temperature testing ${ }^{85} \mathrm{Kr}$ release.

In some of these tests, there is an indication of progressive failure of particles, with sudden increases followed by longer term releases. Assuming 100\% release from the failed particles results in an estimate of four failed particles in AVR 90/20 and two failed particles in AVR 90/2. Again, the tests are listed in order of decreasing release in the legend. It is noteworthy that the releasing particles are from the spheres with the highest burnup, and that all of the AVR spheres in this test had higher burnup than those in the isothermal tests of Figure A-6. The elevated temperatures likely experienced by fuel irradiated in the AVR, as discussed in Section A-1.1, in conjunction with the higher burnup, may be a factor.

The small spheres irradiated in HFR-P4 and SL-P1 provide valuable data with regard to particle performance to high burnup. However, they represent a substantial departure from the geometry of the full-sized spheres, and thus are not included in the performance statistics regarding normal operation (no failures were observed during irradiation; thus, their inclusion would slightly reduce the failure fraction). The overall results of the $1,600^{\circ} \mathrm{C}$ testing of the prototypical GLE 3 and LEU Phase 1 spheres are summarized in Table A-3. In summary, for the $1,600^{\circ} \mathrm{C}$ heating tests, a total of six failed particles was observed out of a total of 213,200 particles. AVR spheres 88/15 and 88/33 were included with the other spheres heated for $100 \mathrm{~h}$, although their test durations at $1,600^{\circ} \mathrm{C}$ were $50 \mathrm{~h}$. They were subsequently tested at $1,800^{\circ} \mathrm{C}$, and their inclusion is based on their performance at both temperatures.

The average burnup and fast fluence of the population of spheres subjected to heating tests at $1,600^{\circ} \mathrm{C}$ $\left(8.3 \%\right.$ FIMA and $2.2 \times 10^{2} 5 \mathrm{n} / \mathrm{m}^{2}$ from Table A-3) are considerably higher than the average NGNP pebble-fuel discharge burnup and fast fluence (8.31 and 2.01 as given in Table 10). Thus, the data can be conservatively applied to project the performance of NGNP pebble-bed fuel. A possible trend between particle failure during heating testing and higher burnup and temperature during irradiation is observed, but the statistics are limited. The release profiles of the failures indicate progressive failure of individual particles in some cases, and multiple failure modes. The maximum through-coating failure fractions from these $1,600^{\circ} \mathrm{C}$ heating tests at 50 and $95 \%$ confidence are $3.1 \times 10^{-5}$ and $5.6 \times 10^{-5}$ respectively. It is worth 
noting that these failure fractions would include any failed particles resulting from manufacturing and irradiation, and the $50 \%$ confidence value is lower than the mean as-manufactured free-uranium fraction for both the GLE 3 and LEU Phase 1 fuels. As noted earlier in the normal operation discussion, this is not surprising, since the burn-leach process used to determine the free-uranium fraction identifies both particles with through-coating failures and particles with defective $\mathrm{SiC}$ layers but intact pyrocarbon layers. The latter particles would not be identified by gaseous fission-product release but will show up in solid fission-product release, as discussed in Section A-1.3.3.

Table A-3. Summary of $1,600^{\circ} \mathrm{C}$ heating test krypton release results.

\begin{tabular}{|c|c|c|c|c|c|c|}
\hline Identifier & $\begin{array}{l}\text { Burnup } \\
\text { (\% FIMA) }\end{array}$ & $\begin{array}{l}\text { Fast Fluence } \\
\left(10^{21} \mathrm{n} / \mathrm{cm}^{2}\right)\end{array}$ & $\begin{array}{l}\text { Irradiation } \\
\text { Temperature } \\
\left({ }^{\circ} \mathrm{C}\right)\end{array}$ & Test Type & $\begin{array}{l}\text { Number of } \\
\text { Particles }\end{array}$ & $\begin{array}{c}\text { Exposed } \\
\text { Kernels }\end{array}$ \\
\hline \multicolumn{7}{|c|}{ AVR Spheres (GLE 3) } \\
\hline $90 / 20$ & 9.8 & 2.94 & Not available & Transient & 16,400 & 4 \\
\hline $90 / 2$ & 9.2 & 2.66 & Not available & Transient & 16,400 & 2 \\
\hline $90 / 5$ & 9.2 & 2.66 & Not available & Transient & 16,400 & 0 \\
\hline $85 / 18$ & 9.15 & 2.63 & Not available & Transient & 16,400 & 0 \\
\hline $89 / 13$ & 9.1 & 2.61 & Not available & Transient & 16,400 & 0 \\
\hline $82 / 9$ & 8.9 & 2.52 & Not available & Isothermal & 16,400 & 0 \\
\hline $88 / 15$ & 8.7 & 2.43 & Not available & Isothermal & 16,400 & 0 \\
\hline $82 / 20$ & 8.6 & 2.38 & Not available & Isothermal & 16,400 & 0 \\
\hline $88 / 33$ & 8.5 & 2.33 & Not available & Isothermal & 16,400 & 0 \\
\hline $71 / 22$ & 3.5 & 0.48 & Not available & Isothermal & 16,400 & 0 \\
\hline \multicolumn{7}{|c|}{ MTR Spheres (LEU Phase 1) } \\
\hline HFR-K3/1 & 7.5 & 4 & 1,200 & Isothermal & 16,400 & 0 \\
\hline FRJ2-K13/2 & 8 & 0.2 & 1,150 & Isothermal & 16,400 & 0 \\
\hline FRJ2-K13/4 & 7.6 & 0.2 & 1,120 & Isothermal & 16,400 & 0 \\
\hline Average & 8.3 & 2.2 & & Total & 213,200 & 6 \\
\hline \multicolumn{6}{|c|}{ Maximum Parent Population Exposed Kernel Fraction, 50\% confidence } & $3.1 \times 10^{-5}$ \\
\hline \multicolumn{6}{|c|}{ Maximum Parent Population Exposed Kernel Fraction, 95\% confidence } & $5.6 \times 10^{-5}$ \\
\hline
\end{tabular}

\section{$1,700^{\circ} \mathrm{C}$ Isothermal and Transient Testing}

The isothermal and transient heating test of irradiated German LEU TRISO fuel to $1,700^{\circ} \mathrm{C}$ was limited to two spheres irradiated in AVR and two small spheres irradiated in Siloe. One of the spheres from the AVR was subjected to a transient temperature profile with a maximum of $1,700^{\circ} \mathrm{C}$, while the remainder were subjected to an isothermal test at $1,700^{\circ} \mathrm{C}$, with results as shown in Figure A-9. In the isothermal tests, it appears that the AVR sphere experienced a partial failure of one particle, while the small spheres irradiated in Siloe remained approximately three orders of magnitude below the level of a single particle failure during the first $100 \mathrm{~h}$.

The AVR sphere subjected to the transient simulation experienced an estimated total of 19 particle failures, with the first failure indicated as the temperature reached $1,600^{\circ} \mathrm{C}$. The statistics for these tests are extremely limited, so it is difficult to reach any conclusions from the results. It is noteworthy that the sphere experiencing the most failure was irradiated in AVR to a significantly higher burnup than the AVR sphere in the isothermal test. While the small spheres in Siloe experienced a higher burnup, the irradiation temperatures were relatively low. Thus, the relative behavior of the tested fuel is consistent with the service conditions experienced during irradiation. 


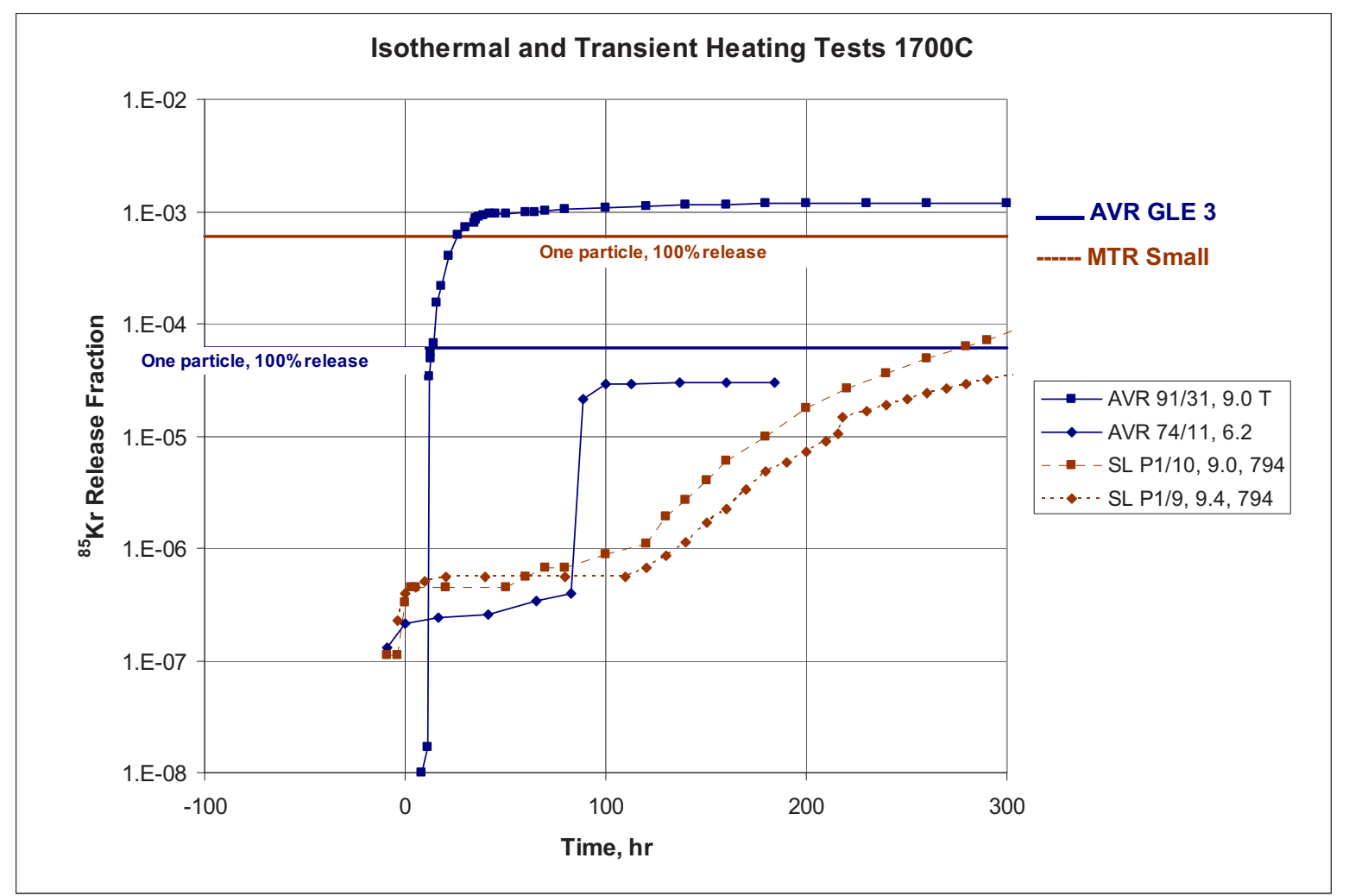

Figure A-9. $1,700^{\circ} \mathrm{C}$ combined testing ${ }^{85} \mathrm{Kr}$ release.

The results of the $1,700^{\circ} \mathrm{C}$ testing for the GLE 3 spheres are summarized in Table A-4. The results are dominated by the failures observed in Sphere AVR 91/31.

Table A-4. Summary of $1,700^{\circ} \mathrm{C}$ heating test krypton release results.

\begin{tabular}{|c|c|c|c|c|c|c|}
\hline Identifier & \begin{tabular}{|c} 
Burnup \\
(\% FIMA)
\end{tabular} & $\begin{array}{c}\text { Fast Fluence } \\
\left(10^{21} \mathrm{n} / \mathrm{cm}^{2}\right)\end{array}$ & $\begin{array}{c}\text { Irradiation } \\
\text { Temperature } \\
\left({ }^{\circ} \mathrm{C}\right) \\
\end{array}$ & Test Type & $\begin{array}{c}\text { Number } \\
\text { of } \\
\text { Particles } \\
\end{array}$ & $\begin{array}{c}\text { Failed } \\
\text { Particles } \\
\end{array}$ \\
\hline \multicolumn{7}{|c|}{ AVR Spheres (GLE 3) } \\
\hline AVR 91/31 & 9.0 & 2.6 & Not available & Transient & 16,400 & 19 \\
\hline AVR 74/11 & 6.2 & 1.4 & Not available & Isothermal & 16,400 & 1 \\
\hline Average & 7.6 & 2.0 & Total & & 32,800 & 20 \\
\hline \multicolumn{6}{|c|}{ Maximum Parent Population Exposed Kernel Fraction, 50\% confidence } & $6.3 \times 10^{-4}$ \\
\hline \multicolumn{6}{|c|}{ Maximum Parent Population Exposed Kernel Fraction, 95\% confidence } & $8.9 \times 10^{-4}$ \\
\hline
\end{tabular}




\section{$1,800^{\circ} \mathrm{C}$ Isothermal Testing}

Isothermal tests at $1,800^{\circ} \mathrm{C}$ were conducted on six GLE 3 spheres irradiated in the AVR, two LEU Phase 1 spheres irradiated in Petten and DIDO, and one small sphere irradiated in Petten. The results are shown in Figure A-10 on the same time scale as the plots of the $1,600^{\circ} \mathrm{C}$ and $1,700^{\circ} \mathrm{C}$ results. It is apparent by comparison with the $1,600^{\circ} \mathrm{C}$ isothermal results of Figure A- 6 that the releases are in general considerably higher and occur much earlier in the $1,800^{\circ} \mathrm{C}$ testing. Also, the burnup dependency that was apparent in the lower temperature tests appears to be absent. In fact, the two highest releasing spheres had the lowest burnup. The AVR 74/10 and AVR 70/33 spheres were heated in the "A"-test furnace, while the remainder were heated in the KÜFA facility. The following was noted in Reference 3:

In some experiments performed with the ' $A$ '-heating furnace the measured temperatures may have been underestimated. The fuel-element temperatures were measured with a hand-held pyrometer through a window in the furnace. It was found that sometimes the window became colored or blackened, thus reducing the measuring effect, which is equivalent of indicating a lower temperature than was actually present.

Thus, the curves in Figure A-10 for AVR 74/10 and AVR 70/33 may represent releases at significantly higher temperature than the other curves from tests conducted in the KÜFA facility. Another factor was that these two spheres were each heated in serial tests conducted several months apart, with the results combined. The two tests were retained in the data set since their inclusion conservatively increases the calculated failure fraction.

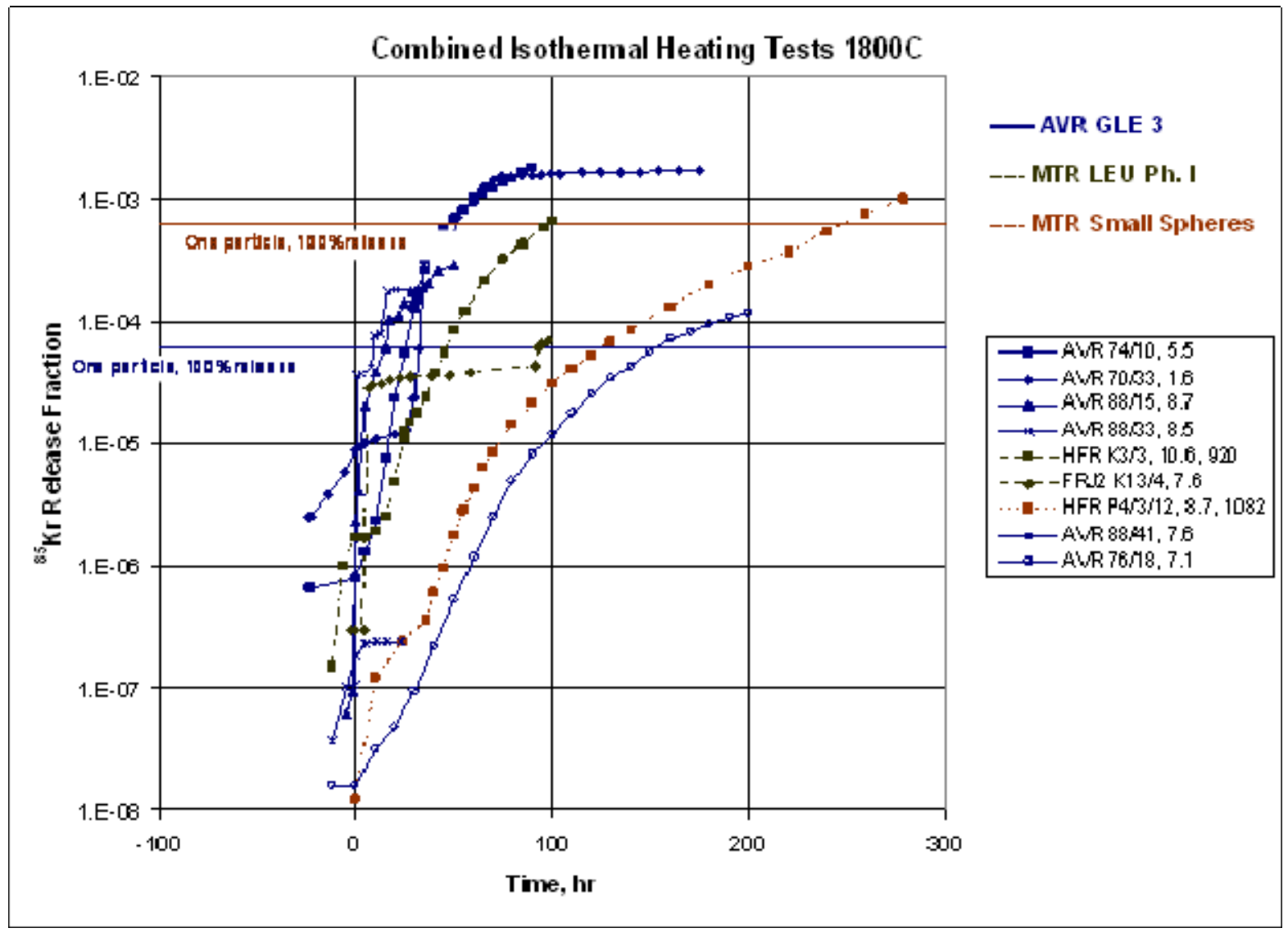

Figure A-10. $1,800^{\circ} \mathrm{C}$ isothermal testing ${ }^{85} \mathrm{Kr}$ release. 
To better illustrate the time dependence of the $1,800^{\circ} \mathrm{C}$ data, Figure A-10 is repeated on a shorter time scale in Figure A-11. In this figure, a sharp inflection in the AVR 70/33 release at $30 \mathrm{~h}$ is apparent. This is the beginning of the second $30-\mathrm{h}$ heating test, which was conducted approximately three months after the first 30-h test. The sudden increase may have been the result of significantly higher temperatures in the second test due to possible temperature control errors noted previously. If the AVR 74/10 and AVR 70/33 data are excluded, the release trends with burnup and irradiation temperature are generally consistent with the observations at the lower temperatures.

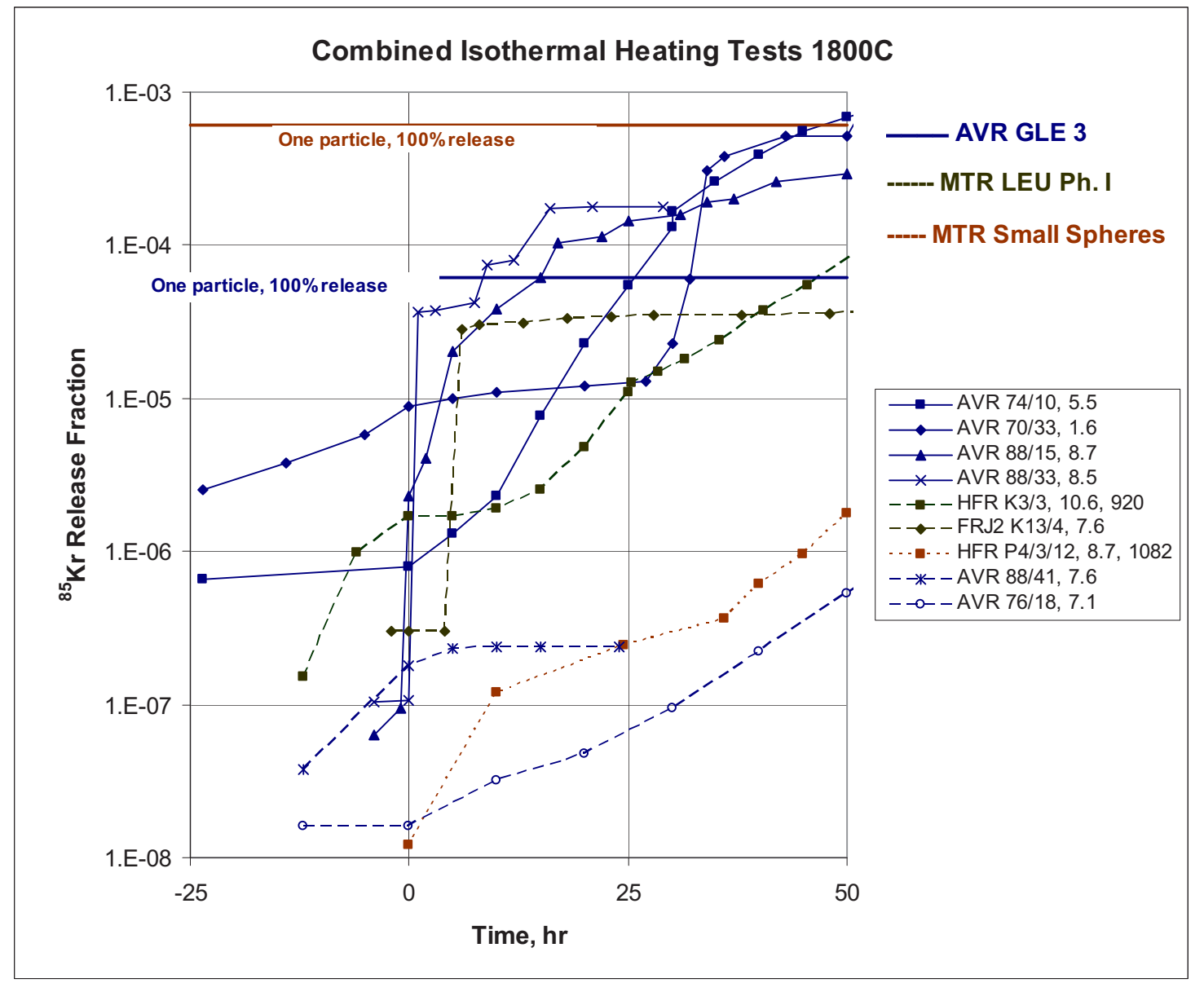

Figure A-11. $1,800^{\circ} \mathrm{C}$ isothermal testing short-term ${ }^{85} \mathrm{Kr}$ release.

The results of the $1,800^{\circ} \mathrm{C}$ heating tests for the GLE 3 and LEU Phase 1 spheres are summarized in Table A-5 for three different heating times. The resulting 50\% and 95\%, confidence failure fractions for each of these three durations are shown. As shown in Table A-5Figure A-13, the results are dominated by the failures in AVR 74/10 and AVR 70/33. Since the basis for inclusion of these data is uncertain (temperatures may have been significantly higher than indicated), the results are also analyzed without them. This results in a reduction in the failure fraction at $100 \mathrm{~h}$ by more than a factor of two. For consistency with the results of the $1,600^{\circ} \mathrm{C}$ and $1,700^{\circ} \mathrm{C}$ testing, the 100 -h duration data will be used for comparison in the summary discussion of the heating test results. 
Table A-5. Summary of $1,800^{\circ} \mathrm{C}$ heating test krypton release results.

\begin{tabular}{|c|c|c|c|c|c|c|c|c|}
\hline \multirow{2}{*}{ Identifier } & \multirow{2}{*}{$\begin{array}{l}\text { Burnup } \\
(\% \\
\text { FIMA })\end{array}$} & \multirow[b]{2}{*}{$\begin{array}{l}\text { Fast Fluence } \\
\left(10^{21} \mathrm{n} / \mathrm{cm}^{2}\right)\end{array}$} & \multirow{2}{*}{$\begin{array}{c}\text { Irradiation } \\
\text { Temperature } \\
\left({ }^{\circ} \mathrm{C}\right) \\
\end{array}$} & \multirow[b]{2}{*}{ Test Type } & \multirow[b]{2}{*}{$\begin{array}{l}\text { Number of } \\
\text { Particles }\end{array}$} & \multicolumn{3}{|c|}{ Failed Particles } \\
\hline & & & & & & \multirow[t]{2}{*}{$30 \mathrm{~h}$} & \multirow[t]{2}{*}{$50 \mathrm{~h}$} & \multirow[t]{2}{*}{$100 \mathrm{~h}$} \\
\hline \multicolumn{6}{|c|}{ AVR GLE 3} & & & \\
\hline $88 / 15$ & 8.7 & 2.4 & & Isothermal & 16,400 & 3 & 5 & $\mathrm{NM}^{*}$ \\
\hline $88 / 33$ & 8.5 & 2.3 & & Isothermal & 16,400 & 3 & NM & NM \\
\hline $88 / 41$ & 7.6 & 1.9 & & Isothermal & 16,400 & 0 & NM & NM \\
\hline $76 / 18$ & 7.1 & 1.7 & & Isothermal & 16,400 & 0 & 0 & 0 \\
\hline $74 / 10$ & 5.5 & 1.1 & & Isothermal & 16,400 & 2 & 11 & 31 \\
\hline $70 / 33$ & 1.6 & 0.2 & & Isothermal & 16,400 & 1 & 8 & 26 \\
\hline \multicolumn{9}{|c|}{ MTR LEU Phase I } \\
\hline HFR K3/3 & 10.6 & 5.9 & 920 & Isothermal & 16,400 & 0 & 1 & 11 \\
\hline $\begin{array}{l}\text { FRJ2 } \\
\text { K13/4 }\end{array}$ & 7.6 & 0.2 & 1,120 & Isothermal & 16,400 & 1 & 1 & 1 \\
\hline \multicolumn{9}{|c|}{ Results Including all Spheres } \\
\hline \multicolumn{4}{|c|}{ Heating Time } & $30 \mathrm{~h}$ & \multicolumn{2}{|c|}{$50 \mathrm{~h}$} & & $100 \mathrm{~h}$ \\
\hline \multicolumn{4}{|c|}{ Average Burnup } & 7.2 & \multicolumn{2}{|c|}{6.9} & & 6.5 \\
\hline \multicolumn{4}{|c|}{ Average Fast Fluence } & 2.0 & \multicolumn{2}{|c|}{1.9} & & 1.8 \\
\hline \multicolumn{4}{|c|}{ Number Failed Particles } & 10 & \multicolumn{2}{|c|}{26} & & 69 \\
\hline \multicolumn{4}{|c|}{ Total Number Particles } & 131,200 & \multicolumn{2}{|c|}{98,400} & \multicolumn{2}{|c|}{82,000} \\
\hline \multicolumn{4}{|c|}{ Exposed Kernel Fraction, 50\% confidence } & $8.1 \times 10^{-5}$ & \multicolumn{2}{|c|}{$2.7 \times 10^{-4}$} & \multicolumn{2}{|c|}{$8.5 \times 10^{-4}$} \\
\hline \multicolumn{4}{|c|}{ Exposed Kernel Fraction, 95\% confidence } & $1.3 \times 10^{-4}$ & \multicolumn{2}{|c|}{$3.7 \times 10^{-4}$} & \multicolumn{2}{|c|}{$1.03 \times 10^{-3}$} \\
\hline Exposed Ke & rnel Fracti & on, $97.5 \%$ con & idence & $1.4 \times 10^{-4}$ & $3.9 \times$ & $10^{-4}$ & 1.0 & $6 \times 10^{-3}$ \\
\hline Results Exc & uding Sph & eres AVR 74/ & 0 and $70 / 33$ & & & & & \\
\hline Heating Tir & & & & $30 \mathrm{~h}$ & & $0 \mathrm{~h}$ & & $100 \mathrm{~h}$ \\
\hline Average $\mathrm{Bu}$ & rnup & & & 8.4 & & 8.5 & & 8.4 \\
\hline Average Fa & t Fluence & & & 2.4 & & 2.6 & & 2.6 \\
\hline Number Ex & osed Kerr & & & 7 & & 7 & & 12 \\
\hline Total Numb & er Particle & & & 98,400 & 65 & 600 & & 49,200 \\
\hline Exposed $\mathrm{Kc}$ & rnel Fracti & on, $50 \%$ confic & lence & $7.8 \times 10^{-5}$ & $1.2 \times$ & $10^{-4}$ & & $2.6 \times 10^{-4}$ \\
\hline Exposed Ke & rnel Fracti & on, $95 \%$ confic & lence & $1.3 \times 10^{-4}$ & $2.0 \times$ & $10^{-4}$ & & $0 \times 10^{-4}$ \\
\hline
\end{tabular}

\section{Higher Temperature Heating Tests}

Although the $1,800^{\circ} \mathrm{C}$ tests were considered sufficient for exploration of performance margins for the HTR-Modul, additional higher temperature tests were conducted in support of other large plant designs (data from References 1, 3 and 5). These include isothermal tests at 1,900; 2,000; and 2,100 ${ }^{\circ} \mathrm{C}$ and linearly increasing temperature up to $2,500^{\circ} \mathrm{C}$. All of these tests were conducted in the "A"-test furnace, so the temperatures could have been higher than indicated in some cases due to fouling of the pyrometer window. The results of these tests are shown in Figure A-12 and Figure A-13. These results show generally consistent effects of burnup and generally increasing failure fractions and release rates with temperature at temperatures far above conditions that are expected in the pebble-bed design. They also show that the failure and release fractions increase progressively and do not indicate any sudden shift in performance. For the 1,900 and $2,000^{\circ} \mathrm{C}$ tests, three of the five spheres tested did not indicate particle failures. Thus, even at temperatures up to $2,000^{\circ} \mathrm{C}$ for $25 \mathrm{~h}$, the releases are on the order of $1 \%$ for the highest releasing spheres, and the majority of the spheres tested did not evidence particle failure. 


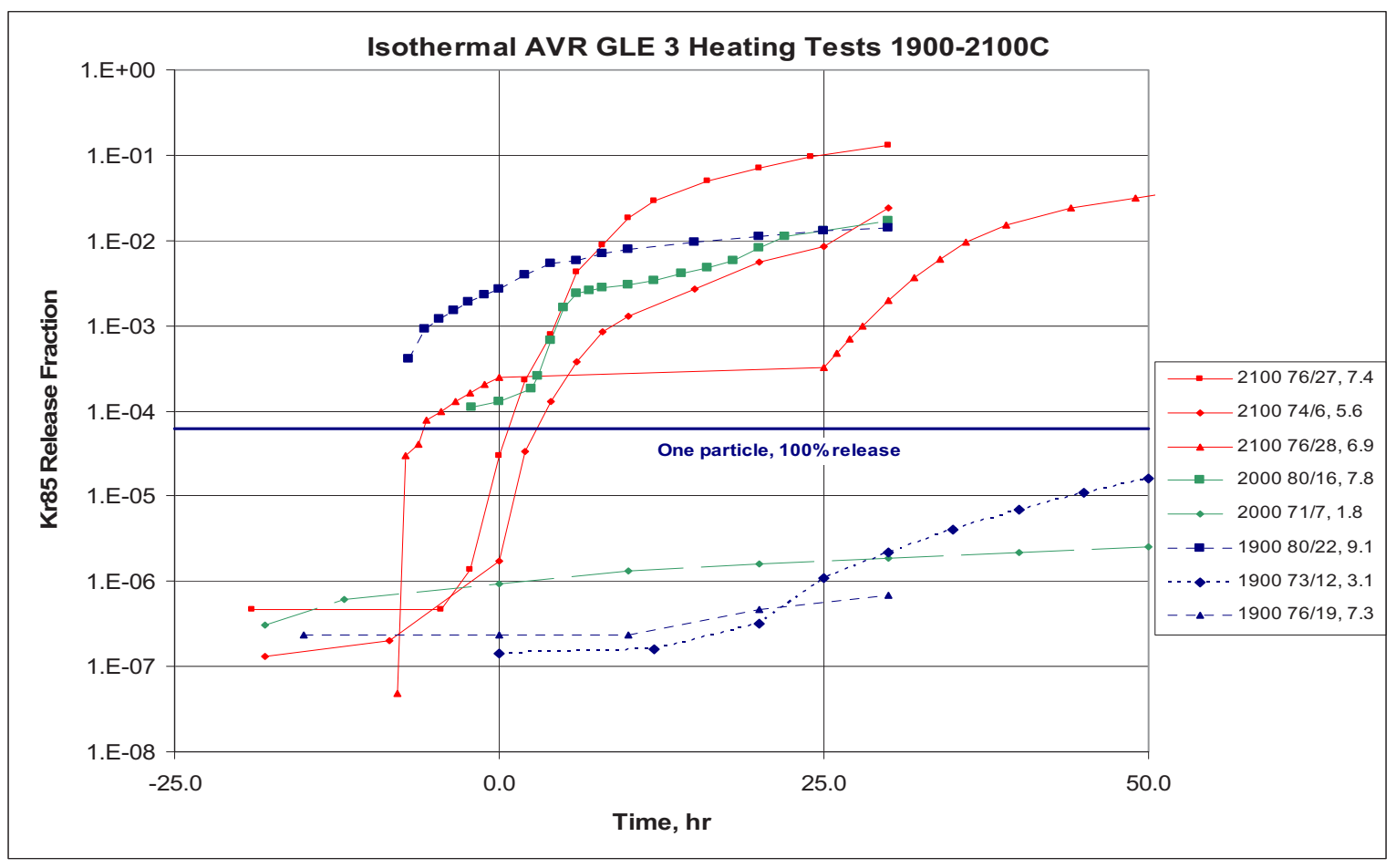

Figure A-12. 1,900 to $2,100{ }^{\circ} \mathrm{C}$ isothermal testing ${ }^{85} \mathrm{Kr}$ release results.

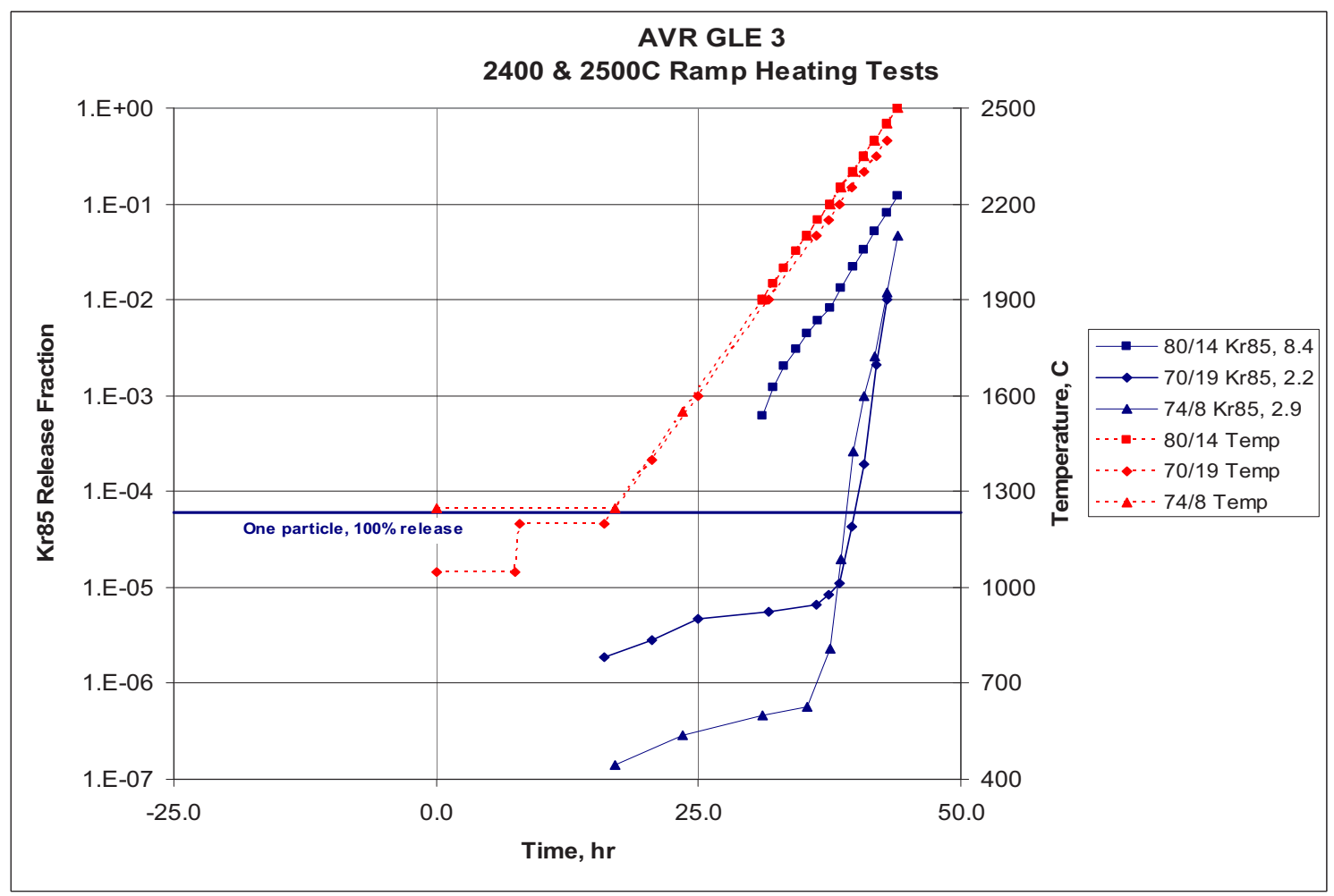

Figure A-13. Temperature ramp testing ${ }^{85} \mathrm{Kr}$ release. 


\section{A-1.3.3 Heating Test Results - Metallic-Fission-Product Release}

The primary metallic fission products of radiological interest for $\mathrm{LEU} \mathrm{UO}_{2}$ TRISO fuel under NGNP pebble-bed service conditions, due to a combination of their yield as well as thermo-chemical and nuclear properties, include silver, cesium, and strontium. Their relative characteristics as they relate to the radiological profile of the NGNP pebble-bed fuel are summarized here:

- Silver is known to begin to be released from TRISO fuel at long-term operating temperatures above $1,200^{\circ} \mathrm{C}$ and from intact particles in significant fractions after several days at $1,600^{\circ} \mathrm{C}$. It deposits in graphite at $\sim 900^{\circ} \mathrm{C}$ and plates out on metallic surfaces at relatively high temperatures $\left(\sim 800^{\circ} \mathrm{C}\right)$ and diffuses into the substrate, where it is effectively captured. As a result, silver does not present an important concern with regard to offsite dose but can be a dominant contributor to occupational dose depending on component maintenance requirements.

- Strontium is retained in oxide kernels during normal operation, even when coatings are defective, and is slowly released at elevated temperatures beyond pebble-bed design accident conditions (i.e., approaching $1,800^{\circ} \mathrm{C}$ for several days). Additionally, it is absorbed in matrix graphite, and little is released from spherical fuel elements. Since strontium does not emit gamma radiation, it is difficult to measure, and the results shown have an uncertainty of an order of magnitude, while the other fission-product release data have an uncertainty of around $10 \%$.

- Cesium is also released from particles with defective SiC layers in normal operation and can be released from the fuel spheres depending on the local conditions. However, there is a significant delay in release from the sphere due to holdup in the matrix.

Since they can be released from particles with intact pyrocarbon layers and have significant lag times for release from a sphere if a through-coating failure develops, metallic fission products are not good indicators of through-coating failures during the heating tests. However, they provide important data on the presence of particles with defective $\mathrm{SiC}$ layers and intact pyrocarbon layers. In order to illustrate the relative behaviors of silver, strontium, and cesium, data on releases of all three are discussed for representative heating tests at $1,600^{\circ} \mathrm{C} ; 1,700^{\circ} \mathrm{C}$; and $1,800^{\circ} \mathrm{C}$. Cesium release is also presented in conjunction with krypton release for all of the available GLE 3 and LEU Phase 1 sphere tests at 1,600; 1,700 ; and $1,800^{\circ} \mathrm{C}$. The primary cesium isotopes of interest are ${ }^{134} \mathrm{Cs}$ and ${ }^{137} \mathrm{Cs}$, whose inventories developed differently as a function of burnup, but whose release fractions under accident conditions are very similar. Thus, to maintain focus and limit the amount of data presented, the ${ }^{137} \mathrm{Cs}$ releases will be provided, recognizing that the ${ }^{134} \mathrm{Cs}$ data are also available. The combination of ${ }^{85} \mathrm{Kr}$ and ${ }^{137} \mathrm{Cs}$ data in the early phase of the heating tests allows determination of both through-coating failure fractions and failure fractions of particles with $\mathrm{SiC}$ defects and an intact pyrocarbon layer. The ${ }^{85} \mathrm{Kr}$ behavior was discussed in Section A-1.3.2 but is also included here to contrast with the ${ }^{137} \mathrm{Cs}$ release.

\section{$1,600^{\circ} \mathrm{C}$ Isothermal and Transient Testing}

The ${ }^{110 \mathrm{~m}} \mathrm{Ag},{ }^{90} \mathrm{Sr}$, and ${ }^{137} \mathrm{Cs}$ release data for a representative $1,600{ }^{\circ} \mathrm{C}$ isothermal heating test are presented in Figure A-14 (data from Reference 3). At $1,600^{\circ} \mathrm{C}$, the silver is released relatively slowly from intact particles. With the exception of low-level initial release likely resulting from contamination near the surface, the strontium is retained within the sphere, although some release may occur from the particles, and the cesium is retained within the particles. (At this temperature, if cesium were released from intact particles, a significant fraction would be released from the spheres.) 


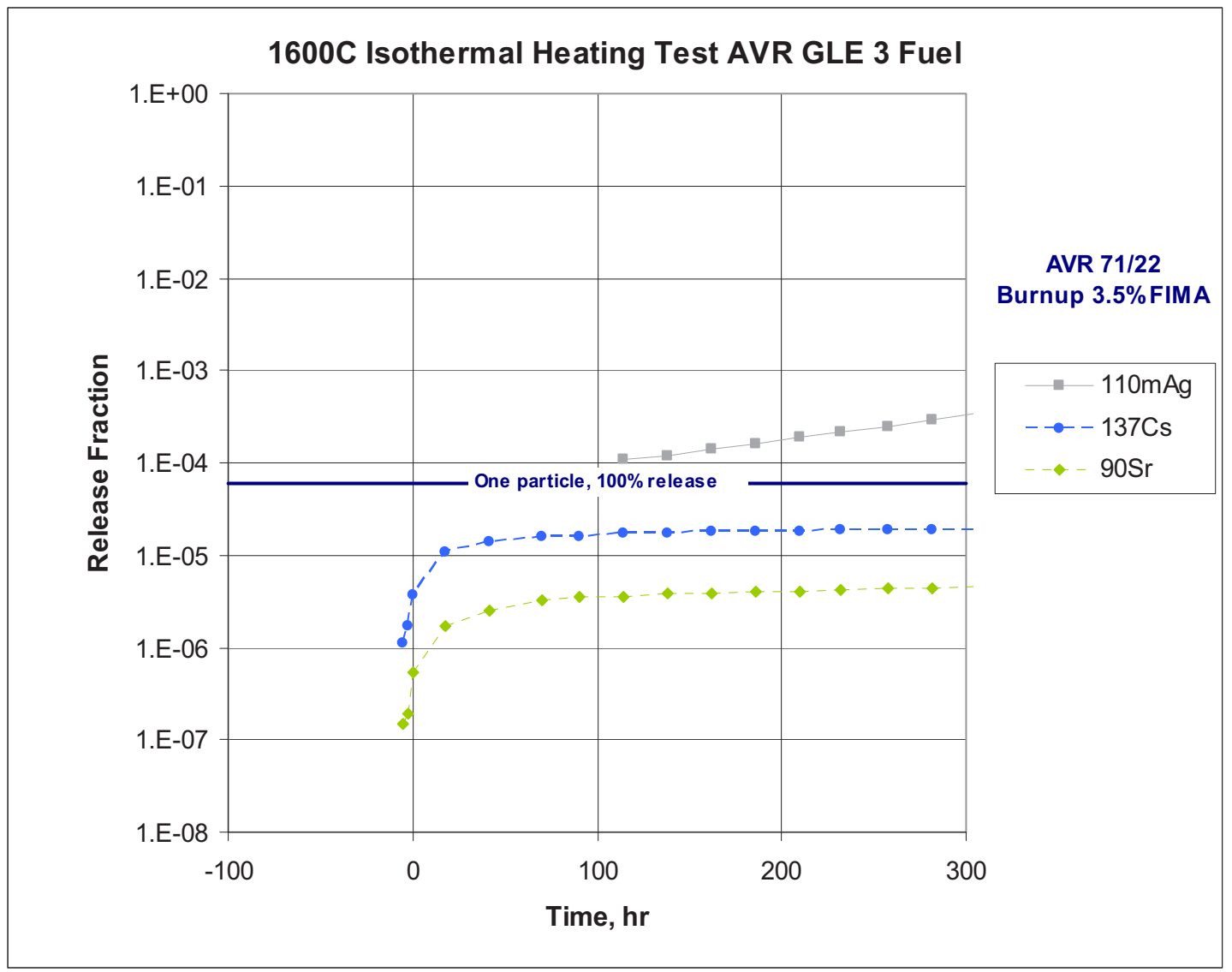

Figure A-14. AVR $71 / 221,600^{\circ} \mathrm{C}$ isothermal testing ${ }^{110 \mathrm{~m}} \mathrm{Ag},{ }^{90} \mathrm{Sr}$, and ${ }^{137} \mathrm{Cs}$ release.

The ${ }^{85} \mathrm{Kr}$ and ${ }^{137} \mathrm{Cs} 1,600{ }^{\circ} \mathrm{C}$ isothermal heating test results for the AVR GLE 3 fuel are shown in Figure A-15. As with earlier plots, the legend includes the sphere burnup in \% FIMA. The primary value of these data is the identification of particles with a defective SiC layer at the end of irradiation, as indicated by the ${ }^{137} \mathrm{Cs}$ release at the beginning of the test. As was discussed in Section A-1.3.2, the ${ }^{85} \mathrm{Kr}$ data show that there were no particles with through-coating failure in any of the four spheres presented. The AVR 82/9 sphere data, which were presented in Section A-1.3.2, are not included here because the ${ }^{137} \mathrm{Cs}$ release data were reported to have been distorted by contamination.

As shown in Figure A-15, the ${ }^{137}$ Cs release for spheres AVR 71/22 and AVR 88/15 levels out well below one particle inventory, indicating that the release is from externally deposited cesium onto the sphere surface and HM contamination in the sphere. (The level of ${ }^{137} \mathrm{Cs}$ due to $\mathrm{HM}$ contamination at the end of irradiation is much higher than that of ${ }^{85} \mathrm{Kr}$ because most of the ${ }^{85} \mathrm{Kr}$ from contamination would have been released from the sphere during the irradiation.) The ${ }^{137} \mathrm{Cs}$ data for AVR 82/20 were asymptotically approaching the single-particle inventory through the first $70 \mathrm{~h}$. The ${ }^{137} \mathrm{Cs}$ release for the last data point of AVR 88/33 corresponds to two particle inventories. Since it is not clear that the curve is approaching the asymptote, the response was interpreted as three particles with defective $\mathrm{SiC}$ layers. In summary, the ${ }^{137} \mathrm{Cs}$ data indicate there were no particles with $\mathrm{SiC}$ defects in spheres AVR 71/22 and AVR 88/15, one in AVR 82/20, and three in AVR 88/33. 


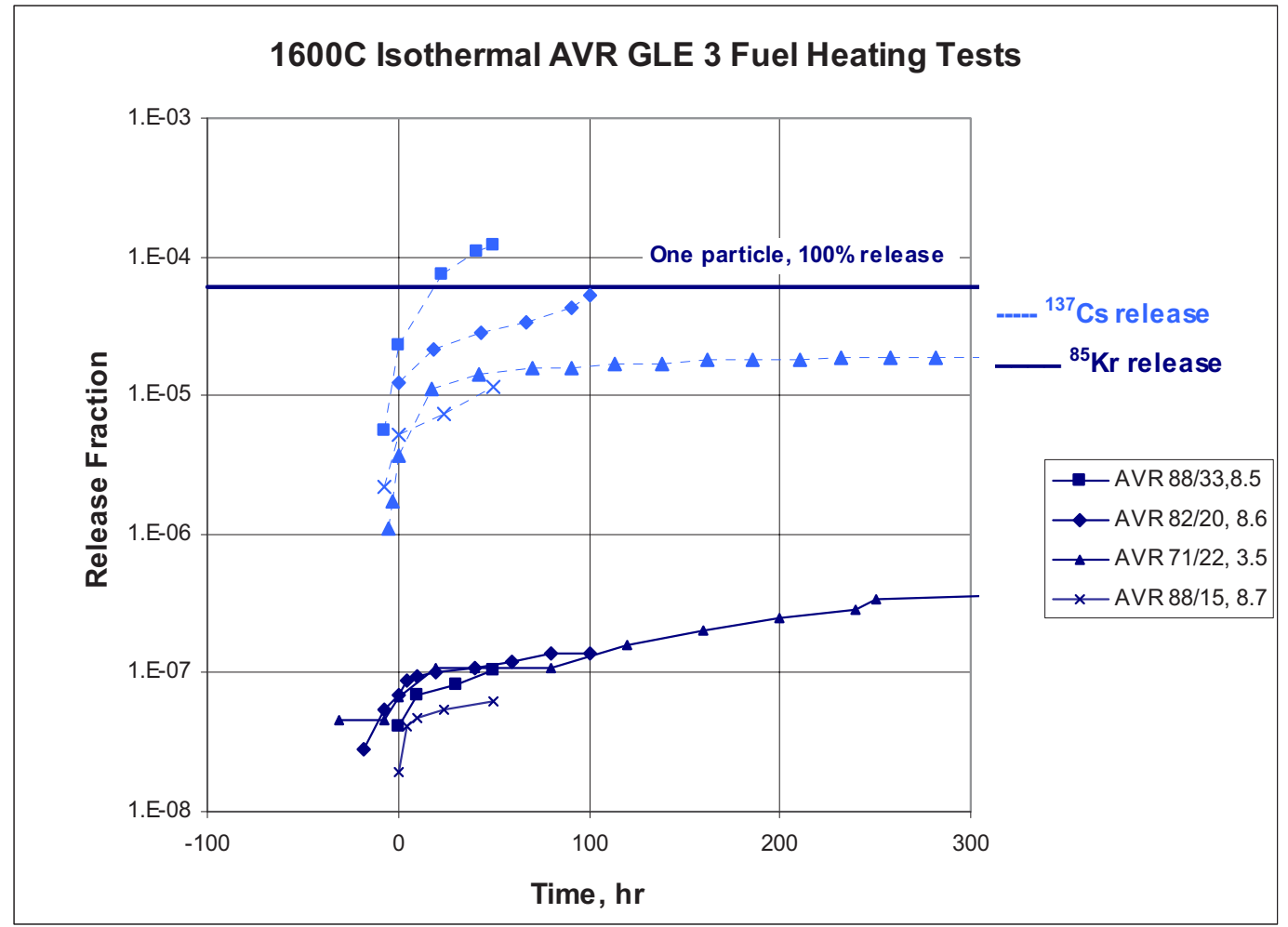

Figure A-15. $1,600{ }^{\circ} \mathrm{C}$ isothermal GLE 3 testing ${ }^{85} \mathrm{Kr}$ and ${ }^{137} \mathrm{Cs}$ release.

The ${ }^{85} \mathrm{Kr}$ and ${ }^{137} \mathrm{Cs} 1,600^{\circ} \mathrm{C}$ transient heating test results for the AVR GLE 3 fuel are shown in Figure A-16.

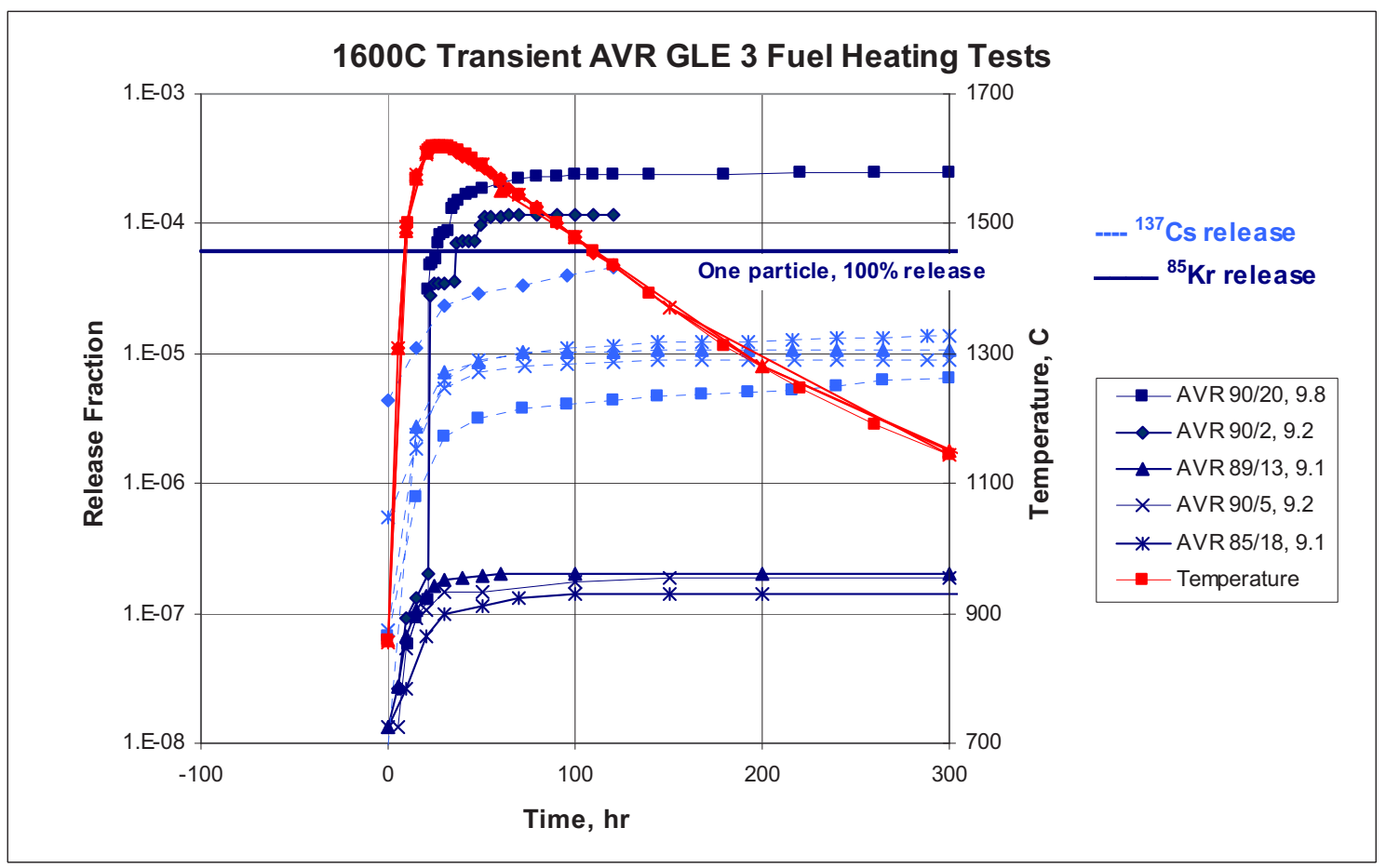

Figure A-16. $1,600^{\circ} \mathrm{C}$ transient GLE 3 testing ${ }^{85} \mathrm{Kr}$ and ${ }^{137} \mathrm{Cs}$ release. 
The initial ${ }^{85} \mathrm{Kr}$ responses for the $1,600^{\circ} \mathrm{C}$ transient tests indicate there were no through-coating particle failures at the end of irradiation for any of the spheres. The ${ }^{137} \mathrm{Cs}$ responses indicate one particle with a SiC defect in sphere AVR 90/2, and no particles with $\mathrm{SiC}$ defects in the other four spheres.

The ${ }^{85} \mathrm{Kr}$ and ${ }^{137} \mathrm{Cs} 1,600{ }^{\circ} \mathrm{C}$ isothermal heating test results for the LEU Phase 1 fuel are shown in Figure A-17. The initial ${ }^{85} \mathrm{Kr}$ responses indicate that there were no through-coating particle failures at the end of irradiation for any of the spheres. The ${ }^{137} \mathrm{Cs}$ responses indicate one particle with a SiC defect in sphere FRJ2 K13/2, and no particles with $\mathrm{SiC}$ defects in the other two spheres at the end of irradiation. The beginning of an upward trend in the cesium release from HFR K3/1 after $200 \mathrm{~h}$ may indicate the onset of increasing permeability in a $\mathrm{SiC}$ layer, with the level of release remaining an order of magnitude below a single-particle inventory after $300 \mathrm{~h}$.

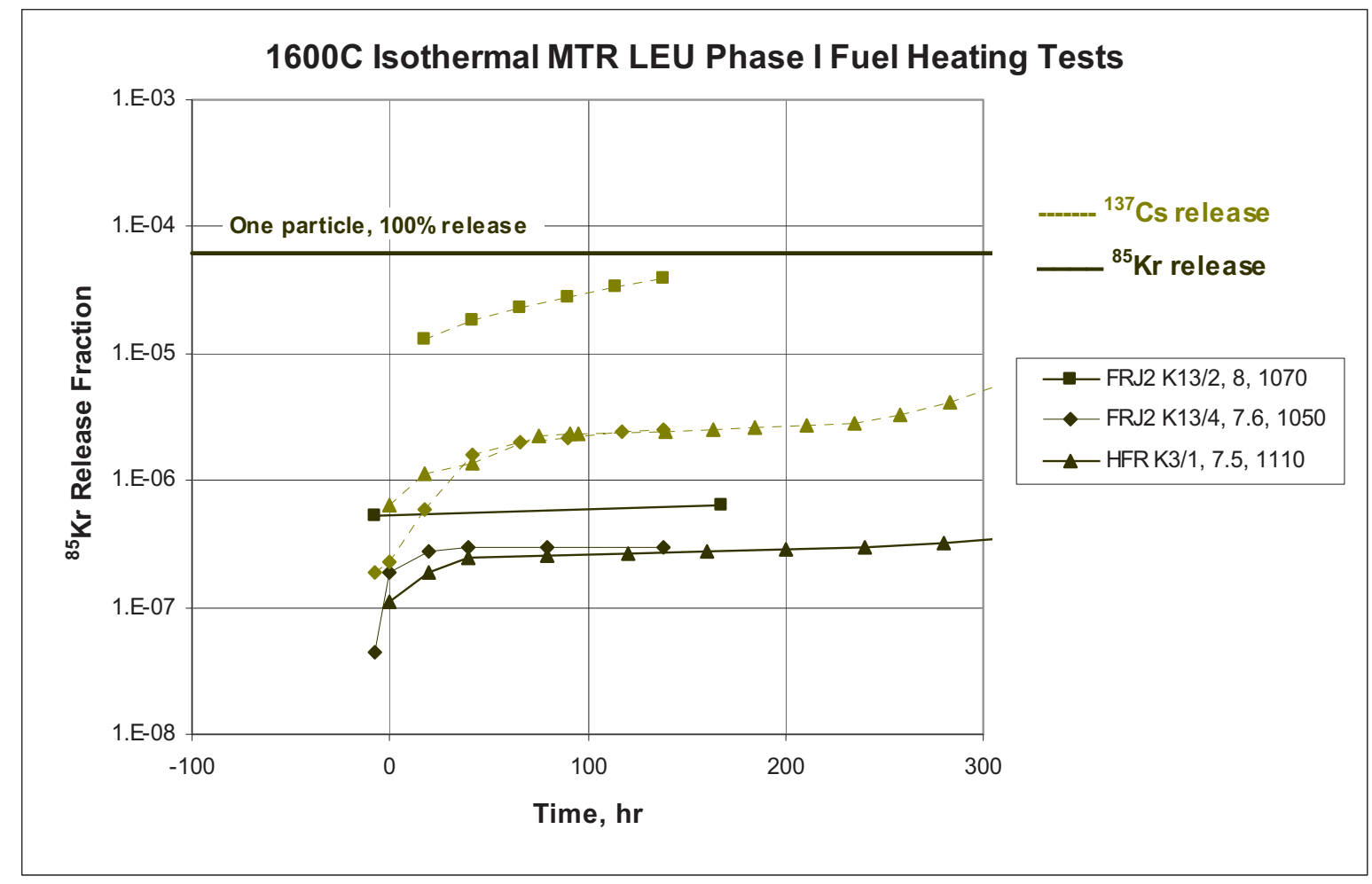

Figure A-17. $1,600^{\circ} \mathrm{C}$ isothermal LEU Phase 1 testing ${ }^{85} \mathrm{Kr}$ and ${ }^{137} \mathrm{Cs}$ release.

\section{$1,700^{\circ} \mathrm{C}$ Isothermal and Transient Testing}

The ${ }^{110 \mathrm{~m}} \mathrm{Ag},{ }^{90} \mathrm{Sr}$, and ${ }^{137} \mathrm{Cs}$ release data for a selected $1,700^{\circ} \mathrm{C}$ isothermal heating test are presented in Figure A-18 (data from Reference 3). At $1,700^{\circ} \mathrm{C}$, the silver is released more quickly from intact particles, the strontium is retained within the sphere as it was at $1,600^{\circ} \mathrm{C}$, and the cesium is retained within the intact particles (as will be discussed in relation to Figure A-19, sphere AVR 74/11 had a particle with a defective SiC layer). As discussed in Section A-1.3.2, the krypton release indicates a partial particle failure at $\sim 80 \mathrm{~h}$. The cesium release after $80 \mathrm{~h}$ changes from an asymptotic approach to a single-particle inventory, associated with a particle with a defective $\mathrm{SiC}$ layer, to an increasing trend, apparently reflecting release from the partially failed particle. 


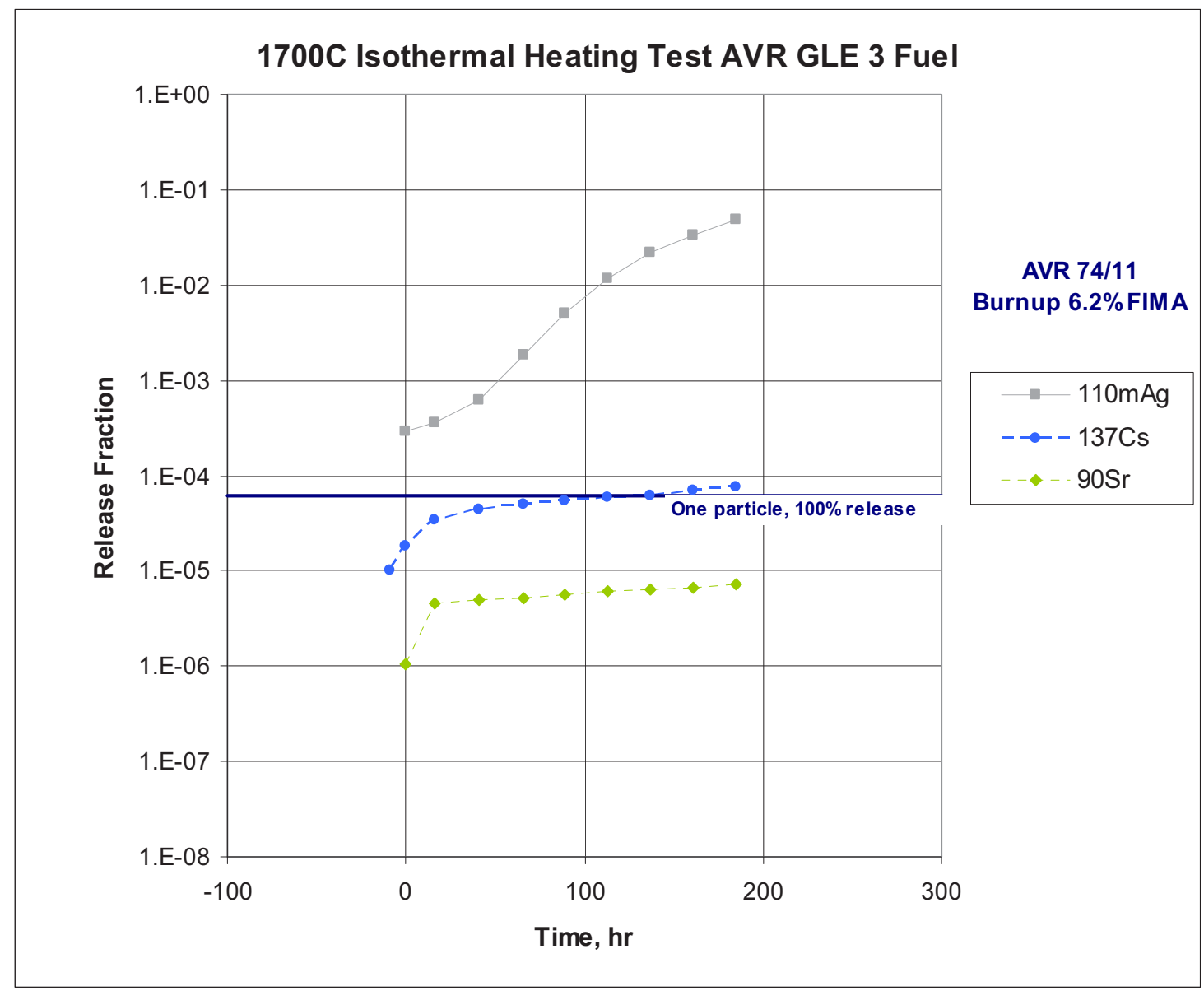

Figure A-18. AVR $74 / 111,700^{\circ} \mathrm{C}$ isothermal testing ${ }^{110 \mathrm{~m}} \mathrm{Ag},{ }^{90} \mathrm{Sr}$, and ${ }^{137} \mathrm{Cs}$ release.

The ${ }^{85} \mathrm{Kr}$ and ${ }^{137} \mathrm{Cs} 1,700^{\circ} \mathrm{C}$ isothermal and transient heating test results for the AVR GLE 3 fuel are shown in Figure A-19. The initial ${ }^{85} \mathrm{Kr}$ responses for the $1,700^{\circ} \mathrm{C}$ tests indicate there were no through-coating particle failures at the end of irradiation for either of the spheres. The ${ }^{137} \mathrm{Cs}$ responses indicate one particle with a SiC defect in sphere AVR 74/11, and no particles with $\mathrm{SiC}$ defects in the AVR 91/31 sphere. (The failure of approximately 20 particles beginning approximately $12 \mathrm{~h}$ into the transient, as indicated by ${ }^{85} \mathrm{Kr}$, produced the subsequent increase in ${ }^{137} \mathrm{Cs}$ release.) 


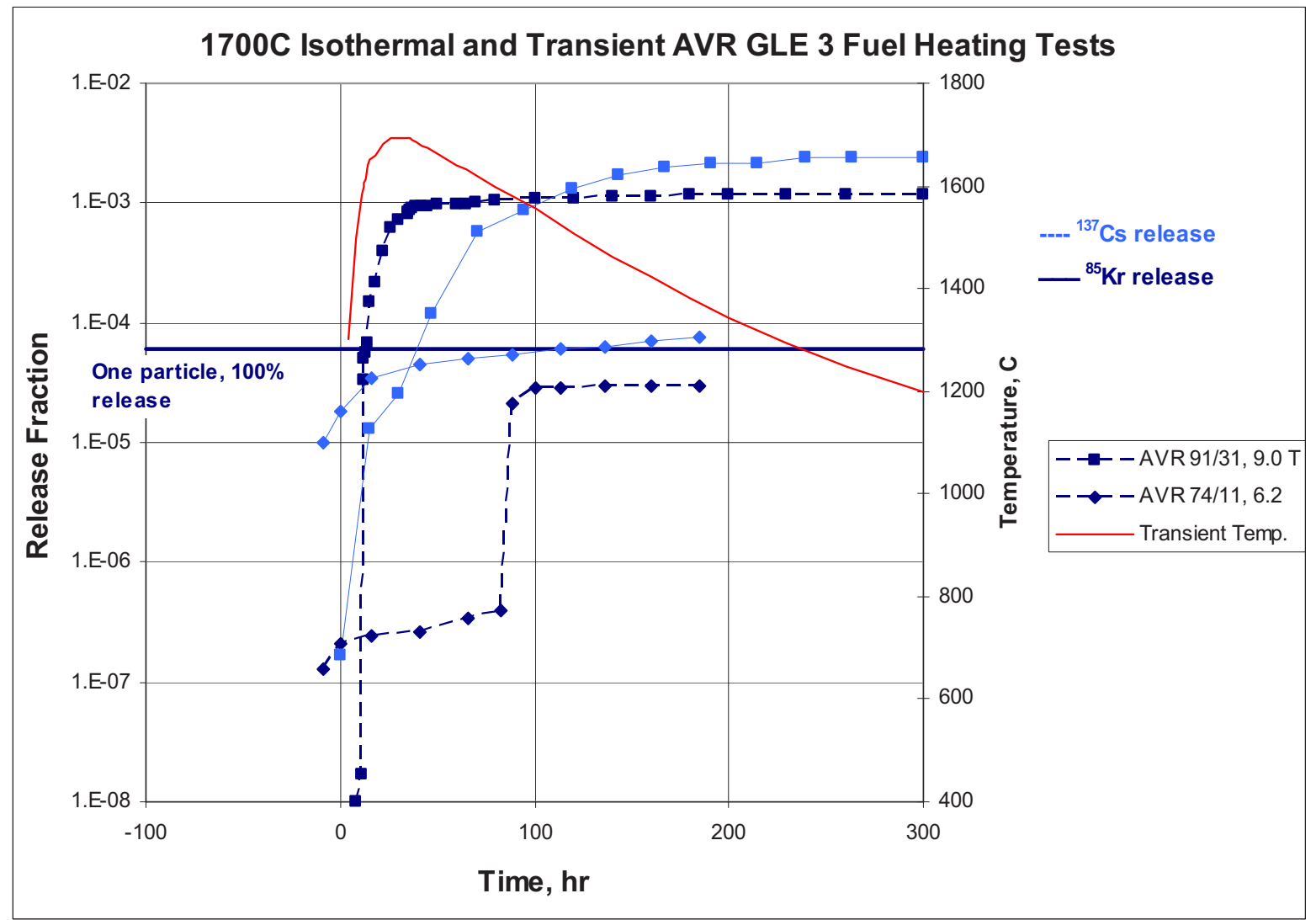

Figure A-19. $1,700{ }^{\circ} \mathrm{C}$ isothermal and transient GLE 3 testing ${ }^{85} \mathrm{Kr}$ and ${ }^{137} \mathrm{Cs}$ release.

\section{$1,800^{\circ} \mathrm{C}$ Isothermal Testing}

The ${ }^{110 \mathrm{~m}} \mathrm{Ag},{ }^{90} \mathrm{Sr}$, and ${ }^{137} \mathrm{Cs}$ release data for a selected $1,800^{\circ} \mathrm{C}$ isothermal heating test are presented in Figure A-20 (data from Reference 3). At $1,800^{\circ} \mathrm{C}$, the silver approaches complete release after several hundred hours. Both the cesium and the strontium indicate high levels of release through "intact" particles. (The krypton release for AVR 76/18 is still only a fraction of a particle inventory at $200 \mathrm{~h}$, as shown in Figure A-21, indicating that the pyrocarbon layers are still intact.) 


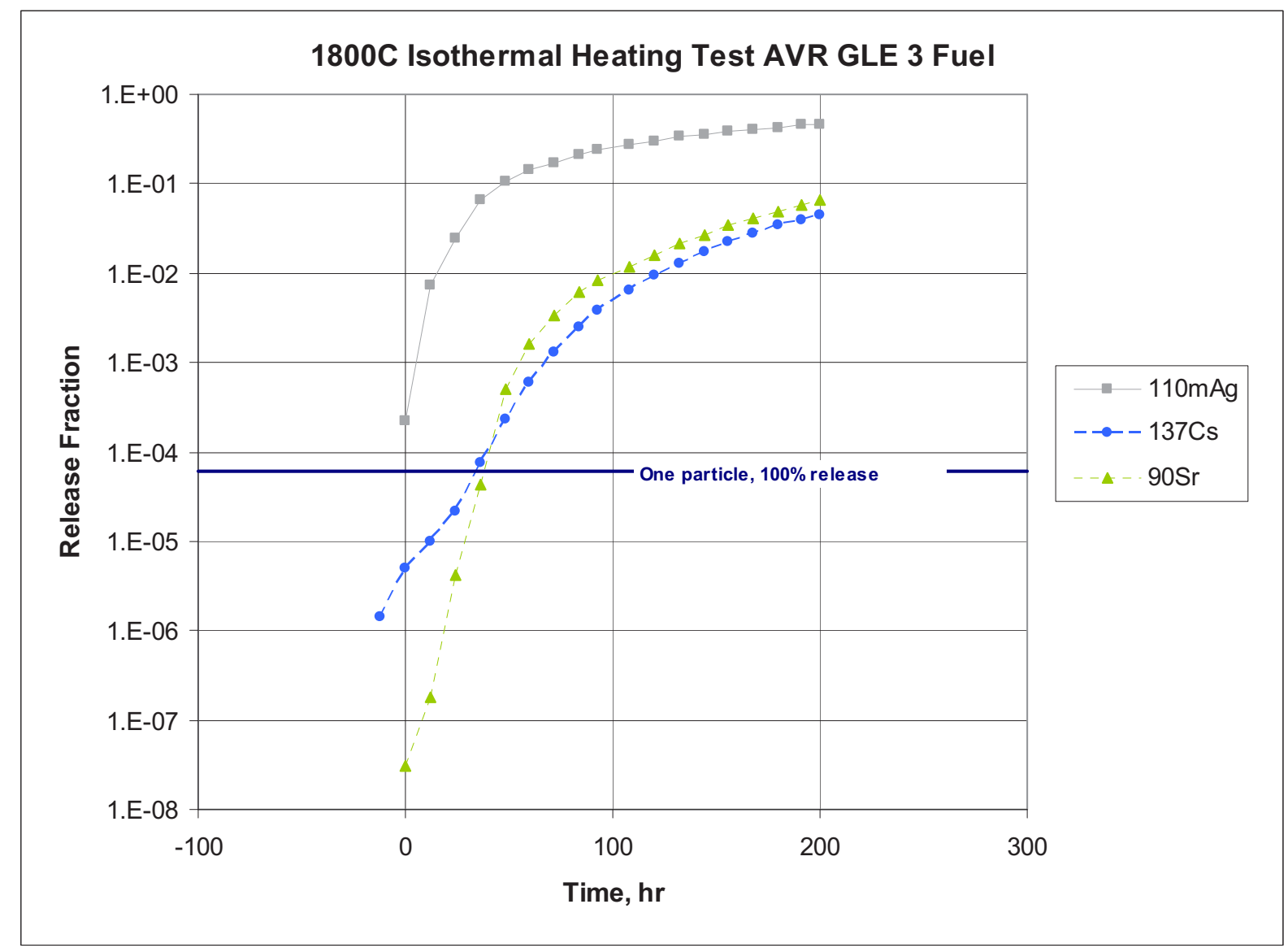

Figure A-20. AVR 76/18 $1,800{ }^{\circ} \mathrm{C}$ isothermal testing ${ }^{110 \mathrm{~m}} \mathrm{Ag},{ }^{90} \mathrm{Sr}$ and ${ }^{137} \mathrm{Cs}$ release.

The ${ }^{85} \mathrm{Kr}$ and ${ }^{137} \mathrm{Cs} 1,800^{\circ} \mathrm{C}$ isothermal and transient heating test results for the AVR GLE 3 and LEU are shown in Figure A-21 and Figure A-22 (data from Reference 3). These responses require more detailed interpretation than the lower temperature tests because the response is faster and the ${ }^{137} \mathrm{Cs}$ is released from intact particles as the test proceeds, as shown in Figure A-20. Spheres AVR 88/15 and AVR $88 / 33$ had been shown to be free of through-coating failures by the response to the $1,600^{\circ} \mathrm{C}$ heating tests. For the other two GLE 3 spheres and the two LEU Phase 1 spheres, the initial ${ }^{85} \mathrm{Kr}$ responses for the $1,800^{\circ} \mathrm{C}$ tests of the other spheres indicate there were no through-coating particle failures at the end of irradiation.

The ${ }^{137} \mathrm{Cs}$ responses to the $1,600^{\circ} \mathrm{C}$ heating tests indicated no SiC defects in AVR 88/15 and three in AVR 88/33, as discussed earlier. The response of the AVR 88/41 sphere was interpreted to indicate two particles with $\mathrm{SiC}$ defects at the end of irradiation. The responses for the other GLE 3 sphere and the two LEU Phase 1 spheres indicate no particles with $\mathrm{SiC}$ defects at the end of irradiation. 


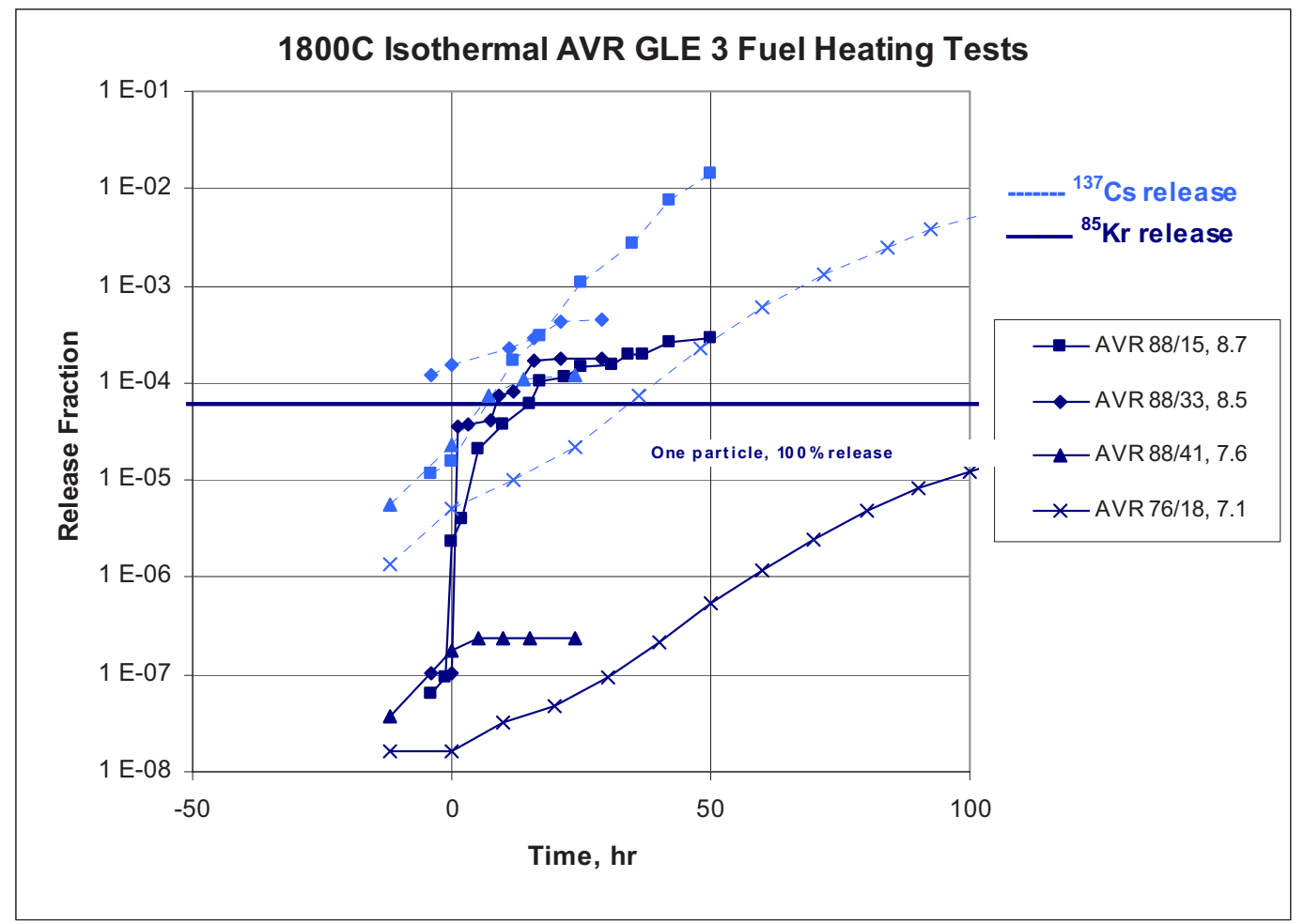

Figure A-21. $1,800{ }^{\circ} \mathrm{C}$ isothermal GLE 3 testing ${ }^{85} \mathrm{Kr}$ and ${ }^{137} \mathrm{Cs}$ release.

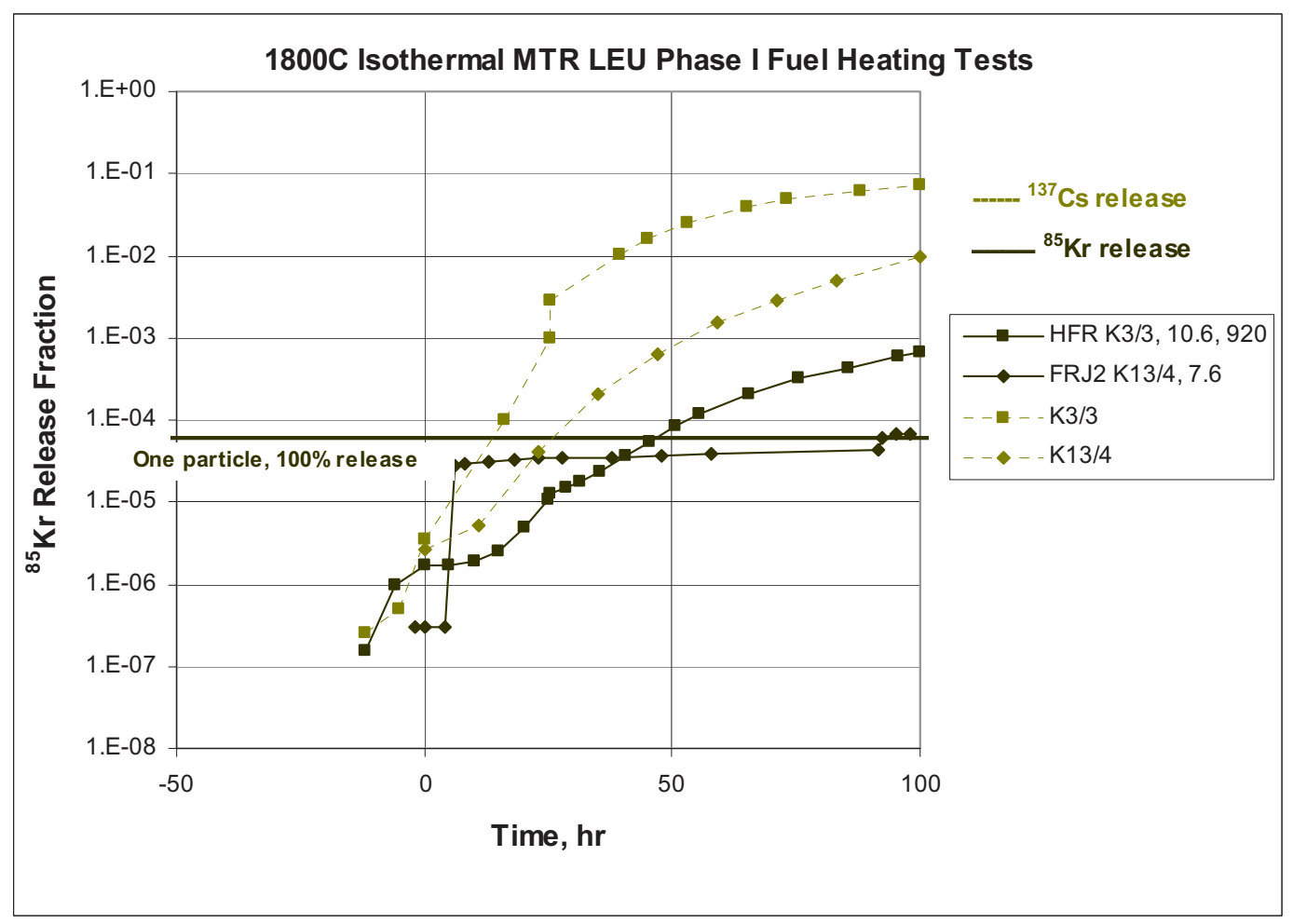

Figure A-22. $1,800^{\circ} \mathrm{C}$ isothermal LEU Phase 1 testing ${ }^{85} \mathrm{Kr}$ and ${ }^{137} \mathrm{Cs}$ release. 


\section{A-1.4 Additional Post-Irradiation Examination Data}

As noted earlier, these data are compiled from References 1, 2, and 3. Table 7 in Section 3.2.3.2 lists exposed kernels and SiC defects in irradiated AVR 19 (GLE 3) spheres that were inferred from the initial response to heating tests.

In addition to the GLE 3 spheres irradiated in AVR that were subjected to heating tests, as discussed in Section 3.2.3, GLE 3 and GLE 4 spheres were destructively examined to determine the fission-product profile in the fuel-free zone, as discussed in Section 7.2.3 of Reference 3. In this procedure, the fuel-free zone was mechanically turned off in steps, and the samples were examined with gamma spectrometry to determine the concentration profile of fission products in the fuel-free zone. The cesium profiles for spheres with no $\mathrm{SiC}$ defects decreased from the outside surface toward the fueled region, reflecting exterior contamination collected as the cooled spheres were in the extraction tube. A sphere containing a particle that was releasing cesium produced a profile that turned upward moving into the fuel-free zone. Some representative profiles, including a sphere with a releasing particle, are provided in Figure A-23.

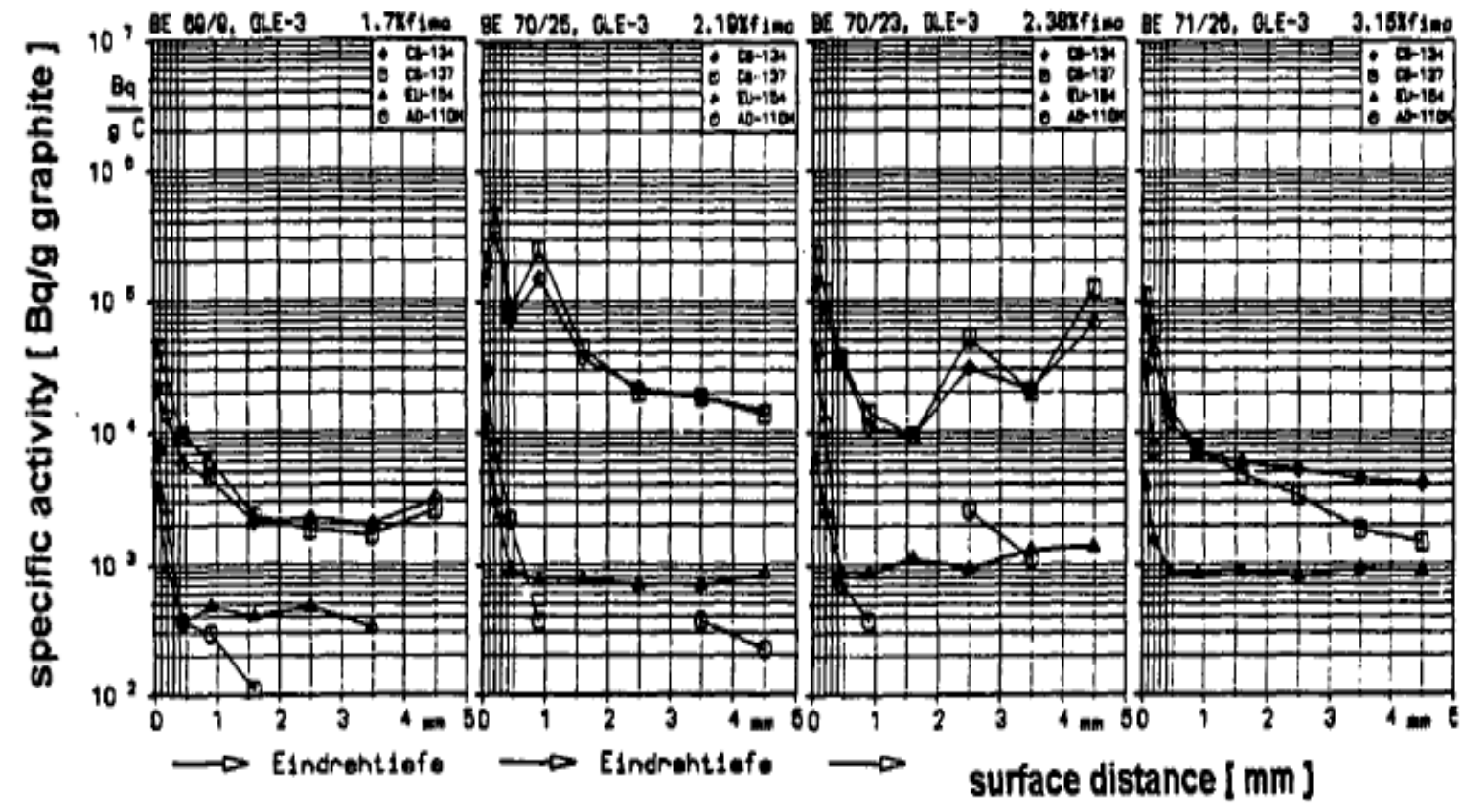

Figure A-23. Representative fission-product profiles in fuel-free zone. ${ }^{3}$

The results of the fission-product profile examinations of fuels irradiated in the AVR are provided in Table A-6. This procedure was indeterminate as to whether the particle releasing fission products was a particle with an exposed kernel or with a $\mathrm{SiC}$ defect with an intact pyrocarbon layer. The heating-test data would strongly indicate that particles releasing cesium are particles with $\mathrm{SiC}$ defects, but since the procedure cannot make the distinction, the exposed-kernel column indicates "N/D" for "not determined," and the sphere is not included in the statistics for exposed kernels. The fast-fluence values of the spheres were estimated by a correlation as noted at the bottom of the table. This is a nominal value, with the actual value for a given sphere determined by the trajectory taken on passes through the core. The variation in fluence due to this effect was estimated to be less than $10 \%$. 
Table A-6. GLE 3 and GLE 4 sphere failure fractions from fission-product profile in fuel-free zone.

\begin{tabular}{|c|c|c|c|c|c|}
\hline Sphere & $\begin{array}{c}\text { No. of } \\
\text { Particles }\end{array}$ & Burnup & Fast Fluence $^{1}$ & $\begin{array}{c}\text { Exposed } \\
\text { Kernels }\end{array}$ & SiC Defects ${ }^{2}$ \\
\hline \multicolumn{6}{|c|}{ GLE 3 Spheres } \\
\hline $69 / 9$ & 16,400 & 1.7 & 0.19 & 0 & 0 \\
\hline $70 / 25$ & 16,400 & 2.2 & 0.24 & 0 & 0 \\
\hline $70 / 23$ & 16,400 & 2.4 & 0.27 & $\mathrm{~N} / \mathrm{D}$ & 1 \\
\hline $71 / 26$ & 16,400 & 3.2 & 0.41 & 0 & 0 \\
\hline $71 / 19$ & 16,400 & 3.9 & 0.58 & 0 & 0 \\
\hline $73 / 31$ & 16,400 & 5.9 & 1.23 & 0 & 0 \\
\hline $76 / 32$ & 16,400 & 6.4 & 1.43 & 0 & 0 \\
\hline $76 / 30$ & 16,400 & 6.7 & 1.55 & 0 & 0 \\
\hline $80 / 19$ & 16,400 & 7.2 & 1.76 & 0 & 0 \\
\hline $76 / 33$ & 16,400 & 7.7 & 1.98 & 0 & 0 \\
\hline $80 / 33$ & 16,400 & 8 & 2.11 & 0 & 0 \\
\hline $80 / 32$ & 16,400 & 8.8 & 2.47 & 0 & 0 \\
\hline $81 / 22$ & 16,400 & 9.1 & 2.61 & 0 & 0 \\
\hline \multicolumn{6}{|c|}{ GLE 4 Spheres } \\
\hline $77 / 11$ & 9,560 & 4 & 0.36 & 0 & 0 \\
\hline $77 / 2$ & 9,560 & 4.5 & 0.42 & 0 & 0 \\
\hline $77 / 7$ & 9,560 & 4.7 & 0.44 & 0 & 0 \\
\hline $80 / 7$ & 9,560 & 7.5 & 0.86 & 0 & 0 \\
\hline $79 / 4$ & 9,560 & 8.3 & 1.02 & 0 & 0 \\
\hline $82 / 4$ & 9,560 & 9.2 & 1.22 & 0 & 0 \\
\hline \multicolumn{6}{|c|}{$\begin{array}{l}\text { lotes: } \\
\text { 1. } \quad \text { Fluence calculated from burnup using correlation from note by Werner (AVR AZ: Hr-X1, 23.5.1984). } \\
\text { 2. } \quad \text { Failure fraction determined by }{ }^{137} \mathrm{Cs} \text { profile. }\end{array}$} \\
\hline
\end{tabular}

Five additional GLE 4 spheres were subjected to deconsolidation for further examination of individual particles. This process supported identification of failed particles by measuring the fission-product concentration in the leachate as the sphere was progressively deconsolidated. The results are interpreted assuming that uranium in the leachate would be from a particle with an exposed kernel, which should be included in both the exposed kernel and SiC defect columns. It is conceivable that the particle was damaged in the deconsolidation process, but it will be included as a failed particle from manufacturing or irradiation. This interpretation produces the results given in Table A-7. 
Table A-7. GLE 4 sphere failure fractions from deconsolidation leachate.

\begin{tabular}{|c|c|c|c|c|c|}
\hline Sphere & No. of Particles & Burnup & Fluence $^{1}$ & $\begin{array}{c}\text { Exposed } \\
\text { Kernels } \\
\end{array}$ & SiC Defects ${ }^{2}$ \\
\hline $78 / 1$ & 9,560 & 3.5 & 0.32 & 0 & 0 \\
\hline $78 / 2$ & 9,560 & 3.5 & 0.32 & 0 & 0 \\
\hline $78 / 3$ & 9,560 & 3.5 & 0.32 & 1 & 1 \\
\hline $78 / 4$ & 9,560 & 3.5 & 0.32 & 0 & 0 \\
\hline $78 / 5$ & 9,560 & 3.5 & 0.32 & 0 & 0 \\
\hline \multicolumn{6}{|c|}{$\begin{array}{l}\text { Notes: } \\
\text { 1. Fluence calculated from burnup using correlation from note by Werner (AVR AZ: Hr-X1, 23.5.1984). } \\
\text { 2. Failed particles identified by progressive deconsolidation and examination of leachate. }\end{array}$} \\
\hline
\end{tabular}

The results listed above from PIE of GLE 3 and GLE 4 fuel spheres irradiated in the AVR are included with the exposed kernel and $\mathrm{SiC}$ defect fractions inferred by initial response during heating tests in the evaluation of normal operation fuel performance in Section 3.2.

The data from MTR irradiations of $\mathrm{LEU} \mathrm{UO}_{2}$ TRISO fuel in the following tables were drawn from References 1,2,3, and 4. Reference 9 lists the German fuel specimens that were irradiated in MTRs in the Netherlands and France in locations that had harder spectra than the pebble-bed design, and thus produced higher fast fluences. The HFR-P4 and SL-P1 specimens were small ( $\sim 2$-cm diameter) fueled spheres embedded in a matrix cylinder. The HFR Kx specimens were full-sized spheres from the LEU Phase 1 (HFR K3) and Proof Test (HFR K5 and K6) campaigns (refer to Table 3). The temperatures are sphere center values consistent with the pebble-bed design service conditions of Table 10.

Table A-8. High fluence irradiations in the Netherlands (HFR) and France (SL).

\begin{tabular}{|l|l|l|l|l|l|l|l|}
\hline Experiment & Capsule & $\begin{array}{c}\text { Compact or } \\
\text { Sphere* }\end{array}$ & $\begin{array}{c}\text { Number of } \\
\text { Particles }\end{array}$ & Burnup & $\begin{array}{c}\text { Irradiation } \\
\text { Temperature }\end{array}$ & $\begin{array}{c}\text { Fast } \\
\text { Fluence }\end{array}$ & $\begin{array}{c}\text { Heating } \\
\text { Temperature }\end{array}$ \\
\hline HFR-P4 & 1 & 1 & 1,631 & 11.6 & 999 & 7 & \\
\hline HFR-P4 & 1 & 2 & 1,631 & 12.4 & 982 & 7.3 & \\
\hline HFR-P4 & 1 & 3 & 1,631 & 12.3 & 965 & 7.6 & \\
\hline HFR-P4 & 1 & 4 & 1,631 & 12.5 & 953 & 7.8 & \\
\hline HFR-P4 & 1 & 5 & 1,631 & 12.5 & 941 & 8 & \\
\hline HFR-P4 & 1 & 6 & 1,631 & 13.5 & 941 & 7.9 & \\
\hline HFR-P4 & 1 & 7 & 1,631 & 12.6 & 940 & 7.5 & \\
\hline HFR-P4 & 1 & 8 & 1,631 & 12.1 & 973 & 7.2 & 1,600 \\
\hline HFR-P4 & 1 & 9 & 1,631 & 12.1 & 1,006 & 7 & \\
\hline HFR-P4 & 1 & 10 & 1,631 & 10.2 & 1,007 & 6.5 & \\
\hline HFR-P4 & 1 & 11 & 1,631 & 10.4 & 1,008 & 6.1 & \\
\hline HFR-P4 & 1 & 12 & 1,631 & 9.7 & 1,008 & 5.5 & 1,600 \\
\hline HFR-P4 & 3 & 1 & 1,631 & 11.0 & 1,010 & 7 & \\
\hline HFR-P4 & 3 & 2 & 1,631 & 11.3 & 1,020 & 7.3 & \\
\hline HFR-P4 & 3 & 3 & 1,631 & 11.7 & 1,030 & 7.6 & \\
\hline HFR-P4 & 3 & 4 & 1,631 & 12.9 & 1,023 & 7.8 & \\
\hline HFR-P4 & 3 & 5 & 1,631 & 12.3 & 1,015 & 8 & \\
\hline
\end{tabular}




\begin{tabular}{|c|c|c|c|c|c|c|c|}
\hline Experiment & Capsule & $\begin{array}{l}\text { Compact or } \\
\text { Sphere* }\end{array}$ & $\begin{array}{c}\text { Number of } \\
\text { Particles }\end{array}$ & Burnup & $\begin{array}{c}\text { Irradiation } \\
\text { Temperature }\end{array}$ & $\begin{array}{c}\text { Fast } \\
\text { Fluence }\end{array}$ & $\begin{array}{c}\text { Heating } \\
\text { Temperature }\end{array}$ \\
\hline HFR-P4 & 3 & 6 & 1,631 & 12.3 & 1,017 & 7.9 & \\
\hline HFR-P4 & 3 & 7 & 1,631 & 12.2 & 1,019 & 7.5 & 1,600 \\
\hline HFR-P4 & 3 & 8 & 1,631 & 11.5 & 1,051 & 7.2 & \\
\hline HFR-P4 & 3 & 9 & 1,631 & 11.1 & 1,082 & 7 & \\
\hline HFR-P4 & 3 & 10 & 1,631 & 11.0 & 1,082 & 6.5 & \\
\hline HFR-P4 & 3 & 11 & 1,631 & 9.6 & 1,082 & 6.1 & \\
\hline HFR-P4 & 3 & 12 & 1,631 & 8.7 & 1,082 & 5.5 & 1,800 \\
\hline SL-P1 & & 1 & 1,666 & 7.5 & 743 & 5 & \\
\hline SL-P1 & & 2 & 1,666 & 8.1 & 750 & 5.4 & \\
\hline SL-P1 & & 3 & 1,666 & 8.8 & 759 & 5.8 & \\
\hline SL-P1 & & 4 & 1,666 & 9.3 & 785 & 6.2 & \\
\hline SL-P1 & & 5 & 1,666 & 9.6 & 788 & 6.5 & \\
\hline SL-P1 & & 6 & 1,666 & 9.4 & 790 & 6.7 & 1,600 \\
\hline SL-P1 & & 7 & 1,666 & 9.8 & 793 & 6.8 & \\
\hline SL-P1 & & 8 & 1,666 & 9.7 & 794 & 6.6 & \\
\hline SL-P1 & & 9 & 1,666 & 9.4 & 794 & 6.3 & 1,700 \\
\hline SL-P1 & & 10 & 1,666 & 9.0 & 794 & 6 & 1,700 \\
\hline SL-P1 & & 11 & 1,666 & 9.1 & 780 & 5.7 & \\
\hline SL-P1 & & 12 & 1,666 & 8.3 & 763 & 5.2 & \\
\hline HFR-K3 & A & 1 & 16,400 & 7.5 & 1,200 & 4 & 1,600 \\
\hline HFR-K3 & B & 2 & 16,400 & 10 & 920 & 5.8 & \\
\hline HFR-K3 & B & 3 & 16,400 & 10.6 & 920 & 5.9 & 1,800 \\
\hline HFR-K3 & C & 4 & 16,400 & 9 & 1,220 & 4.9 & \\
\hline HFR-K5 & A & 1 & 14,580 & 7.8 & 923 & 4 & \\
\hline HFR-K5 & $\mathrm{B}$ & 2 & 14,580 & 10.1 & 909 & 5.8 & \\
\hline HFR-K5 & $\mathrm{B}$ & 3 & 14,580 & 10.3 & 903 & 5.9 & \\
\hline HFR-K5 & $\mathrm{C}$ & 4 & 14,580 & 9.3 & 921 & 4.9 & \\
\hline HFR-K6 & A & 1 & 14,580 & 8.3 & 1,090 & 3.2 & \\
\hline HFR-K6 & $\mathrm{B}$ & 2 & 14,580 & 10.6 & 1,130 & 4.6 & \\
\hline HFR-K6 & $\mathrm{B}$ & 3 & 14,580 & 10.9 & 1,140 & 4.8 & \\
\hline HFR-K6 & $\mathrm{C}$ & 4 & 14,580 & 9.9 & 1,130 & 4.5 & \\
\hline \multicolumn{3}{|c|}{ Total Number of Particles } & 241,376 & 9.8 & 1,010 & 5.3 & Averages \\
\hline
\end{tabular}


Table A-9 lists the German fuel specimens that were irradiated in the DIDO reactor in Germany. The sphere irradiation rigs (FRJ2-Kxx) were located in the reflector region to accommodate the sphere diameter, resulting in very low fast fluence. The compact irradiations (FRJ2-Pxx) were irradiated in the core region with correspondingly higher fast fluence but still a softer spectrum than the pebble-bed design.

Table A-9. Low fluence irradiations in Germany (FRJ2).

\begin{tabular}{|l|r|r|r|r|r|r|r|}
\hline Experiment & Capsule & $\begin{array}{c}\text { Compact or } \\
\text { Sphere }\end{array}$ & $\begin{array}{c}\text { Number of } \\
\text { Particles }\end{array}$ & Burnup & $\begin{array}{c}\text { Irradiation } \\
\text { Temperature }\end{array}$ & $\begin{array}{c}\text { Fast } \\
\text { Fluence }\end{array}$ & $\begin{array}{c}\text { Heating } \\
\text { Temperature }\end{array}$ \\
\hline FRJ2-K13 & A & 1 & 16,400 & 7.5 & 1,125 & 0.2 & \\
\hline FRJ2-K13 & A & 2 & 16,400 & 8 & 1,150 & 0.2 & 1,600 \\
\hline FRJ2-K13 & B & 3 & 16,400 & 7.9 & 1,150 & 0.2 & \\
\hline FRJ2-K13 & B & 4 & 16,400 & 7.6 & 1,120 & 0.2 & 1,600 \\
\hline FRJ2-K15 & A & 1 & 9,560 & 14.1 & 970 & 0.2 & \\
\hline FRJ2-K15 & $\mathrm{B}$ & 2 & 9,560 & 15.3 & 1,150 & 0.2 & \\
\hline FRJ2-K15 & $\mathrm{C}$ & 3 & 9,560 & 14.7 & 990 & 0.1 & \\
\hline FRJ2-P27 & 1 & 2 & 2,424 & 7.2 & 1,080 & 1.4 & \\
\hline FRJ2-P27 & 1 & 3 & 2,424 & 7.6 & 1,080 & 1.4 & \\
\hline FRJ2-P27 & 1 & 4 & 2,424 & 7.6 & 1,080 & 1.4 & \\
\hline FRJ2-P27 & 2 & 9 & 2,424 & 8 & 1,320 & 1.7 & \\
\hline FRJ2-P27 & 2 & 10 & 2,424 & 8 & 1,320 & 1.7 & \\
\hline FRJ2-P27 & 2 & 11 & 2,424 & 8 & 1,320 & 1.7 & \\
\hline FRJ2-P27 & 3 & 14 & 2,424 & 7.6 & 1,130 & 1.3 & \\
\hline FRJ2-P27 & 3 & 15 & 2,424 & 7.6 & 1,130 & 1.3 & 1,400 \\
\hline FRJ2-P27 & 3 & 17 & 2,424 & 7.2 & 1,130 & 1.3 & \\
\hline Total Number of Particles & & 116,096 & 9.4 & 1,119 & 0.4 & Averages \\
\hline
\end{tabular}

The burnup values listed for irradiations HFR-P4 and SL-P1 were adjusted to be consistent with the results of the Seibersdorf burnup measurements on selected compacts. Two independent burnup measurement methods produced nearly identical results that were, on average, approximately $12 \%$ less than the FZJ gamma-scan measurements that were performed on all of the compacts. The Seibersdorf results were used for the three compacts measured, and the other compact burnups were reduced by the average difference. This approach is conservative relative to using the FZJ data and was chosen because the Seibersdorf measurements are considered by some to be more accurate, although questions remain regarding the limited number of particles used in the Seibersdorf measurements. The MTR irradiations listed above included a total of 357,000 particles with an average burnup, fast fluence, and temperature of $9.4 \%$ FIMA, $3.9 \times 10^{21} \mathrm{n} / \mathrm{cm}^{2}$ and $1045^{\circ} \mathrm{C}$.

As noted earlier, these data are compiled from References 1, 2, 3, and 4. Table 7 in Section 3.2.3.2 lists exposed kernels and $\mathrm{SiC}$ defects in irradiated AVR 19 (GLE 3) spheres that were inferred from the initial response to heating tests.

In addition to the GLE 3 spheres irradiated in AVR that were subjected to heating tests (as discussed in Section A-1.3.3), GLE 3 and GLE 4 spheres were destructively examined to determine the fission-product profile in the fuel-free zone, as discussed in Section 7.2.3 of Reference 3. In this procedure, the fuel-free zone was mechanically turned off in steps, and the samples were examined with gamma spectrometry to determine the concentration profile of fission products in the fuel-free zone. The 
cesium profiles for spheres with no $\mathrm{SiC}$ defects decreased from the outside surface toward the fueled region, reflecting exterior contamination collected as the cooled spheres were in the extraction tube. A sphere containing a particle that was releasing cesium produced a profile that turned upward moving into the fuel-free zone. Some representative profiles, including a sphere with a releasing particle, are provided in Figure A-23.

\section{A-1.5 REFERENCES}

1. Schenk, W. and H. Nabielek, 1988, "Kugelbrennelemente mit TRISO-Partikeln bei Stöfalltemperaturen,” KFA-Jül-Spez-487, Oktober 1988.

2. Gontard, R. and H. Nabielek, 1990, "Performance Evaluation of Modern HTR TRISO Fuels," KFA-HTA-IB-05/90, July 1990.

3. Hantke, H., 1992, "Performance of High Quality HTR-LEU Fuel Elements with TRISO Coated Particles," KFA-HTA-IB-7/92, December 1992.

4. IAEA-TECDOC-978, "Fuel Performance and Fission Product Behaviour in Gas Cooled Reactors," November 1997.

5. Personal communication, $\mathrm{H}$. Nabielek, spreadsheets of KÜFA heating test data.

6. Scherer, W. and H. Gerwin, 1990, "Progress and Problems in Modelling HTR Core Dynamics," IAEA-IWGGCR/24, May 1990.

7. Petti, D., et al., 2002, Key Differences in the Fabrication, Irradiation and Safety Testing of U.S. and German TRISO-coated Particle Fuel and Their Implications on Fuel Performance, INEEL/EXT-02-00300, April 2002.

8. Nabielek, H., D. T. Goodin, and K. Ikawa, 1983, "High Temperature Behaviour of HTR Fuel Particles," Jahrestagung Kerntechnik, Berlin, June 1983.

9. Schenk, W., R. Gontard, and H. Nabielek, 1994, "Performance of HTR Fuel Samples under High-Irradiation and Accident Simulation Conditions, with Emphasis on Test Capsules HFR-P4 and SL-P1,”Jül 2992, Jülich, November 1994. 
Appendix B

\section{Statistical QC Methods}




\section{Appendix B}

\section{Statistical QC Methods}

\section{B-1. Statistical QC Methods}

Given that the quantities of fuel particles and fuel compacts in the reactor core number in the billions and millions, respectively, acceptance testing of the fuel particles and fuel compacts to determine conformance to specification requirements is necessarily performed on a statistical basis (i.e., statistical quality control). The statistical methods are summarized below, and the risks of false acceptance and false rejection that are inherent in statistical sampling are discussed.

The basic approach is to collect a representative sample, apply an acceptance test to the sample, and accept or reject the product based on this test. Even though a sample satisfies the acceptance test, it is not certain that the population meets the acceptance criteria. A chance of a wrong decision always exists when the decision is based on a random sample, but this can be quantified and made small.

Two types of errant decisions can be made. The first is made when a product that does not meet the specifications is accepted (false acceptance). A test corresponds to c\% confidence when any unacceptable product has at most a $(100-\mathrm{c}) \%$ chance of being accepted. For example, if the acceptance test has a $95 \%$ confidence level, there is no more than a $5 \%$ chance of accepting a product that should be rejected.

The second type of wrong decision is made when an acceptable product is rejected (false rejection). The risk associated with making this decision must also be minimized. For a fixed sample size, the two kinds of wrong decisions are inversely related. As the sample size increases, both risks decrease.

The product specifications establish acceptance criteria for the properties of concern as well as the confidence levels with which the population must meet the criteria. A property may be stated in terms of kernels, coated particles, or compacts. Each property is one of two types: attribute or variable.

An attribute property is discrete in the sense that the particle is either defective or not in terms of that property. For example, "missing buffer" is an attribute property-either the buffer is present or it is missing. The acceptance criterion for an attribute property is stated in terms of the allowable fraction of defective particles. To test whether the population satisfies a criterion for an attribute property, a sample is drawn and each item is found to be either acceptable or defective in terms of the criterion. If the number of defective items is small enough, the population is accepted. The numbers defining the test are adjusted so that the probability of a false acceptance is, at most, $5 \%$.

A variable property is a property defined by a continuous distribution, such as the normal distribution. The acceptance criterion for a variable property is stated in terms of the population mean and/or the population dispersion. For the population mean, the criterion is that the mean must lie within a specified interval. In some instances, this interval is one-sided. The endpoints of the interval are the acceptance limits for the mean. For population dispersion, the criterion is that no more than a specified fraction of the population can exceed and/or be less than predetermined values. These values are called the critical limits for the dispersion.

A confidence interval is used to test whether the population meets a criterion for the mean. There are two ways to test whether the population meets a criterion for dispersion. The first way is to assume that the population is normally distributed, and to base the test on the sample mean, the sample standard deviation, and tabulated tolerance factors for the normal distribution. The second way, if the normality assumption is not justified, is to treat the property as an attribute property, in which case the particle is called defective if it exceeds the critical limit and is acceptable otherwise. The test is based on the number 
of defective items found in a sample. The price for not assuming normality is that a considerably larger sample size is required.

An acceptance test is simply a decision rule for determining acceptance or rejection of a population based on a sample. When testing for a variable property based on the population mean, and given a two-sided acceptance criterion, the quantities A and B are calculated:

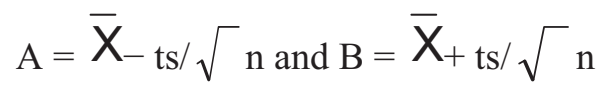

where

$\overline{\mathrm{X}}=$ sample mean,

$\mathrm{s}=$ sample standard deviation,

$\mathrm{t}=$ Student's $\mathrm{t}$ value based on sample size and confidence level, and

$\mathrm{n}=$ sample size.

If $\mathrm{A}<\mathrm{L}_{\mathrm{m}}$, the lower acceptance limit for the mean, or $\mathrm{B}>\mathrm{U}_{\mathrm{m}}$, the upper acceptance limit for the mean, the population is rejected. Otherwise, the population is accepted based on the sample. The 95\% confidence level is achieved by use of the $95^{\text {th }}$ percentile of Student's t distribution, with n- 1 degrees of freedom. For a one-sided interval, the method is the same, except that only A or B applies. The $95^{\text {th }}$ percentile of Student's t ensures that an unacceptable population is rejected with probability 0.95 .

The acceptance test of a variable property based on the population dispersion, using the assumption of normality, is as follows. Given a two-sided acceptance criterion, the quantities C and D are calculated:

$\mathrm{C}=\overline{\mathrm{X}}-\mathrm{ks}$ and $\mathrm{D}=\overline{\mathrm{X}}+\mathrm{ks}$

where

$\bar{X}=$ sample mean,

$\mathrm{s}=$ sample standard deviation, and

$\mathrm{k}=$ tolerance factor for normal distribution based on sample size, confidence level, and allowable fraction outside of critical limit

If $\mathrm{C}<\mathrm{L}_{\mathrm{p}}$, the lower critical limit for the population, or $\mathrm{D}>\mathrm{U}_{\mathrm{p}}$, the upper critical limit for the population, the population is rejected. Otherwise, the population is accepted. For one-sided acceptance criteria, the method is the same except that only C or D applies. The confidence level is achieved by the appropriate use of the tolerance factor, $\mathrm{k}$. One-sided tolerance factors are used for both one- and two-sided acceptance criteria.

For testing attribute properties, a double sampling plan is generally employed. Under such a plan, the first sample is drawn and inspected. If the first sample is sufficiently good (in terms of the number of defective particles), the product is accepted without further testing. If it is sufficiently poor, the product is rejected. If the sample falls into neither category, a second sample is taken and inspected before the decision is made. For acceptance testing of product populations for attribute properties, the sample sizes are based on binomial probabilities to ensure a $<5 \%$ false acceptance rate.

A variable property may be treated as an attribute property and subjected to the type of test described above if the normality assumption is not justified. One such property is the sphericity (aspect ratio). It is ideally 1.0; it may be larger, but it cannot be smaller. Therefore, it has an asymmetrical distribution rather than a normal distribution. To treat sphericity as an attribute property, a particle is counted as defective if 
the particle's aspect ratio is greater than the allowed limit and counted as acceptable if its aspect ratio is less than the allowed limit.

Table B-1 provides an example of the relationship between the sample size and acceptance criterion for an attribute test based on the binomial distribution. This example is for an attribute having an acceptance limit of $5.0 \times 10^{-5}$.

Table B-1. Acceptance number vs. sample size for attribute property acceptance test.

\begin{tabular}{|c|c|c|}
\hline Sample Size & $\begin{array}{c}\text { Max. Number of Defects for Acceptance at } \\
\text { 95\% Confidence Level }\end{array}$ & Indicated Defect Level \\
\hline 59914 & 0 & 0 \\
\hline 94876 & 1 & $1.1 \times 10^{-5}$ \\
\hline 183068 & 4 & $2.2 \times 10^{-5}$ \\
\hline 314101 & 9 & $2.9 \times 10^{-5}$ \\
\hline 996164 & 38 & $3.8 \times 10^{-5}$ \\
\hline
\end{tabular}

As noted above, two kinds of acceptance test errors may occur-false acceptance, which is acceptance of product that does not actually satisfy the required criteria, and false rejection, which is rejection of product that actually satisfies the criteria. These errors can occur because each decision to accept or reject is based on a random sample, not on examination of the entire population. The probability of each kind of error can be found by calculating the probability of rejecting the population, assuming that the population is specified. Ideally, the probability of rejection should be large for an unacceptable population and small for an acceptable population. This is accomplished by careful selection of the sample size.

As an example, consider the acceptance criterion for the mean kernel diameter of a composite. In this particular example, the acceptance criterion requires that the population mean be less than the upper acceptance limit of $360 \mu \mathrm{m}$ and greater than the lower acceptance limit of $340 \mu \mathrm{m}$. Figure B-1 shows the probability of rejection (power curve) of the composite for the kernel diameter criterion as a function of sample mean value and sample size, assuming a standard deviation of $10 \mu \mathrm{m}$. The specifications on the mean are shown as vertical lines at 340 and $360 \mu \mathrm{m}$. The figure shows that for a small sample size $(\mathrm{n}=10)$, the probability of rejection when the true mean is within the specifications is unacceptably high. For example, if the true mean is $355 \mu \mathrm{m}$, the probability of rejecting the composite based on a sample size of 10 is more than 0.50 . If the sample size is increased to 50, the probability of rejecting a composite with a true mean of $355 \mu \mathrm{m}$ is less than 0.05 . This suggests that a sample size of at least 50 kernels should be collected for this property.

Table B-1 and Figure B-1 illustrate a very important aspect of statistical QC. Specifically, as the true value of a property in a population that is within specification with respect to that specification approaches the specification limit, the minimum sample size that will be needed in order to accept the population at the $95 \%$ confidence level (and to avoid false rejection of the population) becomes quite large. Indeed, for testing of an attribute such as the SiC defect fraction, essentially $100 \%$ inspection would be required if the actual value of the $\mathrm{SiC}$ defect fraction is just below the specification limit. Consequently, the economics of fuel manufacturing dictate that the fuel manufacturer must strive to achieve a quality level that is significantly better than specification requirements to avoid excessive rejection of good product with reasonable sample sizes. What this means is that the necessary use of statistical QC for acceptance testing of HTGR fuel effectively guarantees that the average fuel quality delivered by the fuel manufacturer to the reactor will significantly exceed that required by the fuel-product specifications. 


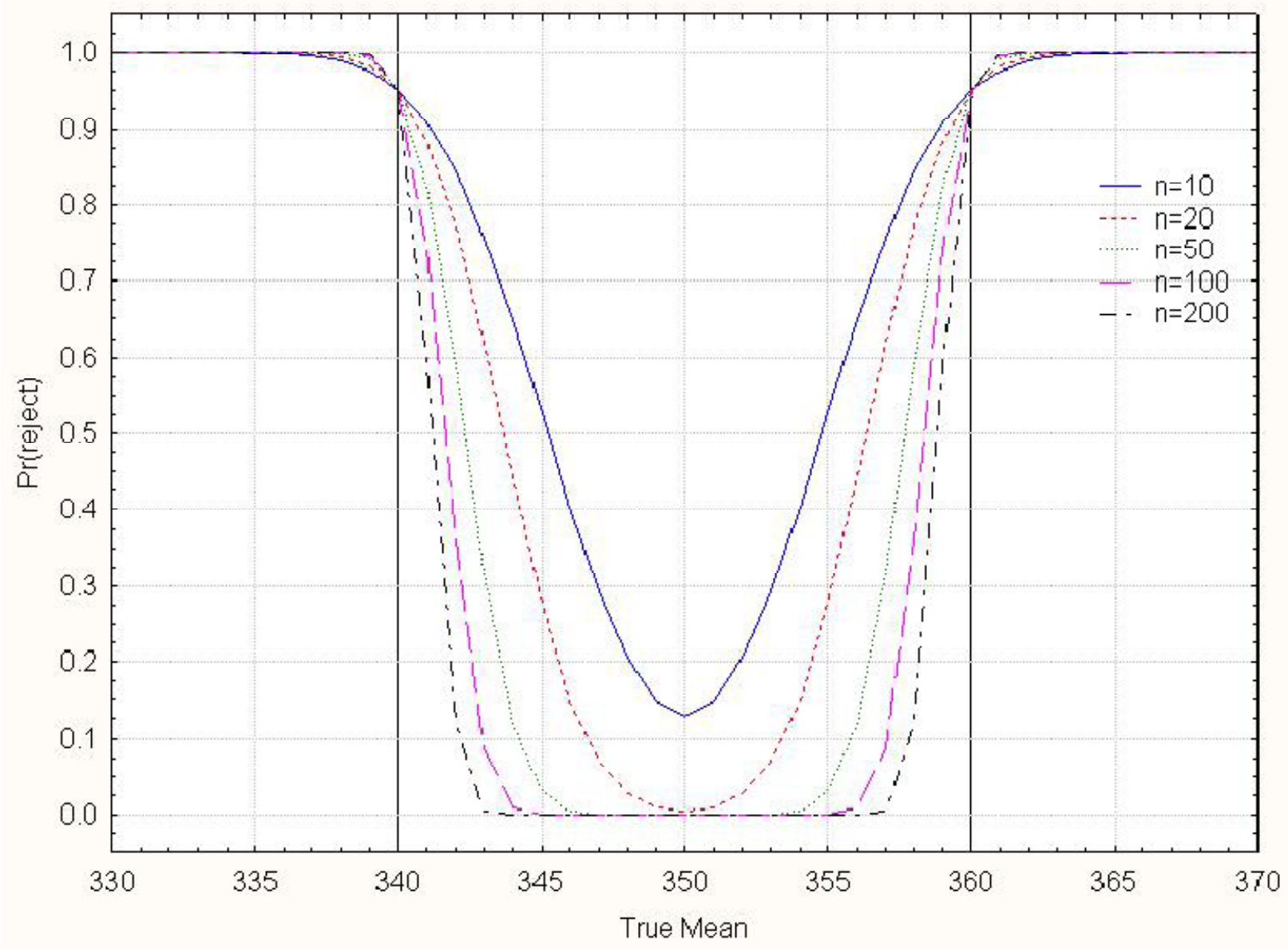

Figure B-1. Probability of rejecting composite for mean kernel diameter. 